\title{
WestVirginiaUniversity
}

THE RESEARCH REPOSITORY @ WVU

Graduate Theses, Dissertations, and Problem Reports

2003

\section{Dowel-concrete contact characteristics}

Sri Vani Sirisha Motamarri

West Virginia University

Follow this and additional works at: https://researchrepository.wvu.edu/etd

\section{Recommended Citation}

Motamarri, Sri Vani Sirisha, "Dowel-concrete contact characteristics" (2003). Graduate Theses,

Dissertations, and Problem Reports. 1353.

https://researchrepository.wvu.edu/etd/1353

This Thesis is protected by copyright and/or related rights. It has been brought to you by the The Research Repository @ WVU with permission from the rights-holder(s). You are free to use this Thesis in any way that is permitted by the copyright and related rights legislation that applies to your use. For other uses you must obtain permission from the rights-holder(s) directly, unless additional rights are indicated by a Creative Commons license in the record and/ or on the work itself. This Thesis has been accepted for inclusion in WVU Graduate Theses, Dissertations, and Problem Reports collection by an authorized administrator of The Research Repository @ WVU. For more information, please contact researchrepository@mail.wvu.edu. 
By

\section{SRI VANI SIRISHA MOTAMARRI}

Thesis

Submitted to the College of Engineering and Mineral Resources

At

West Virginia University

In Partial Fulfillment of the Requirements

For the Degree of

Master of Science in Mechanical Engineering

Committee Members

Dr. Samir N.Shoukry

Dr. Jacky Prucz

Dr. Kenneth Means

Morgantown, West Virginia

2003 


\section{ABSTRACT \\ DOWEL-CONCRETE CONTACT CHARACTERISTICS}

\section{SRI VANI SIRISHA MOTAMARRI}

Dowel-jointed concrete pavements often show serious cracks long before their design life expires. The most common forms of cracks are mid-slab transverse cracking and transverse joint damage. Steel dowel bars embedded in transverse joints (for efficient load-transfer from one slab to the next) contribute to both forms of damage. The interfacial friction forces between dowel bars and the surrounding concrete hinder the free axial movement of the slabs as the concrete expands or contracts due to ambient temperature changes. This induces excessive axial dowel-forces that may cause mid-slab transverse cracks. Strong dowel-concrete bonds induce large shear stresses at dowelconcrete interfaces that combine with the dowel-concrete contact stresses (due to traffic loading an slab curling) to induce tri-axial state of stress that often result in failure of the concrete that support the dowels. While dowel-concrete friction forces are the major parameter contributing to such forms of damage, current concrete pavement design procedures are based on the assumption that such forces do not exist. Design specification state that the steel dowels should be coated with bond-breaking fluid that is assumed to fully eliminate dowel-concrete frictional forces. However, laboratory studies as well as field-testing using instrumented dowel bars, indicate that bond-breaking agents such as Tectyl (605) or Silicone are incapable of achieving zero coefficient of friction at dowel concrete interfaces. Lack of measured values of dowel-concrete friction coefficient hinders accounting for dowel-concrete axial forces in the design of dowel jointed concrete pavements.

In this thesis, the dowel-pulling force and the dowel-concrete coefficient of friction were measured using a novel laboratory setup of vibrating wire strain gauges embedded in both the dowel and concrete. The gages are set to measure the shrinkage strain induced in the concrete that surrounds the dowel as it cures causing the solidified concrete to clamp on the steel dowel. The measurements reveal that radial strain in concrete around the dowel is not uniform along the dowel circumference. As the dowel is pulled out of concrete, both the dowel-pulling force and the elastic strain recovery in concrete are recorded versus the dowel displacement. A theoretical model is developed to enable calculation of the dowel-concrete friction coefficient. Three-dimensional finite element analysis is used to estimate the stress field in the concrete surrounding dowel bars. Experiments are conducted to examine the effect of dowel bar diameter and type of bond-breaking agent on the friction coefficient and the magnitude of dowel-pulling force. The results indicate that the use of Silicone as bond-breaker produces lower dowelconcrete coefficient of friction than that obtained using Tectyl (506). The results from finite element analysis indicate that the magnitudes of stresses in concrete surrounding uncoated steel dowels is higher than those obtained if the dowels are coated using bondbreaker. 


\section{ACKNOWLEDGEMENTS}

I take this opportunity to express my profound gratitude to my advisor Dr. Samir.N.Shoukry for his technical guidance, continuous motivation towards research and his parental support during my stay in WVU. I sincerely thank him for providing me an excellent research atmosphere and invaluable assistance for the completion of work. This work could not have been done without his assistance.

I am thankful to my committee members Dr. Jacky Prucz and Dr. Kenneth Means for their assistance.

I express my sincere thanks to Gergis W. William and Mourad Y.Riad for their assistance and guidance in all aspects throughout my research work.

I sincerely acknowledge the timely assistance of David Turner and Bill in machining the components for test rig and specimens. I express my sincere thanks to one and all my friends and teammates of my research group under Dr. Samir N. Shoukry for their continuous assistance through out my work.

I am deeply indebted to my parents and brother for their tremendous encouragement and support throughout my work. I thank all my friends for supporting me throughout duration of this research work.

I express my gratitude to the Department of Highways (DOT) for funding this project. 


\section{DEDICATION}

Dedicated to my parents and brother. 


\section{TABLE OF CONTENTS}

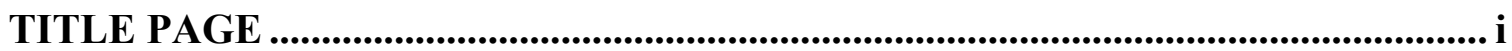

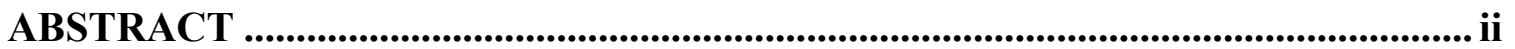

ACKNOWLEDGEMENTS ........................................................................................ii

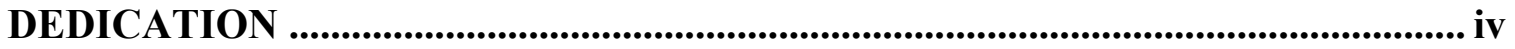

TABLE OF CONTENTS ................................................................................................. v

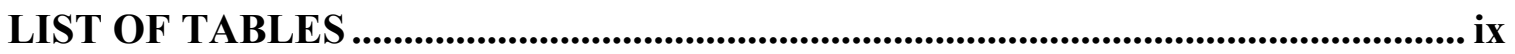

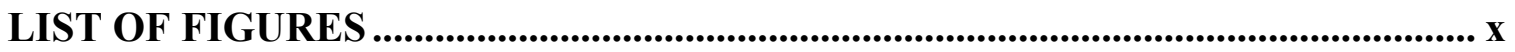

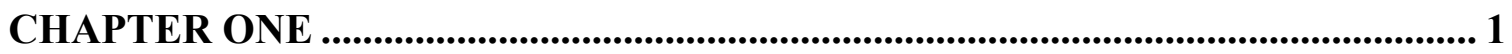

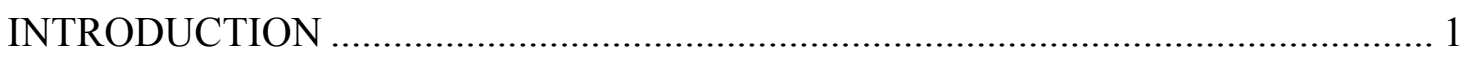

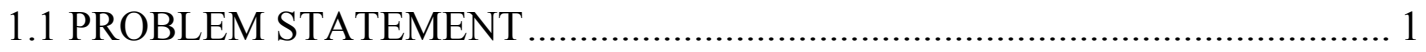

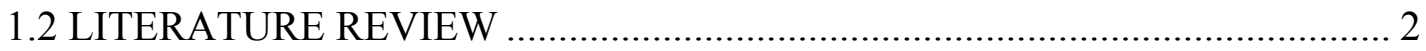

1.3 NEED FOR CURRENT RESEARCH.......................................................... 5

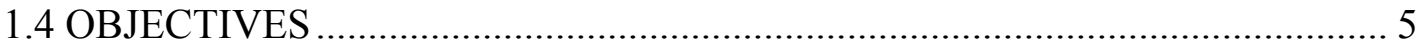

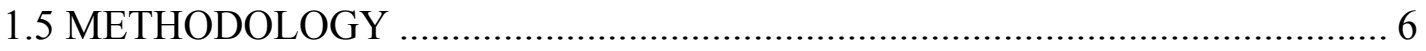

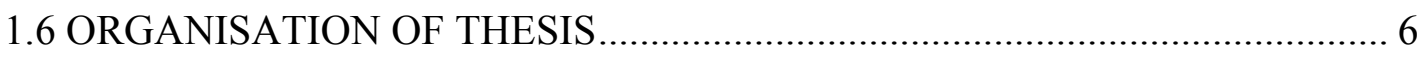

CHAPTER TWO

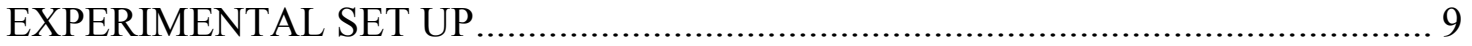

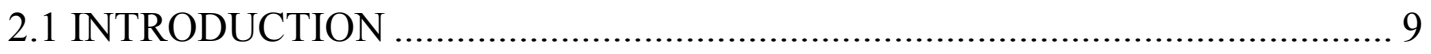

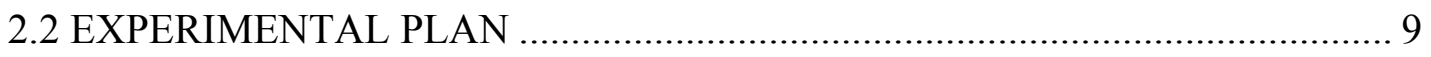

2.3 SPECIMEN DESIGN AND PREPARATION ............................................... 9

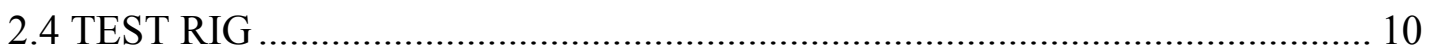

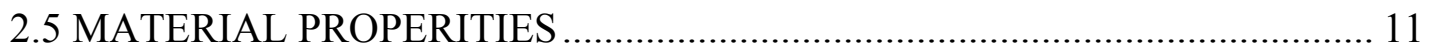

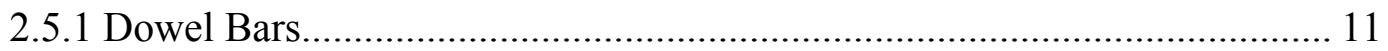

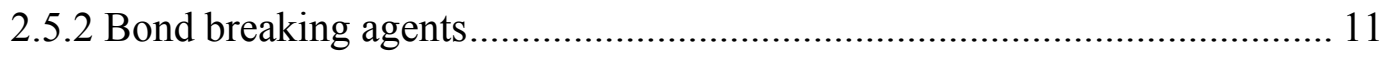

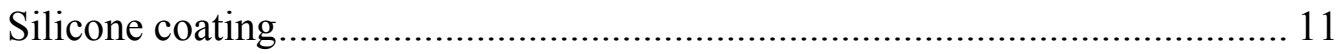

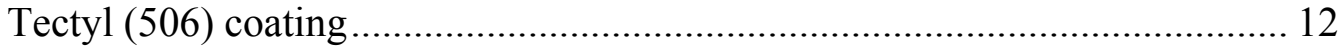

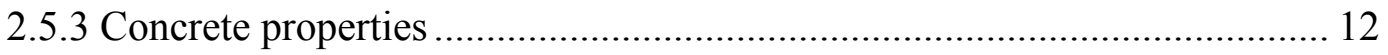

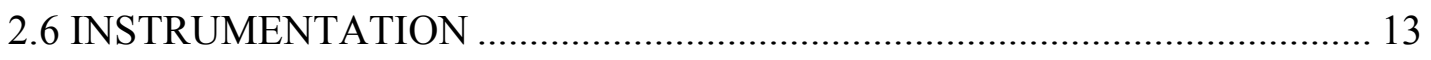

2.6.1 Measuring the Applied load and Dowel Bar Displacement........................ 13 
2.7 POSITION OF CONCRETE SPECIMEN AND DESIGNATION OF STRAIN

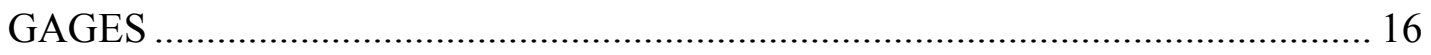

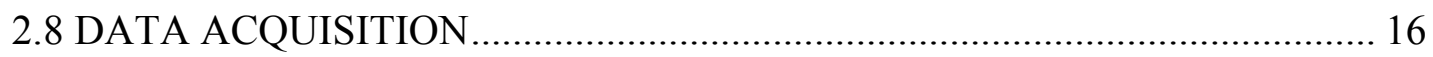

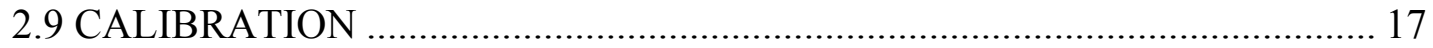

2.9.1 Calibration of LVDT with Datalogger........................................................ 17

2.9.2 Calibration of Load Cell with Datalogger ................................................. 17

2.9.3 Validation of Datalogger Strain Reading using Bridge Completion Module

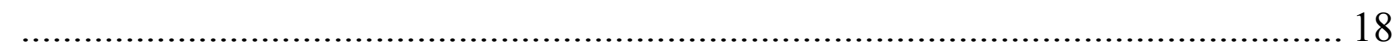

CHAPTER THREE ..................................................................................................... 32

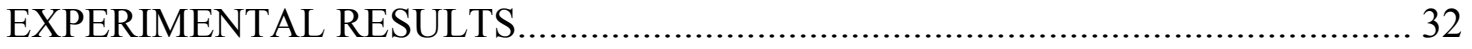

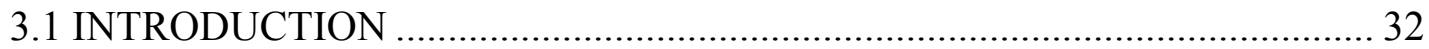

3.2 STRAINS RECORDED IN THE CONCRETE DURING CURING ……......... 32

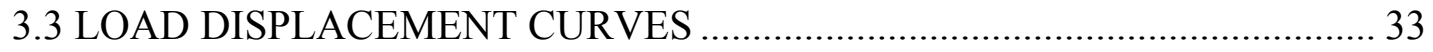

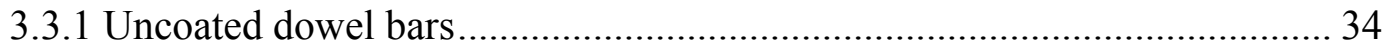

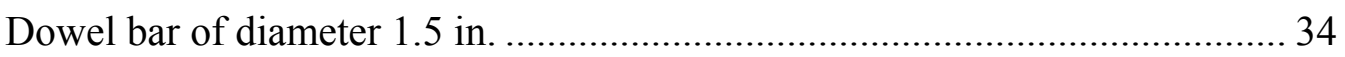

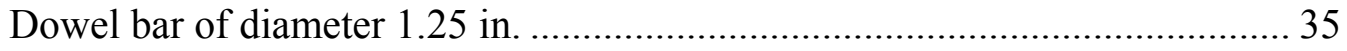

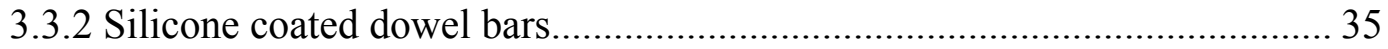

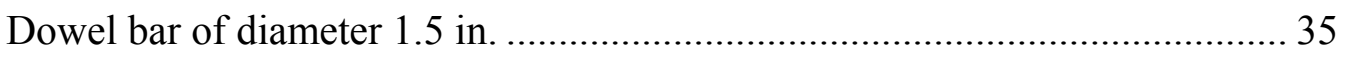

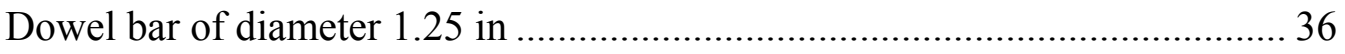

3.3.3 Tectyl (506) Coated dowel bars .................................................................. 37

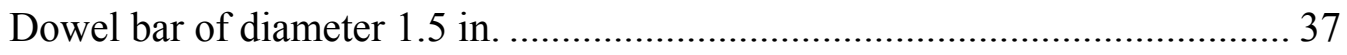

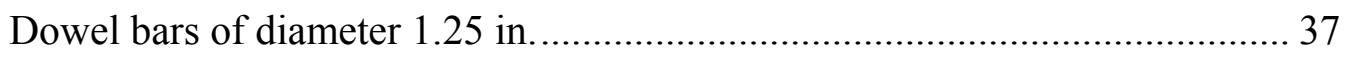

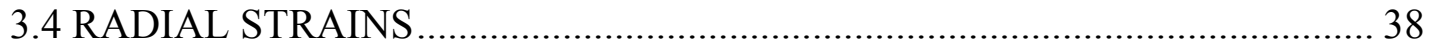

3.4.1 Radial strains in the specimens with 1.5in diameter dowel bar................... 38

3.4.2 Radial strains in the specimens with 1.25 in diameter dowel bar................ 39

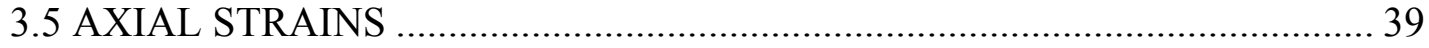

3.5.1 Axial strains in the specimens with 1.5 in diameter dowel bar ................... 39

3.5.2 Axial strains in the specimens with 1.25 in diameter dowel bar ................. 40

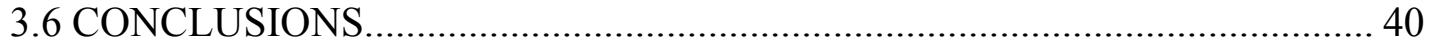

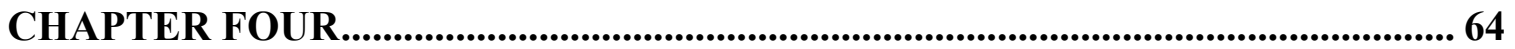




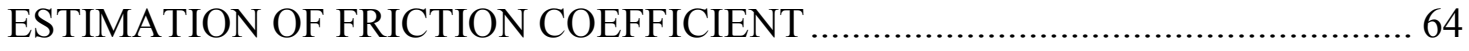

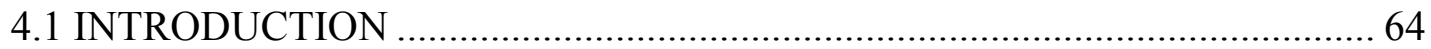

4.2 PREDICTION OF FRICTION COEFFICIENT BASED ON A COUPLED EXPERIMENTAL-THEORECTICAL APPROACH .............................................. 64

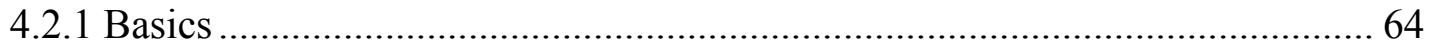

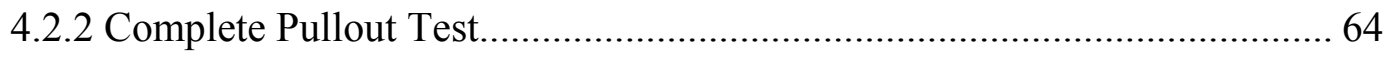

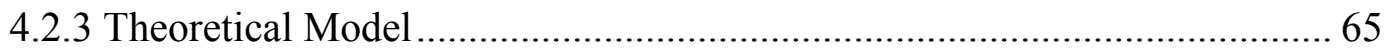

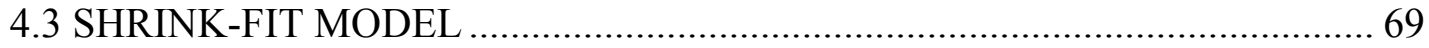

4.4 INFERENCES BASED ON THE RESULTS .............................................. 71

CHAPTER FIVE

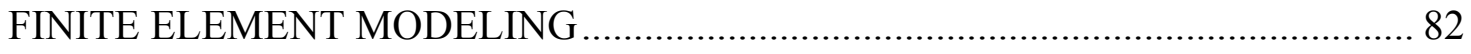

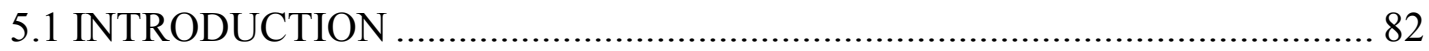

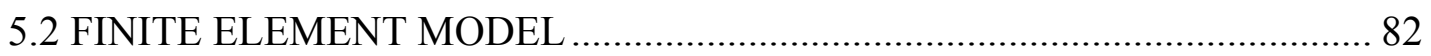

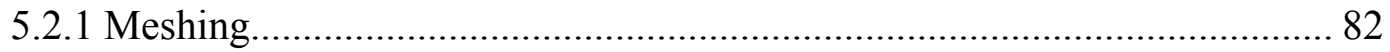

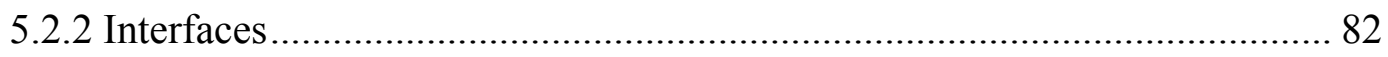

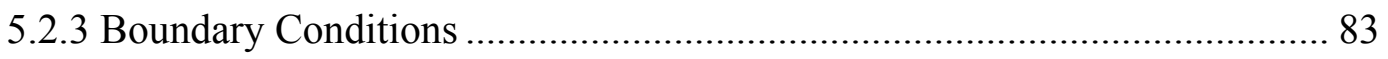

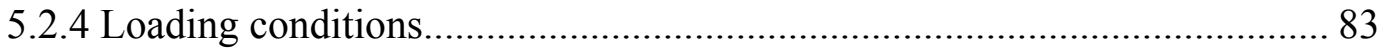

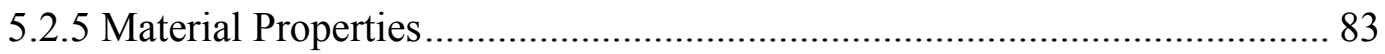

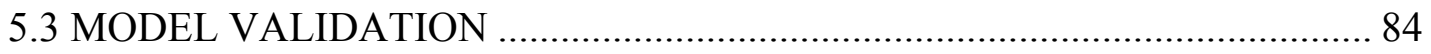

5.3.1 Strains in concrete before dowel bar pullout ................................................. 84

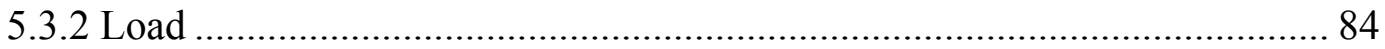

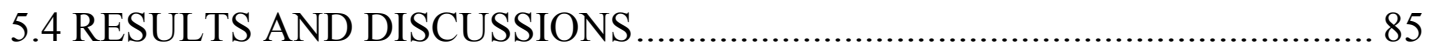

5.4.1 Maximum Principal Stress and Shear Stress .............................................. 85

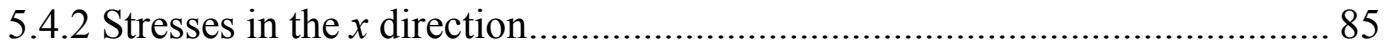

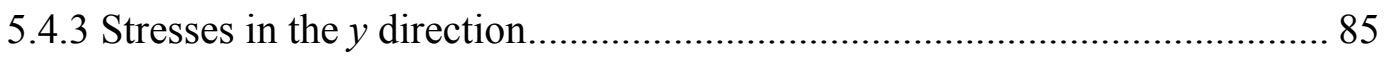

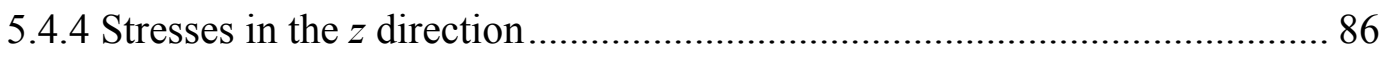

5.5 EFFECT OF MODULUS OF ELASTICITY ………………………………..... 86

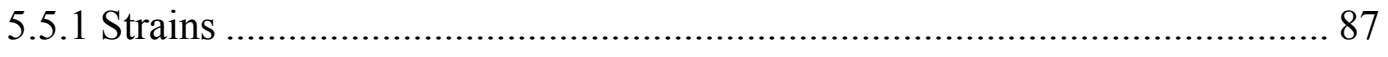

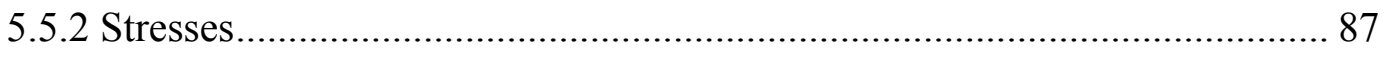

CHAPTER SIX ........................................................................................................................ 100

CONCLUSIONS AND RECOMMENDATIONS ………………....................... 100 


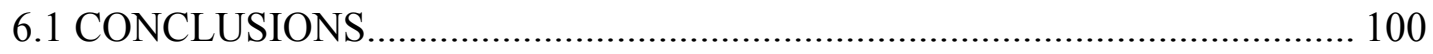

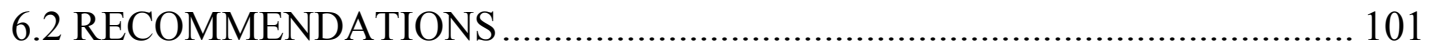

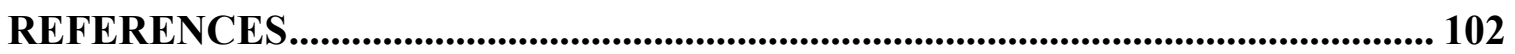

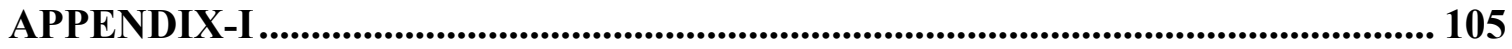

APPENDIX-II .................................................................................................................... 106

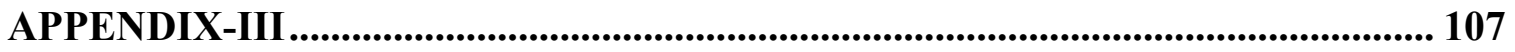

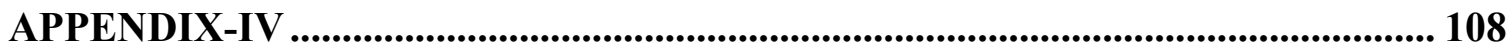

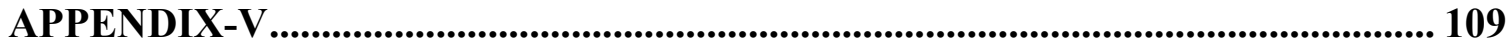

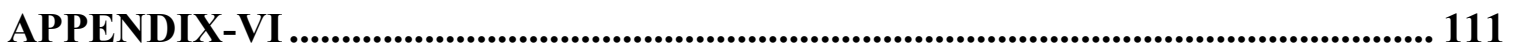

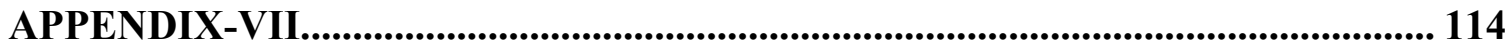




\section{LIST OF TABLES}

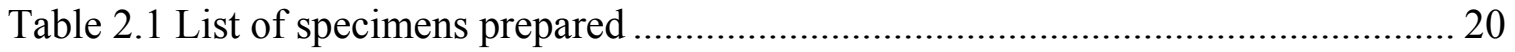

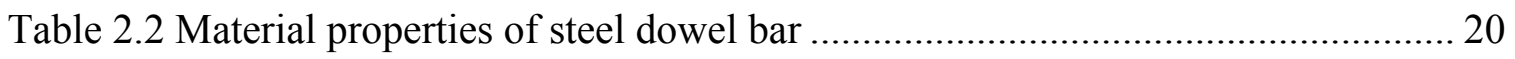

Table 3.1 Maximum axial strains in specimens with 1.25-in. diameter dowel bars......... 41

Table 4.1 Maximum pulling forces and strain recorded during the pullout test.............. 72

Table 4.2 Value of friction coefficient estimated from two mathematical models .......... 72

Table 5.1 Comparison of load to initiate sliding of dowel bar .................................... 88 


\section{LIST OF FIGURES}

Figure 1.1 Recorded Ambient Temperature and Dowel Axial force ............................. 7

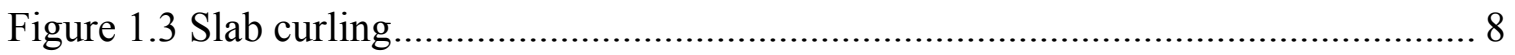

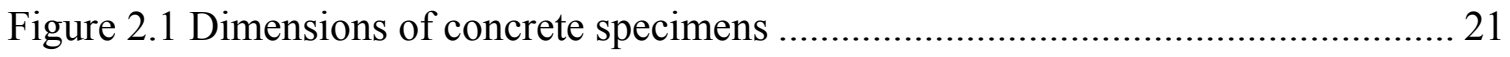

Figure 2.2 Stress fields around the dowel bar in cylindrical and prism specimens ......... 21

Figure 2.3 Dowel bar fixed in a wooden form for casting ........................................ 22

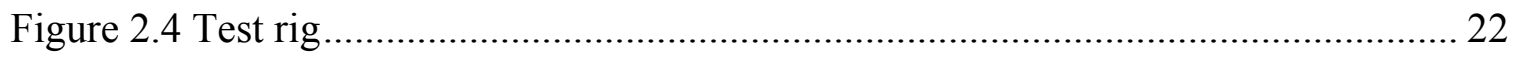

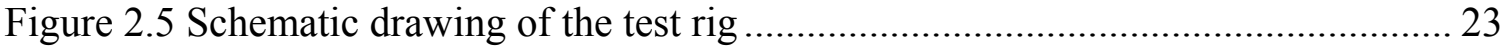

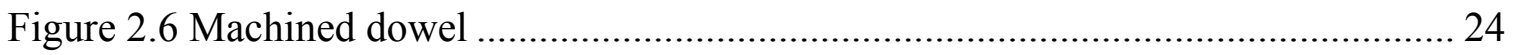

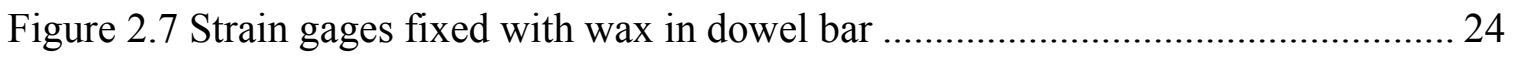

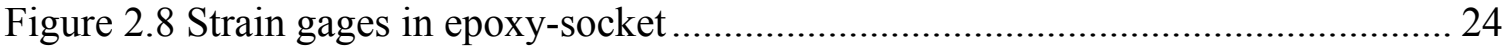

Figure 2.9 Strain gages in epoxy-socket detached from dowel bar ............................. 25

Figure 2.11 Embedment strain gage installed on the dowel bar ................................. 25

Figure 2.12 Schematic picture depicting the position of the specimen during casting.... 26

Figure 2.13 Schematic picture depicting the position of the specimen during test phase 26

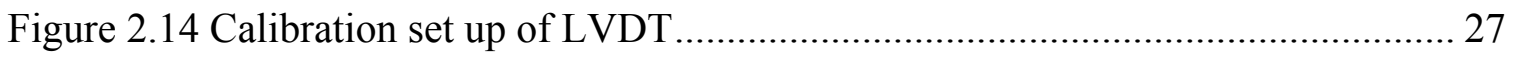

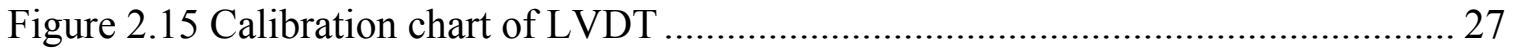

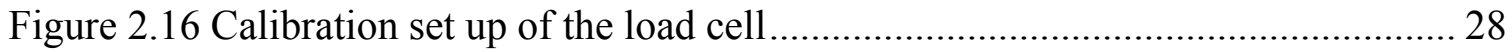

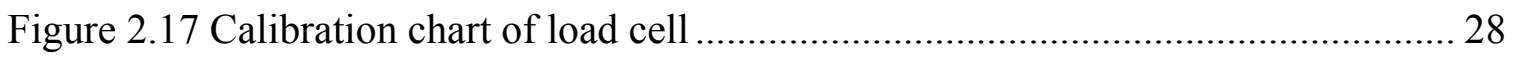

Figure 2.18 Bonded resistance strain gages on dowel bar ....................................... 29

Figure 2.19 Calibration set up for embedment strain gages ...................................... 29

Figure 2.20 Schematic picture of calibration set up of embedment strain gages ............ 30

Figure 2.21 Comparison of strains measured from data acquisition systems and

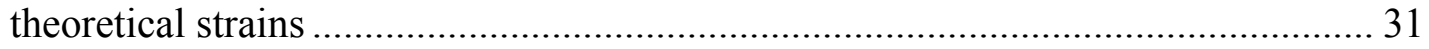

Figure 2.22 Calibration curve of embedment strain gage ........................................ 31

Figure 3.1 Strains in specimens with uncoated and coated dowel bars ......................... 42

Figure 3.2 Sectional view of concrete specimen with strain gages and dowel bar.......... 43

Figure 3.3 Load-displacement curve of specimen No.1 with uncoated dowel bar of

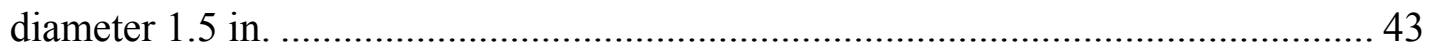


Figure 3.4 Load-displacement curve of the specimen No.2 with uncoated dowel bar of diameter $1.5 \mathrm{in}$.

Figure 3.5 Load-displacement curve of the specimen No.3 with uncoated dowel bar of diameter $1.5 \mathrm{in}$.

Figure 3.6 Load-displacement curve of the specimen No.1 with uncoated dowel bar of diameter $1.25 \mathrm{in}$.

Figure 3.7 Load-displacement curve of the specimen No.2 with uncoated dowel bar of diameter $1.25 \mathrm{in}$. 45

Figure 3.8 Load-displacement curve of the specimen No.3 with uncoated dowel bar of diameter $1.25 \mathrm{in}$. 46

Figure 3.9 Load-displacement curve of the specimen No.1 with silicone coated dowel bar of diameter $1.5 \mathrm{in}$. 46

Figure 3.10 Load-displacement curve of the specimen No.2 with silicone coated dowel bar of diameter $1.5 \mathrm{in}$.

Figure 3.11 Load-displacement curve of the specimen No.3 with silicone dowel bar of diameter $1.5 \mathrm{in}$.

Figure 3.12 Load-displacement curve of the specimen No.1 with silicon coated dowel bar of diameter $1.25 \mathrm{in}$. 48

Figure 3.13 Load-Displacement curve of the Specimen No.2 with silicone coated dowel bar of diameter $1.25 \mathrm{in}$. 48

Figure 3.14 Load-displacement curve of the specimen No.3 with silicone coated dowel bar of diameter $1.25 \mathrm{in}$.

Figure 3.15 Load-displacement curve of the specimen No.1 with tectyl coated dowel bar of diameter 1.5 in.

Figure 3.16. Load-displacement curve of the specimen No.2 with tectyl coated dowel bar of diameter 1.5 in. 50

Figure 3.17 Load-displacement curve of the specimen No.3 with tectyl coated dowel bar of diameter $1.5 \mathrm{in}$. 50

Figure 3.18 Load-displacement curve of the specimen No.1 with tectyl coated dowel bar of diameter $1.25 \mathrm{in}$. 
Figure 3.19 Load-displacement curve of the specimen No.2 with tectyl coated dowel bar of diameter $1.25 \mathrm{in}$.

Figure 3.20 Load-displacement curve of the specimen No.3 with tectyl coated dowel bar of diameter $1.25 \mathrm{in}$.

Figure 3.21 Strain-displacement curve of the specimen with uncoated dowel bar of diameter $1.5 \mathrm{in}$.

Figure 3.22 Strain-displacement curve of the specimen with uncoated dowel bar of diameter $1.5 \mathrm{in}$. 53

Figure 3.23 Strain-displacement curve of the specimen with silicone coated dowel bar of diameter $1.5 \mathrm{in}$.

Figure 3.24 Strain-displacement curve of the specimen with silicone coated dowel bar of diameter $1.5 \mathrm{in}$. 54

Figure 3.25 Strain-displacement curve of the specimen with tectyl coated dowel bar of diameter $1.5 \mathrm{in}$. 55

Figure 3.26 Strain-displacement curve of the specimen with tectyl coated dowel bar of diameter $1.5 \mathrm{in}$.

Figure 3.27 Strain-displacement curve of the specimen with uncoated dowel bar of diameter 1.25 in. 56

Figure 3.28 Strain-displacement curve of the specimen with uncoated dowel bar of diameter $1.25 \mathrm{in}$. 56

Figure 3.29 Strain-displacement curve in the specimen with silicone coated dowel bar of diameter 1.25 in.

Figure 3.30 Strain-displacement curve in the specimen with silicone coated dowel bar of diameter $1.25 \mathrm{in}$. 57

Figure 3.31 Strain-displacement curve of the specimen with tectyl coated dowel bar of diameter 1.25 in 58

Figure 3.32 Strain-displacement curve of the specimen with tectyl coated dowel bar of diameter 1.25 in 58

Figure 3.33 Strain-displacement curve of the specimen No.1 with uncoated dowel bar of diameter $1.5 \mathrm{in}$. 59 
Figure 3.34 Strain-displacement curve of the Specimen No.2 with uncoated dowel bar of diameter $1.5 \mathrm{in}$.

Figure 3.35 Strain-displacement curve of the Specimen No.3 with uncoated dowel bar of diameter 1.5 .

Figure 3.36 Strain-displacement curve of the Specimen No.1 with silicone coated dowel bar of diameter $1.5 \mathrm{in}$.

Figure 3.37 Strain-displacement curve of the Specimen No.2 with silicon coated dowel bar of diameter $1.5 \mathrm{in.}$

Figure 3.38 Strain-displacement curve of the Specimen No.3 with silicon coated dowel bar of diameter $1.5 \mathrm{in}$

Figure 3.39. Strain-displacement curve of the specimen No.1 with tectyl coated dowel bar of diameter 1.5 in

Figure 4.1 Internal pressure at dowel-concrete interface 73

Figure 4.2 The radial displacement of the concrete along the internal diameter due to the shrinkage of the concrete 73

Figure 4.3 Strains recorded in specimens with uncoated dowel bar during complete pullout test. 74

Figure 4.4 Strains recorded in specimens with silicone coated dowel bar during complete pullout test 75

Figure 4.5 Strains recorded in specimens with tectyl coated dowel bar during complete pullout test. 76

Figure 4.6 Details of the geometry of the concrete specimens 77

Figure 4.7 The quarter cross-section of the concrete specimen with dowel bar showing the radial and tangential stresses at the radial distance $r$ 77

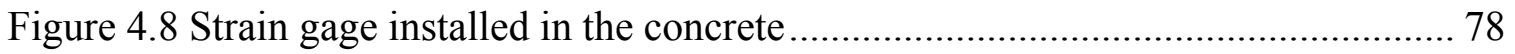

Figure 4.9 Geometry of the dowel bar embedded in the concrete block ........................ 78

Figure 4.10 Magnified view of the shrink-fit of concrete cylinder on the dowel bar...... 79

Figure 4.11 The cross-section of thick walled cylinder............................................ 79

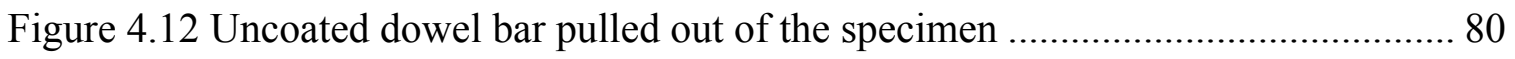

Figure 4.13 Silicon coated dowel bar pulled out of the specimen ................................ 80

Figure 4.14 Tectyl coated dowel bar pulled out of the specimen ................................. 81 
Figure 5.1 FEM of the concrete specimen with dowel bar. 89

Figure 5.2 Side view of the FEM of the concrete specimen with dowel bar 89

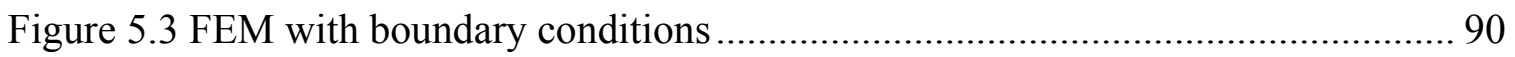

Figure 5.4 Maturity Graph of concrete .................................................................. 90

Figure 5.5 Maximum Principal Stress in concrete during pullout test of an uncoated dowel bar

Figure 5.6 Maximum Principal Stress in concrete during pullout test of a silicon coated dowel bar..... 91

Figure 5.7 Maximum Principal Stress in concrete during pullout test of a tectyl coated dowel bar. 92

Figure 5.8 Maximum Shear Stress in concrete during pullout test of an uncoated dowel bar. 92

Figure 5.9 Maximum Shear Stress in concrete during pullout test of a silicon coated dowel bar. 93

Figure 5.10. Maximum Shear Stress in concrete during pullout test of tectyl coated dowel bar. 94

Figure 5.11. X-Stress Vs Angular position in concrete surrounding dowel bar 95

Figure 5.12. Y-Stress Vs Angular position in concrete surrounding dowel bar 96

Figure 5.13 Z-Stress Vs Angular position in concrete surrounding dowel bar 97

Figure 5.14 Y-Maximum strains around dowel bar during pullout test 98

Figure 5.15 Z-Maximum strains around dowel bar during pullout test.......................... 98

Figure 5.16 Y-Maximum stress around dowel bar during pullout test .......................... 99

Figure 5.17 Z-Maximum stress around dowel bar during pullout test 99 


\section{CHAPTER ONE INTRODUCTION}

\subsection{PROBLEM STATEMENT}

Dowel-jointed Portland Cement Concrete (PCC) pavements are extensively used for their durability and high strength. The dowel bars installed at the transverse joints of the concrete slabs reduces the deflections and stresses at the joint edges while transferring the traffic load from one slab to the adjacent slab (1). These pavements provide a comfortable, smooth, fast, and safe transportation.

The dowel-jointed concrete slabs curl and warp due to the variation of temperature through the thickness of the pavement. Slabs are assumed to contract and expand freely $(2,3)$. The dowel bars are assumed to be friction free and allow free relative axial movement of the slab due to changes in its mean temperature. This assumption simplifies the design of dowel-jointed pavements. However, in practice the dowel bars are observed to violate this assumption. A recent study (4) conducted on a newly constructed pavement section revealed the development of axial forces in the dowel bars due to friction with changes in the slab temperature as illustrated in Figure 1.1. The restriction of free movement of the concrete slabs over the dowel bars produces high tensile stresses which in turn result in mid-slab cracking $(5,6,7)$.

The early stage of concrete curing is characterized by shrinkage. The relatively rigid dowel bar embedded in the concrete restrains internal deformations of concrete surrounding it. Thus, the concrete clamps the dowel bar producing contact stresses at the dowel-concrete interface. These contact stresses generate frictional forces at the interface and axial forces in the dowel bar, which resist free axial movement of the slab. The concrete develops its strength gradually at its early age as shown in Figure 1.2. When the tensile forces produced in the slab due to the restraint exceed the modulus of rupture of concrete (i.e., concrete tensile strength), it leads to premature transverse mid-slab cracking, as shown in Figure 1.3. 
In pavements, localized cracks are also observed to form in the concrete around some dowel bars. This situation arises if the bond resistance at the dowel-concrete interface is not the same in all the bars. Pullout tests of dowel bars conducted by ERES consultants (8) showed a large variation in the forces required to displace dowel bars. Therefore, controlling the resistance caused by the dowel bars to slab movement is very essential to enhance their expected design life.

During the construction of pavements, contractors make an effort to minimize the bond resistance between concrete and dowel bars by applying a layer of bond breaking agents such as tar or other lubricants. An initial clearance is assumed to develop between dowel and concrete with the application of bond breaking agents on the surface of dowel bars reducing the bond resistance $(9,10)$. However, this initial clearance is expected to reduce due to the shrinkage of concrete. The lubricant should also withstand the heat of hydration of cement. If this fine clearance between the concrete and dowel bar narrows down, frictional forces will be generated at the interface as the slab contracts or expands.

The magnitude of dowel pulling forces and bonding force should be quantified to account for these in the design of concrete pavements. The effects of different bondbreaking agents should be explored. Hence, a profound study of dowel-concrete interface is very crucial for the development of durable and efficient dowel jointed pavements.

\subsection{LITERATURE REVIEW}

Dowel jointed concrete pavements have been in use for a long time. Through the years there have been many studies to understand the mechanism of interaction at the interface between the concrete and the dowel bar. There also have been many attempts to reduce the friction at the interface with the aim of reducing concrete deterioration and thus increasing the life of the pavement.

In 1955, Van Breeman (10) presented a report on experimental dowel installations in New Jersey. The prime motive of these installations was to identify the factors for the restraints to opening of the joints, which resulted in overstressing and causing failure in 
the reinforcing steel. Having identified corrosion as the major factor, the author used various coatings such as red paint, transmission oil, tar paint, asphaltic oil, and graphite paint on the dowel bar during the installation. The other techniques employed were protective treatments such as like galvanization and hot rolling on the dowels. Some of the dowels consisted of the cold-finished carbon steel bars partly encased in Monel tubing. His field investigations revealed that all the joints opened more than the normal amount. However during winter, except for the joint with Monel dowel bar, the various means employed to facilitate free movement were not successful. The author stated that the various coatings used to prevent rusting or abrasion did not meet estimated expectations, with an exception to the dowel bars with Monel casing. Consequently, it was decided to continue the usage of Monel or stainless steel tubing for dowel bars. This increased the construction cost by $\$ 6000$ per mile of divided highway consisting of four 12-ft lanes of 9-in. thick reinforced concrete.

In 1998, Channel (11), conducted pullout tests on dowel bars to study joint movements of the $4.57 \mathrm{~m}$ (15-ft) concrete highway pavements. He conducted pullout tests on 12 specimens of which six had dowel bars coated with bond breaker Tectyl 506, while in the other six specimens the dowel bars were left uncoated. Dowel bars of diameter 1.5 in. were embedded in the cylindrical concrete moulds with an embedment length of $9 \mathrm{in}$. The ends of the dowel bars were rusted to simulate the test under practical conditions. The concrete mix was prepared at the laboratory and field conditions were simulated during curing. Each time, four (two of each kind) specimens were tested at intervals of 12, 25, and 48 hours. During the tests he observed that the behavior of the dowel bars with the bond breaker differed from that of uncoated dowel bars. For the coated dowel bars, he noted a smooth loading history and a sudden drop in loading once the bond was broken. The plain dowel bars recorded a fluctuating loading history when the bar was pulled out of the concrete cylinders. He concluded from the results that the coated dowel bars reduced the overall stress around the dowel bar in the concrete. $\mathrm{He}$ also stated that there still existed a bond between the concrete and the dowel bar even in dowel bars coated with the bond breaker. 
In 1999, Crovetti (12), conducted laboratory pullout tests of coated dowel bars following the American Association Standards for Highway and Transportation Officials Designation (AASHTO 1995): T 253-76 (13), standard method of test for coated dowel bars, as a part of an investigation to validate the constructability and cost-effectiveness of alternative concrete pavement designs incorporating variable dowel strategies and slab thicknesses. The dowel patterns the author used in the experiments were based on the earlier research on pavement design analysis, which was to reduce the number of installed dowels across the transverse pavement joints. The types of the dowels used in the tests were epoxy-coated dowels, polished and brushed stainless steel dowels and composite material dowels. The dowels were pulled out for about $0.5 \mathrm{in}$. (12.7 mm).

From the test results of uncoated dowel bars, he made the following observations:1) maximum pullout loads were recorded during the initial 0.05 in. $(0.127$ $\mathrm{mm}$ ) of relative displacement, 2) the maximum pullout stress obtained using the epoxy coated dowel was 40 percent higher than that using polished stainless steel dowel and 60 percent lower than the brushed stainless steel dowel bar, and 3) the smallest value of maximum pullout stress was with the composite bar. In the case of oiled dowels tests, he observed that the maximum pullout stress decreased in all different dowels used. But the author noted an exceptional increase in the maximum stresses for oiled epoxy coated dowel bars from a post freeze thaw test.

In 2000, ERES (14) consultants conducted an evaluation of dowel bar assemblies as a part of "Evaluation of Pennsylvania I-80 JPCP Performance in Pennsylvania DOT Districts 1-0 and 3-0". Their field investigations revealed that the poor performance of the transverse joints might be due factors such as: 1) uncoated ends of the dowel bar getting corroded and 2) the thickness of tectyl coating on the dowel bar not being uniform. Concrete sections, removed for the field survey projects SR80-A01 and SR8A03, disclosed that epoxy coating was bound to surrounding concrete. The pullout forces recorded from the pullout test on three blocks withdrawn from section SR80-A03 were 820,2290 , and $3938 \mathrm{lb}$, which show significant resistance and variation at transverse joints. 


\subsection{NEED FOR CURRENT RESEARCH}

The attempts to minimize the restraining forces to the dowel bar movement along the dowel-concrete interface have not been very successful in spite of a number of investigations, as seen from the above review. In the investigations of dowel bar installations in New Jersey (10), the solution to the problem was not economical. The installations of Monel bars would lead to high construction costs. Coating of dowel bars with oil did not meet expectations, rather it was observed to enhance the restraining forces around the dowels bars. Channell's (11) laboratory studies indicated that the application of the tectyl coating on the dowel bars minimize the pulling forces, but he had not quantified the reduction in pulling forces as it can be used in design of pavements. The evaluation of the I- 80 by ERES consultants addressed potential problems in the long run with application of tectyl coat on the surface of dowel bars.

It is very essential that strategies should be formulated to identify an effective bond-breaking agent and quantify the tensile forces in the dowel bar when the dowel bar displaces. It is also necessary to estimate the friction coefficient at the dowel-concrete interface. As there is no information provided with regard to the coefficient of friction between the dowel and concrete in the American Association of State Highway and Transportation Officials (AASHTO) supplement (15), as well. Thus there is a need to conduct an extensive laboratory and analytical study to understand the dowel-concrete interface characteristics and to estimate the coefficient of friction at the interface.

\subsection{OBJECTIVES}

The major objectives of this research are as follows:

1. To measure the magnitude of force required to displace the dowel bar from concrete with the application of different bond-breaking agents on the dowel surface.

2. To determine the coefficient of friction at the concrete-dowel interface with different coatings of bond-breaking agents on the surface of the dowel bar.

3. To estimate the stress fields in concrete around the dowel bar due to concrete shrinkage and pulling of dowel bar during the early age of concrete. 


\subsection{METHODOLOGY}

To achieve the stated objectives, the research is to be carried in the following steps:

1. Construction of a test rig to measure the dowel pulling force, which will serve to quantify the bond resistance and to explore the mechanics of dowel-concrete interaction under different coatings on dowel surface.

2. Determination of the friction coefficient at dowel-concrete interface for different coatings on the dowel bar by considering appropriate analytical models.

3. Development of a Three Dimensional Finite Element Model (3D FEM) to predict the stress-strain fields around the dowel bar due to concrete shrinkage and during the pullout stage.

\subsection{ORGANISATION OF THESIS}

The procedures of specimen preparation, test set up, and the data acquisition system are described in Chapter 2. The experimental results are presented and the analyzed in Chapter 3 The mathematical model used to estimate the friction coefficient from the experimental results of complete pullout test is discussed in Chapter 4. Chapter 5 presents the finite element model developed to simulate the stress strain distribution. Chapter 6 includes the conclusions of current work. 


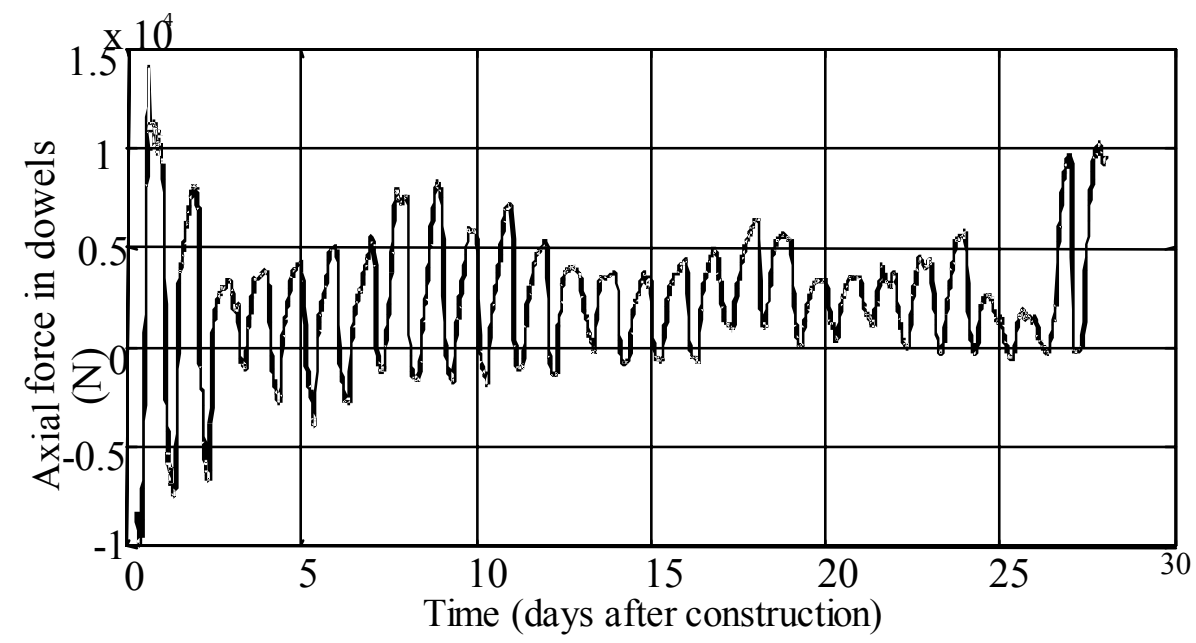

(a) Dowel Axial force

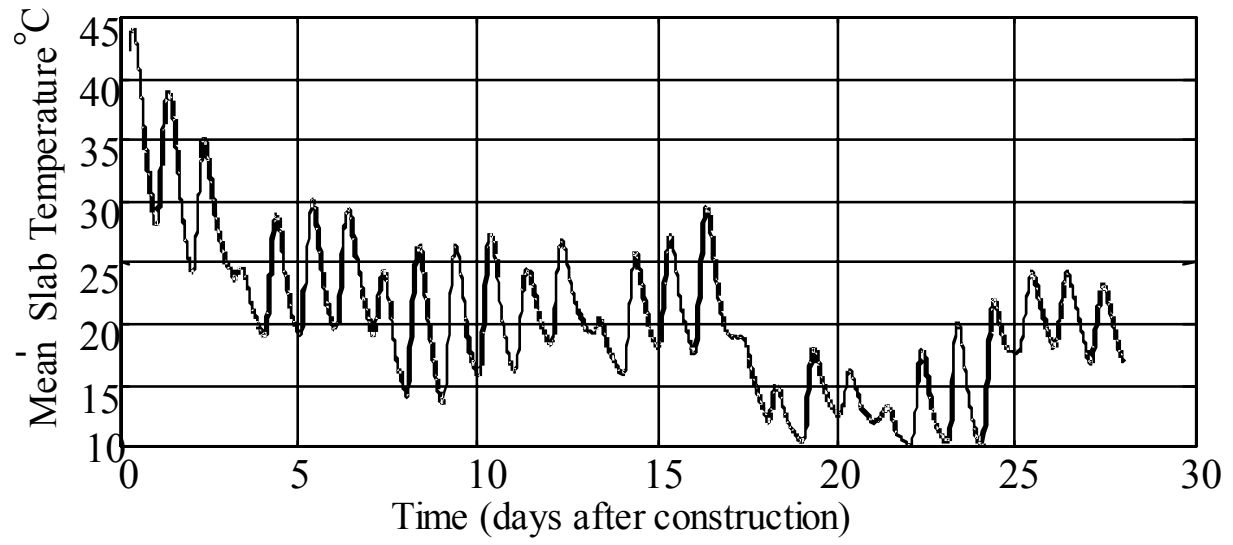

(b) Mean Slab Temperature

Figure 1.1 Recorded Ambient Temperature and Dowel Axial force 


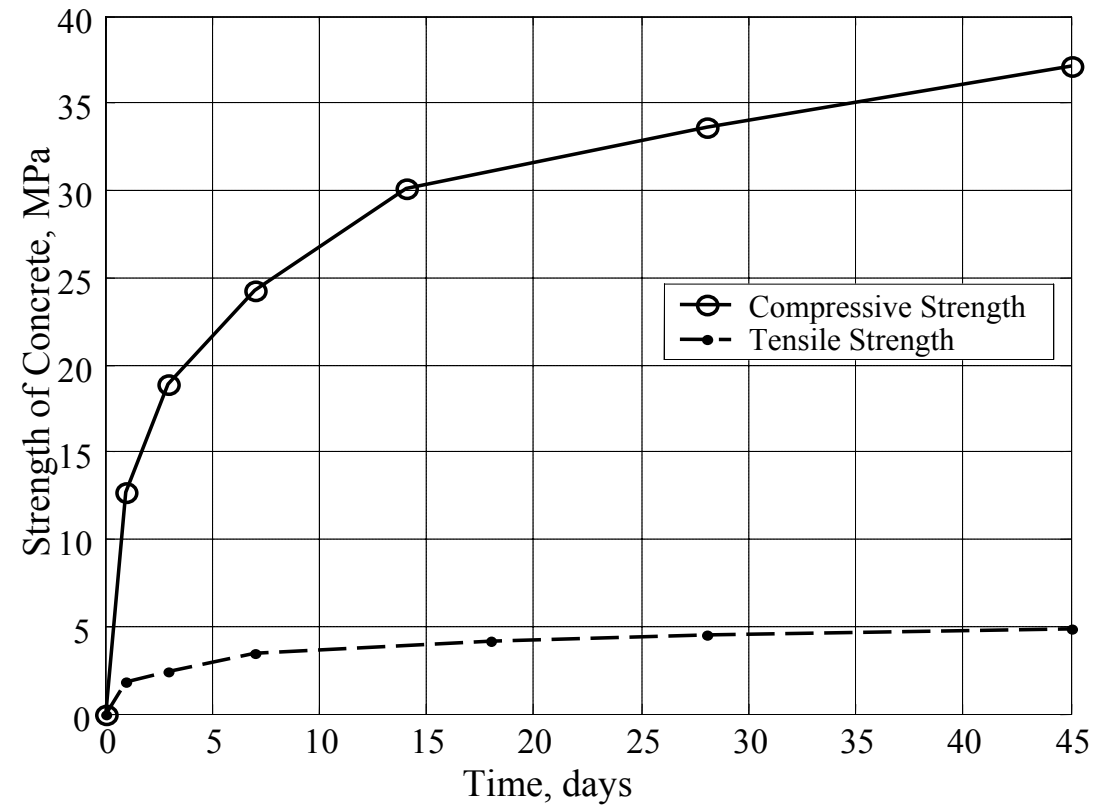

Figure 1.2 Concrete Maturity

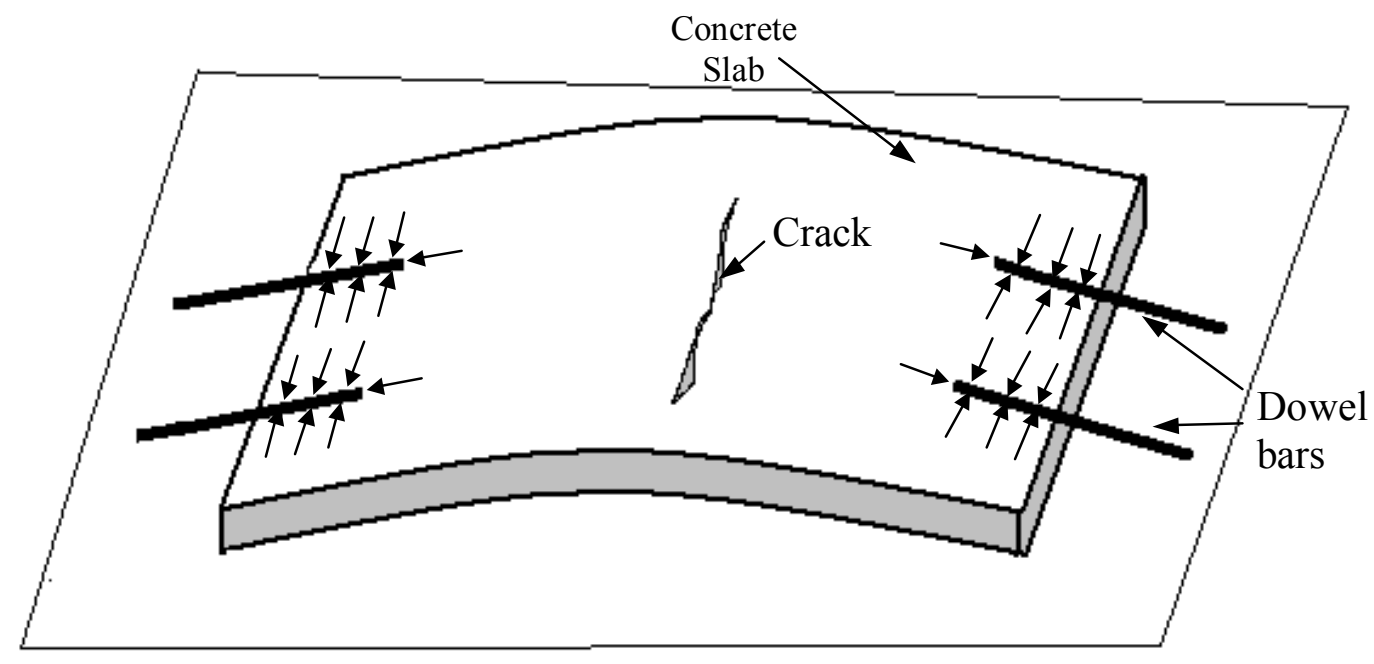

Figure 1.3 Slab curling 


\section{CHAPTER TWO \\ EXPERIMENTAL SET UP}

\subsection{INTRODUCTION}

This chapter focuses on the design of experiments and specimens to achieve the objectives of the laboratory study. It includes the description of test rig designed to determine the pullout forces of the dowel bar. It also addresses the details of the data acquisition systems. A novel approach devised to instrument the specimens to determine concrete strains surrounding the dowel bar during its early age and during the dowel displacement is also detailed in the following sections.

\subsection{EXPERIMENTAL PLAN}

A total of 18 specimens were prepared consisting of two groups of nine each. The diameter of dowel bar in the first group of specimens was $1.5 \mathrm{in} .(38.1 \mathrm{~mm})$ while that of the second group was 1.25 in. $(31.75 \mathrm{~mm})$. As shown in Table 2.1, three dowel bars from each group were left uncoated, and the other six dowels from each group were coated with bond breaking agents such as Silicone and Tectyl (506). Silicone and Tectyl (506) are non-volatile and they maintain lubricating and anti-stick properties over a wide range of temperature and their properties are detailed in the following sections. On each set of specimens, the pullout and push-in tests were conducted twice at certain intervals of time to investigate the effect of increase in concrete strength on the bond strength of dowelconcrete interface. Complete pullout tests were conducted to estimate the friction coefficient at the dowel-concrete interface.

\subsection{SPECIMEN DESIGN AND PREPARATION}

Concrete specimens of 12 in. (304.8 mm) width, 10 in. $(254 \mathrm{~mm})$ thickness and 11 in. $(279.4 \mathrm{~mm})$ length were prepared, with a dowel bar positioned at the center of the block as shown in Figure 2.1. The thickness of the actual pavements varies from 8 in. $(203.2 \mathrm{~mm})$ to $12 \mathrm{in}$. $(304.8 \mathrm{~mm})$. Thus the specimen thickness of $10 \mathrm{in}$. represents an average value. The $12 \mathrm{in}$. width of the specimen represents the dowel bar spacing in actual pavements. In the specimens prepared, the embedment length of the dowel bar 
into the concrete block was 9 in. $(228.6 \mathrm{~mm})$, same as that in the pavements since each slab shares half of the $18 \mathrm{in}$. (457.2 $\mathrm{mm})$ long dowel bar.

The main advantage of the choice of a prismatic concrete specimen is that it replicates the geometry of the concrete surrounding the dowel bar in actual concrete pavements. As shown in Figure 2.2, cylindrical specimens have the advantage of producing uniform stress and strain fields around the dowel due to the axi-symmetric nature of such specimens, simplifying the theoretical analysis. However, cylindrical specimens do not accurately represent the actual field conditions of dowel bars. Additionally, technical problems are associated with holding the dowel bar in place at the center while the concrete is poured.

The specimens were cast in prepared wooden forms as shown in Figure 2.3. The dowel bar was rigidly fixed in the wooden form prior to concrete casting with an angular holder. The dowel bars were meticulously fixed in the wooden forms maintaining perpendicularity of the longitudinal axis of the dowel bar with respect to the vertical face of the specimen to minimize the effect of misalignment.

\subsection{TEST RIG}

A special test rig was designed to carry out laboratory tests of dowel bars, as shown in Figure 2.4. The test rig was capable of not only pulling out the dowel bar but also pushing it back, if desired. The loading and unloading of the dowel bar was controlled manually in order to exercise the desired rate of loading and unloading.

Figure 2.5 schematically illustrates the test setup used in the experiments conducted in the laboratory. The concrete specimen [1] rests on a rigid steel plate [2], which in turn sits on a rigid base [3]. A double acting hydraulic cylinder [4] is placed on the specimen. To impart uniform pressure from hydraulic cylinder onto the specimen, a half-inch thick steel plate [5] is placed between the hydraulic cylinder and the specimen. The saddle [6] of the hydraulic cylinder is threaded on its outer diameter. One end of the saddle is connected to an adapter [7] at one end and a load cell [8] at the other end. The adapter ensures that the saddle and the load cell move in unison. The dowel bar [9] 
embedded in the concrete specimen is coupled to a bolt by a coupling nut [10]. The bolt passes through the holes, drilled at the center, of the adapter and the load cell. To maintain perpendicularity of the bolt, a spherical washer [12] is used as this eliminates the misalignment of the axis of the dowel bar and the bolt ensuring proper transverse loading and unloading of the dowel bar. A hexagonal nut [11] locks the whole set up at the end. The hydraulic cylinder is held firmly with the base steel plate with bolts [13] and nuts [14] and this arrests the relative motion between the concrete specimen and the hydraulic cylinder when the dowel bar is pushed back into the specimen. The spindle of the LVDT [15] rests on the surface of the load cell. The load cell and LVDT are connected to a data acquisition system [16].

\subsection{MATERIAL PROPERITIES}

\subsubsection{Dowel Bars}

All the dowel bars used in the experiments were of length 18 in. but two different diameters, namely 1.25 in. and 1.5 in were considered. The mechanical properties of the dowel bars are listed in Table 2.2. Appendix I contains a copy of the certificate of the steel properties of the dowel bars provided by the suppliers, American Highway Technology.

\subsubsection{Bond breaking agents}

Bond breaking agents were used to minimize the friction between the dowel bar and concrete. The bond breaking agents should not evaporate due to the heat of the hydration of the cement. The bond breaking agent would be effective if it does not become a hard brittle layer on the surface of the dowel bar upon drying. If coating becomes brittle upon drying it would easily get abraded during the displacement of the dowel bar. The coating should fill the asperities on the surfaces of the dowel as well as concrete. Examining the physical properties of the Tectyl (506) and silicone coating, it was recognized that they satisfied the basic requirements as bond-breaking agents.

\section{Silicone coating}


Silicone coating acts as an anti stick agent between contact surfaces. When applied on the cleaned surface of the dowel bar, it resembled a white shining layer. It is chemically resistant and acts as a good lubricant as well. It is resistant to moisture and oxidation. It is nonvolatile and can withstand wide range of temperature such as -57 to $204{ }^{\circ} \mathrm{C}$. It remains as a thin layer on the surface of the dowel bar. These desirable properties make it a good bond-breaking agent to minimize the friction coefficient at the dowel-concrete interface. The properties of Silicone coating are listed in Appendix II.

\section{Tectyl (506) coating}

Tectyl (506) coating is a non-volatile liquid. When a thin layer was coated on the dowel bar it formed a dry, translucent, brownish-yellow layer after drying completely in 24 hours. This film was slightly firm but not brittle. It protects the metal surface against corrosion as well. Appendix III contains the data sheet of Tectyl (506), which was provided by the supplier, Daubert Chemical Company, INC.

\subsubsection{Concrete properties}

The Hoy Redi-Mix Corporation, LLC supplied the ready concrete mix of type Class K for casting the specimens. A slump test, as per ASTM C143 (16), was conducted on the concrete resulting in an average slump of 2-3 in. Such a slump ensures a good balance between the concrete consistency required for workability during casting and the strength (17). For each cast of the specimens prepared, 12 to 18 standard cylinders 6 in. by $12 \mathrm{in}$. according to the ASTM C39 (18) were prepared to test for the compressive strength of the concrete on a standard compression test machine. The average compressive strength of the specimens with the 1.25-in. diameter dowel bar was found to be $3334 \mathrm{psi}$ on the 3rd day and $5830 \mathrm{psi}$ on the 28th day, and the slump of the concrete mix was 3 in. In the other set of specimens with 1.5-in. diameter dowel bars, the average compressive strength was found to be 955 psi after 24 hours and 4775 psi after 14 days and the slump of the mix was $2.5 \mathrm{in}$. 


\subsection{INSTRUMENTATION}

\subsubsection{Measuring the Applied load and Dowel Bar Displacement}

Sensors were selected for measuring the magnitude of the applied load, the displacement of the dowel bar, and strains in the concrete around and along the dowel bar. The load applied was to pull and push the dowel bar, by means of a double acting hollow plunger cylinder, manufactured by Enerpac, with a capacity of 60 tons and a stroke of $3.5 \mathrm{in}$. A precision load cell, which has a capacity of 50,000 lb. in tension, measured the applied load and its certified calibration sheet is included in Appendix IV.

Two different types of Linear Voltage Differential Transducers (LVDT) were used to measure the displacement of the dowel bar. The first LVDT was a model DLA (060-3621-02), manufactured by Sensotec with a range of \pm 1.00 in. The second LVDT was a model (060-A797-05), which was also manufactured by Sensotec with a range of \pm $0.50 \mathrm{in}$. In few of the tests conducted two different acquisition systems were used for data collection, CR10X datalogger to acquire data from vibrating wire strain gages, LVDT, and load cell and System 5000 to collect data from embedment strain gages and LVDT, which are detailed in the following section. Hence two LVDTs were used with each data acquisition system for correlation of data, as the displacement was the common parameter that could be measured by both data acquisition system, efficiently. The calibration certificates provided by Sensotec are included in Appendix V.

\subsubsection{Measurement of Shrinkage Strains in Concrete}

The selection of sensors, installation procedures for them, and location of instrumentation are based on experience gained from detailed three-dimensional finite element modeling of concrete pavements and long-term field measured response of concrete pavement sections constructed in Elkins, West Virginia (4). The magnitude of the frictional force at the concrete-dowel interface depends on the radial pressure exerted by the concrete on the dowel bar due to shrinkage in the early age of curing. Therefore, monitoring the shrinkage of concrete surrounding the dowel bar is essential in quantifying the concrete clamping force on the dowel bar. Vibrating wire strain gages work on the vibrating wire principle. A steel wire is tensioned between two end blocks, 
made of steel. This wire vibrates at its natural resonant frequency. The frequency varies according to the wire tension. The electromagnetic coil stationed around the wire, senses and measures the frequency of the tensioned wire. The advantage of these gages is that the frequency signals are transmitted to a long distance without any of effect cable resistance to ambient conditions and these are highly resistant to corrosion. Two types of vibrating wire strain gages were used, models VK-4100 and VK-4150 manufactured by Geokon Instrumentation Company. Both models are similar except for one feature. The VK-4150 model has small flanges at the two end steel blocks, while the steel blocks in VK-4100 model are free from flanges. The gage length of these strain sensors is $2.25 \mathrm{in}$. with a diameter of $0.25 \mathrm{in}$. The gages have a range of $\pm 2500 \mu$-strain and a sensitivity of 0.5 to $1 \mu$-strain.

A novel and unique technique of sensory system was developed to measure the shrinkage strains in concrete. This sensory system was capable of measuring continuously the shrinkage strains in concrete and also the strains in concrete at the dowel bar during dowel pull-push operation. The sensory system consisted of a pair of vibrating wire strain gages (either VK 4100 or VK 4150) arranged in a cross pattern, one on top of the other.

To accommodate the strain gages, two diametrical U-slots of $0.25 \mathrm{in}$. width are machined at one end of the dowel bar as shown in Figure 2.6. The length of one slot is 1.75 in. while that of the other is 2 in.. The grooves surfaces were smoothened to eliminate any sharp edges and surface asperities, since these might affect the gage sensitivity. The machined dowel bars were cleaned thoroughly to remove grease and other impurities from the surface. The end of the cleaned dowel bar with U-slots was dipped into a hot molten wax and allowed to dry. This process was repeated until a thin layer of wax was formed on the machined slots. A vibrating wire strain gage was positioned into the longer U-slot without any inclination, in such a way that the longitudinal axis of the dowel bar bisects the length of the strain gage. And it was firmly fixed in place by pouring a moderately cool liquid wax. Holding the strain gage in this way, the two end steel blocks protrude out of dowel bar to be clamped by the surrounding 
concrete after casting of the specimens. After the first gage was set in place, a second strain gage was fixed in a similar fashion, as shown in the Figure 2.7. The surface of the dowel was cleaned from lumps of wax in order to place a plastic sleeve, which closes around circumference and the end of the bar. A small amount of molten wax was poured into the plastic sleeve, to hold the sensors in the slots properly. The lead wires of the vibrating wire strain gages were soldered to extension cables. The soldered ends of the wires emerging from the strain gages were managed to avoid any contact from each other in order to obtain a noise free and continuous signal during data collection. Prepared epoxy resin was poured into the plastic sleeve that encloses the machined grooves and strain gages and was allowed to cure. After the epoxy resin was completely cured and hardened, the surface of the dowel bars was cleaned from wax and epoxy resin, Figure 2.8. The dowel bar was heated at the free end slightly to melt the wax layer to ensure the free movement between the cast epoxy socket and the dowel bar as shown in Figure 2.9. This was to ensure that the epoxy-socket securing embedded strain gages remained in the concrete to record strains when the dowel bar is pulled out. Finally, the surfaces of end blocks of the strain gages were cleaned thoroughly to attain direct contact with the concrete surface.

The VK-4150 strain gages were used with the 1.25 in. diameter dowel bars, shown in Figure 2.10, and the VK-4100 strain gages with the 1.5 in. diameter dowel bar. The flange edged VK-4150 would not provide enough clearance around the dowel bar for proper concrete adhesion in the case of 1.5 in. dowel bar. Embedment strain gages (EGP5-120 series resistance type) supplied by Micro Measurements were used to record longitudinal strains. The embedment strain gages are special purpose strain gages to embed in the concrete to measure the strains accurately. In the present experimental study, these gages were used to measure the strains in the concrete in the longitudinal direction of the dowel bar during dowel pulling and pushing operations. They consist of $\mathrm{K}$-alloy strain gages mounted on a carrier and cast into a proprietary polymer/cement composite material. This entire assembly measures the concrete strains after the embedment. The strain gage has resistance of $120 \Omega$ with a gage factor of 2.05 and a gage length of 4 in. The embedment strain gages were held in the position by fastening 
their ends to the dowel bar, as shown in Figure 2.11. But in the case of the 1.25-in. diameter dowel bars, only instrumented dowels to measure the radial strains, vibrating wire strain gages were used to measure the longitudinal strains. The clearance between the gages would not accommodate for proper installation of the embedment strain gage.

\subsection{POSITION OF CONCRETE SPECIMEN AND DESIGNATION OF STRAIN GAGES}

The orientation of the concrete specimen during casting was different from that during testing. During casting of the specimen, the longitudinal axis of dowel bar was parallel to the ground as shown in Figure 2.12. When the test was conducted, the longitudinal axis of the dowel bar was perpendicular to the ground as shown in Figure 2.13. The strain gages were designated by assigning an $x, y, z$ coordinate system to the concrete specimen as seen in Figure 2.12. The strain gages used in $y, z$ directions were vibrating wire strain gages, which were perpendicular to each other and perpendicular to the longitudinal axis of the dowel bar, whereas the embedment strain gage was along the axis ( $x$-axis) of the dowel bar. During the test, the strain gages in $y, z$ directions measured the change in strains in the concrete in radial direction and the embedment strain gage in the axial direction.

\subsection{DATA ACQUISITION}

All the sensors used in the tests are connected to two data acquisition systems to collect and store data acquired. The first data acquisition system is a datalogger manufactured by Campbell Scientific Company. It has a CR10X control module with multisensor interface and a SC32A RS232 interface. These features enable it to connect multiple types of sensors to it, using 8032 16/32 channel multiplexer, and to collect and store measurements from all the sensors with specific time intervals. The MultiLogger Software 2.1.0 version specifically designed for Campbell Scientific Products is used to execute all the operations of datalogger. In order to ensure the accuracy of the data recorded using the datalogger, the load cell, embedment strain gages, and LVDT's are periodically calibrated with datalogger to adjust the gage factor in the configuration file 
of the MultiLogger Software. The calibration procedures are briefly explained in the next section.

The second data acquisition system utilized is a System 5000 manufactured by Micro Measurements Group, and it is operated by Strain Smart software. It was specifically chosen for collecting data from embedment strain gages. It also contains modules, which can acquire data from load cells and LVDT's. It also has a provision to increase the number of channels.

\subsection{CALIBRATION}

\subsubsection{Calibration of LVDT with Datalogger}

The calibration setup for LVDT developed to adjust the gage factor in the MultiLogger Software is shown in Figure 2.14. The LVDT [1] with a range of $+/-1.00$ in. was held tightly with a clamp holder [2]. The clamp holder was fixed to a magnetic base [3], which sat on a flat highly polished smooth steel plate [4]. Once the entire set up was firmly fixed, the wires of the LVDT were connected to the datalogger [5]. The steps followed to connect the LVDT to the datalogger and configure multiplexer software file are detailed in Appendix VI. Known displacements, in very small incremental steps, were given to the LVDT using gage blocks [6]. The surfaces of gage blocks were thoroughly cleaned with a neat cloth and they were wrung perfectly to avoid thin films of air, which might alter the accuracy of the measurement. The corresponding values measured using the datalogger were noted. From these two sets of known displacements and corresponding measured value of displacement, the gage factor for the configuration file in the software was estimated. The obtained value of the gage factor was set in the configuration file and the process was repeated at regular intervals to check the repeatability and accuracy of measured values. With these sets of data, graphs were plotted to observe its measuring accuracy as shown in Figure 2.15.

\subsubsection{Calibration of Load Cell with Datalogger}

To calibrate the load cell, a special fixture was manufactured and the set up is shown in Figure 2.16. It consisted of a steel plate [1], 0.75-in. thick, 8-in. long and 8-in. wide, and a steel rod [2] of 1.25-in. diameter and 10-in. long, with one end threaded. The 
steel rod was welded strongly at the center of the plate to endure high pulling forces. The fixture was rigidly positioned on a flat base [3]. Over this, a single-acting hollow-plunger hydraulic cylinder, manufactured by Enerpac [4] was placed. The load cell [5] was placed over the actuator of the hydraulic cylinder and a pressure was applied to washer using a hand pump [6]. To provide uniform pressure to the load cell, a washer [7] 1.5-in. thick and with the same outer diameter of the load cell was placed between the cylinder and the load cell. A bolt passing through the load cell was connected to the steel rod welded to the steel plate by a coupling nut [8]. A hexagonal nut [9] locks the whole system from the other end of the bolt. When the actuator of the cylinder was moved, it would exert uniform pressure on the load cell.

Then the load cell was connected to its reading unit as well as the datalogger [10] and the sequence of steps followed to connect it is detailed in Appendix VI. A considerable amount of pressure was applied to the load cell using the hydraulic cylinder, which generates tensile forces in the steel rod and these tensile forces which were measured by the load cell. From the recorded sets of data from the reading unit and datalogger, the gage factor was estimated. After setting the gage factor in the MultiLogger software the process was repeated and readings were taken. With the recorded data, a calibration curve for the load cell was plotted, as shown in Figure 2.17.

\subsubsection{Validation of Datalogger Strain Reading using Bridge Completion Module}

The embedment strain gage consists of a long strain gage grid. The embedment strain gage is sensitive to changes in strains in the direction of the long axis of the gage. It is connected to the strain gage instrumentation as a one-quarter bridge.

The motive was to record all the measurements obtained from these strain gages during the test using the datalogger. To determine the gage factor and ensure the accuracy of the embedment strain gage the measured strains using datalogger, the gage was calibrated as follows. A method was devised to validate the embedment strain gage readings. In this method, a foil type uni-axial resistance strain gage, connected to instrumentation as a one-quarter bridge, was used which was similar to long strain gage grid as the one present inside the embedment strain gage. Two of these resistance strain 
gages were bonded meticulously following the steps of bonding instructions at the midpoint on the machined flat surface of the steel round bar as shown in Figure 2.18. One of the strain gages was connected to the standard data acquisition system, System 5000, which scans the strains at specified sampling rate, while other gage was connected to another data acquisition system, CR10X datalogger, to which it should be calibrated. The CR10X datalogger is designed to record data from a resistance strain gage, which has full bridge resistance. The resistance strain gage was converted into full bridge resistance by connecting it to a bridge completion module. The output from this circuit was connected to the datalogger through multiplexer. The instrumented bar was simply supported at the ends placed on rigid base as shown in Figure 2.19. The test set up is similar to a three-point bending test rig, illustrated in Figure 2.20. A point load was applied at the midpoint of the bar. To minimize the errors, care was taken to adjust the point of load application to coincide exactly with an imaginary line passing through the point at which resistance strain gages were bonded. The load cell was placed over the pressure plate to record the amount of load being applied. The load cell was connected to the CR10X datalogger through the multiplexer. When all the circuit connections were complete, an axial load was applied to the bar by slowly rotating the handle to move the ram towards the bar. The data from the two resistance strain gages were recorded into their respective data acquisition systems. From this comparison, the gage factor for the datalogger was estimated. The same procedure was repeated until measurements from both the data acquisition systems matched with each other. From the loads recorded theoretical strains were also calculated, equations are as follows,

Stress, $\boldsymbol{\sigma}=M C / I$, where $M=P L / 4$ and $I=\pi d^{4} / 64$.

Strain, $\boldsymbol{\varepsilon}=\sigma / E$

All the three strains measured and calculated were plotted as a function of time as shown Figure 2.21. The measured strain using the datalogger and theoretical strains were calculated and plotted against the applied load in Figure 2.22. From the graphs it can be 
observed the measured strains were about the same as the theoretical strains. Hence, the embedment strain gage measurements were calibrated..

Table 2.1 List of specimens prepared

\begin{tabular}{|c|c|c|}
\hline Description of & \multicolumn{2}{|c|}{ Number of specimens prepared } \\
\cline { 2 - 3 } specimen & 1.5 -in. diameter & 1.25 -in. diameter \\
\hline $\begin{array}{c}\text { Uncoated Dowel } \\
\text { Bars }\end{array}$ & 3 & 3 \\
\hline $\begin{array}{c}\text { Silicone Coated } \\
\text { Dowel Bars }\end{array}$ & 3 & 3 \\
\hline $\begin{array}{c}\text { Tectyl (506) Coated } \\
\text { Dowel Bars }\end{array}$ & 3 & 3 \\
\hline $\begin{array}{c}\text { Total number of } \\
\text { Specimens }\end{array}$ & 9 & 9 \\
\hline
\end{tabular}

Table 2.2 Material properties of steel dowel bar

\begin{tabular}{|c|c|c|c|}
\hline Description & Yield strength & Tensile strength & Elongation \\
\hline $\begin{array}{c}\text { SMI Steel, SC } \\
\text { Dia., 1 1/2 and 1 1/4 in. } \\
\text { (ASTM A615M-96A) }\end{array}$ & $\begin{array}{c}73,800 \mathrm{psi} \\
(508.9 \mathrm{MPa})\end{array}$ & $\begin{array}{c}99,800 \mathrm{psi} \\
(687.8 \mathrm{MPa})\end{array}$ & $14.0 \%$ \\
\hline
\end{tabular}




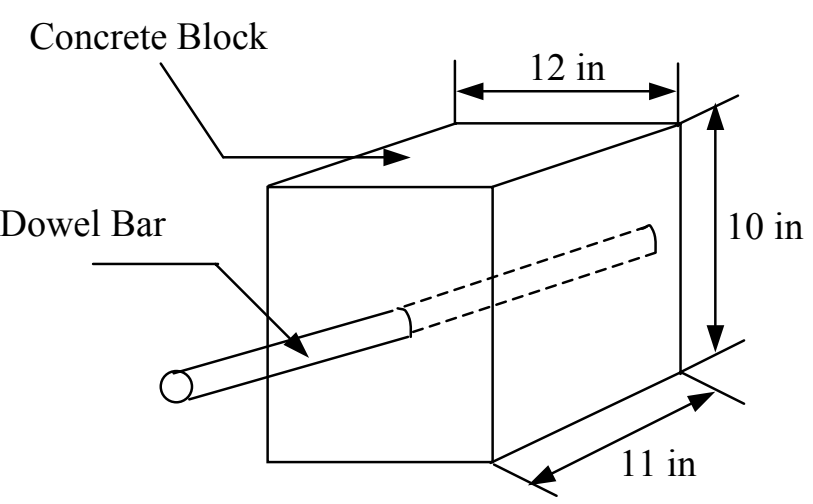

Figure 2.1 Dimensions of concrete specimens

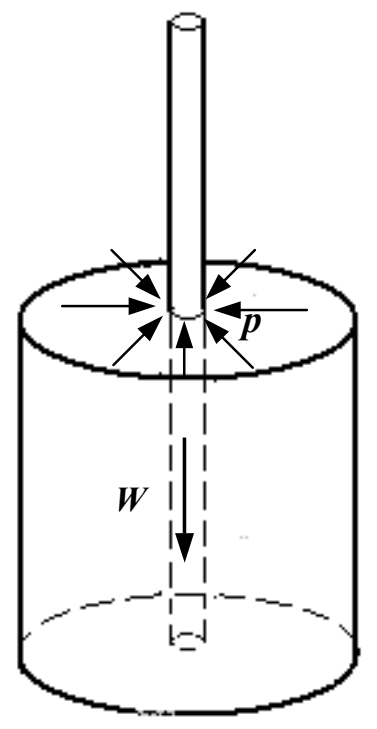

(a)

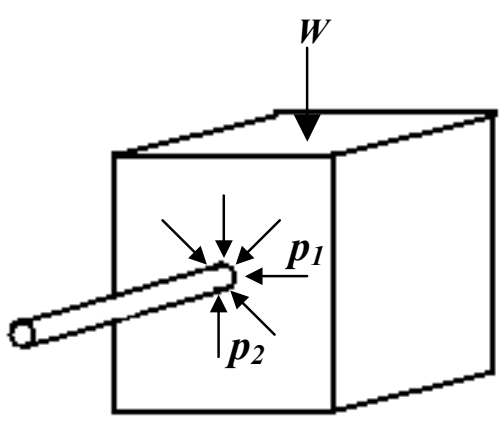

(b)

Figure 2.2 Stress fields around the dowel bar in cylindrical and prism specimens 


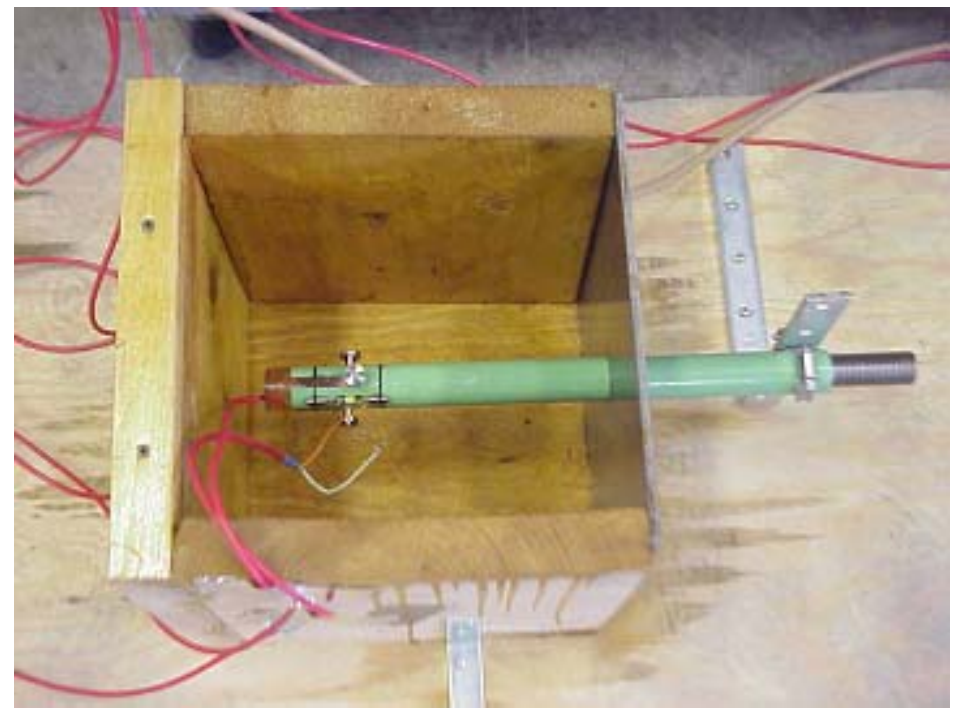

Figure 2.3 Dowel bar fixed in a wooden form for casting

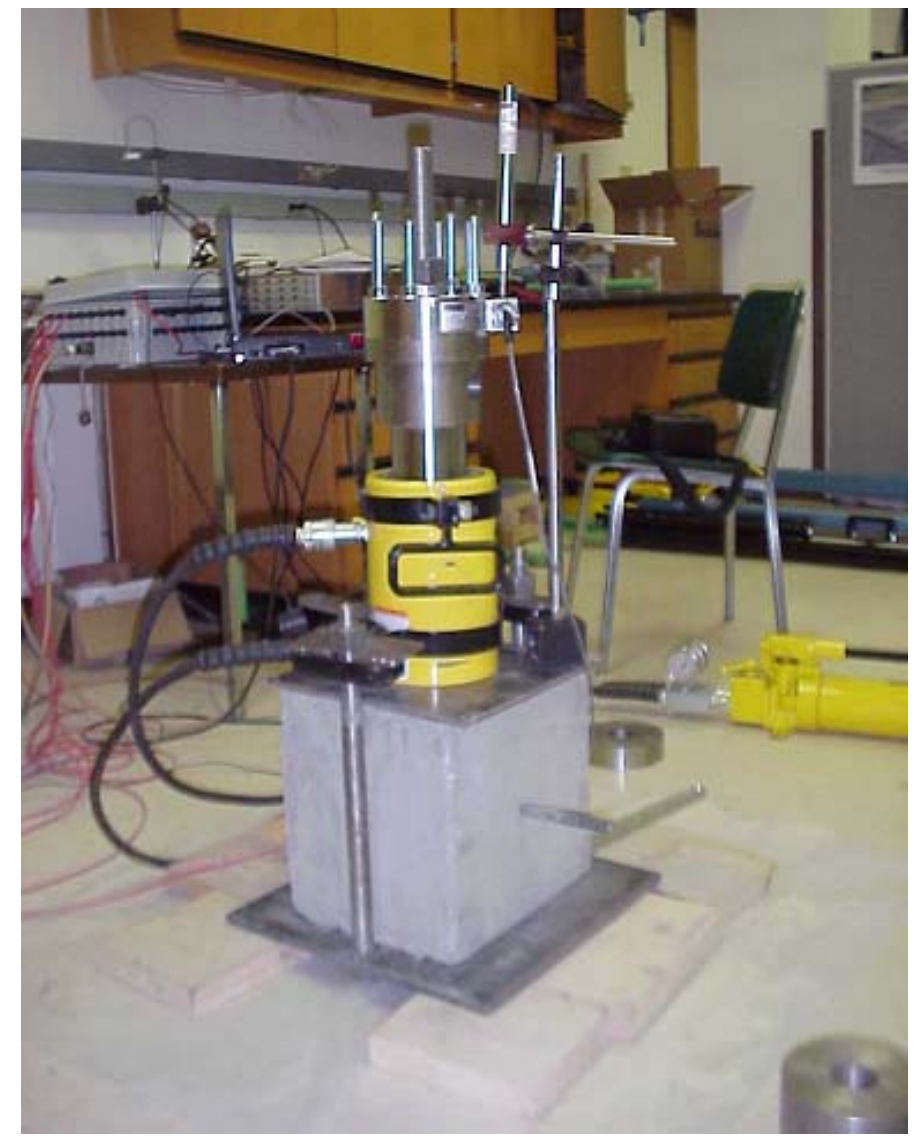

Figure 2.4 Test rig 


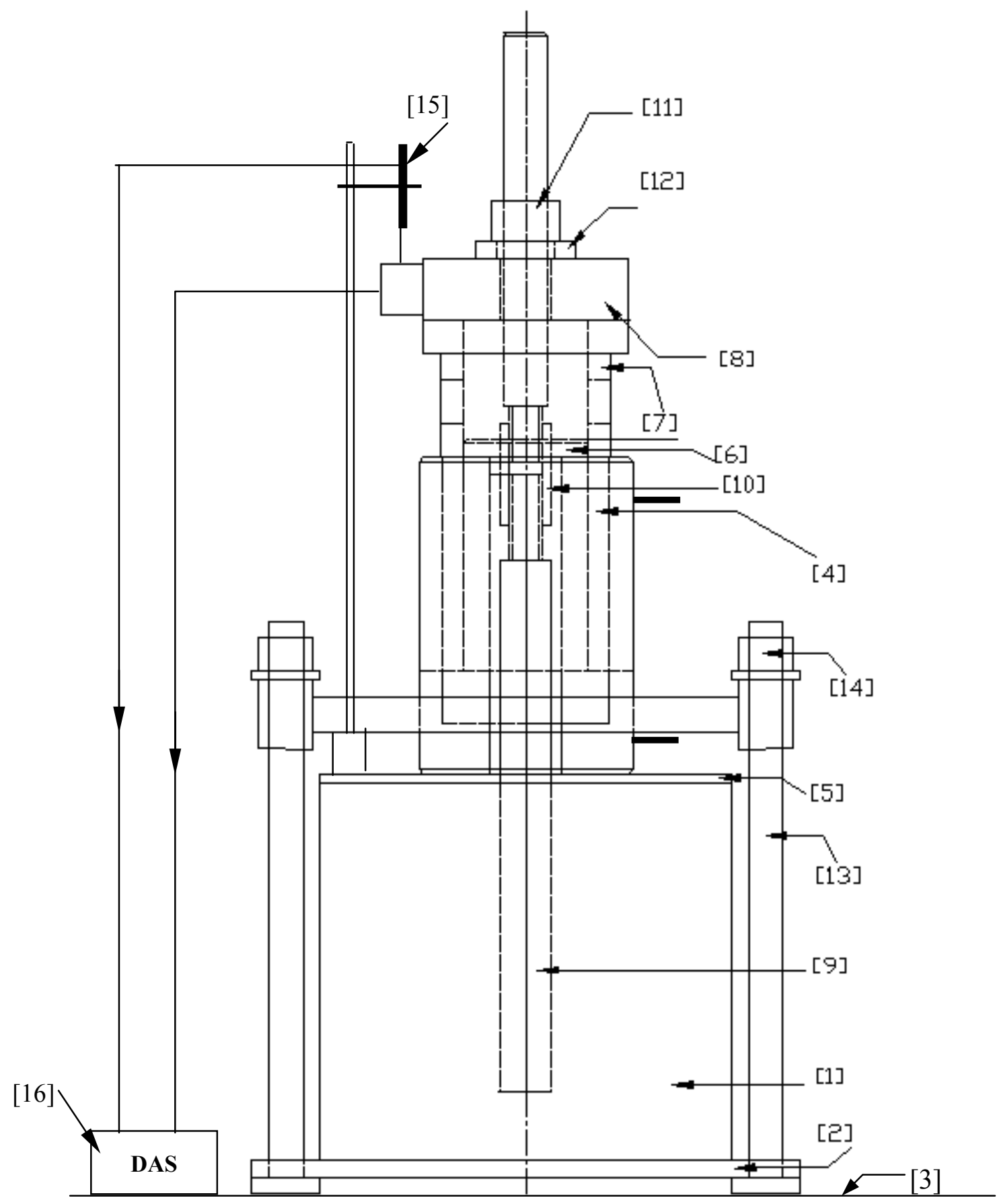

Figure 2.5 Schematic drawing of the test rig 


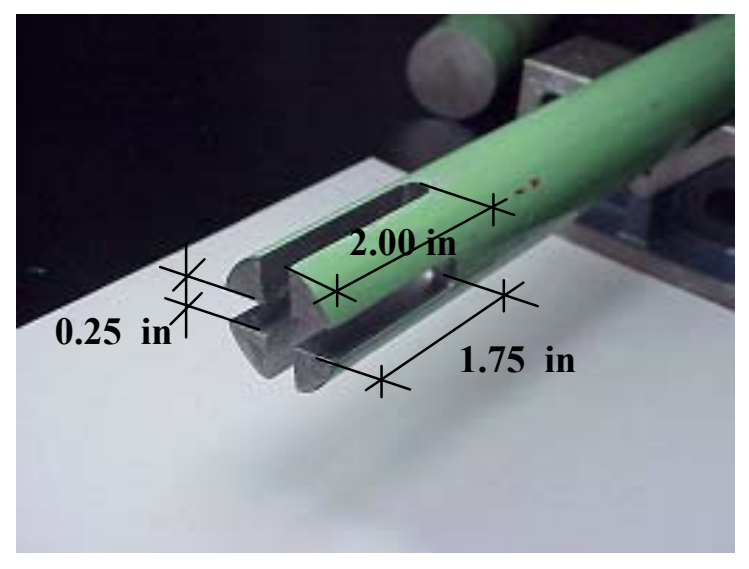

Figure 2.6 Machined dowel

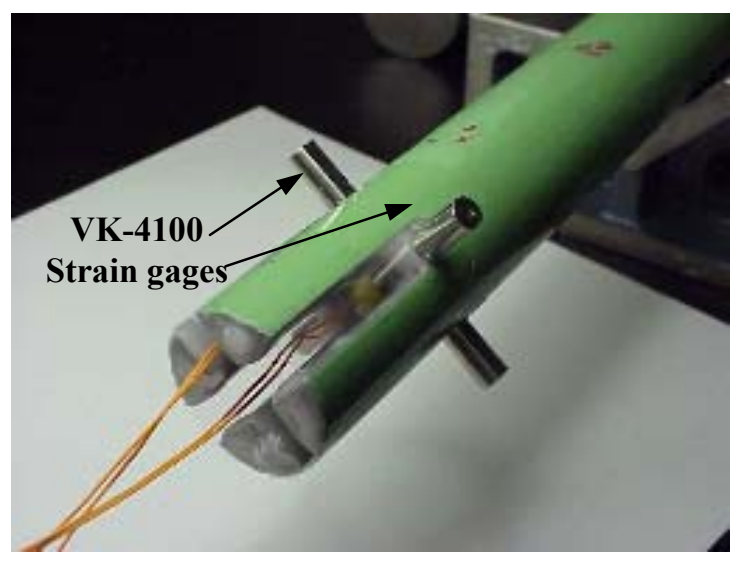

Figure 2.7 Strain gages fixed with wax in dowel bar

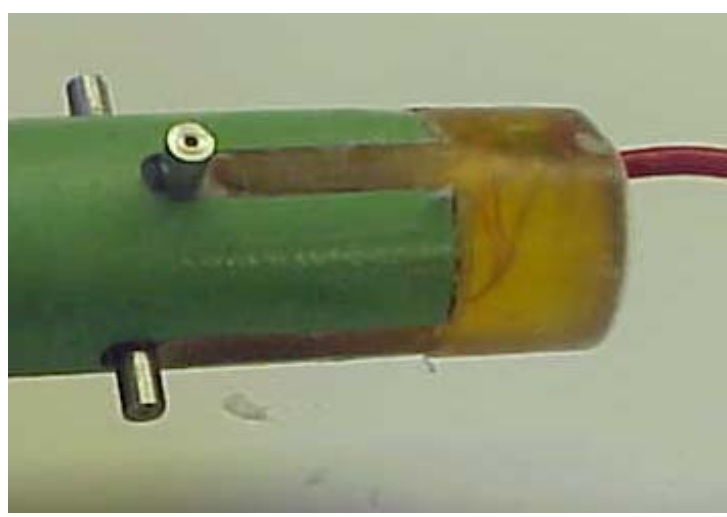

Figure 2.8 Strain gages in epoxy-socket 


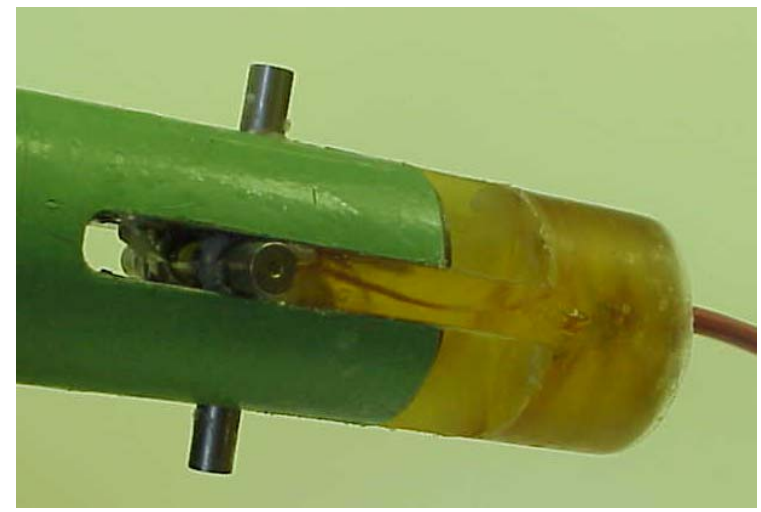

Figure 2.9 Strain gages in epoxy-socket detached from dowel bar

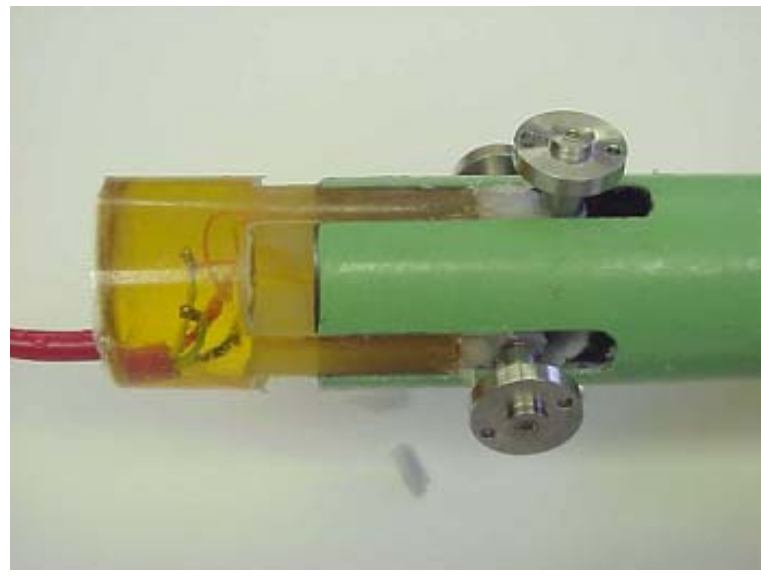

Figure 2.10 Instrumented dowel with VK-4150 strain gages

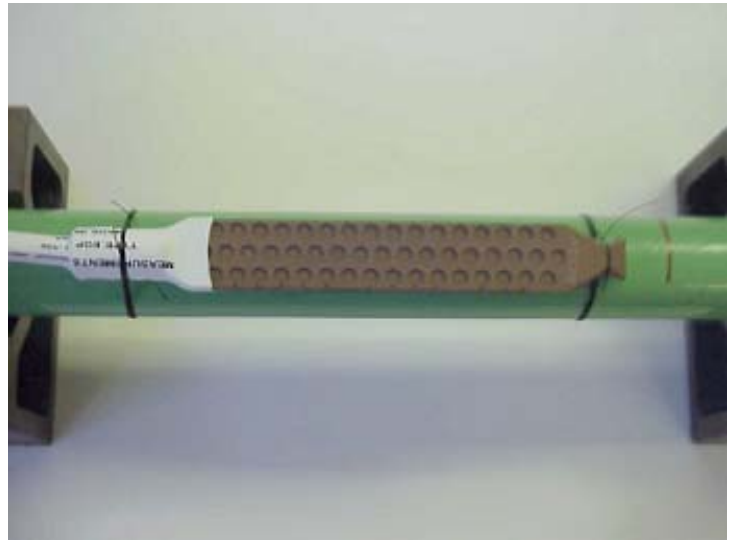

Figure 2.11 Embedment strain gage installed on the dowel bar 


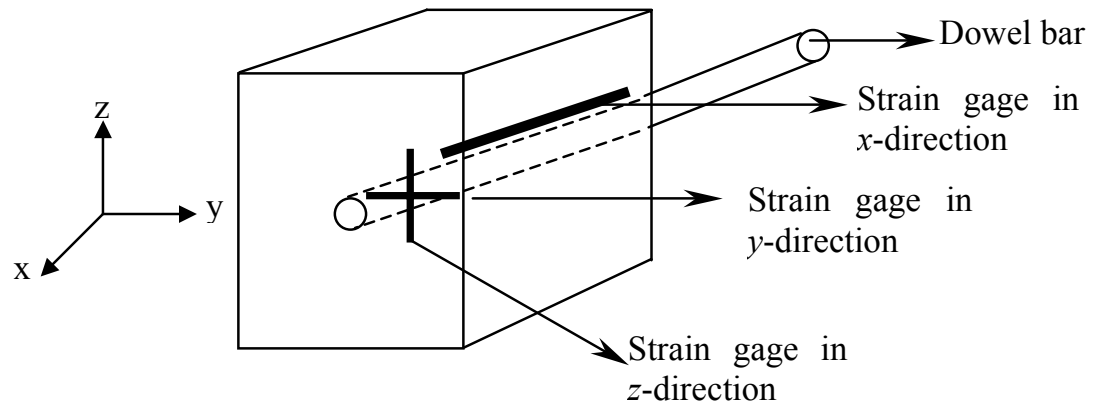

Figure 2.12 Schematic picture depicting the position of the specimen during casting

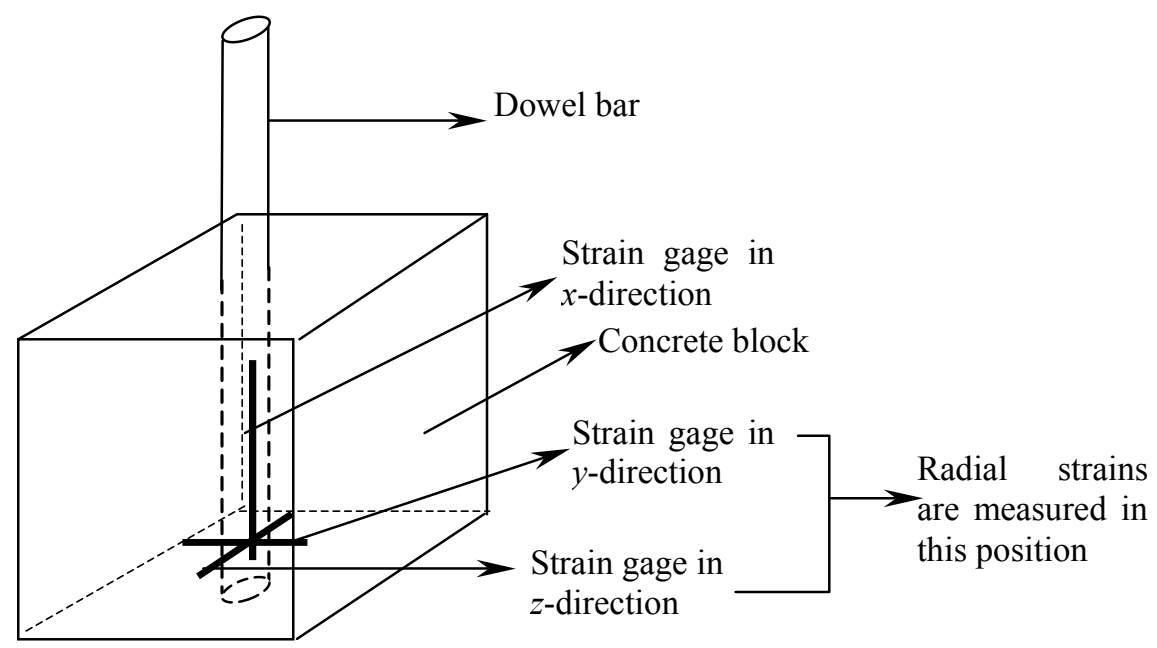

Figure 2.13 Schematic picture depicting the position of the specimen during test phase 


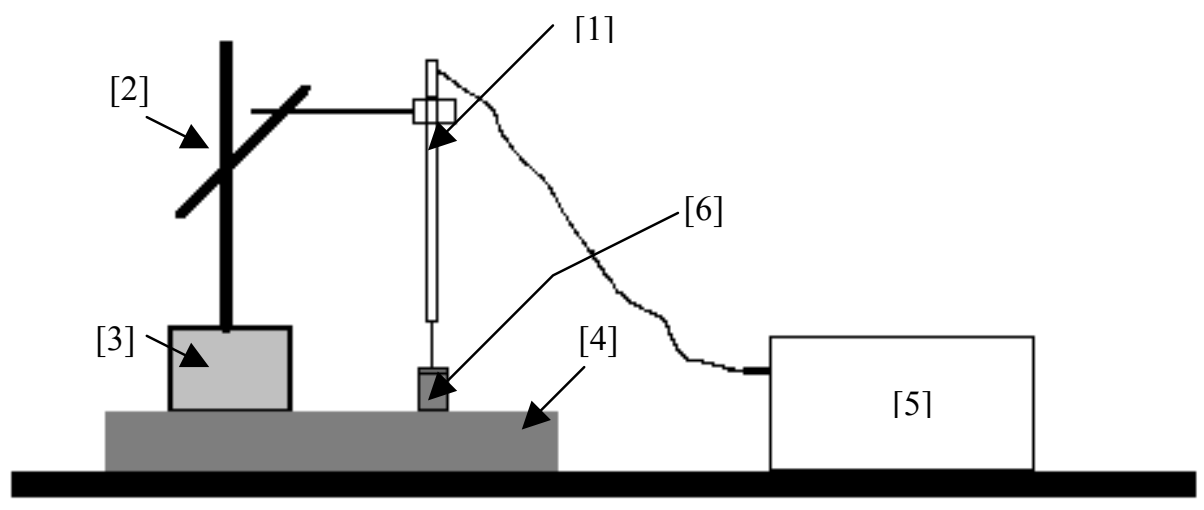

Figure 2.14 Calibration set up of LVDT

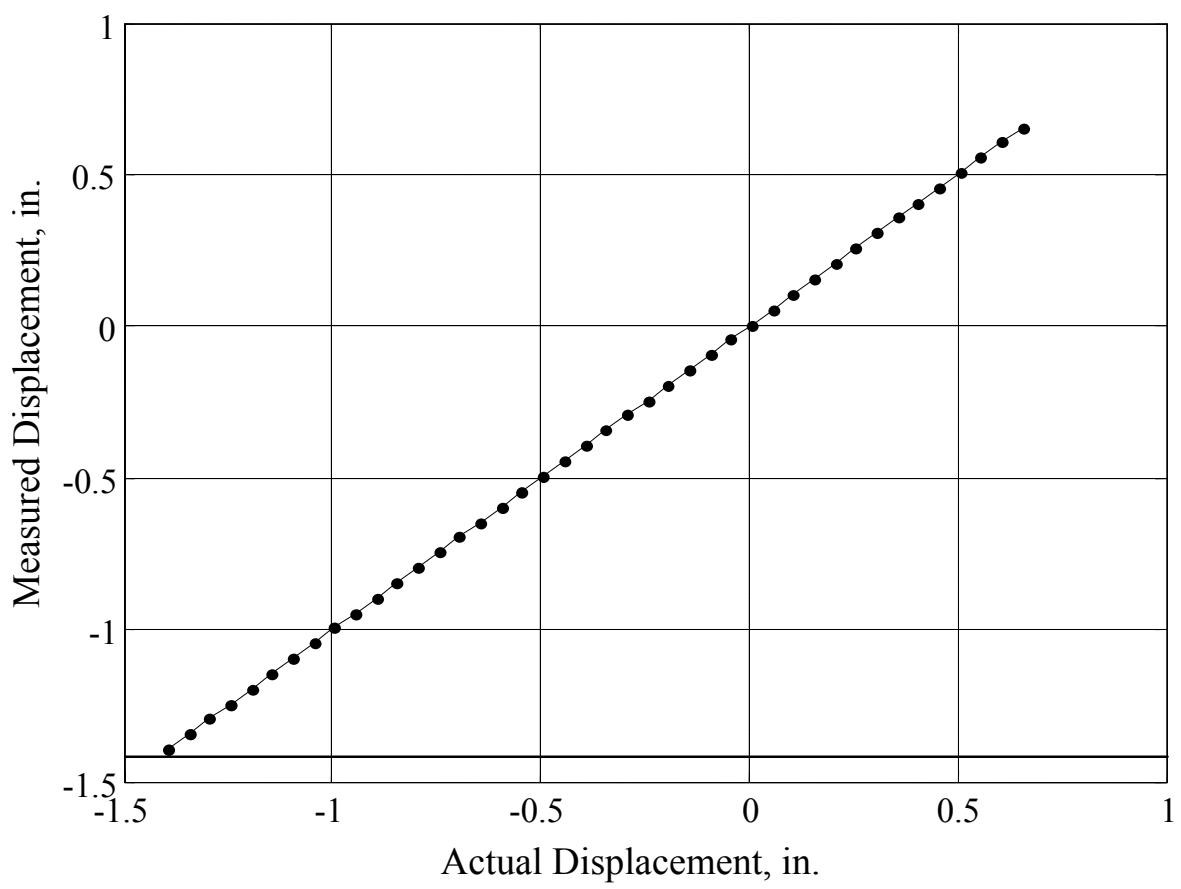

Figure 2.15 Calibration chart of LVDT 


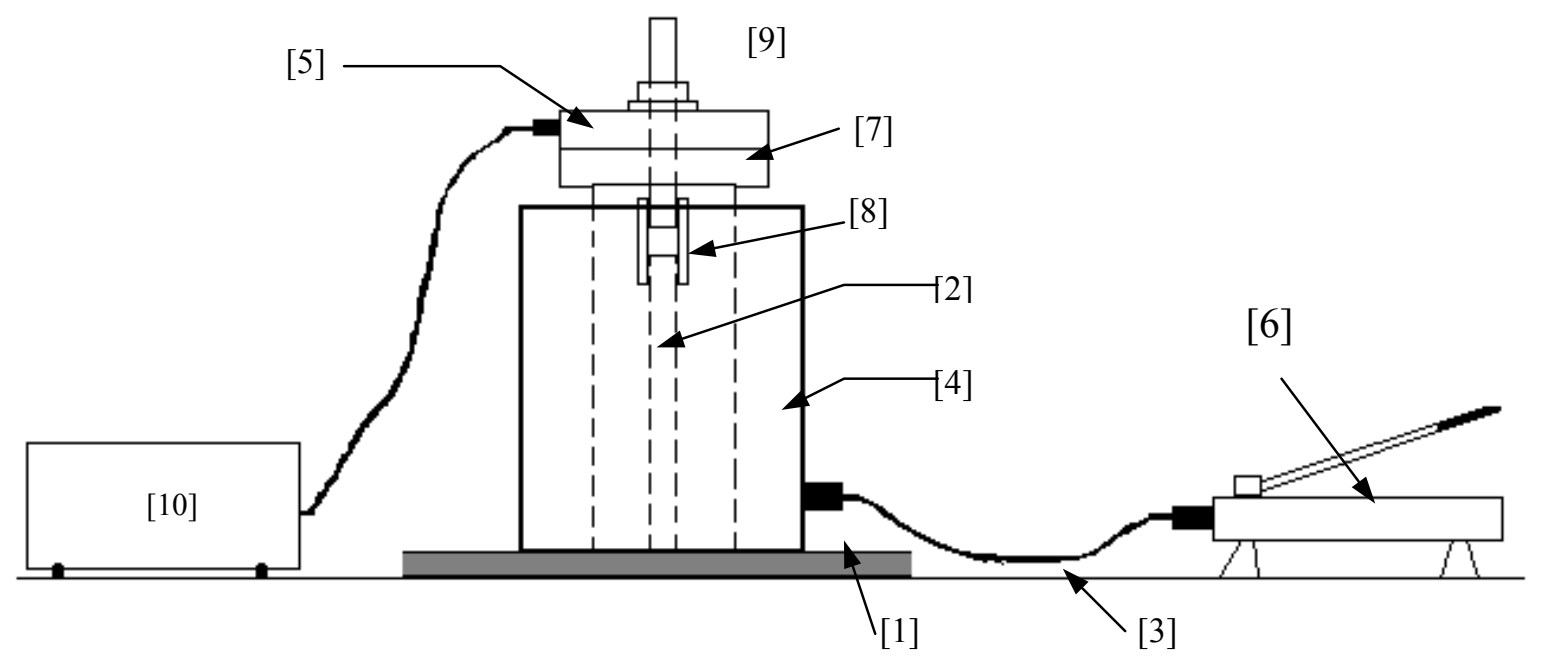

Figure 2.16 Calibration set up of the load cell

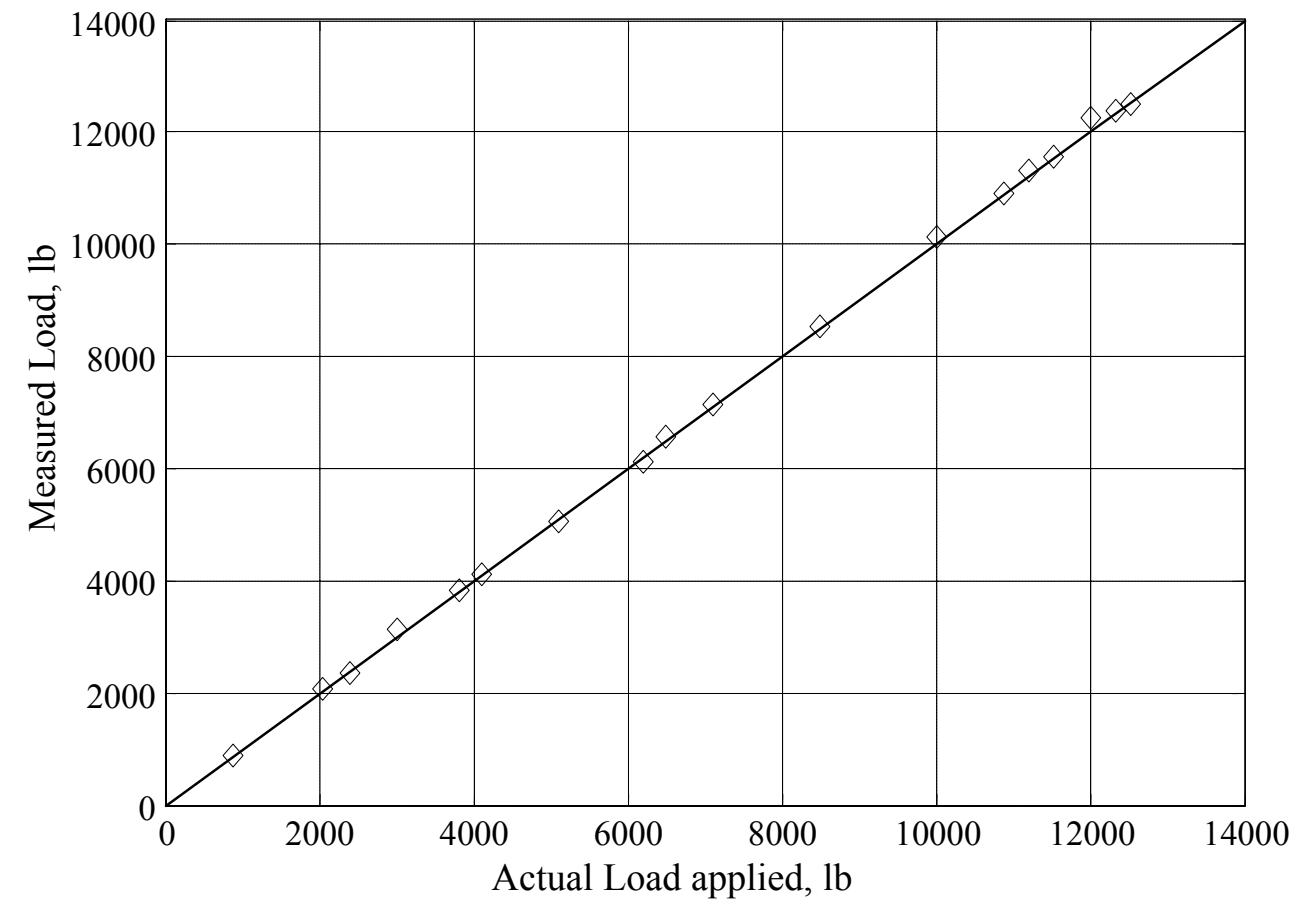

Figure 2.17 Calibration chart of load cell 


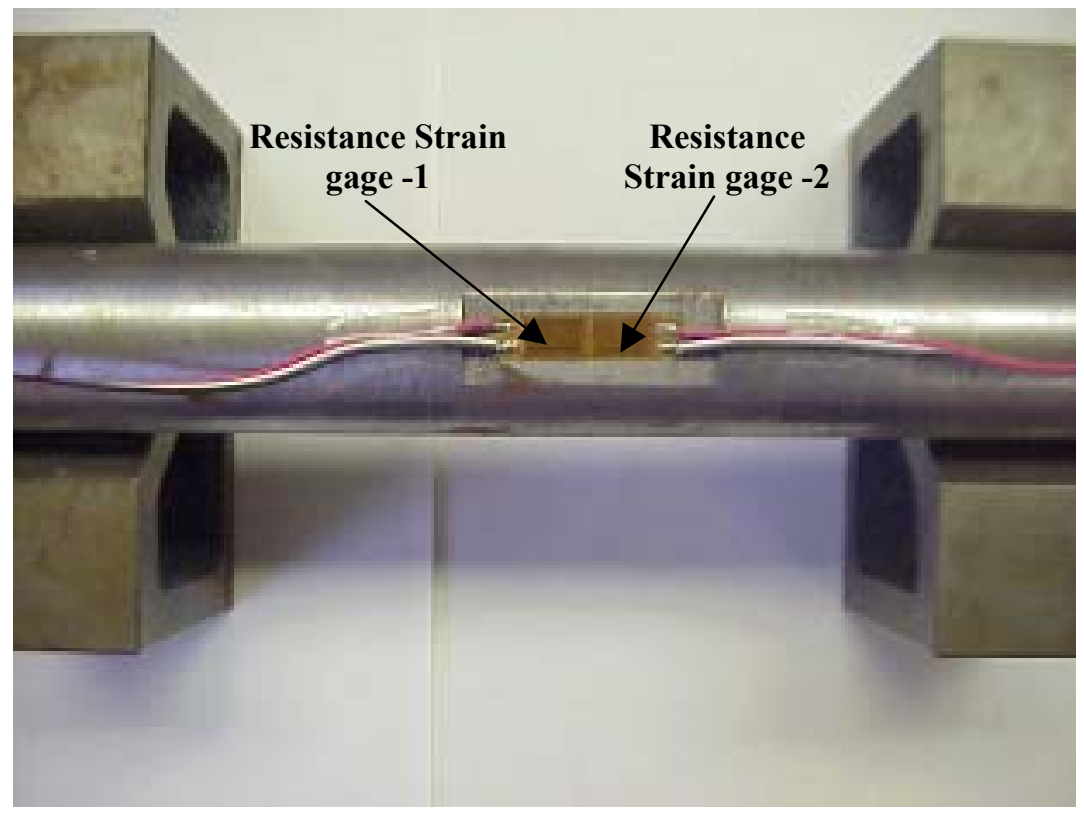

Figure 2.18 Bonded resistance strain gages on dowel bar

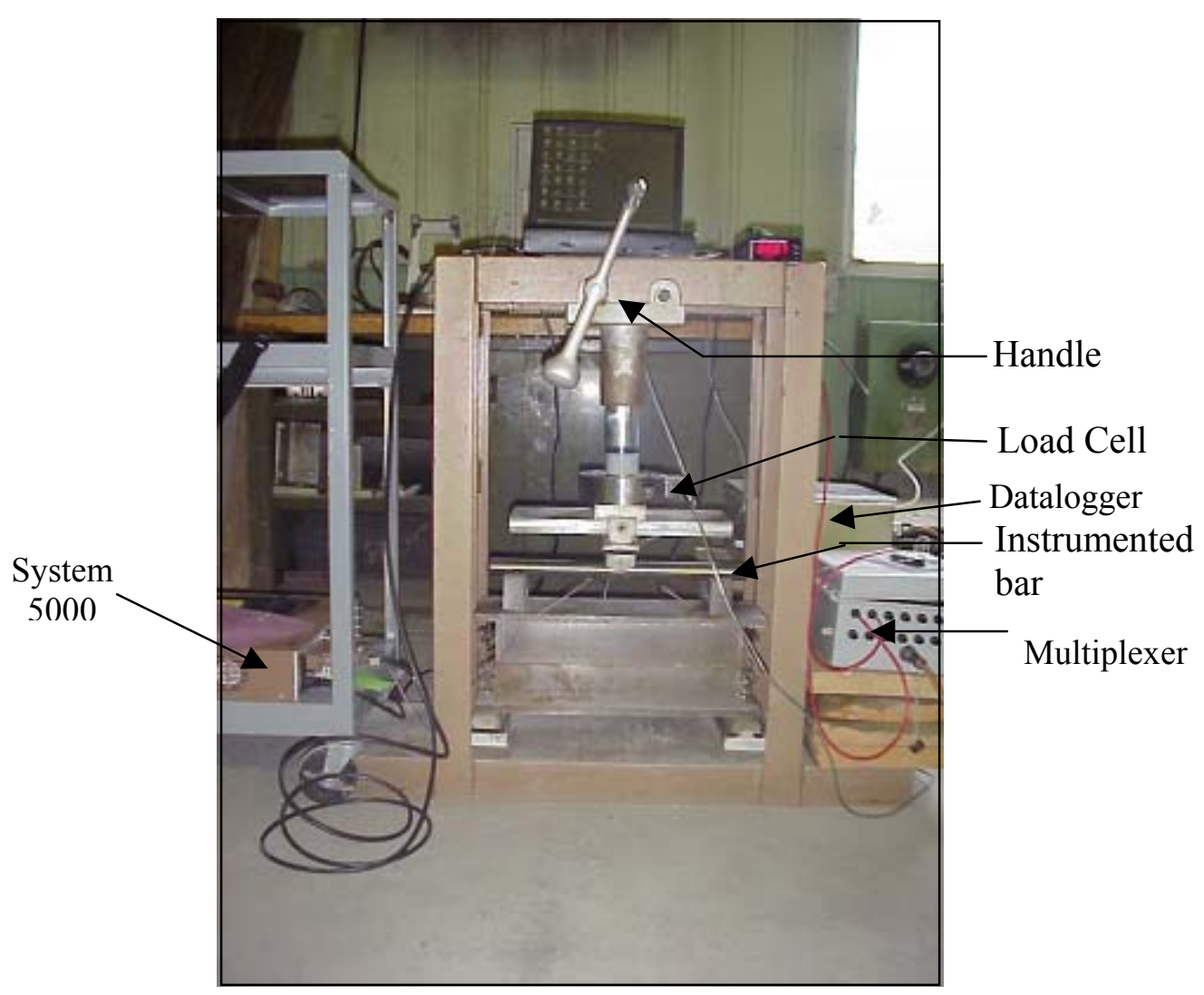

Figure 2.19 Calibration set up for embedment strain gages 


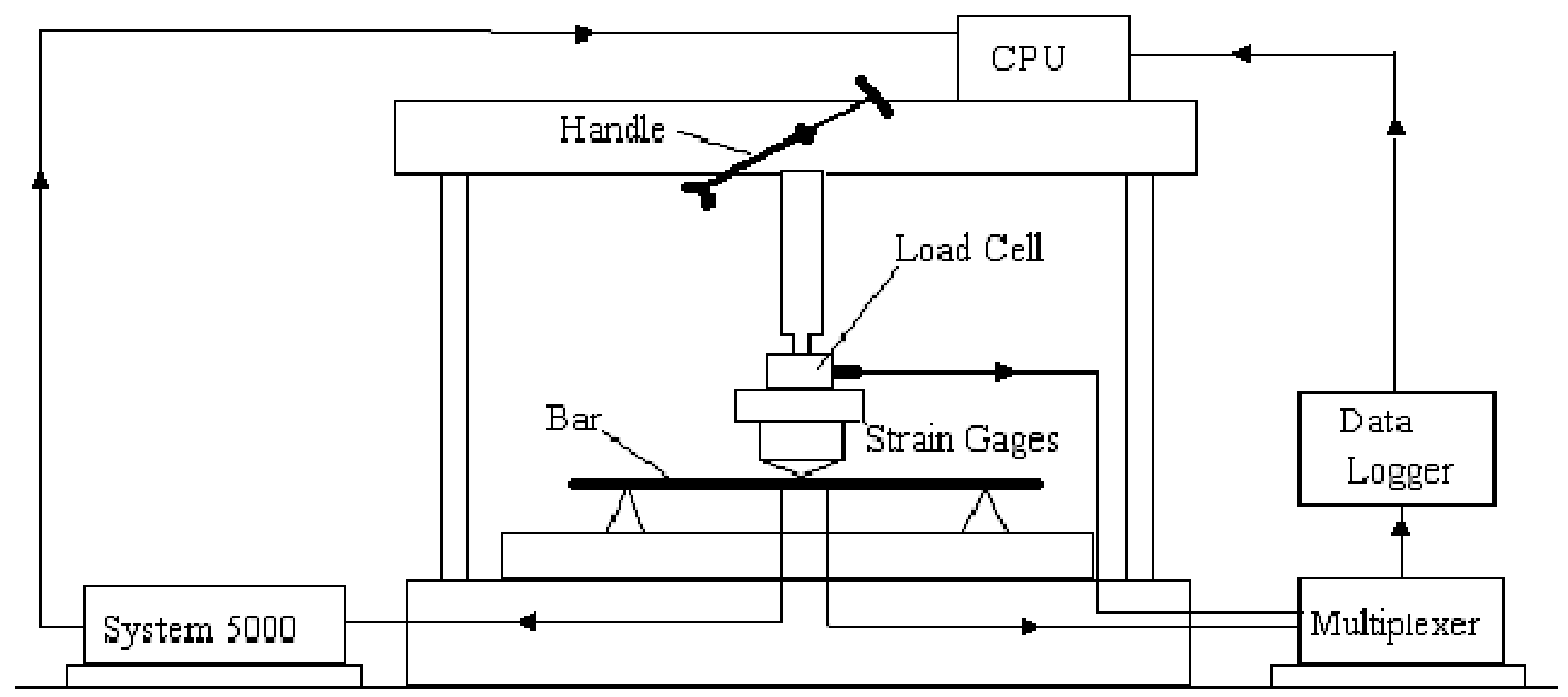

Figure 2.20 Schematic picture of calibration set up of embedment strain gages 


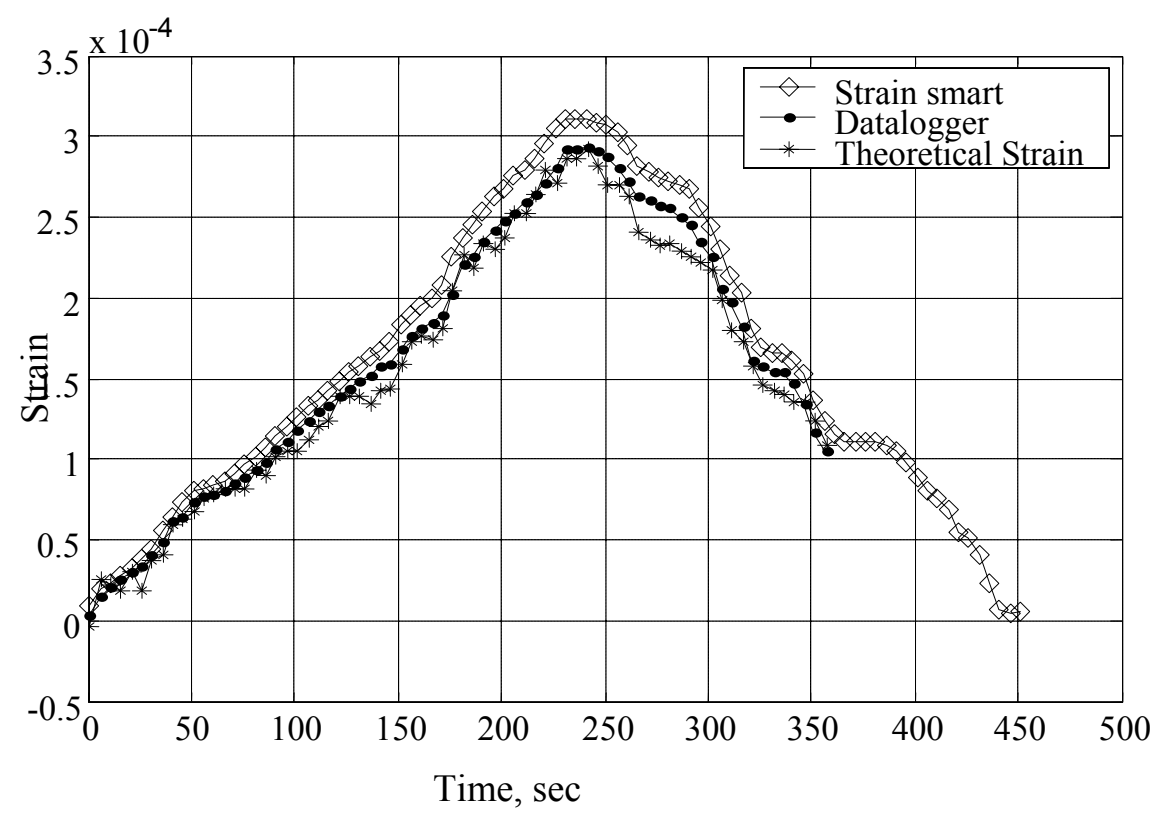

Figure 2.21 Comparison of strains measured from data acquisition systems and theoretical strains

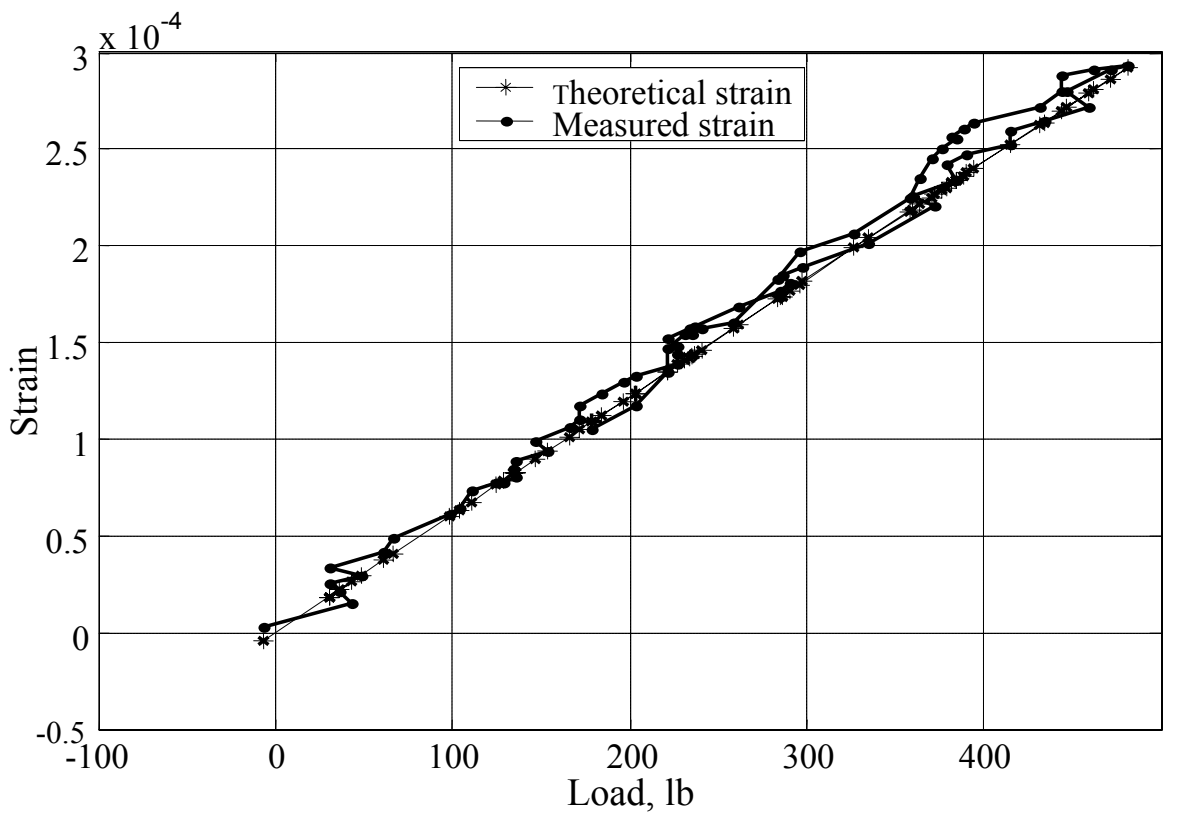

Figure 2.22 Calibration curve of embedment strain gage 


\section{CHAPTER THREE EXPERIMENTAL RESULTS}

\subsection{INTRODUCTION}

In this chapter, the experiments conducted using the set up described in Chapter 2 are detailed. Results in the form of strain histories in concrete around the dowel bar during curing and the magnitude of the pullout force required are presented. The results presented in the form of tables and graphs are analyzed to reveal trends and some major conclusions are drawn.

\subsection{STRAINS RECORDED IN THE CONCRETE DURING CURING}

The readings of the vibrating wire strain gages embedded in the concrete were zeroed just after casting and the strain as a function of time was recorded. To ensure perfect contact between gages and concrete without any voids, the concrete had been vibrated and compacted thoroughly during casting. Figure 3.1 illustrates the comparison of the strain-time histories in the concrete at the dowel bar in the $y$ and $z$ directions during the first two days among the specimens with uncoated, Silicone coated and Tectyl coated dowel bars before any pullout or push-in test was conducted. In the first one and half hours after casting, strain gages in the $y$ and $z$ directions for all cases indicated compressive strains due to contraction of the concrete while the temperature was low during this phase.

At Point $B$, of these graphs, it can be seen that the direction of the strain changed toward tensile values. Tensile strains were recorded as concrete expanded due to rise in temperature (18). This rise in temperature could be attributed to the exothermic reaction associated with the hydration of the cement. Tensile strains in $z$-direction were lower than the strains recorded in $y$-direction, as the weight of concrete acting in $z$-direction opposes the elongation of the gage. The gage in $y$-direction might bend due to weight of concrete acting on protruding blocks of strain gages, as illustrated in Figure 3.2. Hence, it could be surmised that the horizontal orientation of the dowel bar during casting, which 
replicates the field conditions, generated non-uniform strains in concrete around the dowel bar.

Approximately after 18 hours, at Point $C$ shown in Figures 3.1, the strains began to change toward the compressive direction in all cases. This could be due to drop in temperature as the process of cement hydration started to retard. Consequently, the concrete again started to contract due to low temperature prevailing in addition to a significant rise in shrinkage rate of concrete. The concrete around the uncoated dowel contracted more during first one and half hour than the coated dowel bars, as there was no debonding agent to restrain contraction. The difference in value of strains recorded among specimens could be due to variation of pressure exerted by the debonding agent coated on dowel surface, which opposed the contraction of concrete at the interface.

\subsection{LOAD DISPLACEMENT CURVES}

As mentioned before, pullout and push-in tests were conducted to estimate the bond strength of the uncoated dowel and coated dowel bars in concrete. During a typical test, the dowel bar was pulled out until it started to slide with a constant force. In the specimens with uncoated and coated dowel bars, the dowel bars were observed to start sliding within 0.04 in. of dowel displacement, therefore in all the tests the dowel bar was displaced by about 0.04 in. The radial and axial strains and loads in the concrete were recorded during the tests at particular intervals to understand the mechanics of dowelconcrete interface during the displacement of dowel bar. The tests were conducted two times to observe the effect of shrinkage and gain in compressive strength of concrete on the bond strength of concrete-dowel interface. In the case of 1.5-in. diameter dowel specimens, the first and second tests were conducted after two days and again after eights days since casting. Due to certain technical issues, the first and second tests could not be conducted at regular intervals on all the specimens with 1.25-in. diameter dowel bar. In each test, the cycle of pullout and push-in was repeated ten times to determine the change in the bond strength. 


\subsubsection{Uncoated dowel bars}

\section{Dowel bar of diameter $1.5 \mathrm{in}$.}

During the first cycle of first test, the pulling forces were observed to increase linearly with dowel displacement until the bar was displaced approximately $0.02 \mathrm{in.} / 0.5$ $\mathrm{mm}$ as shown in Figures 3.3 - 3.5. At this stage it can be stated the coefficient of friction has reached its peak value, as the bar displaced with a minimum increase in pulling force further from this point. The average of the maximum pullout force of the three specimens tested was $5400 \mathrm{lb}$. During the push-back operation, the resistive force was small initially. Later on the resistance to push the dowel increased, even with a rise in loading rate. The resistance caused by the concrete aggregates at the interface would have opposed to pushing the bar back completely. The mean maximum compressive pushing force recorded was about $1500 \mathrm{lb}$.

In the tenth cycle, the pulling forces were considerably low during the displacement of dowel bar by $0.025 \mathrm{in}$. The maximum pulling force required for sliding the dowel was reduced to $3500 \mathrm{lb}$. But the pushing forces did not change, which might be due to the obstruction caused by fine aggregates of the concrete particles. A permanent displacement of the dowel bar from its original position was noted at the end of tenth cycle. Accumulation of abraded fine aggregates of concrete at the bottom of hole due to breakage of bond could have resulted in the permanent displacement of dowel bar.

From the second test, it was observed that the pulling forces increased moderately while the pushing forces remained the same. The further shrinkage of concrete in the time interval between first and second tests increases the clamping force of concrete around the dowel bar; and this in turn causes an increase in the pullout force. The resistance posed by the fine aggregates to the displacement of dowel bar during push back was observed to remain same, as there was no significant change in the maximum pushing forces. 


\section{Dowel bar of diameter 1.25 in.}

Figures 3.6-3.8 show the load-displacement curves of the specimens with the uncoated 1.25-in. diameter dowel bars. The frictional forces to pull the uncoated 1.25-in. diameter dowel bar were overcome when it was displaced about 0.015 in. from its initial position in the first test. After this point of displacement, the pullout load leveled off similar to that of the specimens with 1.5-in diameter dowel bars. While the bars were pushed back toward their original position, the pushing forces were observed to increase with a constant rate. It was observed that dowel bars did not reach their original position even with the increase in the pushing force as was the case with the 1.5-in. diameter dowel bars. The forces required to displace the dowel bar from its original position were higher after 21 days than those obtained after 14 days. As discussed earlier, the increase in the shrinkage of the concrete increases the clamping force of the concrete around the dowel bar, resulting in higher forces to pull the bar. But the pushing forces were observed to decrease after 21 days. This shows a decrease in the obstruction caused by the particles between the dowel bar and the concrete in this case. Consequently, it was able to push the dowel bar back more toward the original position than with the first test.

In both the cases of uncoated dowel bars, the slope of load-displacement curve was observed to decrease with increase in the number of cycles, which indicates a decrease in the amount of work required to displace the dowel bar. The resistance caused by the aggregates to the sliding of the dowel bars, would have been reduced due to grinding of the particles with the repeated cycles of loading and unloading.

\subsubsection{Silicone coated dowel bars}

\section{Dowel bar of diameter 1.5 in.}

The average maximum pulling forces of the three specimens with silicone coated 1.5-in. dowel bars recorded was $1700 \mathrm{lb}$ as opposed to the value of $5400 \mathrm{lb}$ in the case of uncoated bars. The frictional forces were mobilized at an earlier stage of displacement than in the case of uncoated dowel bar. There was no significant increase in pulling forces after the dowel was displaced about 0.015 in. as shown in Figures 3.9 - 3.11. The 
silicon coating was observed to reduce the bond strength between the dowel bar and concrete.

A discrepancy among three specimens was noted in regard to the amount of compressive forces required to push the dowel bar back. In two of the specimens, the dowel bar reached its initial position with lower values of pushing forces. In the first specimen, shown in Figure 3.9, the dowel bar reached almost its initial position with a constant increase in the compressive force. In the second specimen, shown in Figure 3.10, the push-in force was constant after the initial stage of pushing. In the third specimen, the dowel bar did not return to its original position even at higher values of the compressive force as illustrated in Figure 3.11. The further advancement of the dowel bar to its initial position might have been arrested due to the resistance caused by the aggregates of the concrete at the dowel-concrete interface and/or a thin layer of wax might have accumulated at the bottom of the dowel bar. Any inconsistency in the original alignment of the dowel bar could have been the reason for this.

In the tenth cycle of the first test, the tensile forces required to pullout the dowel bar from the concrete decreased to about half of the value of the tensile forces recorded during the first cycle. The maximum compressive force to push the bar back remained almost constant in all the ten cycles. The obstruction caused by the concrete aggregates to the push back of the dowel bar to its original position did not change significantly.

The pullout forces increased by 4 percent in the second test. In the first and second specimens the forces required to push the bar back to its original position decreased by about 30 percent on average. While in the third specimen, the maximum compressive forces increased by a factor of five the value of the forces recorded in the first test to push the dowel.

\section{Dowel bar of diameter 1.25 in}

Figures 3.12 - 3.15 show the load-displacement history in the case of siliconecoated 1.25 in. diameter bars. In the first test (after 14 days), the average maximum pulling and pushing forces from three specimens were 1000 and 700 pounds respectively. 
The pushing force was high at the initial stage of push back and it gradually decreased with the increase in the displacement of the dowel to its original position. The pulling forces obtained after 21 days were lower than that after 14 days. There was no significant change in the pulling and pushing forces in regard to the tenth cyclic loading and unloading in both the tests conducted. The silicone coated dowel bar was pushed back to its original position with comparatively low forces than in the case of uncoated dowel bars.

\subsubsection{Tectyl (506) Coated dowel bars}

\section{Dowel bar of diameter 1.5 in.}

Figures 3.16 - 3.18 show the load-displacement curves of tectyl coated 1.5-in. diameter dowel bar. Just as in the specimens with silicone coated dowel bars, the frictional forces in the specimens with tectyl coated dowel bars were overcome at dowel displacement of about $0.001 \mathrm{in}$. with a lower average value of pulling forces, namely 900 lb. The figures show a smooth load-displacement curve, and this fact coupled with the fact that the maximum pullout force was about half as that of the bars with silicone coating implies that the surface irregularities at the dowel-concrete interface were minimal. The push-in forces were also lower than the silicone coated bars. For the tenth cycle, the pullout forces reduced by 30 percent while the push-in forces remained constant. The results from the second test did not vary much from that of the first test.

\section{Dowel bars of diameter 1.25 in.}

Figures 3.19 - 3.21 show the load-displacement curves of tectyl coated $1.25 \mathrm{in}$. diameter dowel bars. In these tests, the forces recorded were lower than that of the corresponding 1.25-in. diameter cases. The pullout forces increased linearly with displacement of the dowel bar initially and then they became constant. The pullout and push-in force values did not vary significantly from the first test to second test.

From the above results, it can be concluded that the fine space established between the dowel bar and concrete due to the application of debonding agents silicone and tectyl (506) reduced the resistance to dowel movement very effectively. The 
shrinkage of concrete did not affect the bond strength between coated dowel bars and concrete significantly. They acted as good lubricating agents reducing irregularities and facilitating displacement of dowel with low friction at the interface.

\subsection{RADIAL STRAINS}

\subsubsection{Radial strains in the specimens with 1.5in diameter dowel bar}

Radial strains $\left(\varepsilon_{y}\right.$ and $\left.\varepsilon_{z}\right)$ in the concrete, measured by the vibrating wire strain gages are plotted as Figures 3.21 - 3.22 for the uncoated dowel bars case, Figures 3.23 3.24 for the silicon coated case, and Figures $3.25-3.26$ for the tectyl coated case. The behavior of radial strains of the specimens with tectyl coated dowel bars was different from the specimens with uncoated and silicone coated dowel bars. In the case of uncoated and silicone coated dowel bars, compressive strains were recorded during the early stages of displacement of dowel bar during pulling. When the dowel bar was pulled, a void conceivably was formed in the specimens with uncoated and silicone coated dowel bars. Consequently, the residual strains in the concrete were relieved when the concrete deformed. Hence the strain gages were compressed, recording -11 and -6 $\mu$ strains in uncoated and silicone coated dowel bars, respectively. The silicon coating would have occupied the void, due to which low compressive strains were recorded in specimens with silicone coated dowel bars. After the displacement of $0.0015 \mathrm{in}$. and $0.0225 \mathrm{in}$. during pulling of uncoated and silicone coated dowel bars respectively, the tensile strains were measured in the concrete. The tensile strains were as high as 30 $\mu$ strains in the case of uncoated dowel and they were only about $12 \mu$ strains in silicone coated bars. The surface irregularities on uncoated dowel bar would have caused the concrete to expand more than the silicone dowel during the dowel displacement, as silicone coat would have filled the surface asperities at the interface. The pressure exerted by the silicone coat between the concrete and dowel bar would also have opposed the contraction of concrete. The change of strains recording during pushing in phase of the tenth cycle was not considerable in both the cases. A similar pattern of radial strains was observed in uncoated and silicone coated from the results of second test, but the change in strains of the concrete was low when compared to first cycle in the first test. 
In the case of tectyl coated dowel bars, the strain gages recorded tensile strains of 18-22 $\mu$ strains in concrete during pulling. Tensile strains were reduced by a small value of 3-5 $\mu$ strains when the dowel bar was pushed back. The tectyl coat would have penetrated into concrete making it more elastic to expand and contract during the displacement of dowel bar. Lower value of tensile strains was recorded during the second test.

\subsubsection{Radial strains in the specimens with 1.25 in diameter dowel bar}

The nature of strain-displacement profiles in uncoated dowel bars did not change with size of the diameter of the dowel. Figures 3.27 - 3.28 show 15-20 $\mu$ strains change in the first cycle of pulling of uncoated dowel bars. During pushing the change in strains around the concrete in uncoated dowel noted were only about 3-5 $\mu$ strains. Figures 3.29 3.32 illustrate the strain-displacement curves in the specimens with silicone and tectyl dowel bars. The strains in concrete around the coated dowel bar were very low when compared to uncoated dowel bar, as expected. The maximum strains recorded in the concrete with coated dowel bars were only about 6-8 $\mu$ strains. The strains were even lower for the results of second test.

\subsection{AXIAL STRAINS}

\subsubsection{Axial strains in the specimens with 1.5 in diameter dowel bar}

The axial strain of concrete in the specimens with 1.5 in diameter dowel bar was measured by the embedment strain gages as mentioned in an earlier chapter. Compressive strains were recorded during pulling of dowel bar in all specimens, as can be observed in Figures 3.33 - 3.41. When the dowel bar was pulled the fine aggregates interlocked in the irregularities of dowel surface shear compressing the concrete in the direction of dowel movement. Hence, higher strain values were recorded in specimens with uncoated dowel bars. The axial strain in the concrete around silicone coated dowel bar was 57 percent of the strain in uncoated dowel bars on an average in first cycle. Lower strains were recorded in specimens with tectyl coated dowel bars than in the uncoated and silicone coated dowels. In tenth cycle, the axial strains in the concrete were compressive in all the specimens. 
During the second test (after 8 days of casting), the strains values remained same in uncoated dowel bars. In the specimens with silicone coated and tectyl coated dowel bars, low axial strain values were obtained. The tensile strains in the concrete with tectyl coated dowel bars in axial direction during pulling were not significant.

\subsubsection{Axial strains in the specimens with 1.25 in diameter dowel bar}

Table 3.1 illustrates the maximum axial strains observed during the pullout and push-in operations of the dowel bar. The axial strains in this set of specimens were measured by either embedment strain gages or vibrating wire strain gages. The axial strain-displacement behavior in the specimens with 1.25-in. diameter dowel bar was similar to the set of specimens with 1.5-in. diameter dowel bar in all dowel coated and uncoated specimens.

\subsection{CONCLUSIONS}

From the experimental study, it could be deduced that the bond resistance between the dowel bar and the concrete was effectively minimized with the application of bond breaking agent on the dowel surface but not absolutely. As the initial clearance at dowel-concrete interface was reduced due to shrinkage of concrete, the concrete contracts around the dowel bar compressing the layer of the debonding agent. When the tensile and compressive forces measured during dowel displacement were taken into consideration, it can be stated that the specimens with tectyl coat has significantly reduced the bond resistance. But the radial strains in the specimens with tectyl coat were higher when compared to the one with silicon coat. So, if the friction coefficient at the interface of the dowel bar and the concrete were known in both the cases, it would give a fair judgment to choose the better debonding agent between silicon and tectyl (506). 
Table 3.1 Maximum axial strains in specimens with 1.25-in. diameter dowel bars

\begin{tabular}{|c|c|c|}
\hline \multirow{2}{*}{$\begin{array}{c}\text { Specimen } \\
\text { description and } \\
\text { number }\end{array}$} & \multicolumn{2}{|c|}{$\begin{array}{c}\text { Maximum amount of Axial Strains } \\
\text { recorded during pulling and Pushing } \\
(\mu \text { strains })\end{array}$} \\
\cline { 2 - 3 } & $1^{\text {st }}$ test & $2^{\text {nd }}$ test \\
\hline $\begin{array}{c}\text { Uncoated } \\
\text { dowel bar }-1\end{array}$ & -27 & -32 \\
\hline $\begin{array}{c}\text { Uncoated } \\
\text { dowel bar }-2\end{array}$ & -20 & -57 \\
\hline $\begin{array}{c}\text { Uncoated } \\
\text { dowel bar }-3\end{array}$ & 12 & 19 \\
\hline $\begin{array}{c}\text { Silicon coated } \\
\text { dowel bar-1 }\end{array}$ & -1.25 & -10 \\
\hline $\begin{array}{c}\text { Silicon coated } \\
\text { dowel bar-2 }\end{array}$ & -5.2 & 10 \\
\hline $\begin{array}{c}\text { Tectyl coated } \\
\text { dowel bar-1 }\end{array}$ & -3 & -6 \\
\hline $\begin{array}{c}\text { Tectyl coated } \\
\text { dowel bar-2 }\end{array}$ & 1 & -2 \\
\hline $\begin{array}{c}\text { Tectyl coated } \\
\text { dowel bar-3 }\end{array}$ & -1 & -4 \\
\hline
\end{tabular}




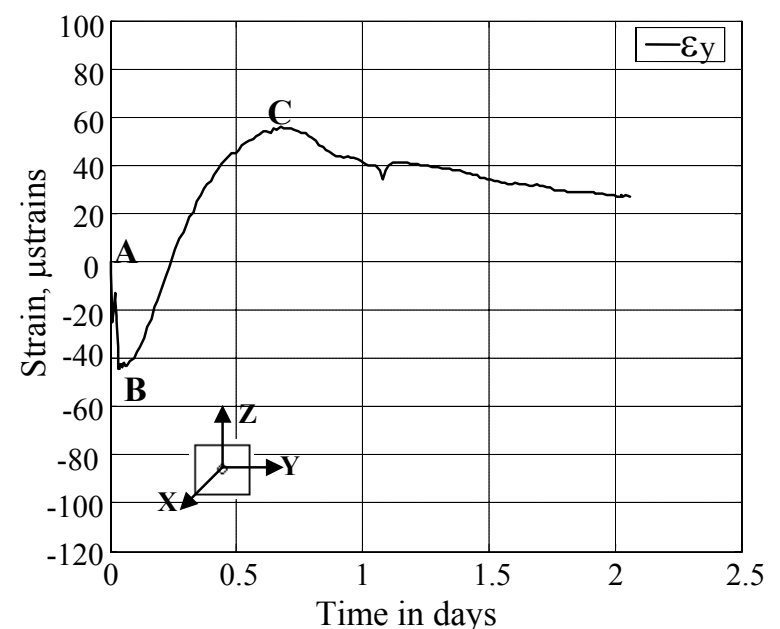

(a) Uncoated bar

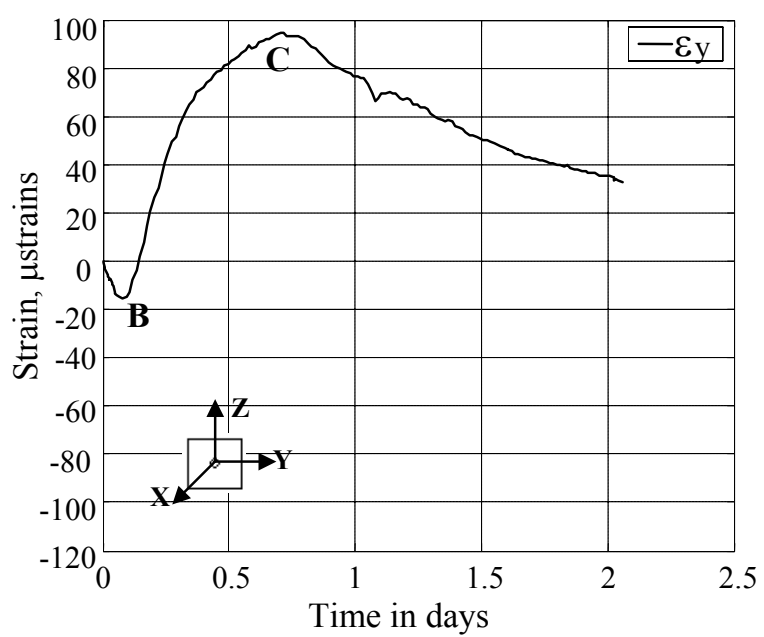

(c) Silicon coated bar

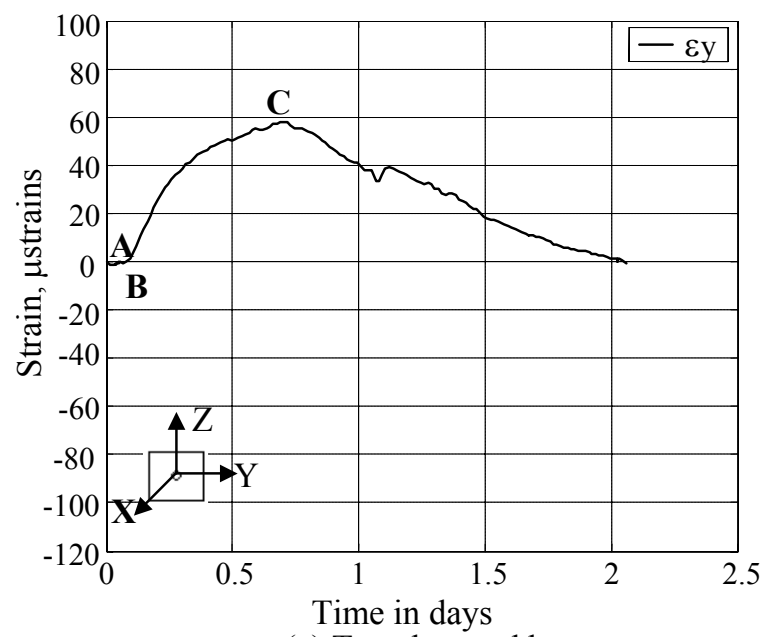

(e) Tectyl coated bar

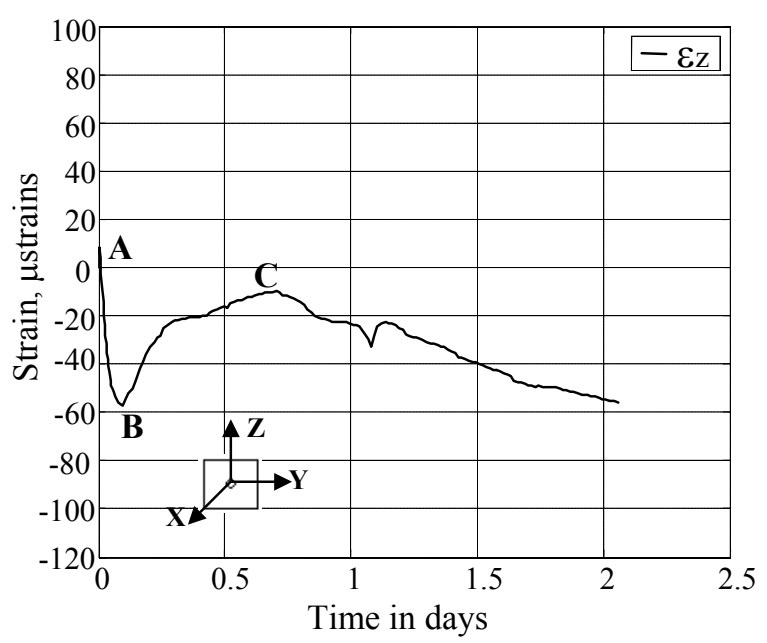

(b) Uncoated bar

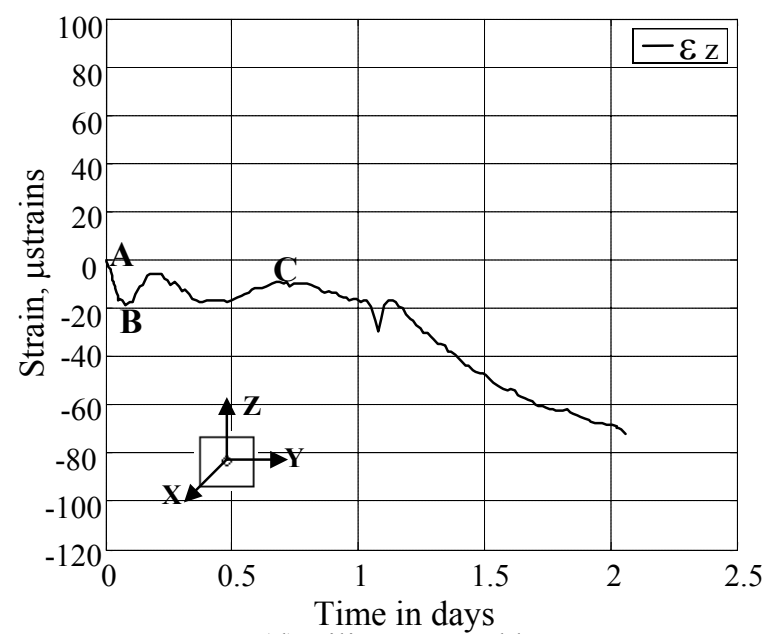

(d) Silicon coated bar

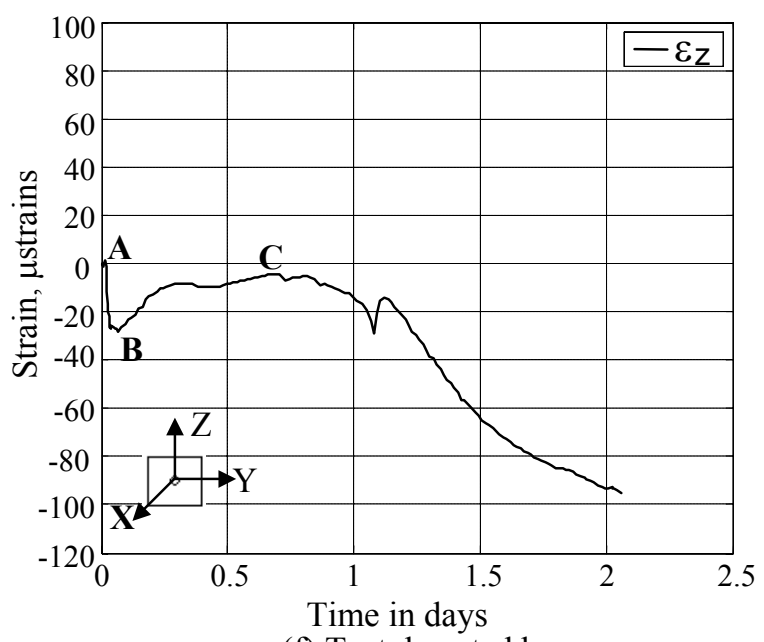

(f) Tectyl coated bar

Figure 3.1 Strains in specimens with uncoated and coated dowel bars 


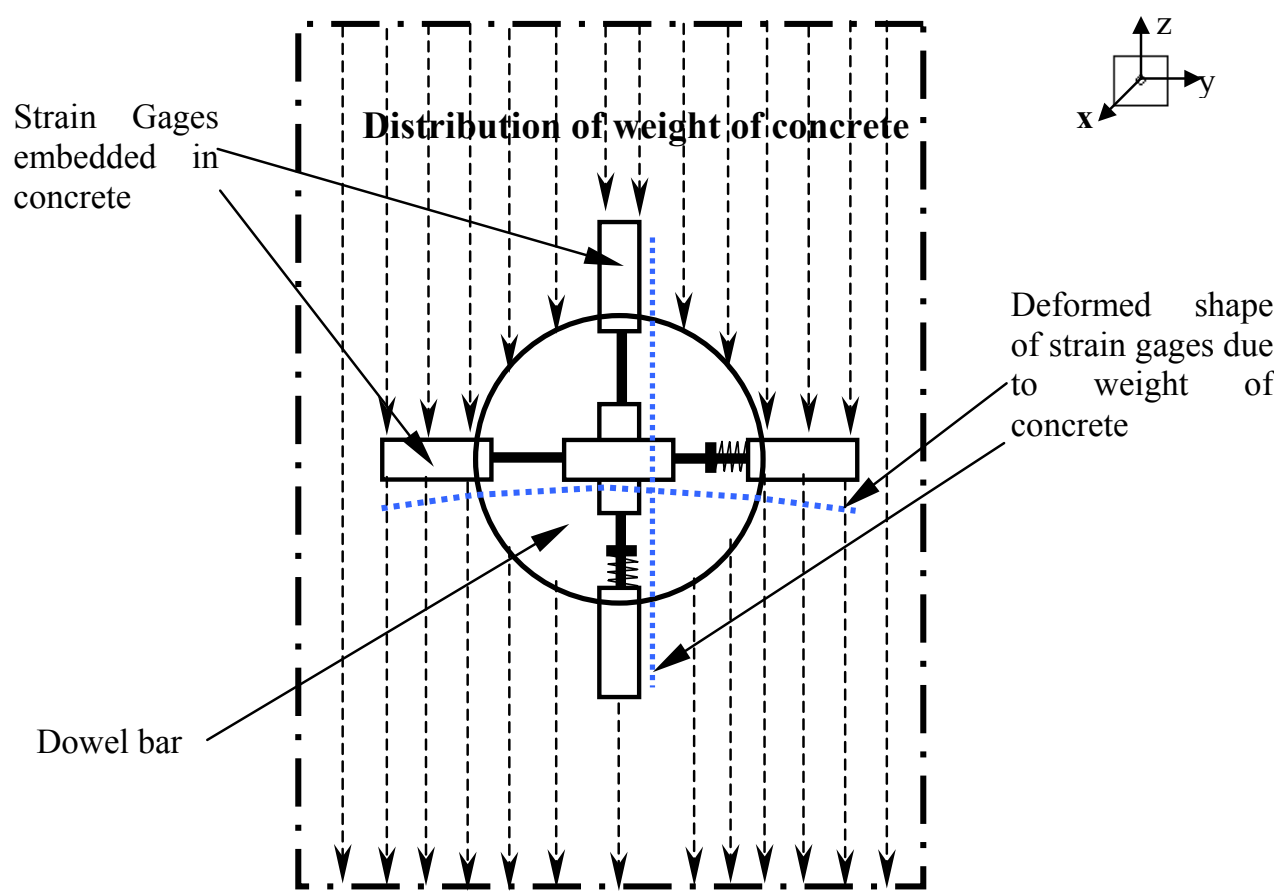

Figure 3.2 Sectional view of concrete specimen with strain gages and dowel bar

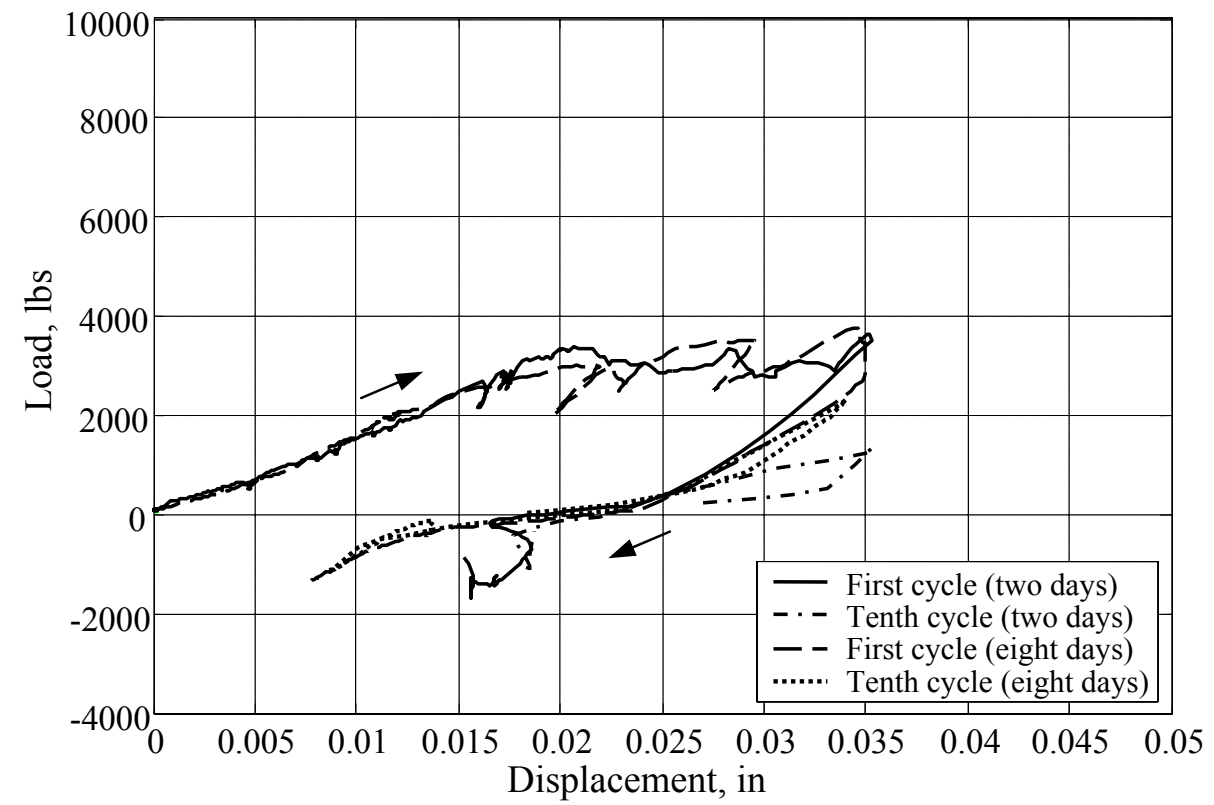

Figure 3.3 Load-displacement curve of specimen No.1 with uncoated dowel bar of diameter $1.5 \mathrm{in}$. 


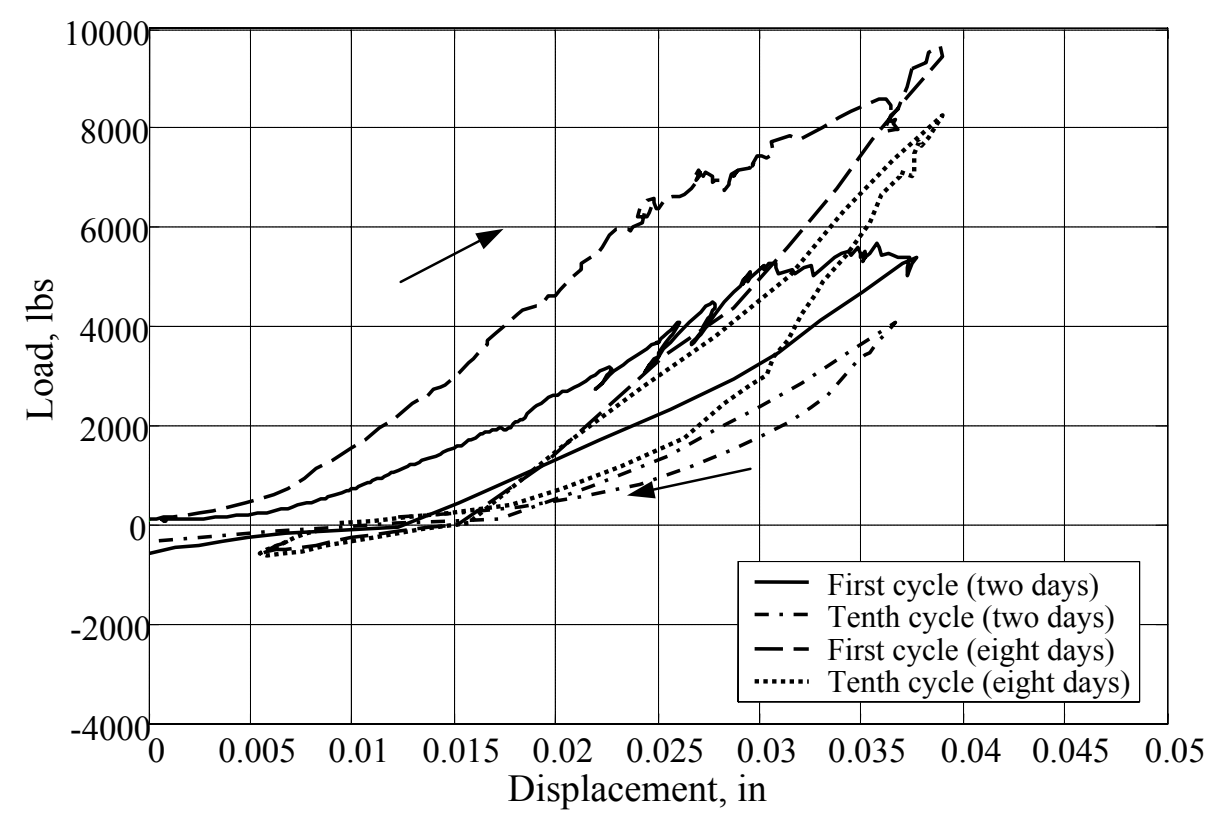

Figure 3.4 Load-displacement curve of the specimen No.2 with uncoated dowel bar of diameter 1.5 in.

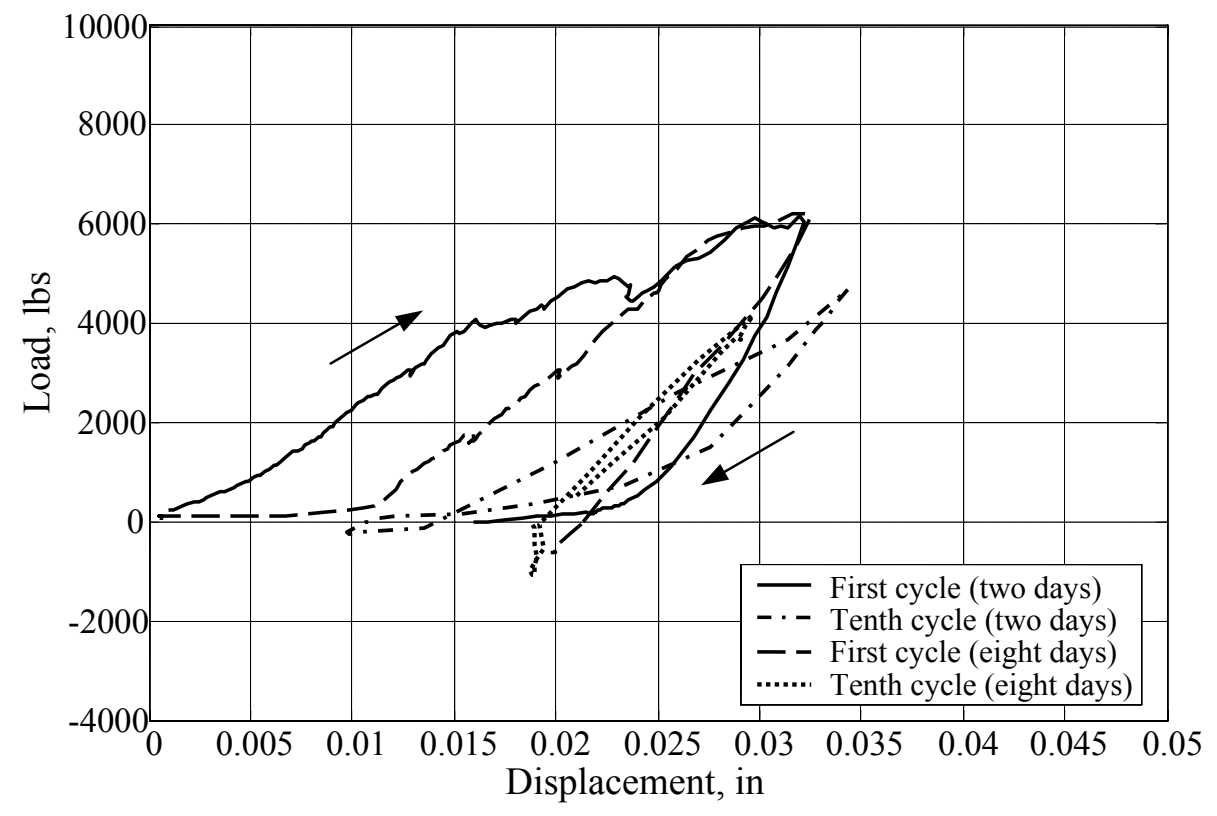

Figure 3.5 Load-displacement curve of the specimen No.3 with uncoated dowel bar of diameter $1.5 \mathrm{in}$. 


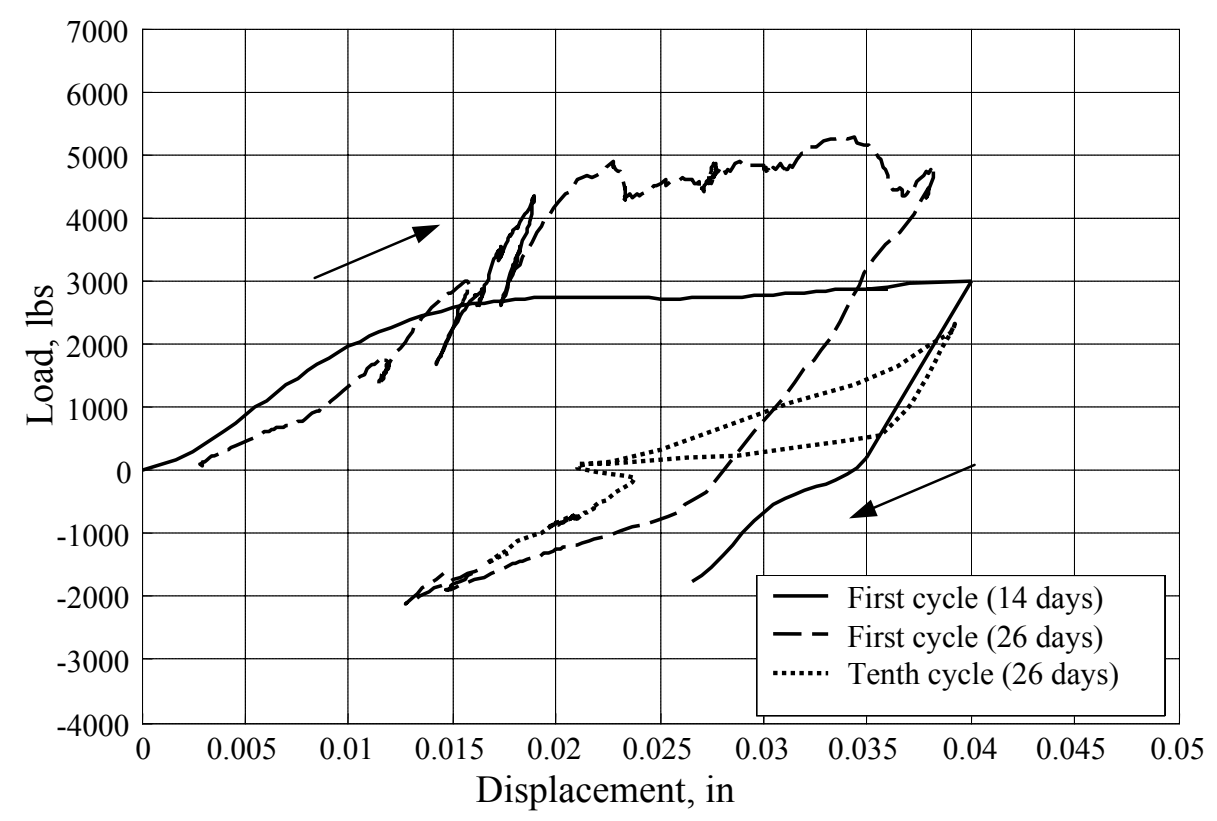

Figure 3.6 Load-displacement curve of the specimen No.1 with uncoated dowel bar of diameter 1.25 in.

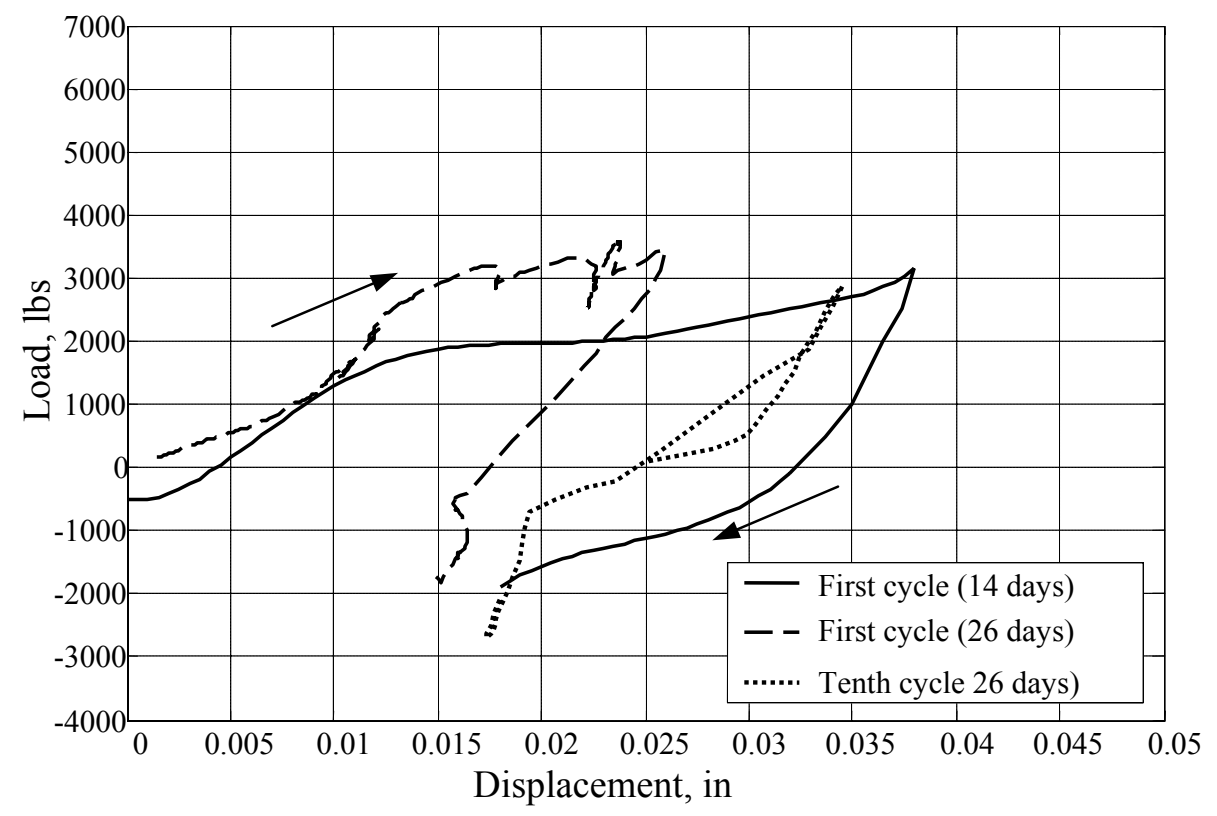

Figure 3.7 Load-displacement curve of the specimen No.2 with uncoated dowel bar of diameter 1.25 in. 


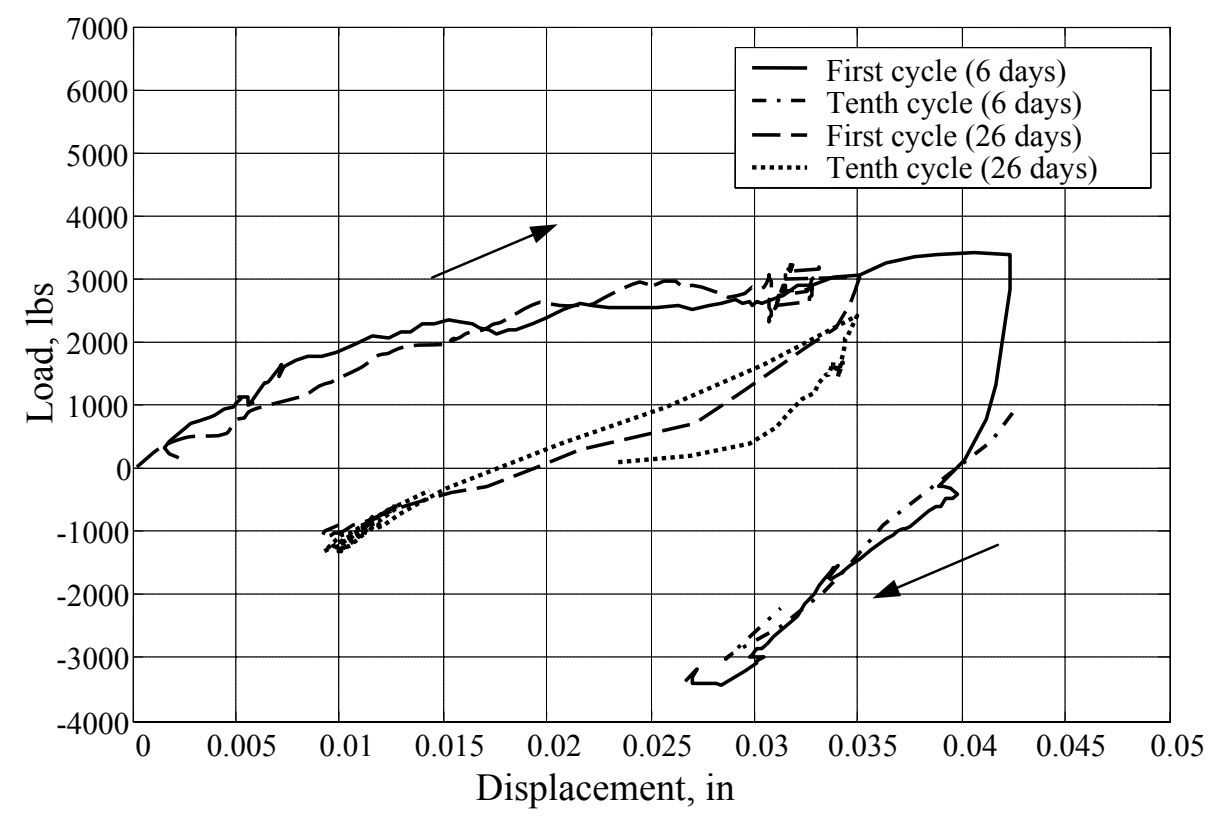

Figure 3.8 Load-displacement curve of the specimen No.3 with uncoated dowel bar of diameter $1.25 \mathrm{in}$.

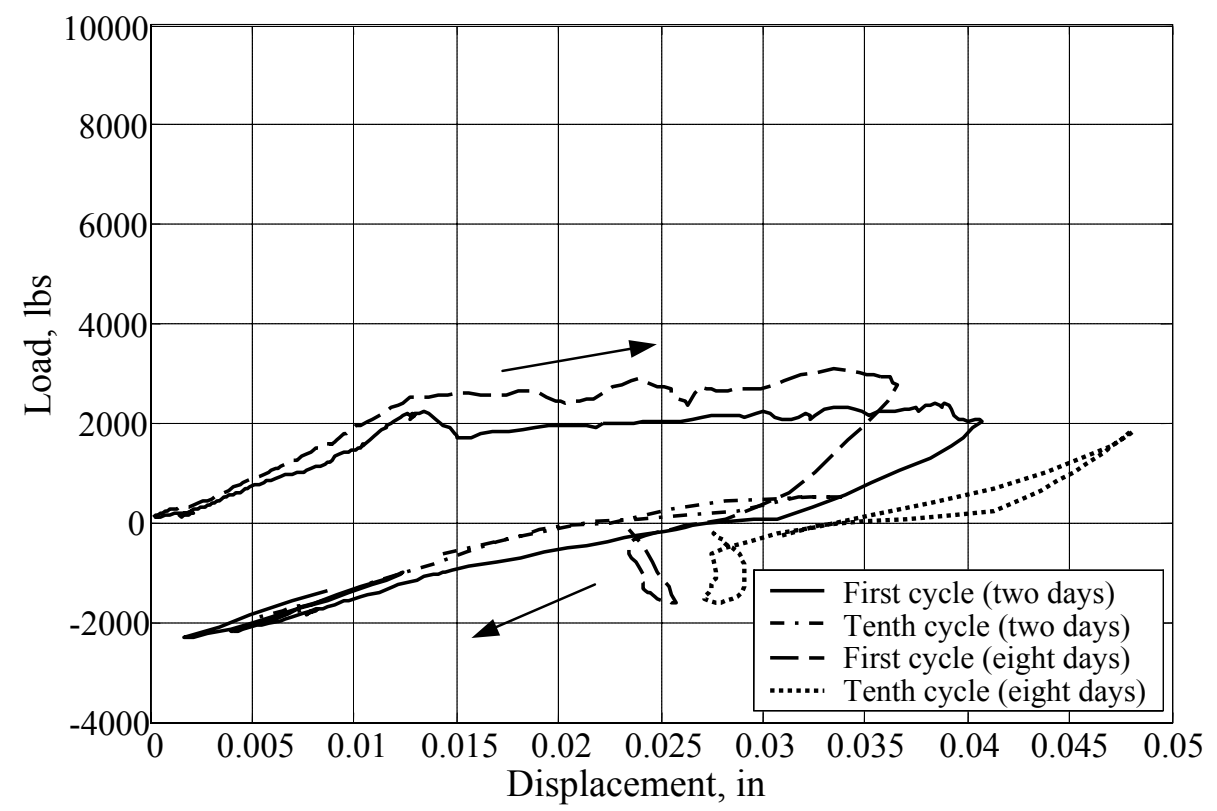

Figure 3.9 Load-displacement curve of the specimen No.1 with silicone coated dowel bar of diameter 1.5 in. 


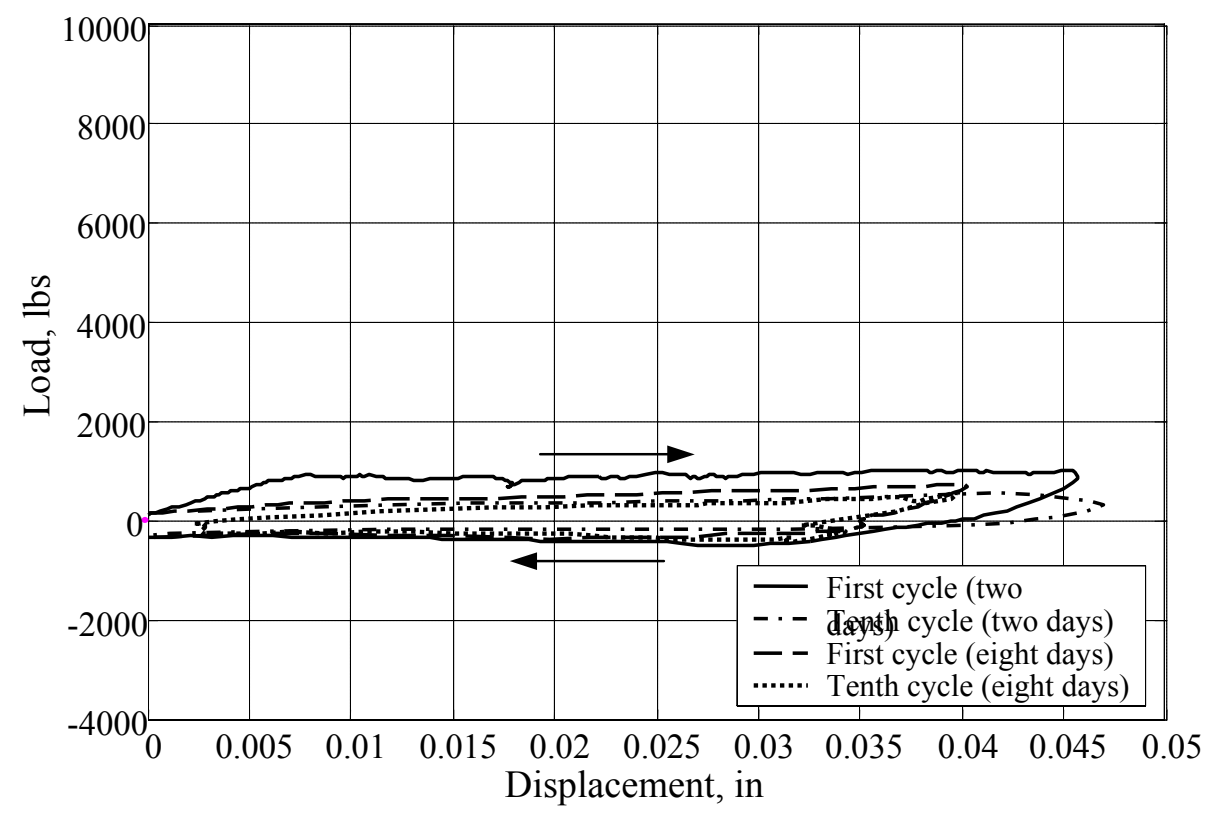

Figure 3.10 Load-displacement curve of the specimen No.2 with silicone coated dowel bar of diameter $1.5 \mathrm{in}$.

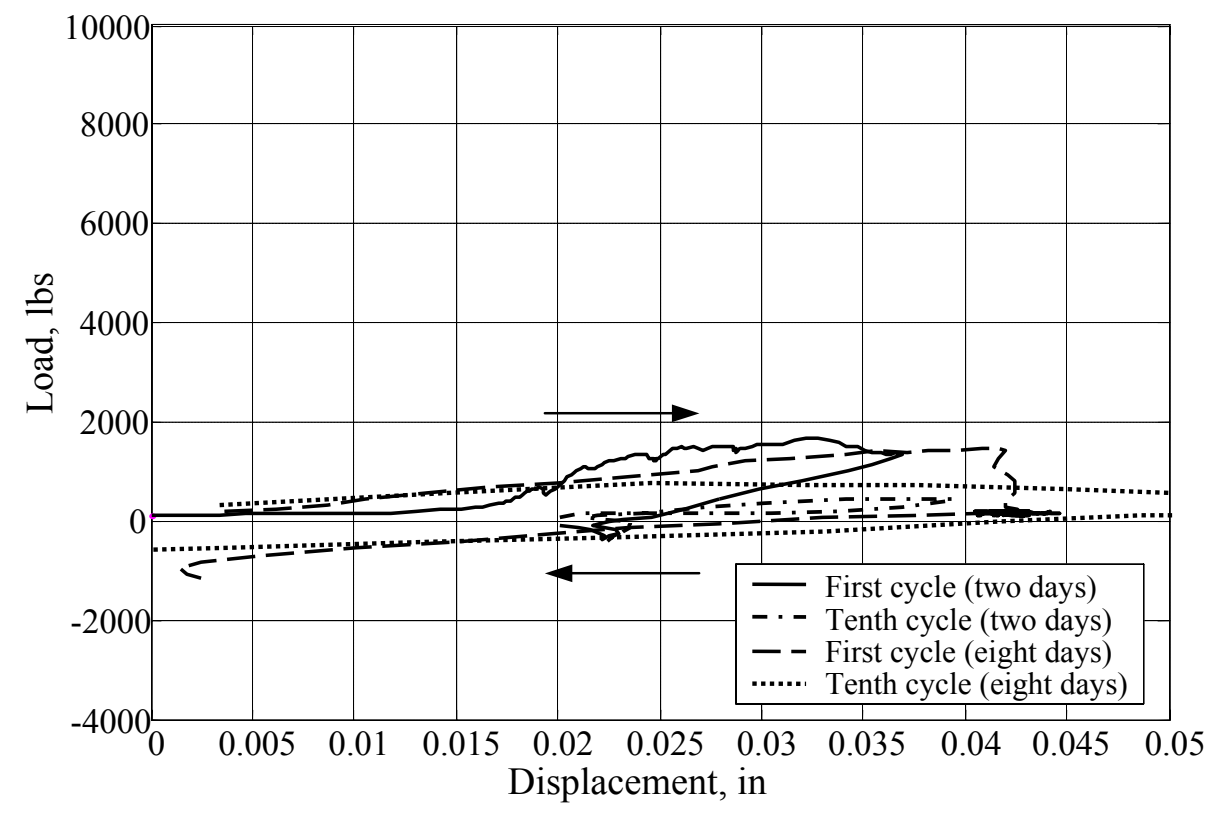

Figure 3.11 Load-displacement curve of the specimen No.3 with silicone dowel bar of diameter $1.5 \mathrm{in}$. 


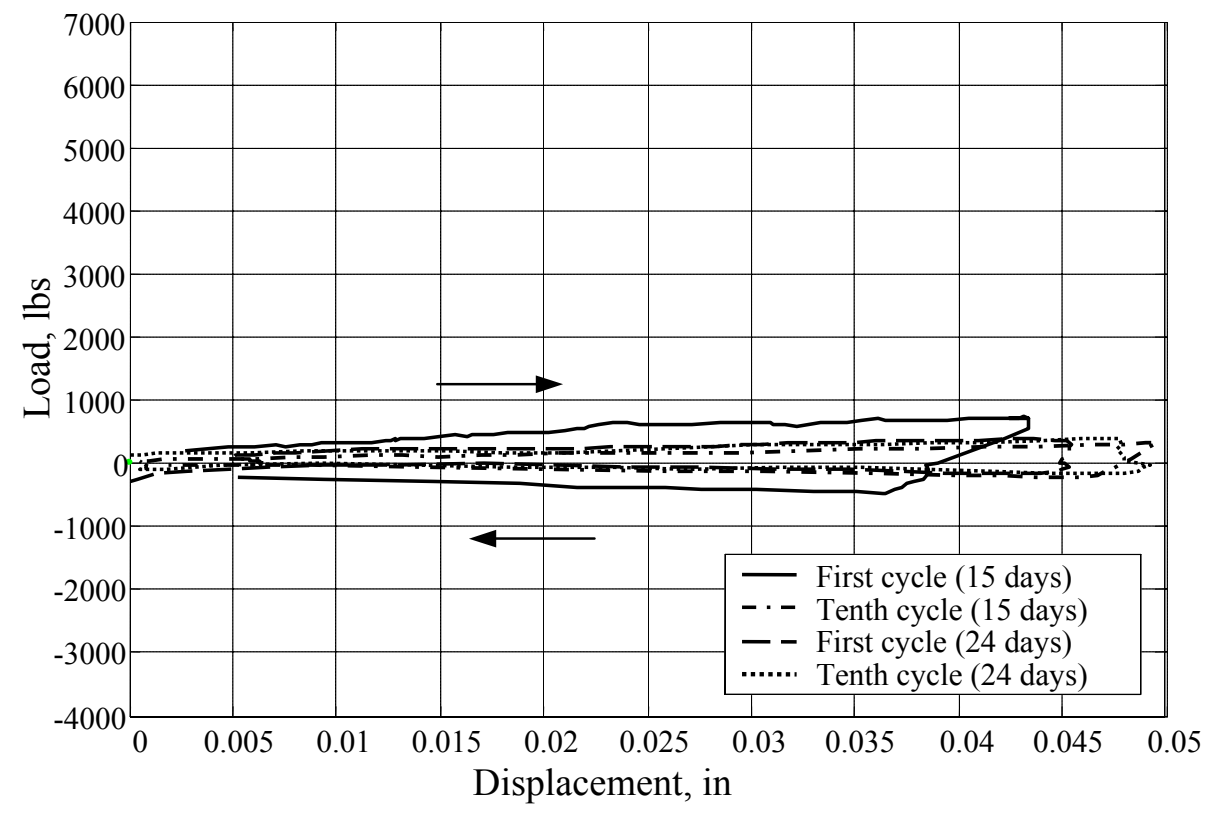

Figure 3.12 Load-displacement curve of the specimen No.1 with silicon coated dowel bar of diameter $1.25 \mathrm{in}$.

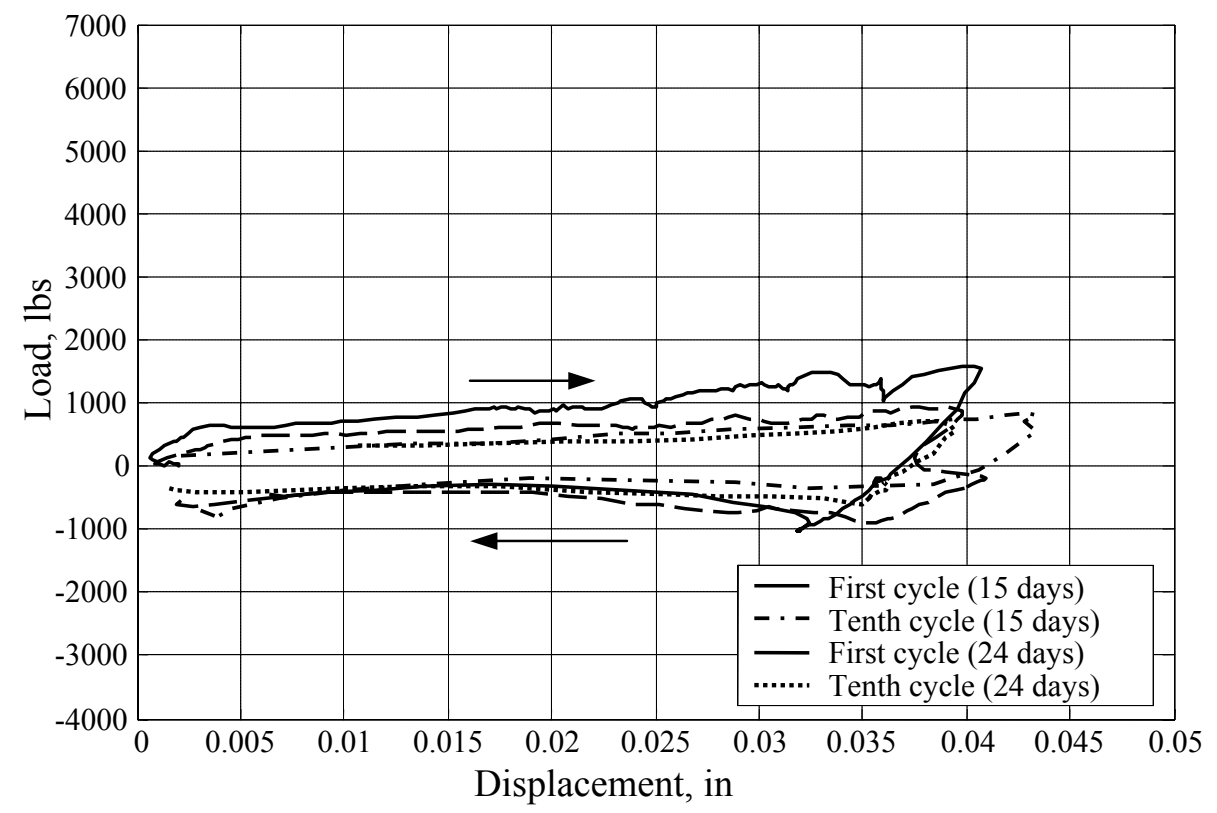

Figure 3.13 Load-Displacement curve of the Specimen No.2 with silicone coated dowel bar of diameter $1.25 \mathrm{in}$. 


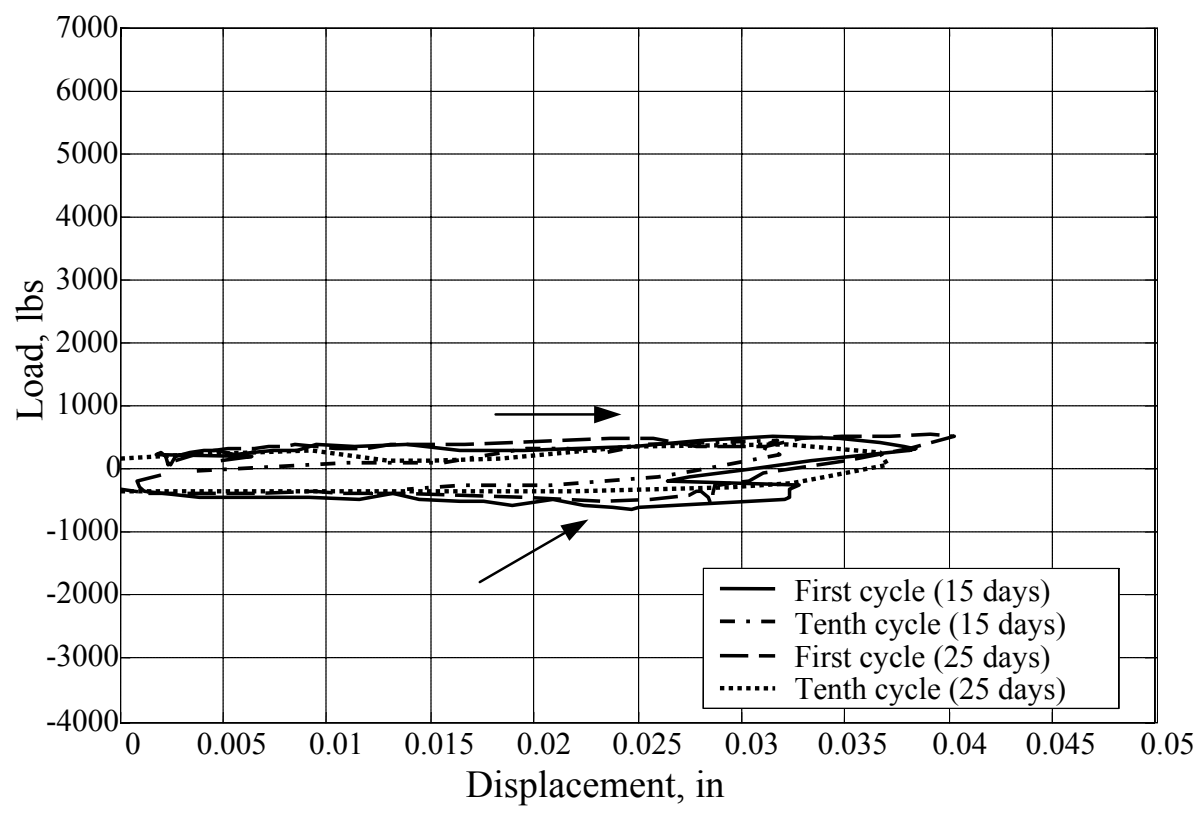

Figure 3.14 Load-displacement curve of the specimen No.3 with silicone coated dowel bar of diameter $1.25 \mathrm{in}$.

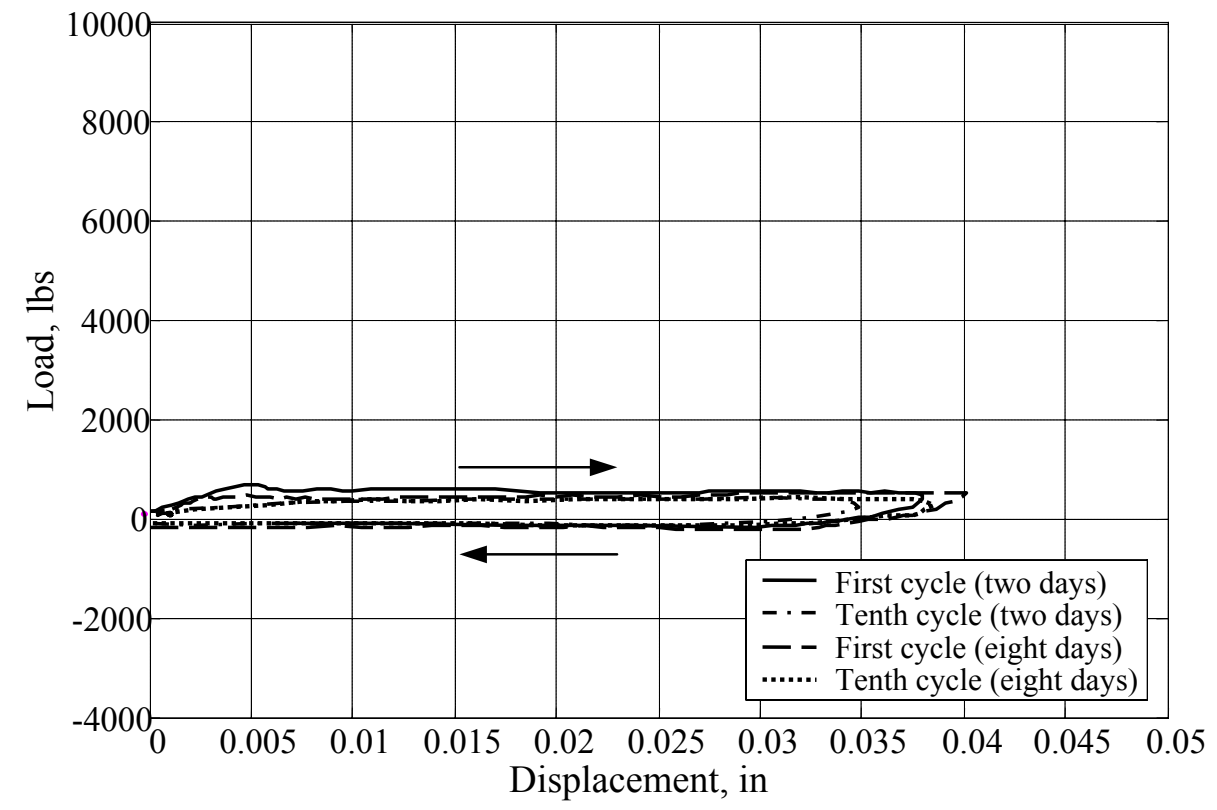

Figure 3.15 Load-displacement curve of the specimen No.1 with tectyl coated dowel bar of diameter $1.5 \mathrm{in}$. 


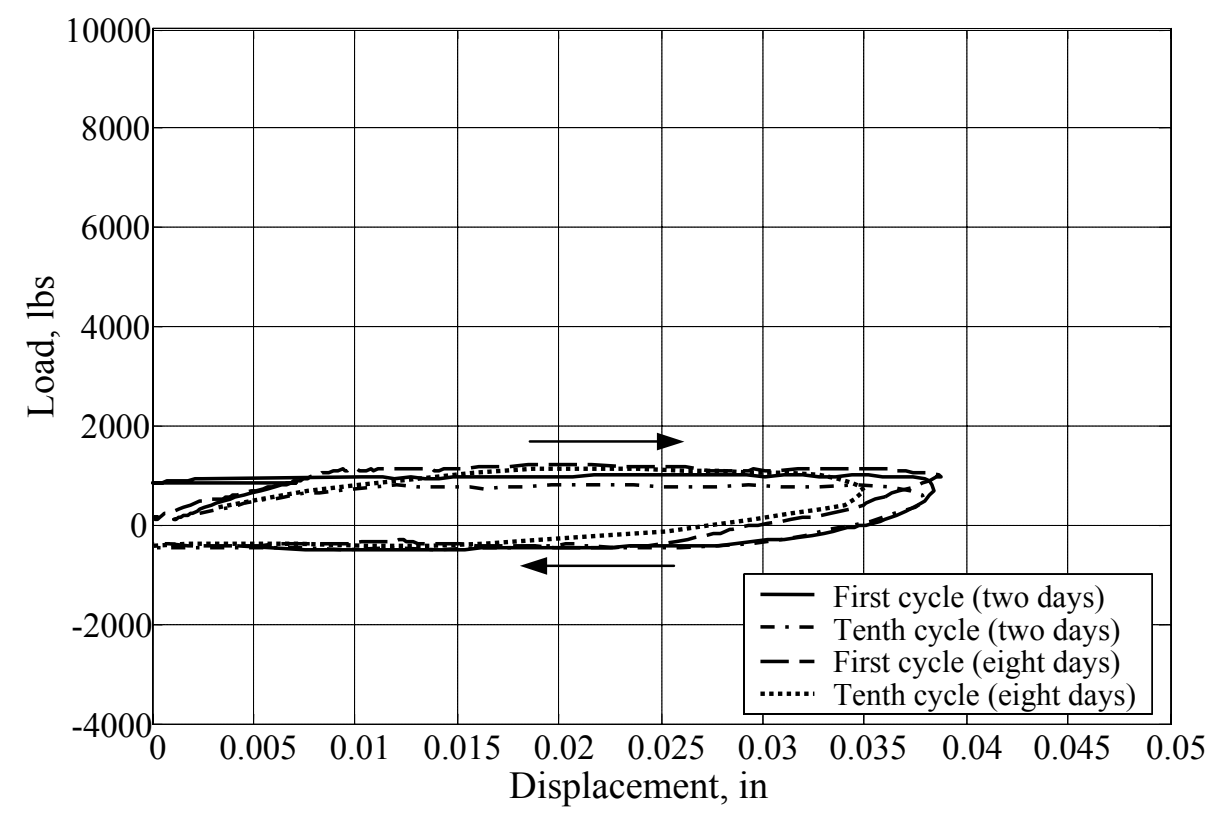

Figure 3.16. Load-displacement curve of the specimen No.2 with tectyl coated dowel bar of diameter $1.5 \mathrm{in}$.

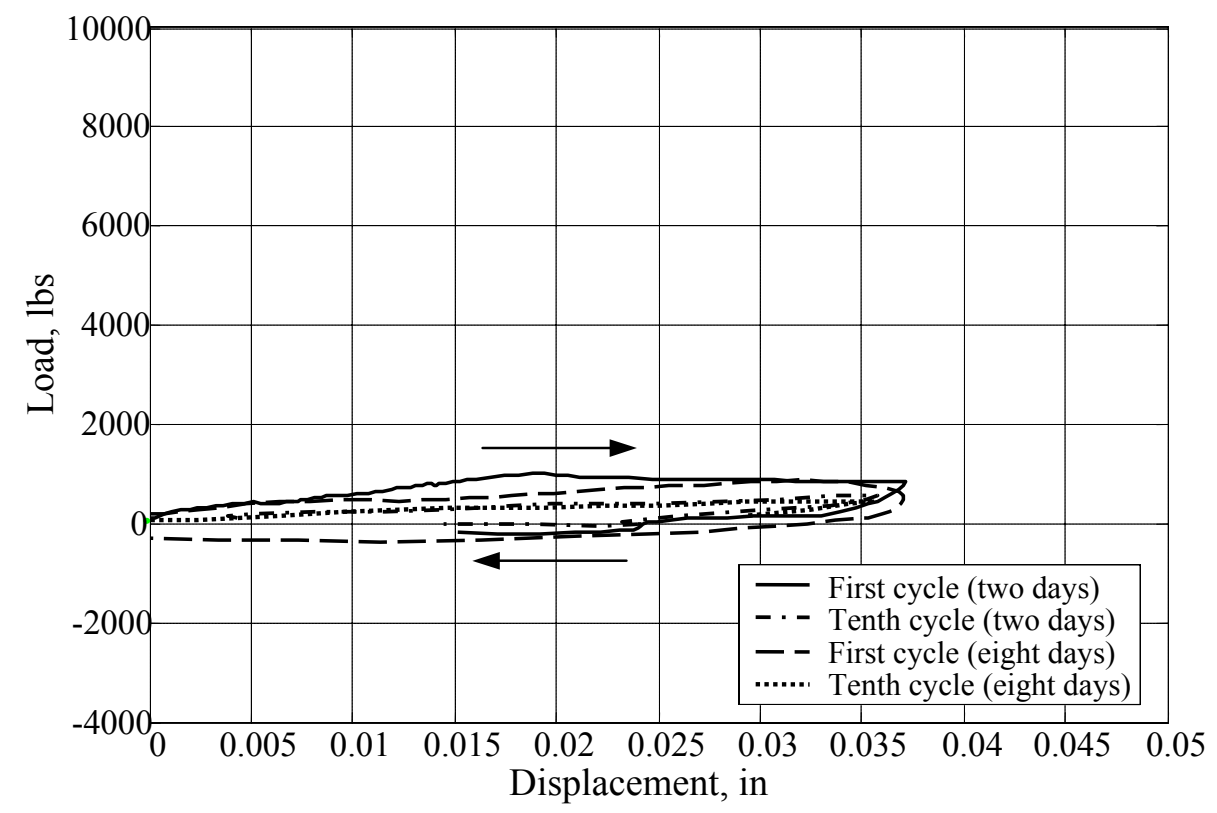

Figure 3.17 Load-displacement curve of the specimen No.3 with tectyl coated dowel bar of diameter $1.5 \mathrm{in}$. 


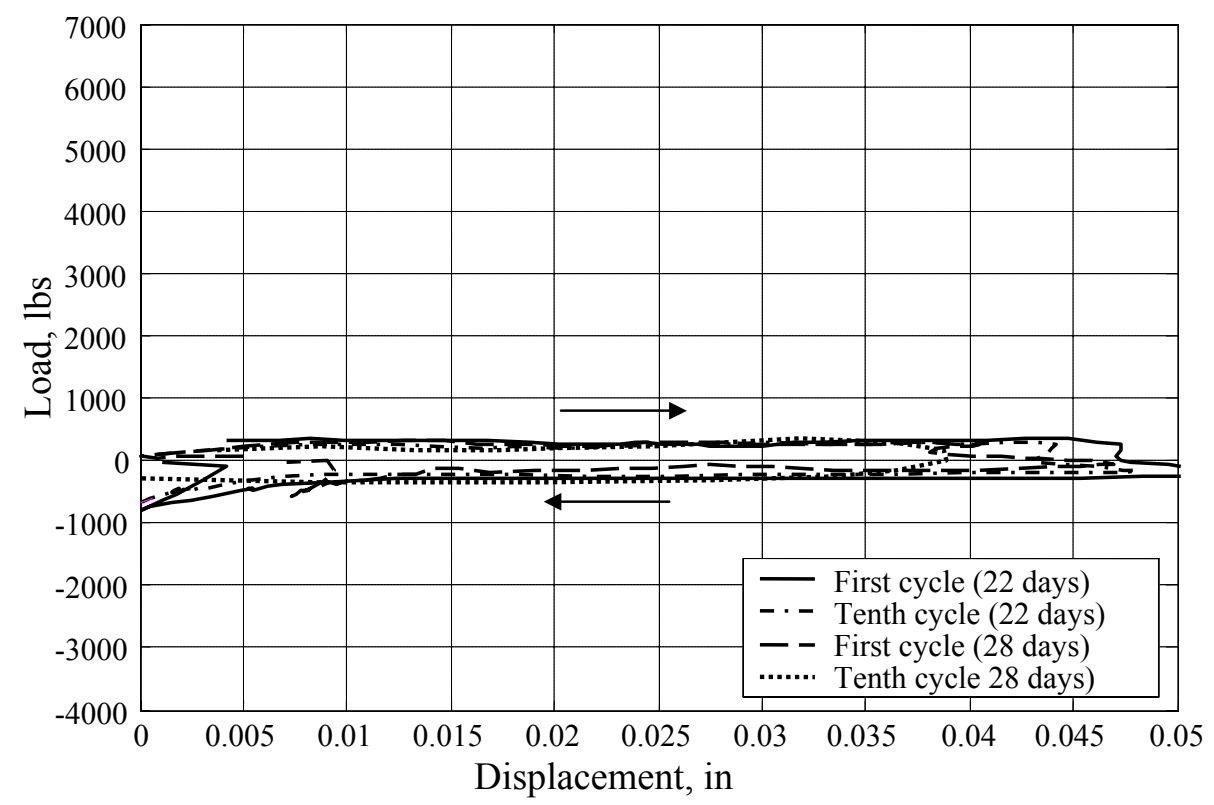

Figure 3.18 Load-displacement curve of the specimen No.1 with tectyl coated dowel bar of diameter $1.25 \mathrm{in}$.

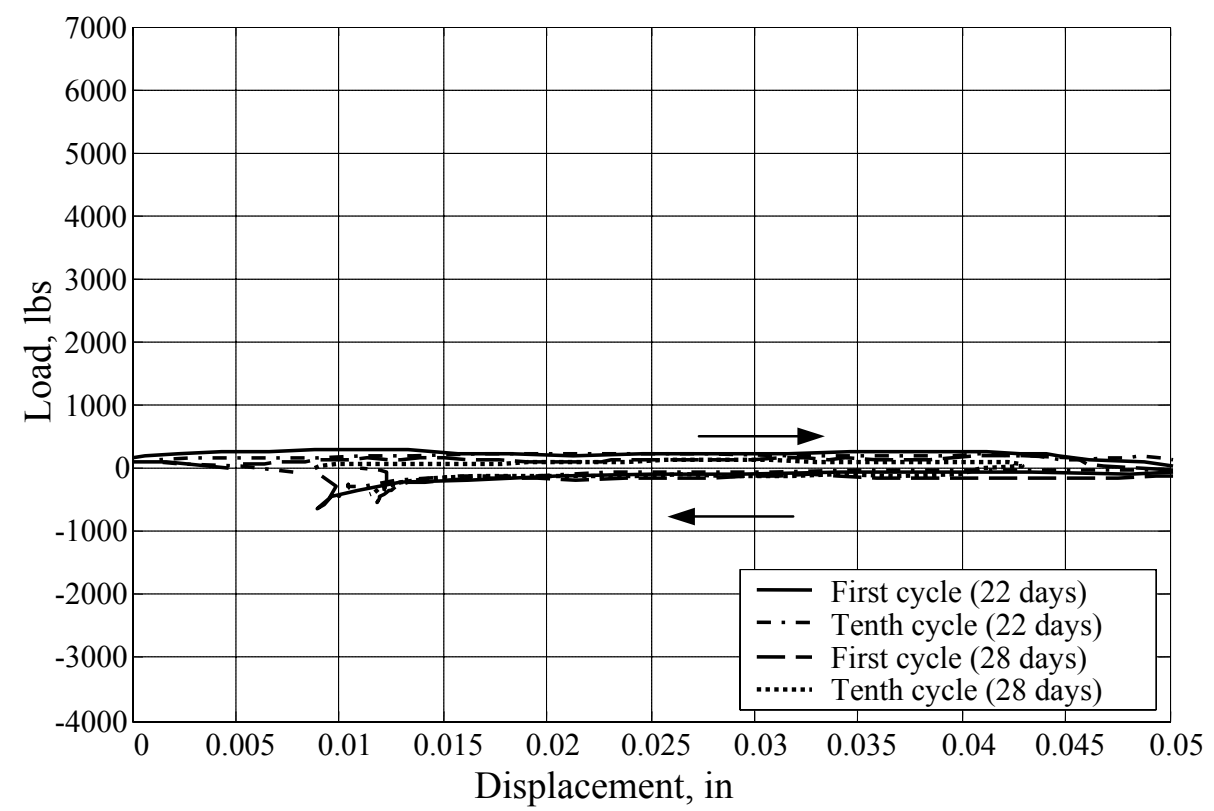

Figure 3.19 Load-displacement curve of the specimen No.2 with tectyl coated dowel bar of diameter 1.25 in. 


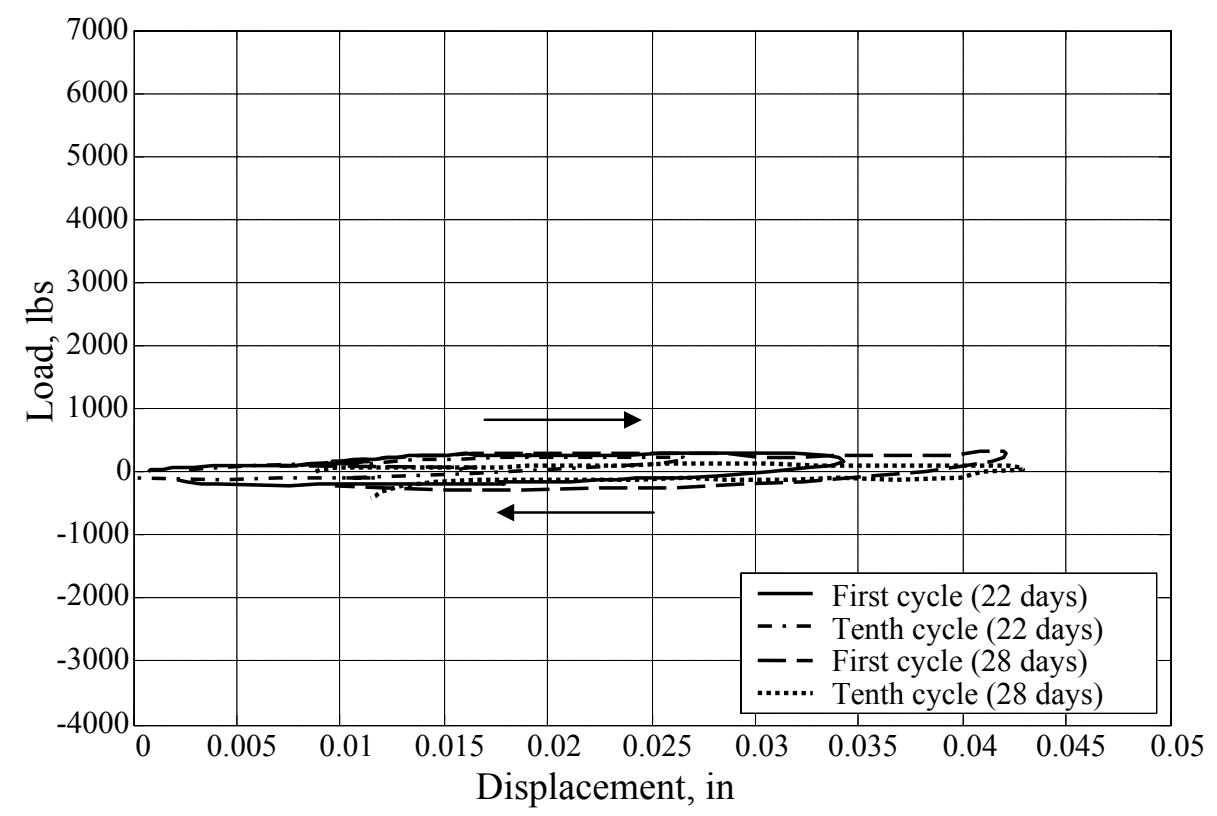

Figure 3.20 Load-displacement curve of the specimen No.3 with tectyl coated dowel bar of diameter 1.25 in. 


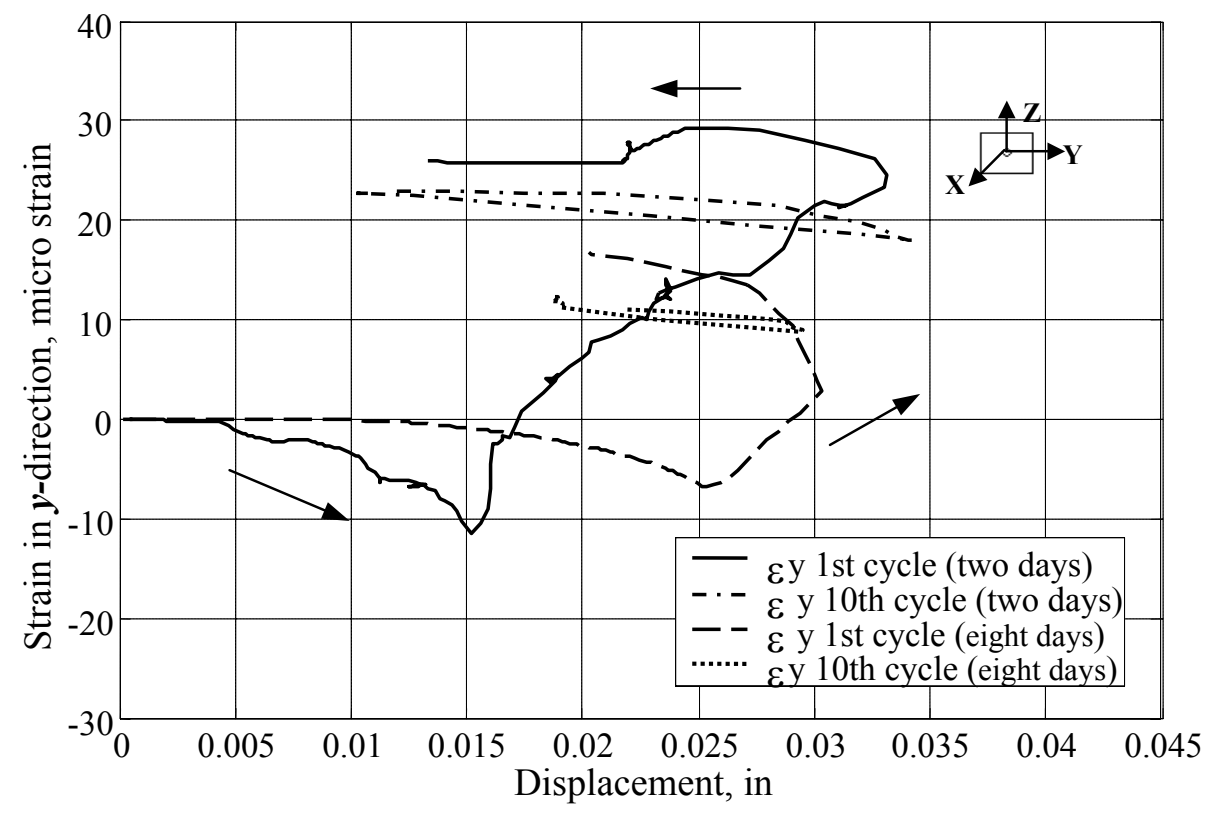

Figure 3.21 Strain-displacement curve of the specimen with uncoated dowel bar of diameter 1.5 in.

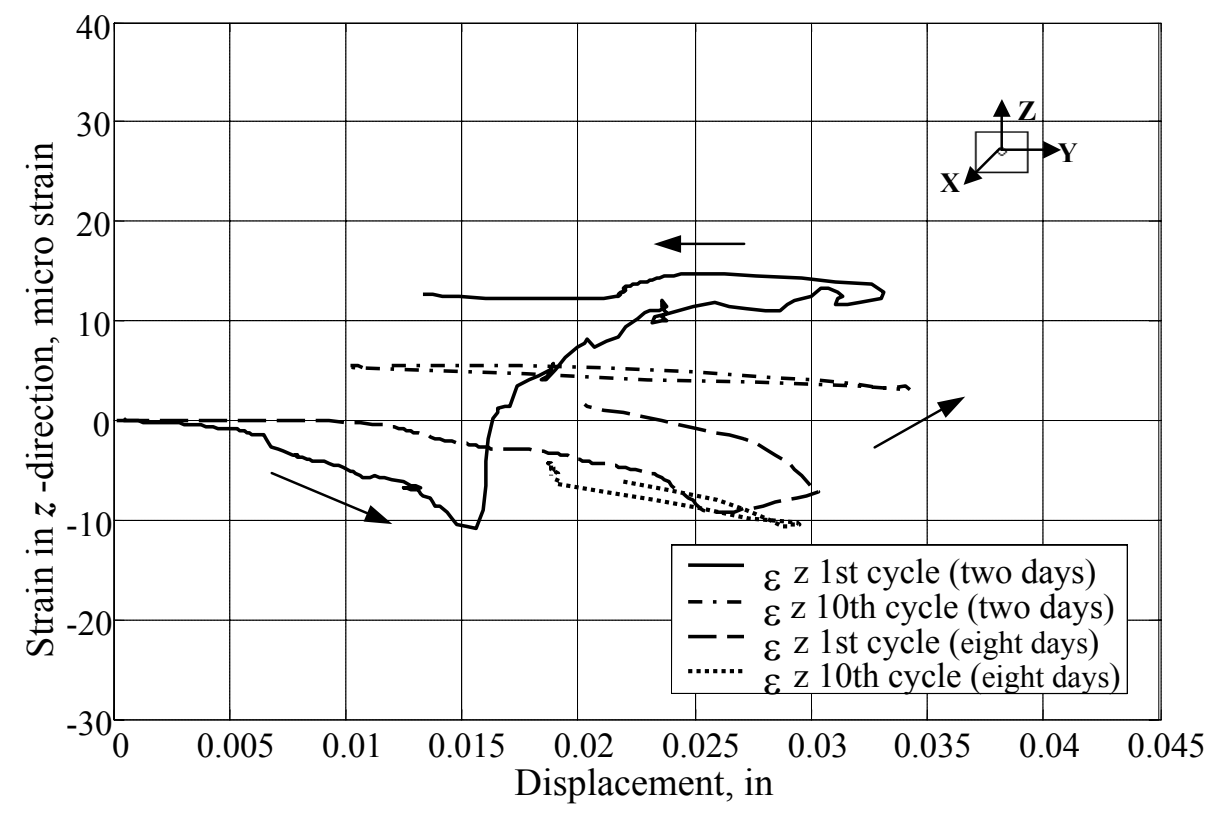

Figure 3.22 Strain-displacement curve of the specimen with uncoated dowel bar of diameter 1.5 in. 


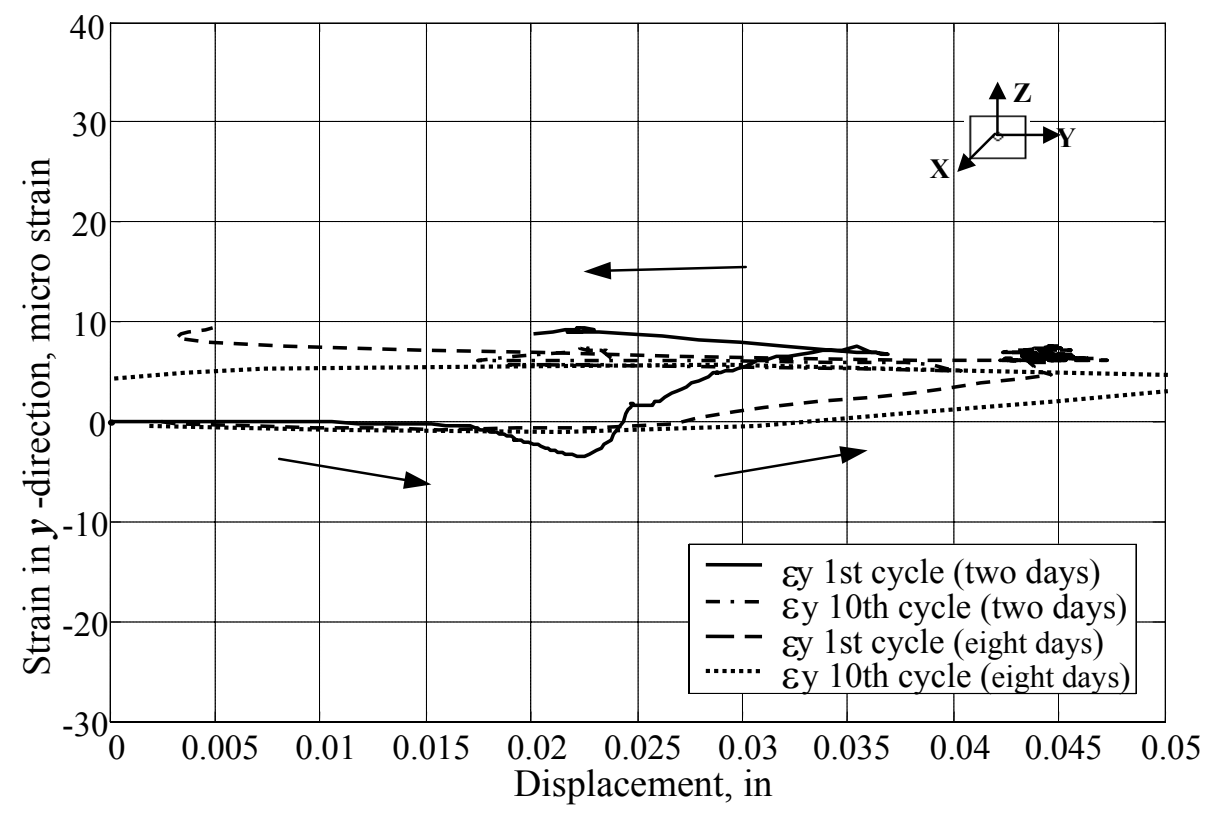

Figure 3.23 Strain-displacement curve of the specimen with silicone coated dowel bar of diameter $1.5 \mathrm{in}$.

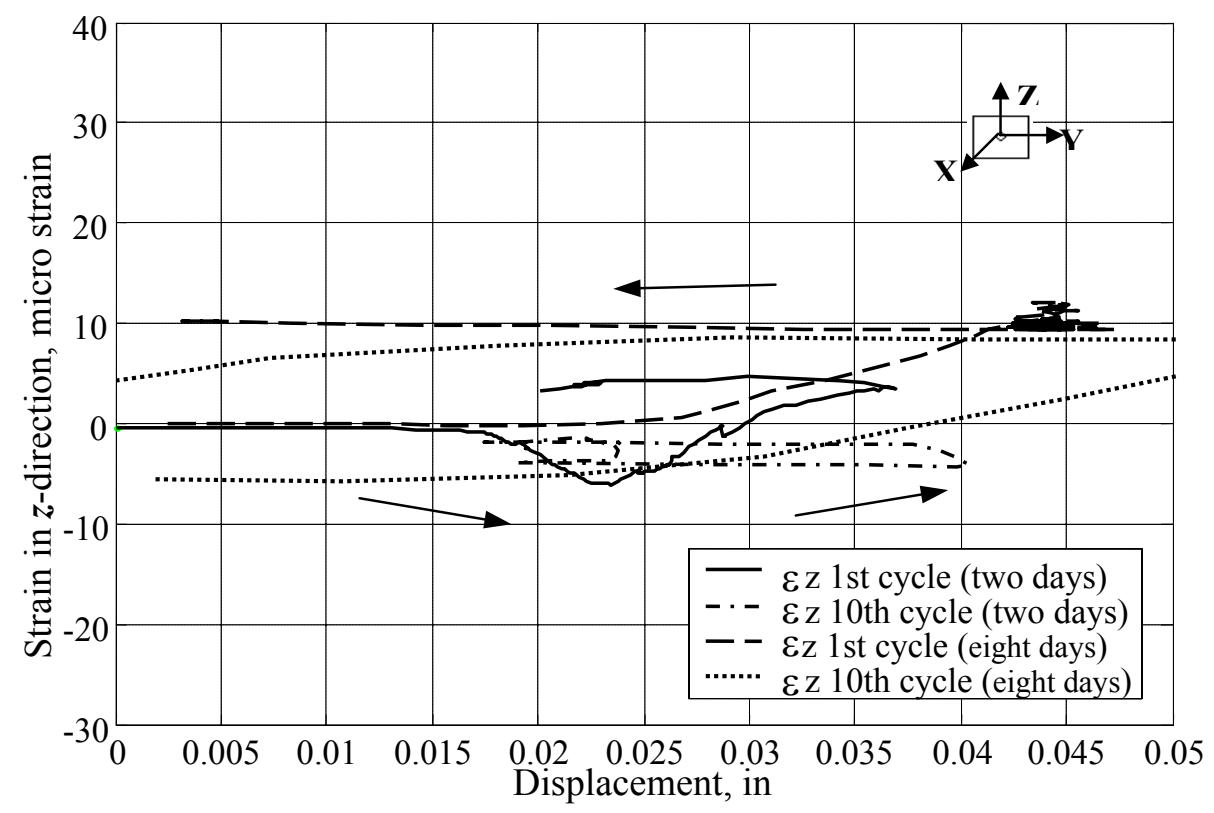

Figure 3.24 Strain-displacement curve of the specimen with silicone coated dowel bar of diameter $1.5 \mathrm{in}$. 


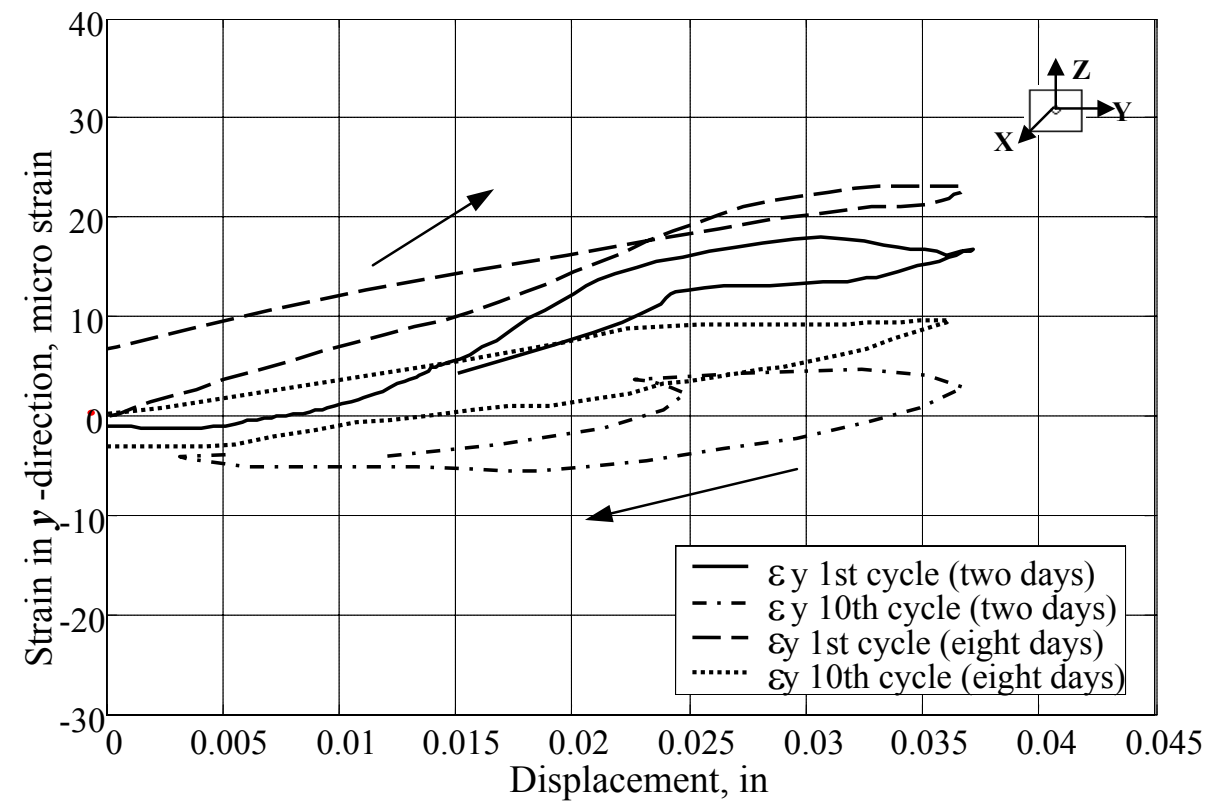

Figure 3.25 Strain-displacement curve of the specimen with tectyl coated dowel bar of diameter $1.5 \mathrm{in}$.

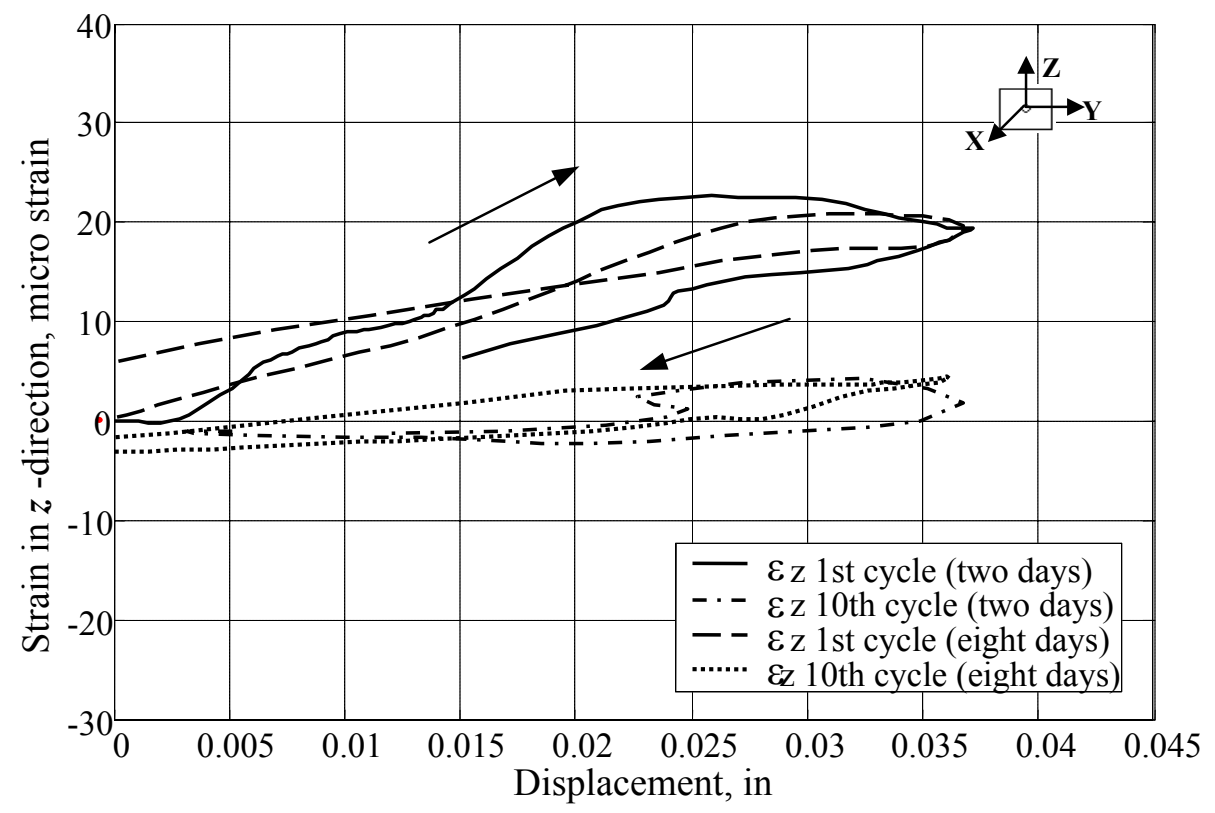

Figure 3.26 Strain-displacement curve of the specimen with tectyl coated dowel bar of diameter $1.5 \mathrm{in}$. 


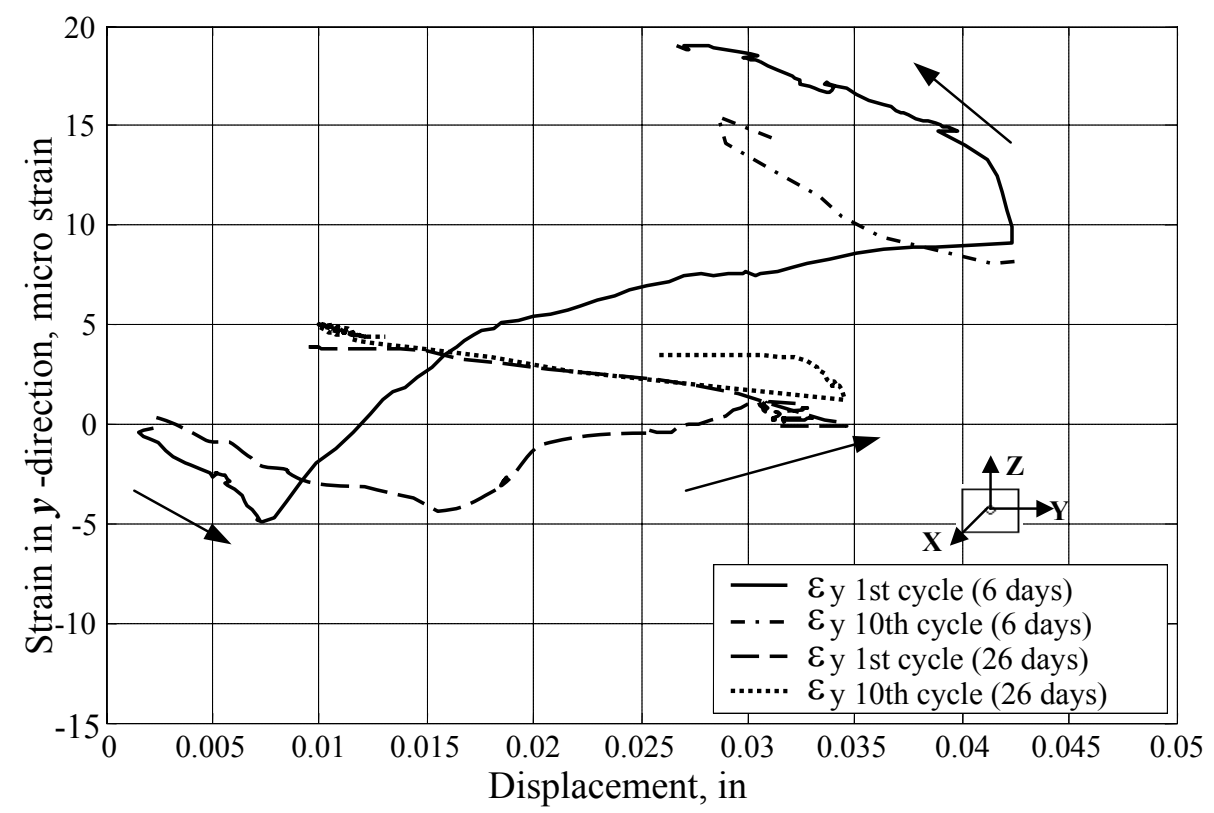

Figure 3.27 Strain-displacement curve of the specimen with uncoated dowel bar of diameter 1.25 in.

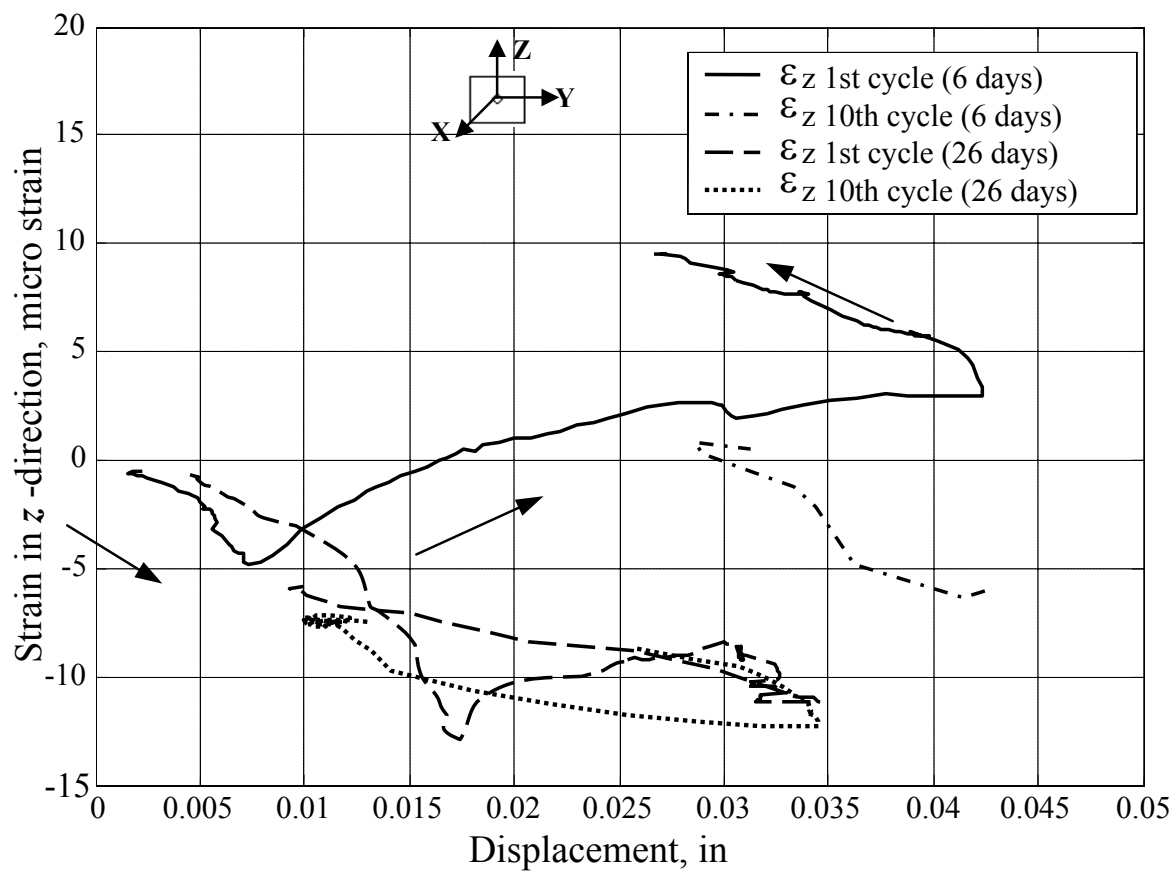

Figure 3.28 Strain-displacement curve of the specimen with uncoated dowel bar of diameter 1.25 in. 


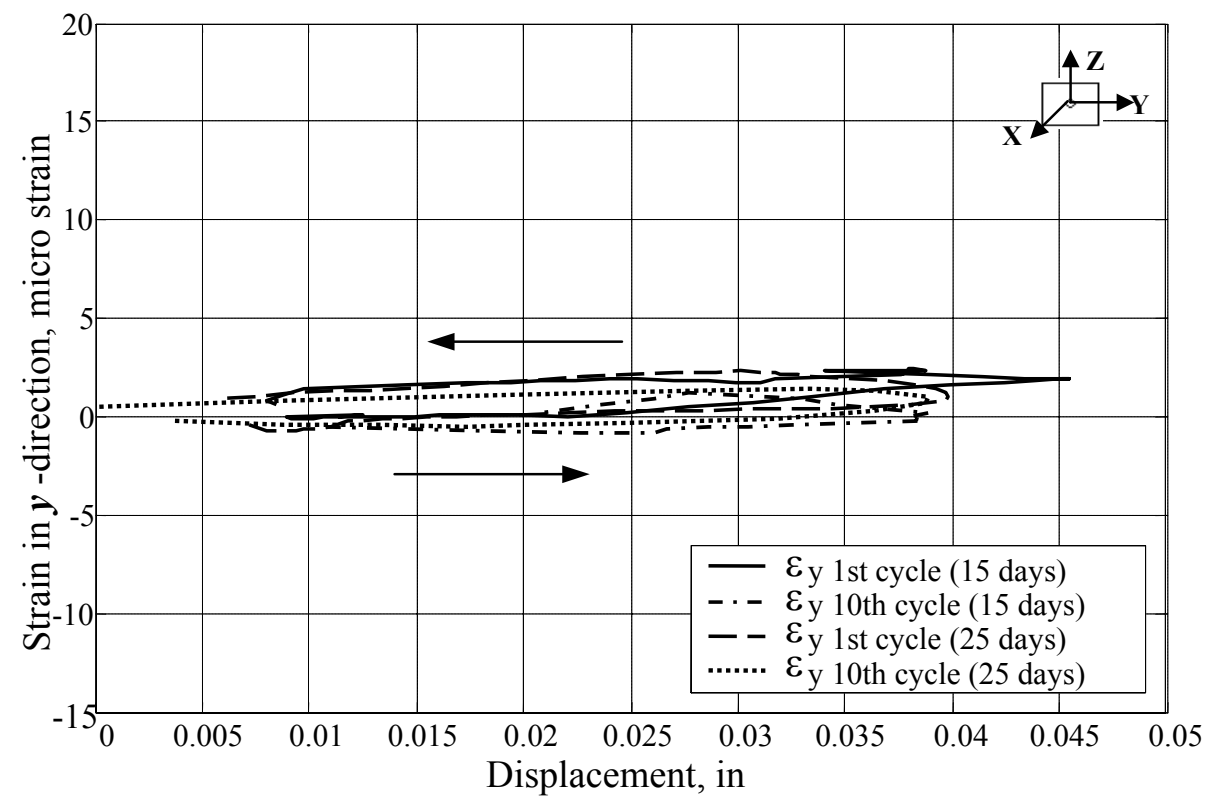

Figure 3.29 Strain-displacement curve in the specimen with silicone coated dowel bar of diameter 1.25 in.

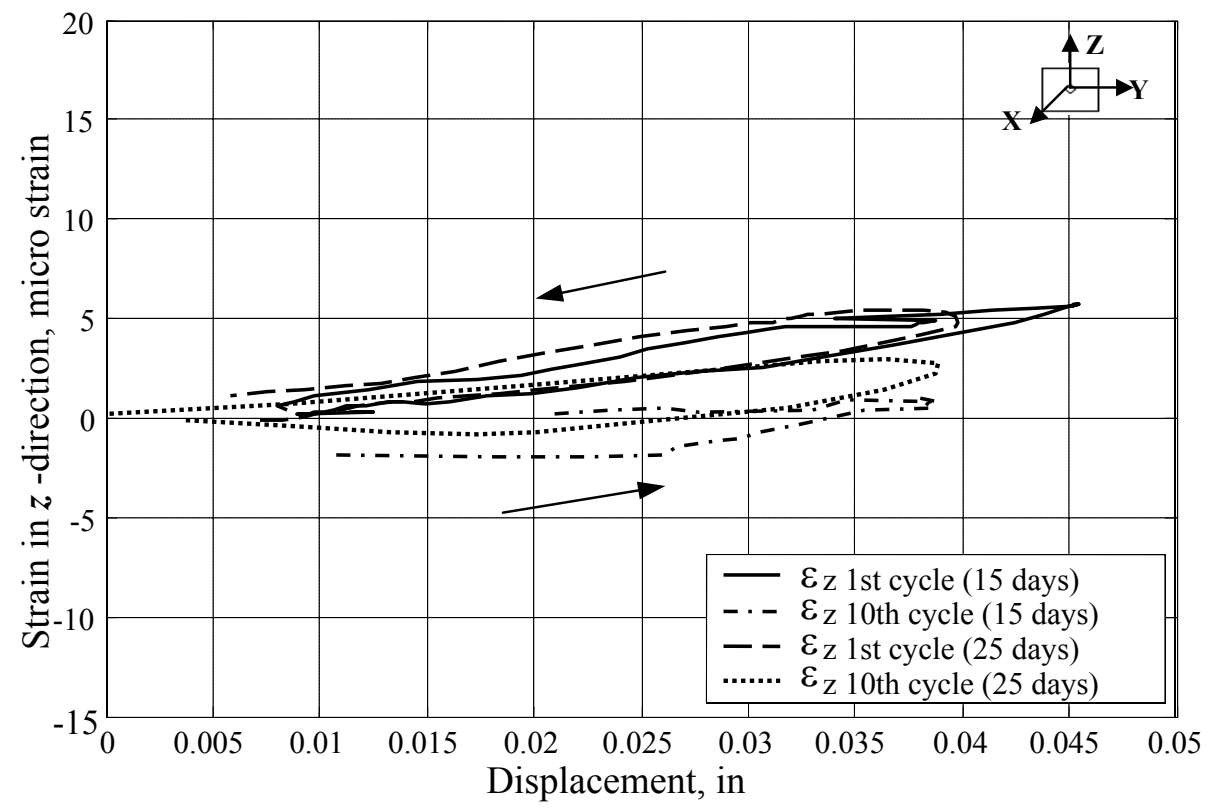

Figure 3.30 Strain-displacement curve in the specimen with silicone coated dowel bar of diameter 1.25 in. 


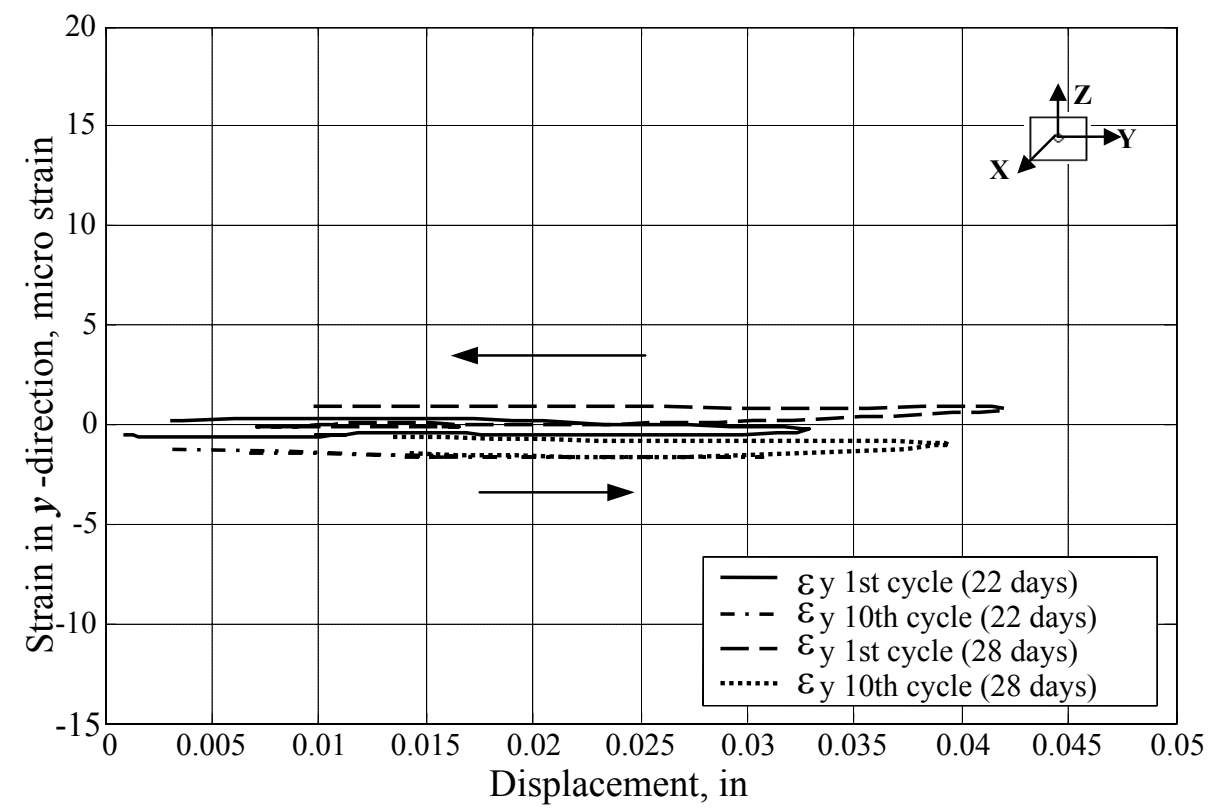

Figure 3.31 Strain-displacement curve of the specimen with tectyl coated dowel bar of diameter 1.25 in

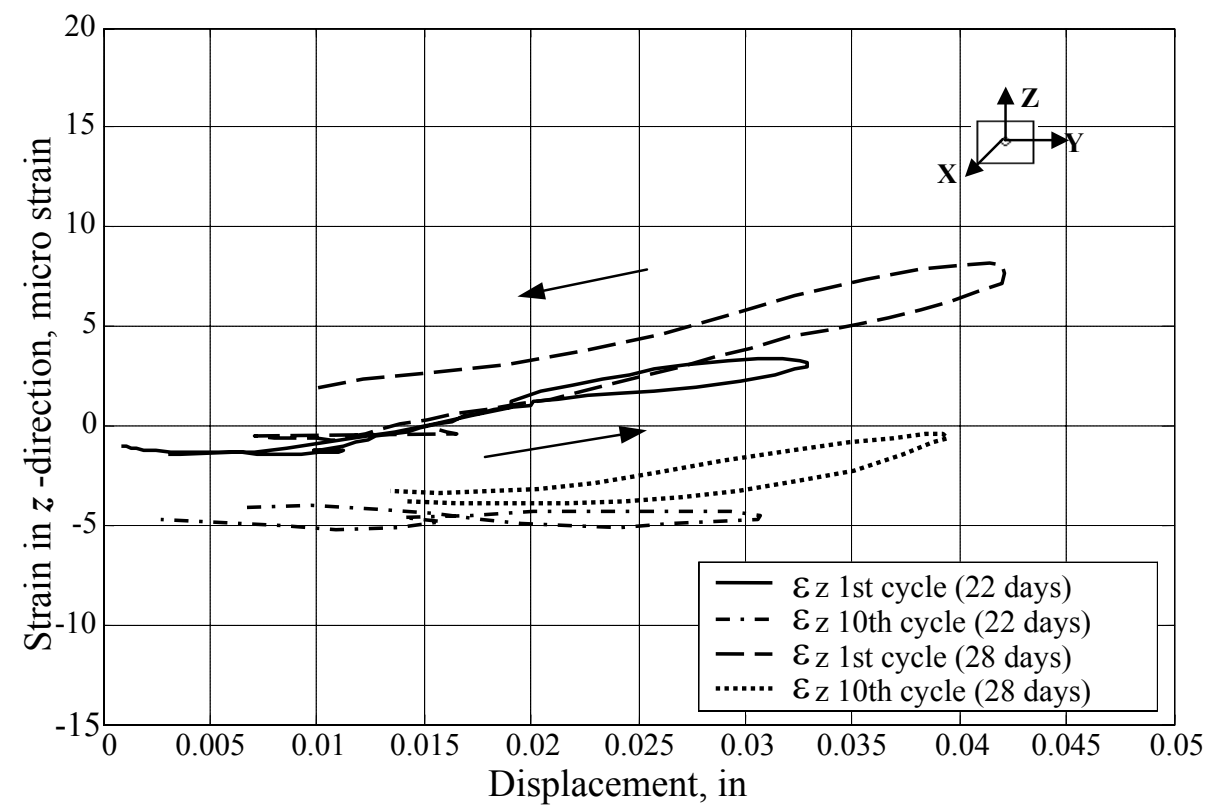

Figure 3.32 Strain-displacement curve of the specimen with tectyl coated dowel bar of diameter 1.25 in. 


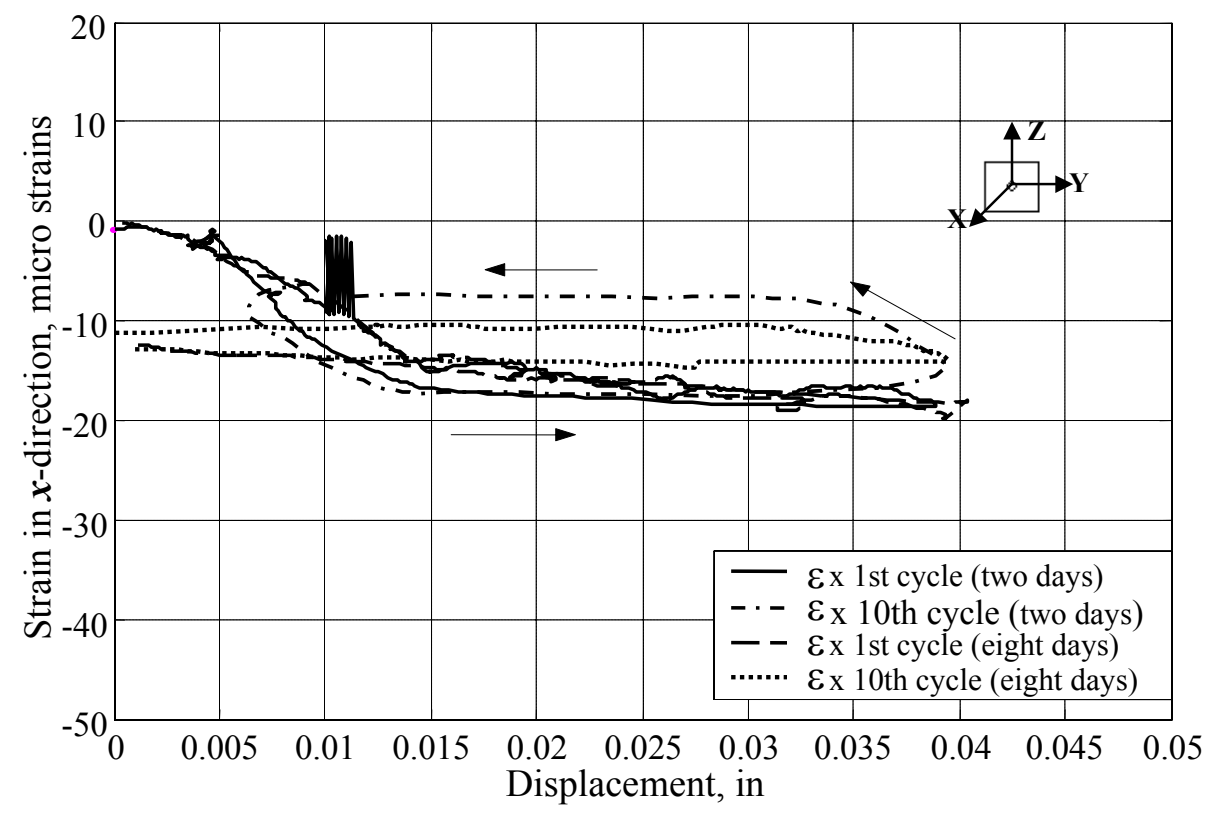

Figure 3.33 Strain-displacement curve of the specimen No.1 with uncoated dowel bar of diameter 1.5 in.

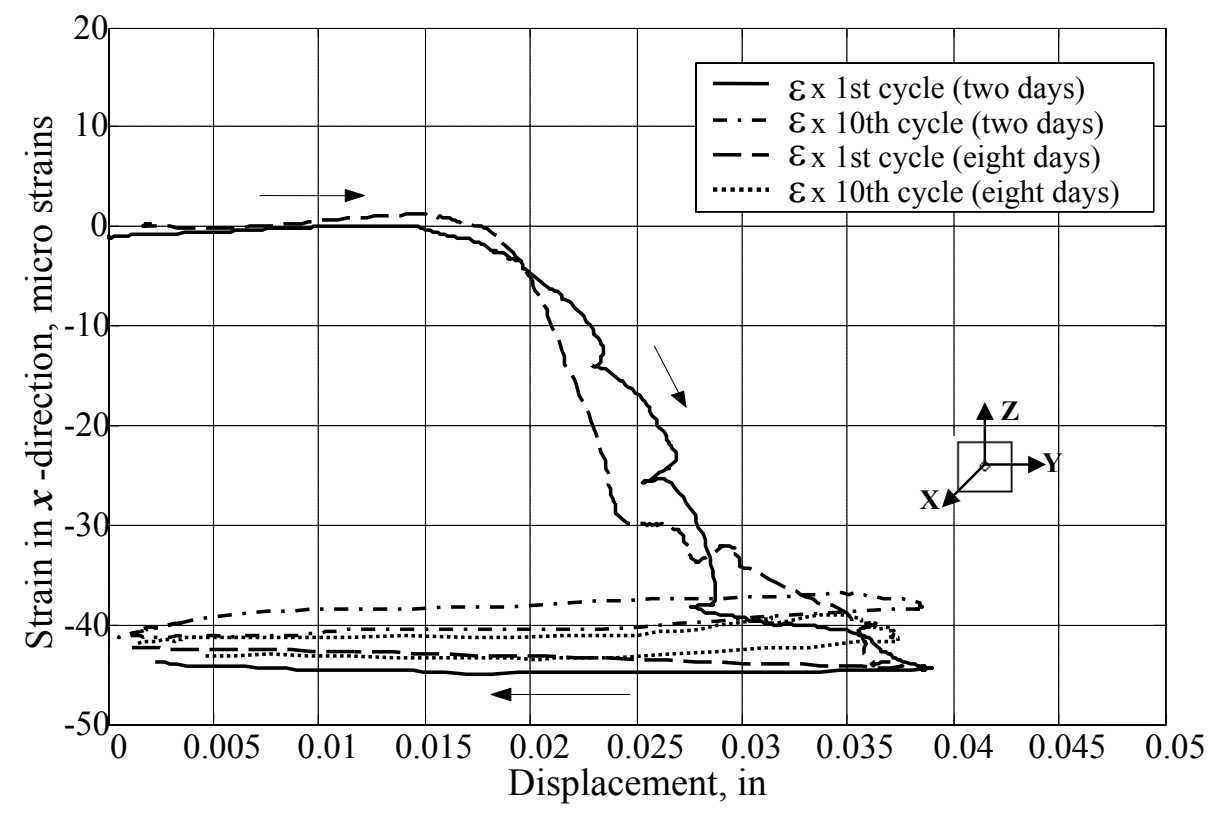

Figure 3.34 Strain-displacement curve of the Specimen No.2 with uncoated dowel bar of diameter 1.5 in. 


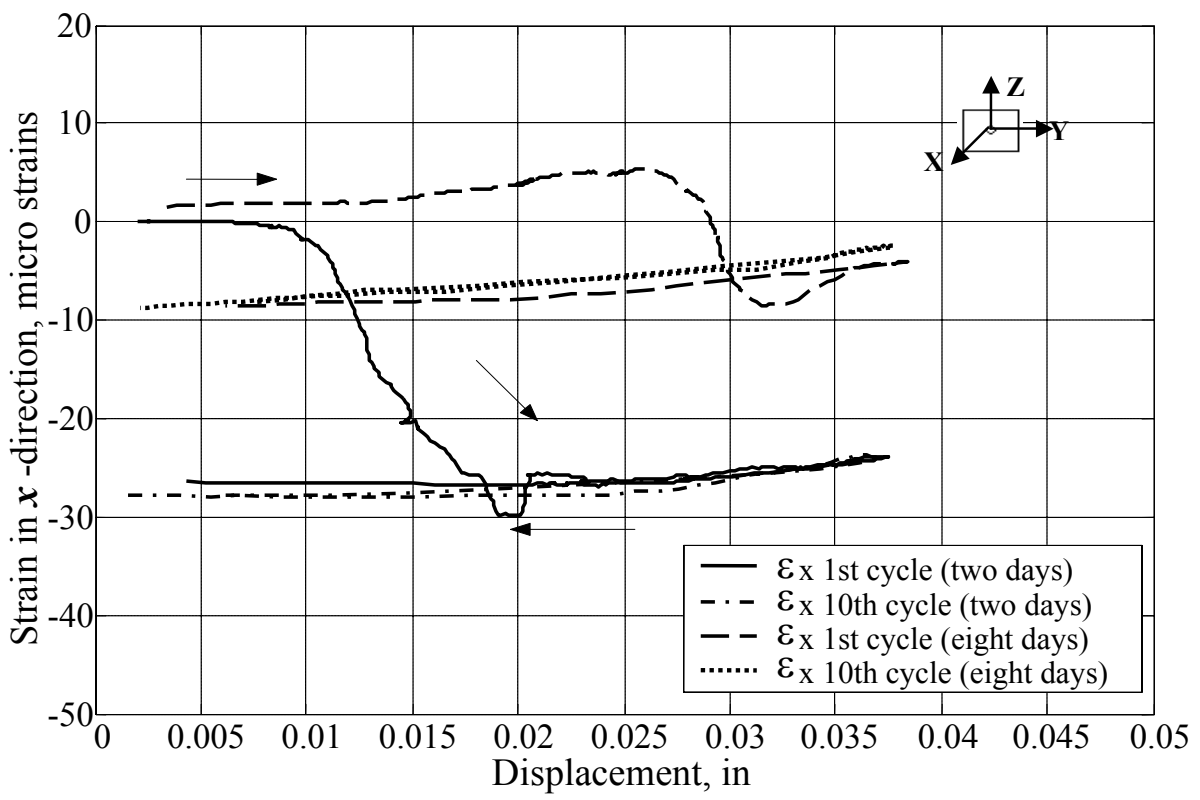

Figure 3.35 Strain-displacement curve of the Specimen No.3 with uncoated dowel bar of diameter 1.5

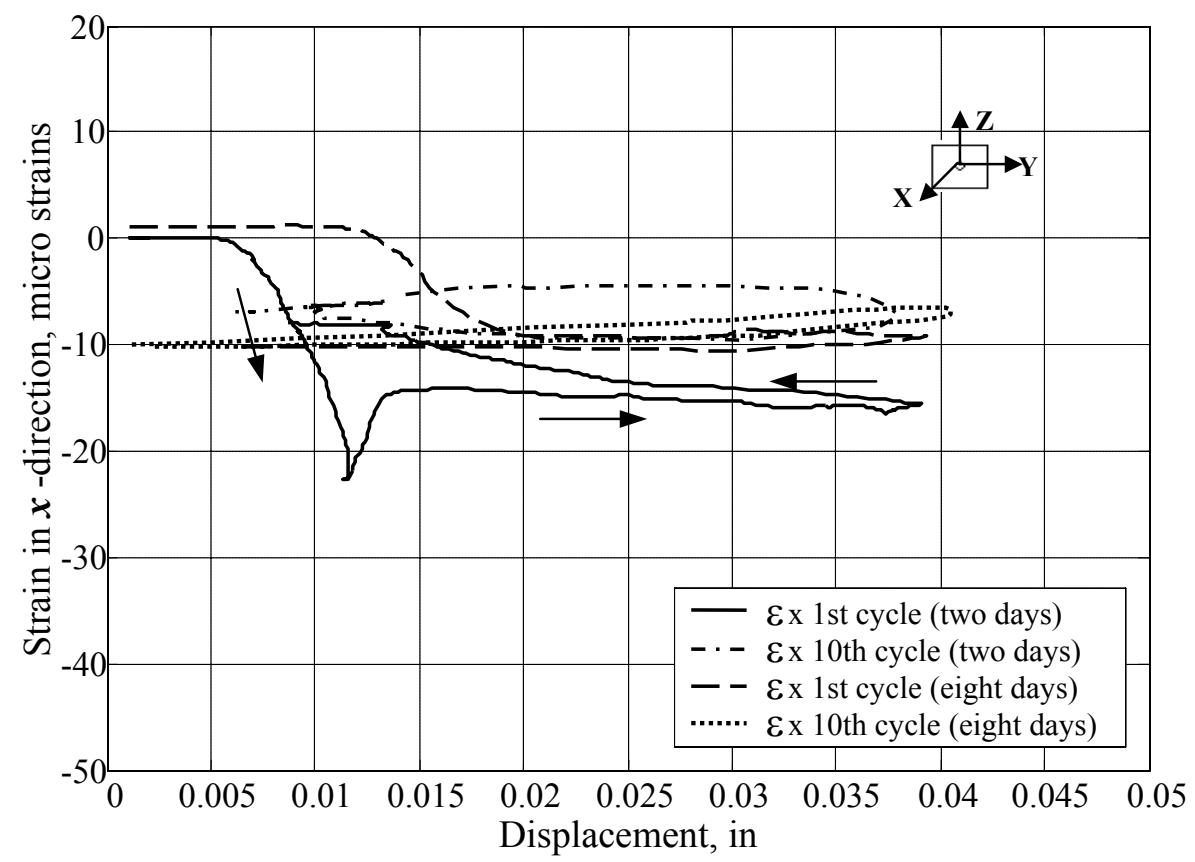

Figure 3.36 Strain-displacement curve of the Specimen No.1 with silicone coated dowel bar of diameter $1.5 \mathrm{in.}$ 


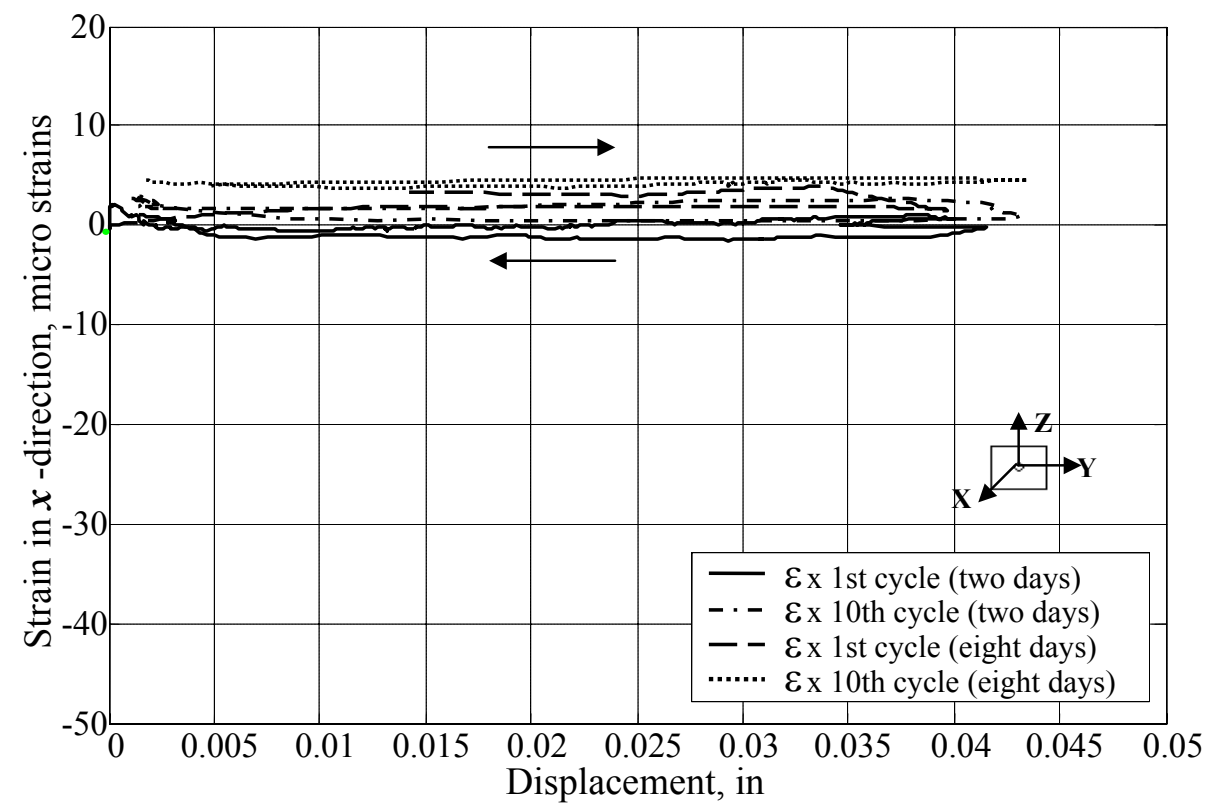

Figure 3.37 Strain-displacement curve of the Specimen No.2 with silicon coated dowel bar of diameter $1.5 \mathrm{in}$.

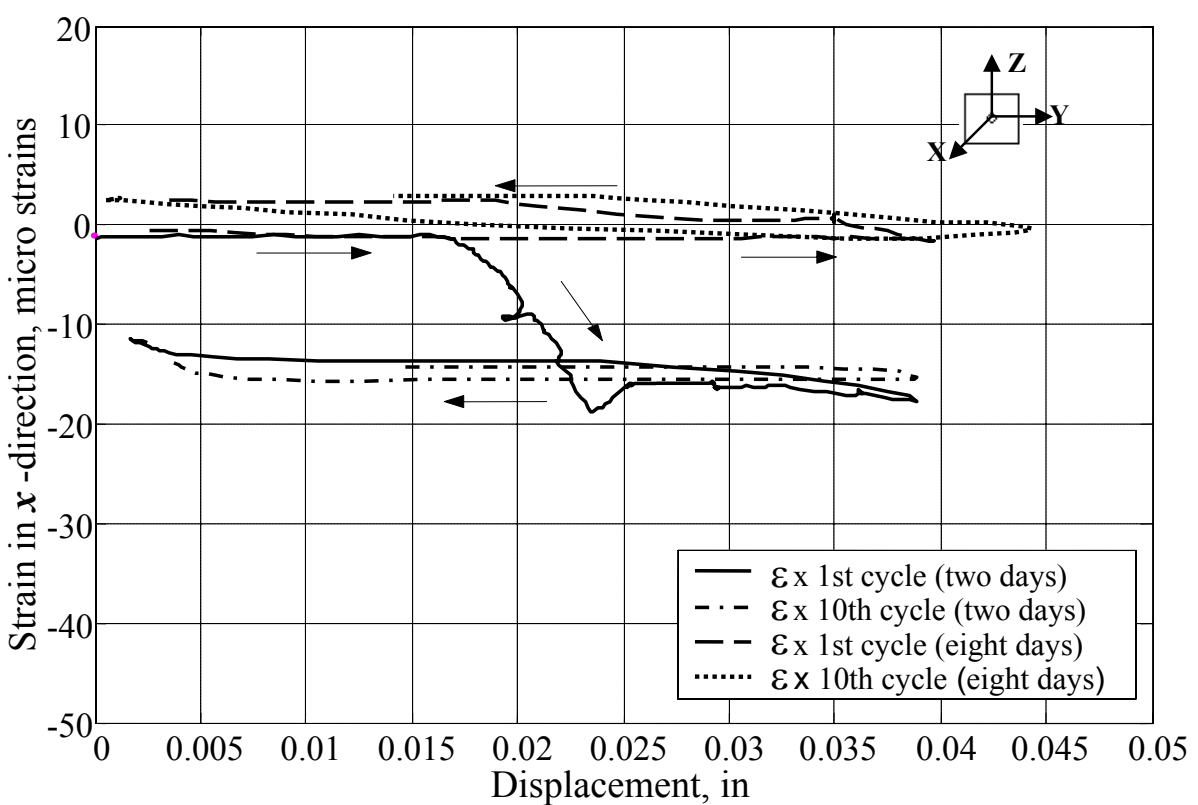

Figure 3.38 Strain-displacement curve of the Specimen No.3 with silicon coated dowel bar of diameter $1.5 \mathrm{in}$. 


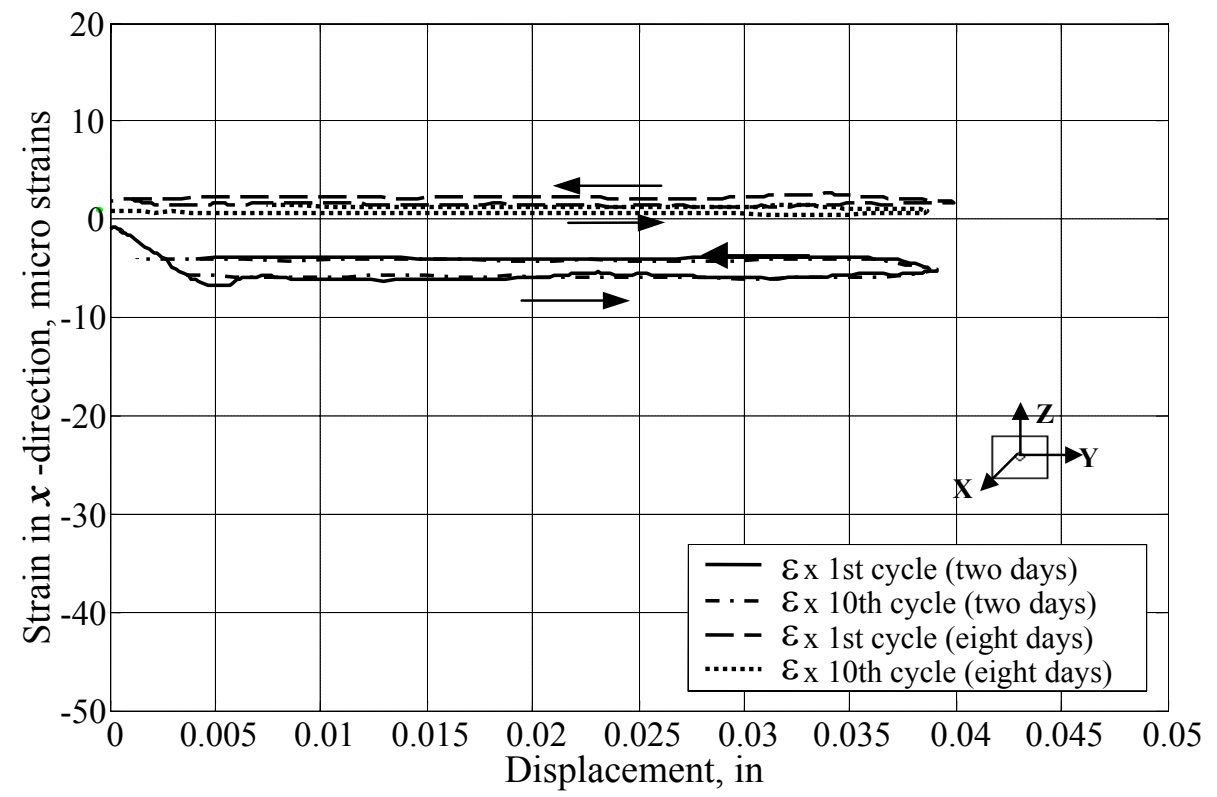

Figure 3.39. Strain-displacement curve of the specimen No.1 with tectyl coated dowel bar of diameter $1.5 \mathrm{in}$.

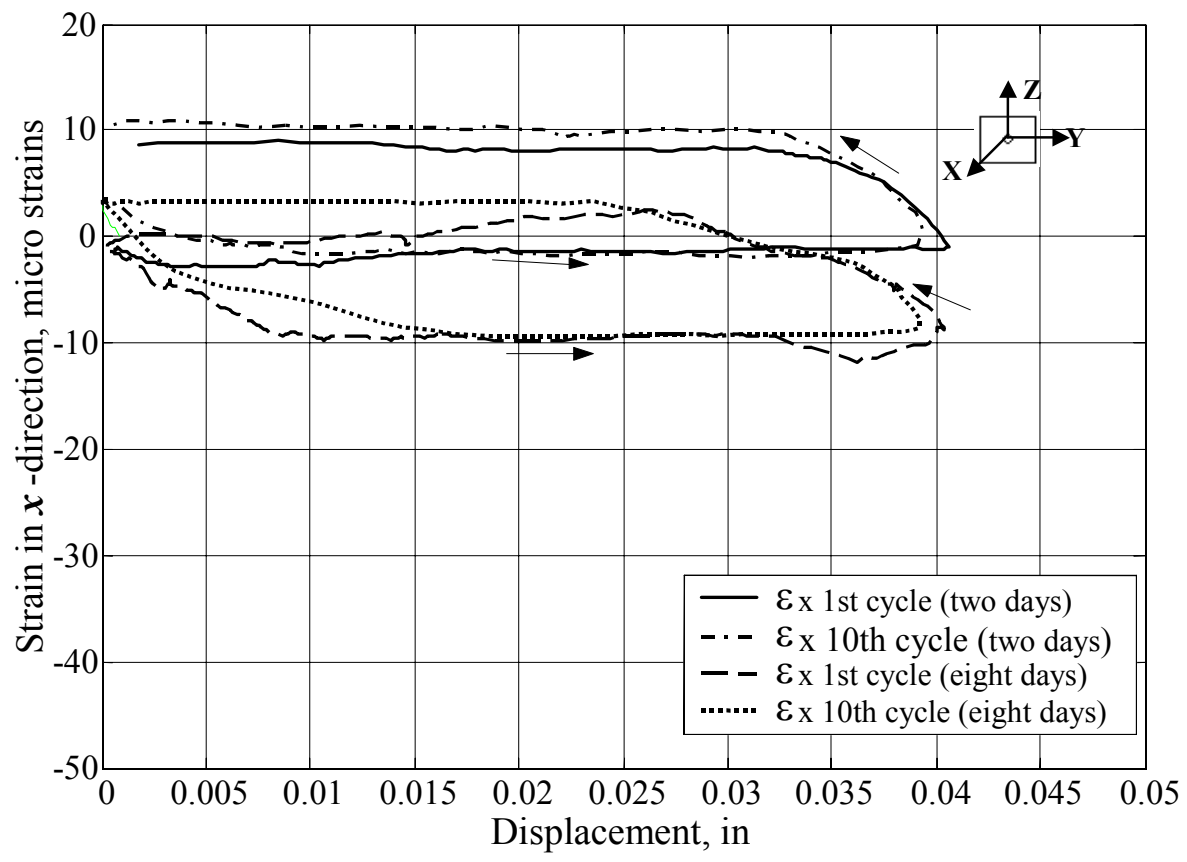

Figure 3.40 Strain-displacement curve of the specimen No.2 with tectyl coated dowel bar of diameter $1.5 \mathrm{in}$. 


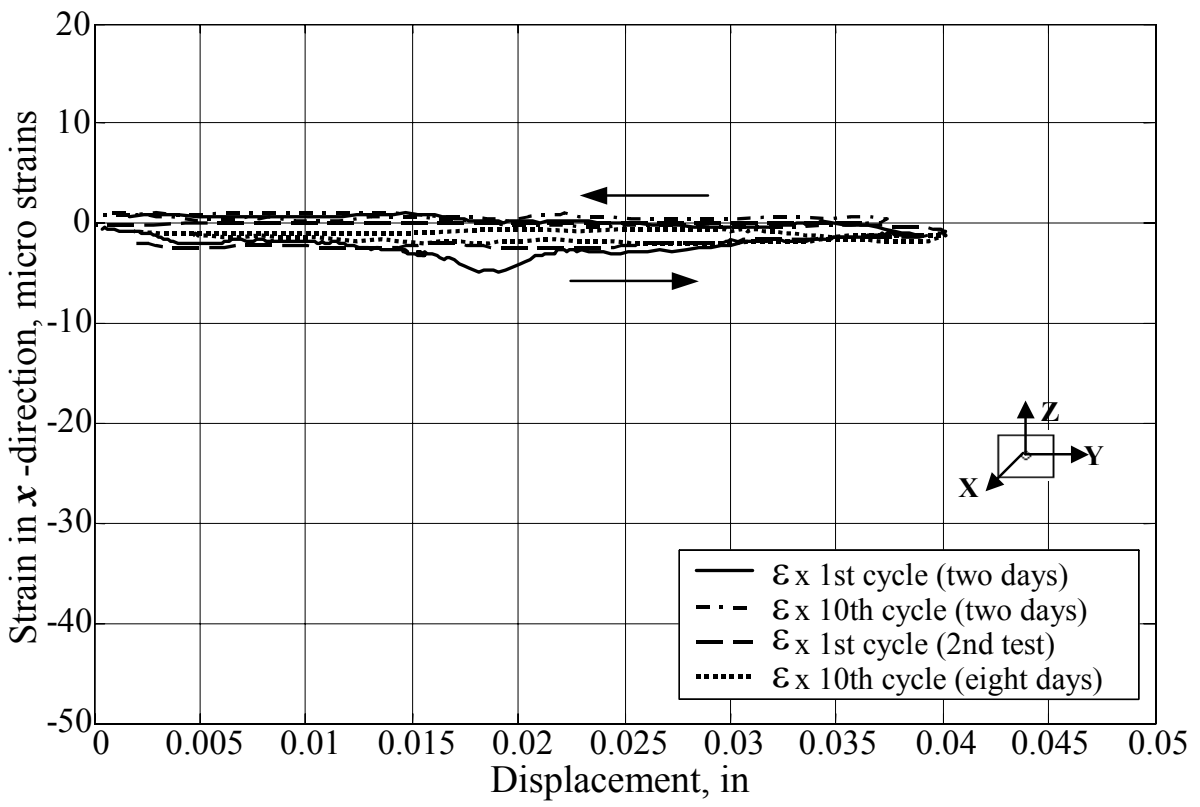

Figure 3.41 Strain-displacement curve of the specimen No.3 with tectyl coated dowel bar of diameter 1.5 in. 


\section{CHAPTER FOUR}

\section{ESTIMATION OF FRICTION COEFFICIENT}

\subsection{INTRODUCTION}

As stated earlier, there is considerable friction at the interface of dowel bar and concrete in spite of debonding agents applied to the dowel bar. In this chapter, two theoretical approaches are developed for the prediction of the friction coefficient based on the experimental results of complete pullout test.

\subsection{PREDICTION OF FRICTION COEFFICIENT BASED ON A COUPLED EXPERIMENTAL-THEORECTICAL APPROACH}

\subsubsection{Basics}

Shrinkage of concrete takes place as the concrete solidifies and dries (19). This shrinkage gradually increases with time until it gets stabilized. The concrete around the dowel bar generates radial pressure on the bar as shown in Figure 4.1. This clamping force on the dowel bar hinders its axial movement during the pullout and push-in actions. The friction coefficient can be estimated knowing the axial force to overcome friction and the clamping radial force. In the current approach, the compressive strains and frictional forces were determined through experiments. A theoretical model was developed to evaluate the clamping forces of concrete around the dowel bar.

\subsubsection{Complete Pullout Test}

A complete pullout test of the dowel bar from the concrete was conducted with the primary objective of measuring the frictional force and the compressive strains produced in the concrete. The same test rig and data acquisition system used for the previous set of experiments were employed in this test also. The changes in compressive strain in the concrete before and after pullout test were measured using the vibrating wire strain gages embedded in the concrete specimen.

If there were no dowel bar or a concrete block was cast with a hole at its center, the hole would close partially by due to the compressive strain induced in it due to the 
shrinkage of the concrete, as illustrated in Figure 4.2. Based on this fact, it was decided to perform an experiment to completely pullout the dowel bar from the concrete block to measure the strains due to elastic recovery. Applying a higher rate of loading the dowel bar was pulled completely out of the specimen very quickly. The load applied and the displacements of the dowel bar were measured by the load cell and LVDT respectively.

Table 4.1 lists the maximum pullout force and the strains recovered in concrete during the experiments. Figures $4.3-4.5$ illustrate the change in strains recorded in radial directions in the specimens with uncoated, silicone coated, and tectyl coated dowel bars during the test. The results confirm that the pullout forces and strains recovered were higher in concrete with uncoated dowel bars than that with the coated bars. In the case of coated dowel bars, the film of debonding agent coated on the dowel bar would have acted as an elastic medium allowing the concrete to contract until the pressure exerted by the layer of debonding agent opposed it. Moreover, the pressurized layer of debonding agent at the interface would have relieved more opposing the contraction of concrete when the dowel bar was completely pulled out.

\subsubsection{Theoretical Model}

The stresses and deformations in the concrete were calculated using the radial strains obtained from the experiments. The equations used for calculating these stresses and deformations are based on the following assumptions. First, the prism specimens measuring 10-in long, 12-in wide, 11-in deep were assumed to be hollow cylindrical specimens with an outer diameter of $10 \mathrm{in}$. and an inner diameter of 1.25/1.5 in. (depending on the dimension of the diameter of dowel bar used in the specimen) and 11in. long as shown in Figure 4.6. Second, the strains developed in the concrete due to shrinkage were assumed to be equivalent to strains developed as a result of a temperature variation across the concrete cross-section. Further, the cylindrical surface or circular disc was assumed to be free of traction forces on outer surface. The measured strains from the experiments were due to the shrinkage of concrete. In the analogous problem the radial displacement due to temperature variation were substituted with that due to the shrinkage of concrete. 
The governing equation of an axisymmetric hollow cylinder of inner radius of $a$ and outer radius $b$ (refer Figure 4.7) subjected to a radial temperature variation is given by (20),

$$
\frac{d}{d r}\left[\frac{1}{r} \frac{d(r u)}{d r}\right]=\alpha(1+v) \frac{d T}{d r}
$$

where, $\alpha=$ coefficient of thermal expansion,

$$
\begin{aligned}
& v=\text { Poisson's ratio, } \\
& r=\text { radial distance, } \\
& u=\text { radial displacement, and } \\
& \mathrm{T}(\mathrm{r})=\text { temperature distribution }
\end{aligned}
$$

The general solution to this equation is,

$$
u(r)=\frac{(1+v) \alpha}{r} \int_{a}^{r} T r d r+C_{1} r+\frac{C_{2}}{r}
$$

where, $C_{1}$ and $\mathrm{C}_{2}$ integration constants to be determined from the boundary conditions:

$$
\begin{gathered}
\left.u\right|_{r=a}=0, \\
\left.\sigma_{r r}\right|_{r=a}=0
\end{gathered}
$$

By applying the strain-displacement relations and Hooke's law, the stresses are

$$
\begin{aligned}
& \sigma_{r r}=-\frac{\alpha E}{r^{2}} \int_{a}^{r} T r d r+\frac{E C_{1}}{1-v}-\frac{E C_{2}}{(1+v) r_{2}} \\
& \sigma_{\theta \theta}=\frac{\alpha E}{r^{2}} \int_{a}^{r} T r d r-\alpha E T+E C_{1}+\frac{E C_{2}}{(1+v) r^{2}} \\
& \sigma_{r \theta}=0
\end{aligned}
$$

On applying the boundary conditions, of zero displacement at $r=a, \mathrm{u}(\mathrm{a})=0$

$$
C_{1} a+\frac{C_{2}}{a}=0 \Rightarrow C_{2}=-C_{1} a^{2}
$$

and at $r=b$, the traction force is zero, $\left.\sigma_{r r}\right|_{r=b}=0$, 


$$
\Rightarrow-\frac{\alpha E}{b^{2}} \int_{a}^{b} \operatorname{Tr} d r+\frac{E C_{1}}{1-v}+\frac{E C_{1} a^{2}}{(1+v) b^{2}}=0
$$

Assuming a uniform temperature $T$ throughout the concrete block

$$
-\frac{\alpha E T}{2 b^{2}}\left(b^{2}-a^{2}\right)+\frac{E C_{1}}{1-v}+\frac{E C_{1} a^{2}}{(1+v) b^{2}}=0
$$

Thus the values of $C_{1}$ and $C_{2}$ are obtained as,

$$
\begin{aligned}
& C_{1}=\frac{\alpha T\left(1-v^{2}\right)\left(b^{2}-a^{2}\right)}{\left(b^{2}+a^{2}\right)+v\left(b^{2}-a^{2}\right)} \\
& C_{2}=\frac{-a^{2} \alpha T\left(1-v^{2}\right)\left(b^{2}-a^{2}\right)}{\left(b^{2}+a^{2}\right)+v\left(b^{2}-a^{2}\right)}
\end{aligned}
$$

When the values of the $C_{1}$ and $C_{2}$ are substituted in Eq. (4.2) and integrated, the radial displacement $u(r)$ is obtained as,

$u(r)=\frac{\alpha T(1+v)}{2 r}\left(r^{2}-a^{2}\right)+\frac{\alpha T\left(1-v^{2}\right)\left(b^{2}-a^{2}\right) r}{\left(b^{2}+a^{2}\right)+v\left(b^{2}-a^{2}\right)}-\frac{\alpha T a^{2}\left(1-v^{2}\right)\left(b^{2}-a^{2}\right)}{\left(b^{2}+a^{2}\right)+v\left(b^{2}-a^{2}\right) r}$

As mentioned above, that the deformations due to temperature variations were substituted by the equivalent deformations due to the shrinkage of concrete.

Now, $\alpha T=\varepsilon_{s h}$

Hence, the radial displacement can be written as follows from Eqs. (4.7) and (4.8),

$$
u(r)=\frac{\varepsilon_{s h}(1+v)}{2 r}\left(r^{2}-a^{2}\right)+\frac{\varepsilon_{s h}\left(1-v^{2}\right)\left(b^{2}-a^{2}\right)}{\left(b^{2}+a^{2}\right)+v\left(b^{2}-a^{2}\right)} r-\frac{\varepsilon_{s h} a^{2}\left(1-v^{2}\right)\left(b^{2}-a^{2}\right)}{\left(b^{2}+a^{2}\right)+v\left(b^{2}-a^{2}\right) r}
$$

As shown in Figure 4.8, from the experimental study the vibrating wire strain gages in $y$ and $z$ directions measure the radial strains in the concrete dowel bar at its gage length. The dowel bar is assumed to be rigid and there are no radial displacements in it due to shrinkage of concrete. The measured strains were used to calculate the radial displacements in the concrete at the gage length of the vibrating wire strain gage and thus the strains due to shrinkage were estimated in order to calculate the stresses in the concrete, which act as the clamping forces around the dowel bar. 
The measured strain, $\varepsilon_{\text {measured }}=\frac{\Delta L}{L}=\frac{\Delta L / 2}{L / 2}$,

Therefore, the radial displacement, $u(r)=\Delta L / 2=L / 2 * \varepsilon_{\text {measured }}$

From the Eqs. (4.9) and (4.11), the shrinkage strain, $\varepsilon_{s h}$ is determined.

The stresses at the dowel-concrete interface of the concrete can be estimated from Eq. (4.3) using the estimated shrinkage of the concrete from the Eqs. (4.9) and (4.11).

The stresses induced in the concrete due to the radial displacement act as the clamping forces around the dowel bar, it has to overcome these clamping forces to have axial displacement.

Therefore, the clamping force on the dowel bar is,

$$
F_{\text {clamp }}=\left.\sigma_{r r}\right|_{r=a} * A \text {, }
$$

where $A=2 \pi a l$, from Figure 4.9

$a=$ the radius of the dowel bar

$l=$ the embedded length of the dowel bar in the concrete.

The forces $\left(F_{\text {pull }}\right)$ required to overcome the clamping forces for the displacement of the dowel bar were determined from the complete pullout test, as discussed in the previous section.

As we now know the normal force $\left(F_{\text {clamp }}\right)$ and frictional force $\left(F_{\text {pull }}\right)$, friction coefficient at the interface of dowel bar and concrete can be estimated.

Hence the friction coefficient, $\mu=\frac{F_{\text {pull }}}{F_{\text {clamp }}}$

The evaluated values of friction coefficient at interface in all the specimens are given in Table 4.2 under Method-1. These results indicate that the $\mu$ values calculated, show a considerable difference between the 1.5-in. and 1.25-in. diameter cases. The coefficient of friction should be independent of the contact area of surfaces under similar conditions (21). It appears that this model for the prediction of the friction coefficient is not adequate. Hence, a different approach was developed to determine the coefficient of friction. 


\subsection{SHRINK-FIT MODEL}

This model assumes that the radial forces generated at the concrete-dowel interface due to shrink fitting of the concrete over the dowel bar. In a general case of hollow cylinder shrink fitted on a shaft, the internal radius of cylinder increase and radius of shaft decreases. In the present case, the comparatively rigid dowel bar is assumed to have no displacement. The clamping force in concrete was calculated with application of basic equations of stresses and deformations of thick walled cylinders with pressure acting on the internal surface of outer cylinder (22). Deformations and stresses at any point in the cylinder are a function of internal and external pressures acting on the cylinder and the radial distance from the axis of cylinder.

Consider a thick-walled axi-symmetric cylinder of internal radius $a$ and external radius $b$ subjected to a pressure $p$ on the inner surface as shown in Figure 4.11. The radial and tangential stresses, $\sigma_{r}$ and $\sigma_{\theta}$ as shown on a radial element in the Figure 4.11. The only nontrivial equilibrium equation is the radial one,

$$
\frac{d \sigma_{r}}{d r}-\frac{\sigma_{\theta}-\sigma_{r}}{\sigma_{r}}=0,
$$

$\sigma_{r}$ and $\sigma_{\theta}$ are radial and tangential stresses at a radial distance $r$.

If $u$ is radial displacement of a point at a radial distance $r$, when deformation is small and symmetrical, the strains at that point are given as,

$$
\varepsilon_{r}=\frac{d u}{d r} \text { and } \varepsilon_{\theta}=\frac{u}{r}
$$

while deformations in axial direction are assumed to be constant,

$$
\varepsilon_{z}=C \text { (constant) }
$$

From Eq. (4.15), the radial strain can be expressed as,

$$
\varepsilon_{r}=\frac{d\left(r \varepsilon_{\theta}\right)}{d r}
$$

The boundary conditions are:

$$
\begin{aligned}
& \sigma_{r}=0 \text { at } r=b \\
& \sigma_{r}=-p \text { at } r=a
\end{aligned}
$$


In axial direction, for overall equilibrium, $p \pi a^{2}=\int_{a}^{b} 2 \pi \sigma_{z} r d r$

On substituting the elastic constitutive relations in Eq. (4.17) and using relation in Eq. (4.14), radial and tangential stresses are obtained as follows when subjected to the boundary conditions as in Eqs. (4.18),

$$
\begin{gathered}
\sigma_{r}=\frac{p a\left(r^{2}-b^{2}\right)}{r^{2}\left(b^{2}-a^{2}\right)} \\
\sigma_{\theta}=\frac{p a\left(r^{2}+b^{2}\right)}{r^{2}\left(b^{2}-a^{2}\right)} \\
\sigma_{z}=2 v \frac{p a^{2}}{b^{2}-a^{2}}+E C
\end{gathered}
$$

The value of $C$ is obtained by substituting $\sigma_{z}$ into Eq. (4.19)

Thus the radial displacement, $u$, is obtained from Eq. (4.15) and elastic constitutive equations,

$$
u=r \varepsilon_{\theta}=\frac{(1+v) a^{2} p}{E\left(b^{2}-a^{2}\right)}\left[\frac{(1-2 v) r}{(1-v)}+\frac{b^{2}}{r}\right]
$$

From the measured strains radial displacement at gage length of strain gage is obtained as, (refer to Figure 4.6)

$u=\varepsilon_{\text {measured }} * L / 2$, while $r=L / 2$.

The internal pressure $p$ is estimated from Eqs. (4.21) and (4.22).

The normal force that acts as a clamping force around dowel bar $F_{c l a m p}=p *$ area, $F_{\text {pull, }}$ represents pulling force, which was obtained from load required to pull the bar during test.

Thus, the friction coefficient, $\mu=\frac{F_{\text {pull }}}{F_{\text {clamp }}}$

Table 4.2 lists, under Method-2, the value of friction coefficient evaluated. The friction coefficient did not vary much with the diameter of dowel bar. Hence, this second approach is deemed to be a more accurate predictor of the friction coefficient. 


\subsection{INFERENCES BASED ON THE RESULTS}

The debonding agents undeniably reduced the friction coefficient at interface. The coefficient of friction in the case of uncoated dowel bar was four times as high as the coated bar. The surface of the uncoated dowel bar had a large number of scratches on it as opposed to coated dowel bars as shown in Figures 4.12 - 14. A close examination of the pulled out tectyl coated dowel bar (Figure 4.14) indicated patches of missing coating which led to the obvious conclusion that the coating stuck to the concrete. This probably would increase the friction coefficient in the long run. The tectyl coating is likely to disintegrate during early stages of curing, as the flash point of tectyl coating is $41^{\circ} \mathrm{C}$. On the other hand silicone coat is highly resistant to heat and humidity. The highly viscous silicone coat on the dowel surface was intact on examination of the pulled out bar. Hence, it can be stated that silicone coat provides durable service to reduce the friction at the concrete-dowel interface. 
Table 4.1 Maximum pulling forces and strain recorded during the pullout test

\begin{tabular}{|c|c|c|c|c|c|c|}
\hline \multirow{3}{*}{$\begin{array}{l}\text { Dowel-bar } \\
\text { Diameter }\end{array}$} & \multicolumn{2}{|c|}{$\begin{array}{l}\text { Maximum pulling force } \\
\text { required to pull the dowel bar } \\
\text { of diameter (Pounds) }\end{array}$} & \multicolumn{4}{|c|}{$\begin{array}{l}\text { Change in compressive strains } \\
\text { recorded from the Vibrating wire } \\
\text { strain gage in }\end{array}$} \\
\hline & \multirow{2}{*}{1.5 in. } & \multirow{2}{*}{$1.25 \mathrm{in}}$. & \multicolumn{2}{|c|}{$\begin{array}{c}\text { Y-direction } \\
\text { (Micro strains) }\end{array}$} & \multicolumn{2}{|c|}{$\begin{array}{c}\text { Z-direction } \\
\text { (Micro strains) }\end{array}$} \\
\hline & & & $1.5 \mathrm{in.}$ & $\begin{array}{l}1.25 \\
\text { in. }\end{array}$ & $1.5 \mathrm{in.}$ & $\begin{array}{l}1.25 \\
\text { in. }\end{array}$ \\
\hline $\begin{array}{l}\text { Specimens with } \\
\text { uncoated dowel } \\
\text { bars }\end{array}$ & 8500 & 6500 & 64 & 32 & 72 & 52 \\
\hline $\begin{array}{l}\text { Specimens with } \\
\text { silicon coated } \\
\text { dowel bars }\end{array}$ & 1500 & 700 & 47.5 & 15.5 & 46.35 & 22 \\
\hline $\begin{array}{l}\text { Specimens with } \\
\text { tectyl coated } \\
\text { dowel bars }\end{array}$ & 1000 & 1000 & 27.5 & 25 & 28.2 & 40 \\
\hline
\end{tabular}

Table 4.2 Value of friction coefficient estimated from two mathematical models

\begin{tabular}{|c|c|c|c|c|}
\hline & $\begin{array}{c}\text { Dowel-bar } \\
\text { Diameter }\end{array}$ & \multicolumn{2}{|c|}{$\begin{array}{c}\text { Friction coefficient } \\
\text { estimated from Method-1 }\end{array}$} & \multicolumn{2}{c|}{$\begin{array}{c}\text { Friction coefficient } \\
\text { estimated from Method-2 }\end{array}$} \\
\cline { 2 - 5 } & 1.5 in. dia., & 1.25 in. dia., & 1.5 in. dia., & 1.25 in. dia., \\
\hline $\begin{array}{c}\text { Description } \\
\text { Specimens with uncoated } \\
\text { dowel bar }\end{array}$ & 0.3516 & 0.587 & 0.34334 & 0.383736 \\
\hline $\begin{array}{c}\text { Specimens with silicon } \\
\text { coated dowel bar }\end{array}$ & 0.08393 & 0.142 & 0.08195 & 0.092568 \\
\hline $\begin{array}{c}\text { Specimens with tectyl } \\
\text { coated dowel bar }\end{array}$ & 0.10101 & 0.117 & 0.09862 & 0.076293 \\
\hline
\end{tabular}




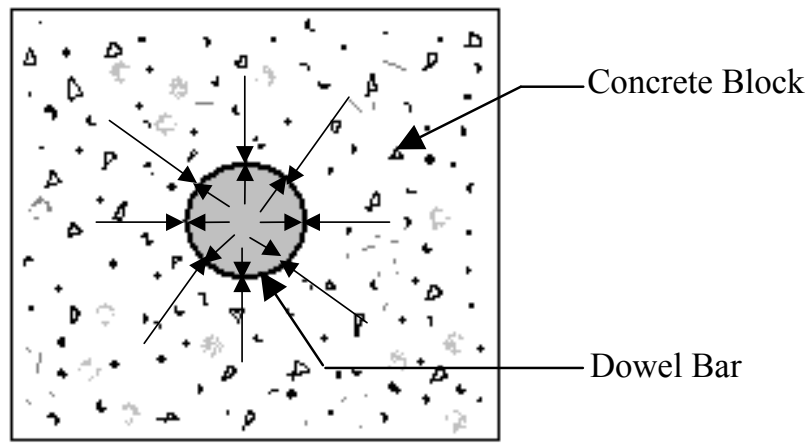

Figure 4.1 Internal pressure at dowel-concrete interface

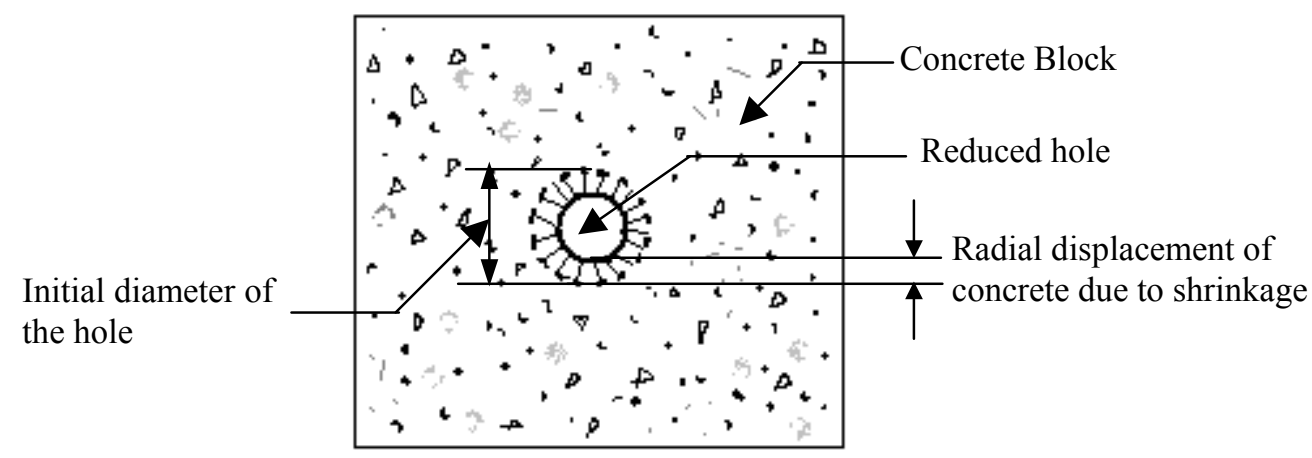

Figure 4.2 The radial displacement of the concrete along the internal diameter due to the shrinkage of the concrete 


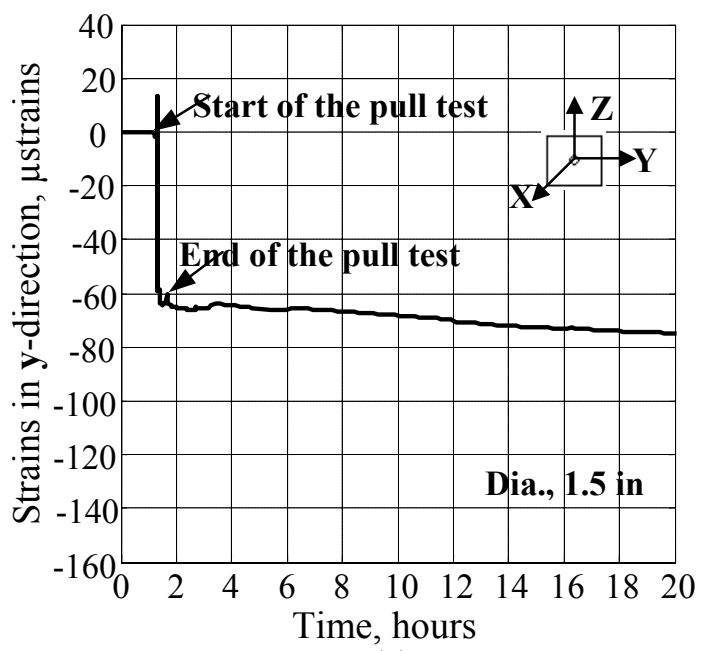

(a)

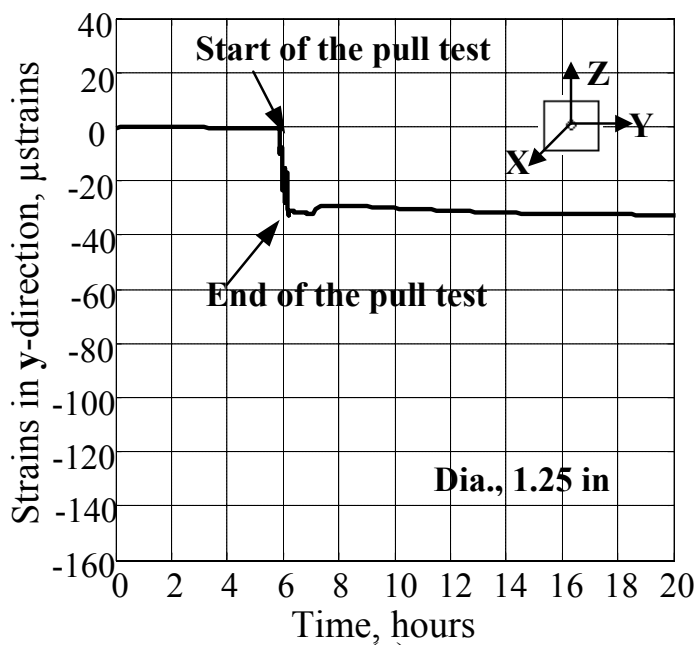

(c)

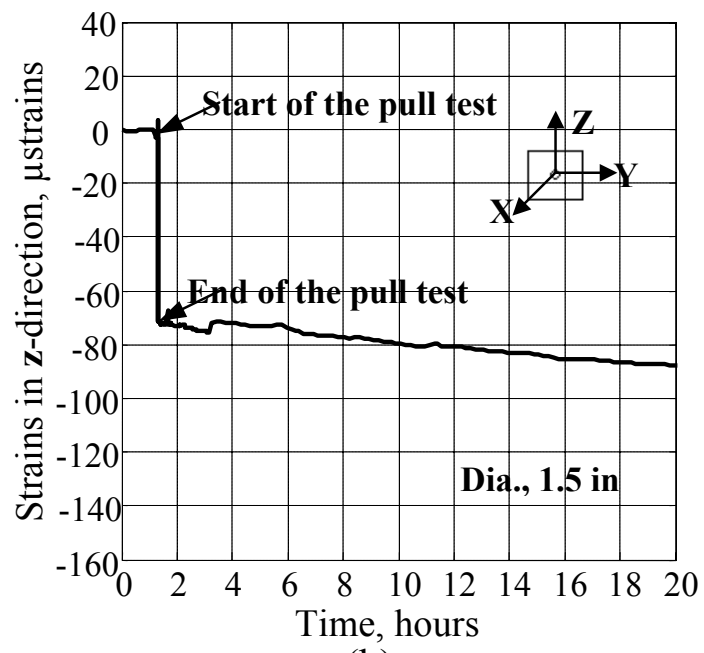

(b)

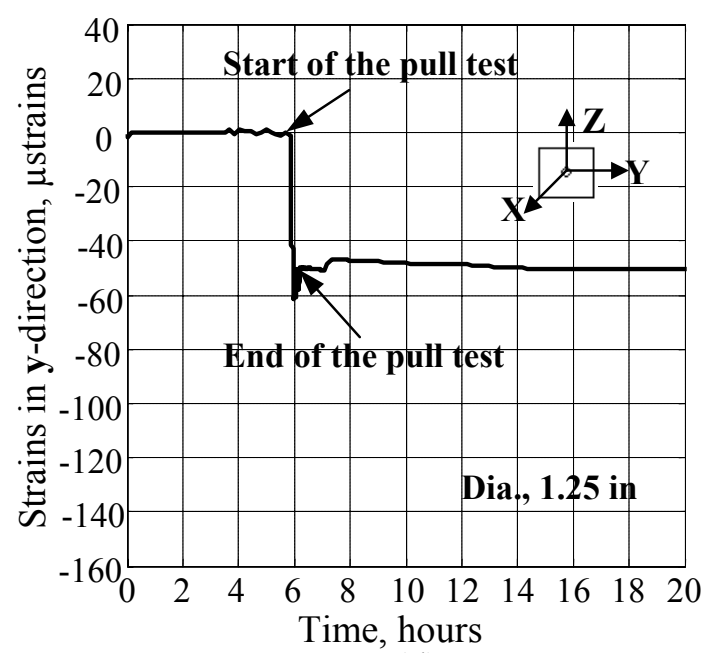

(d)

Figure 4.3 Strains recorded in specimens with uncoated dowel bar during complete pullout test. 


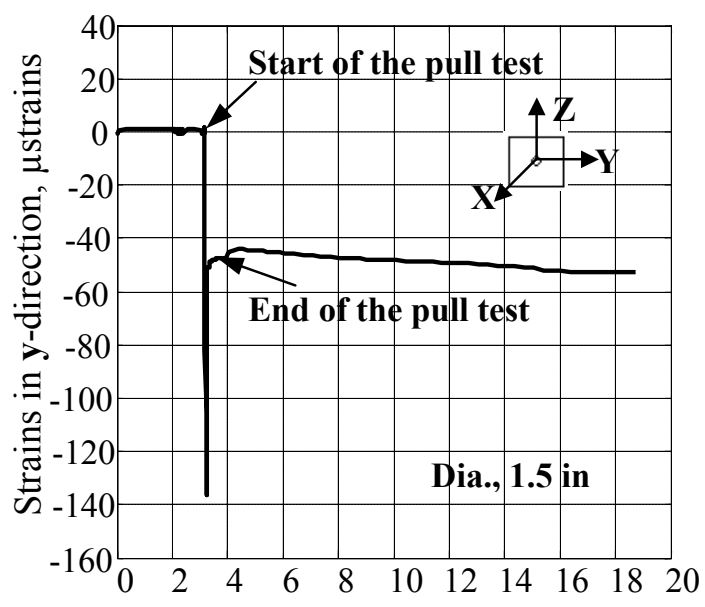

(a)

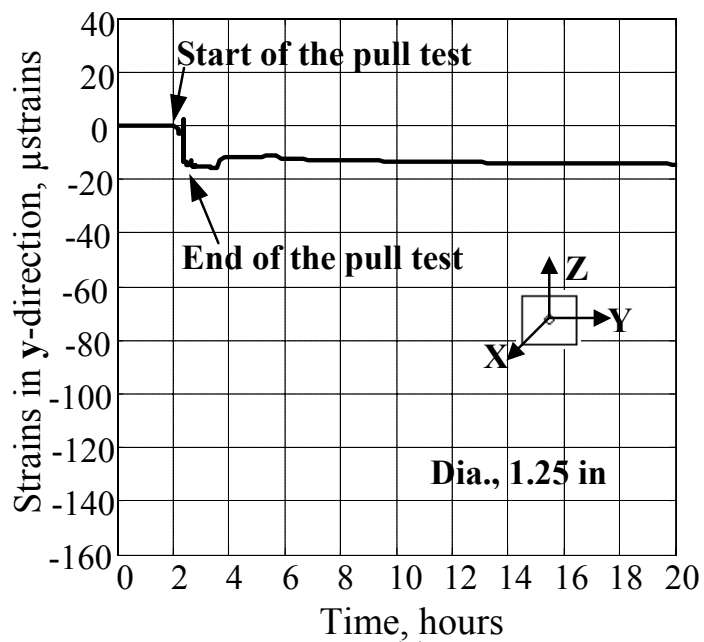

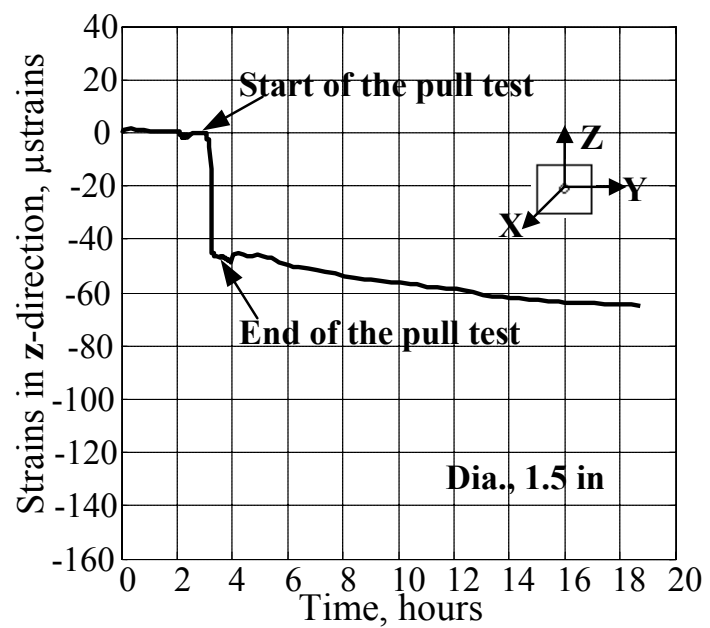

(b)

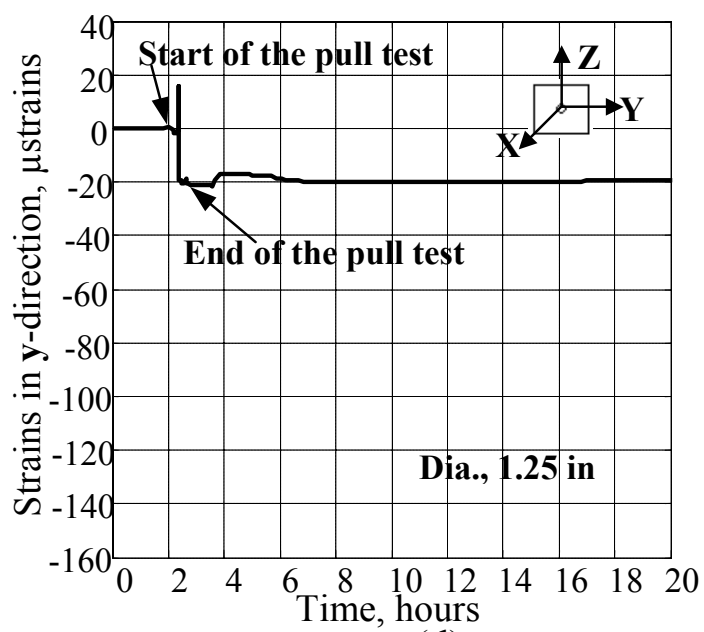

Figure 4.4 Strains recorded in specimens with silicone coated dowel bar during complete pullout test 


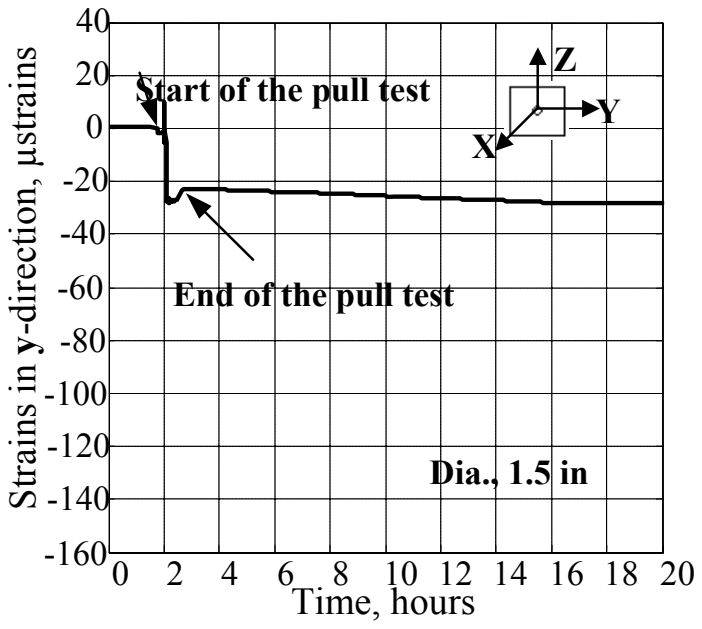

(a)

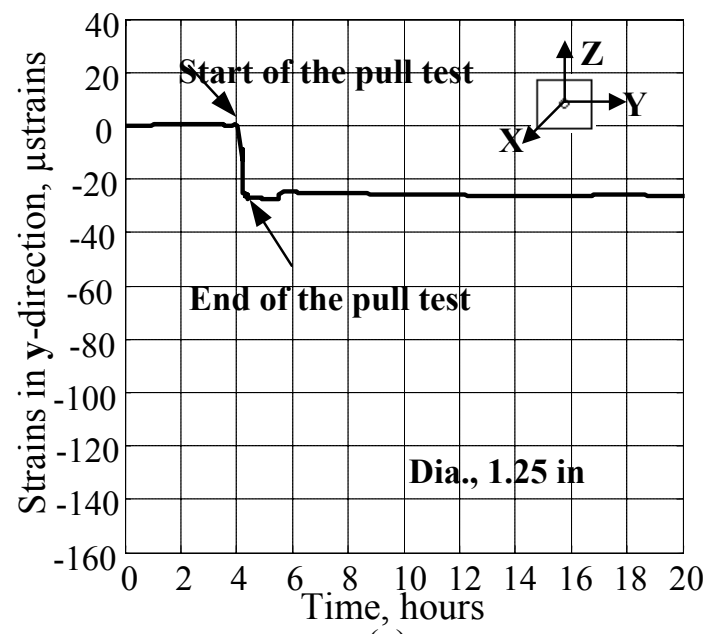

(c)

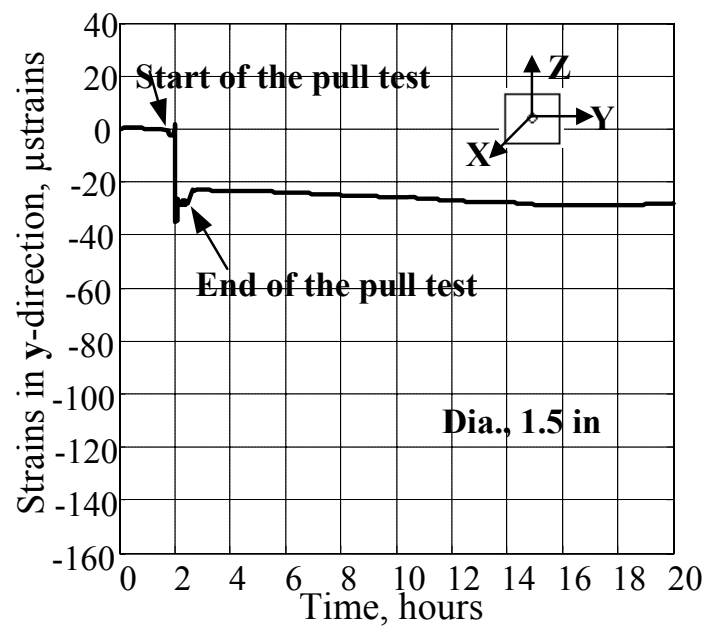

(b)

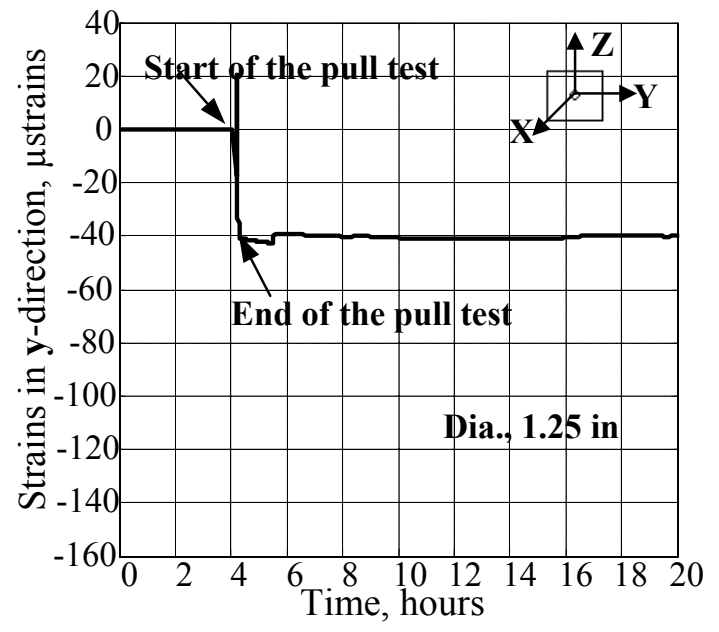

(d)

Figure 4.5 Strains recorded in specimens with tectyl coated dowel bar during complete pullout test 


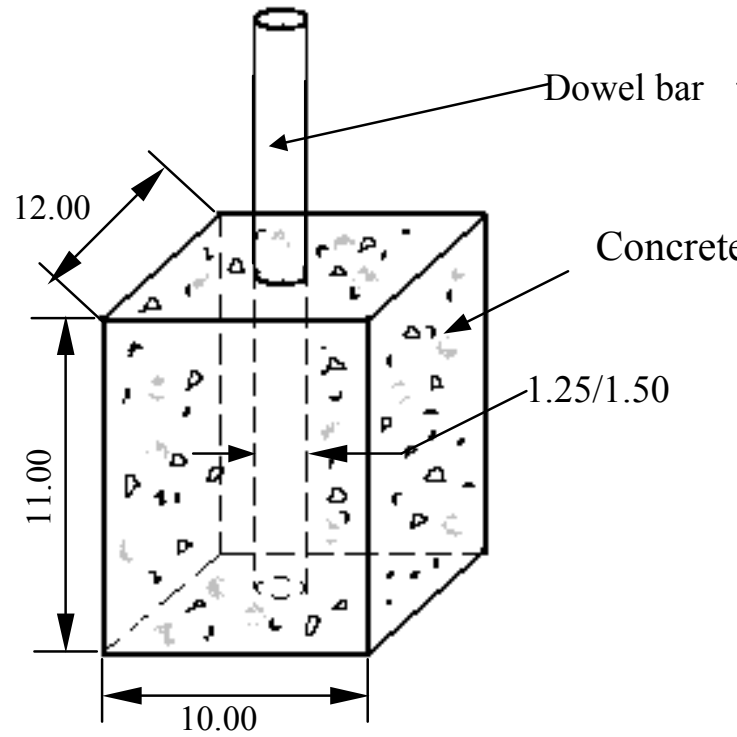

(a) Concrete specimen prepared for laboratory study

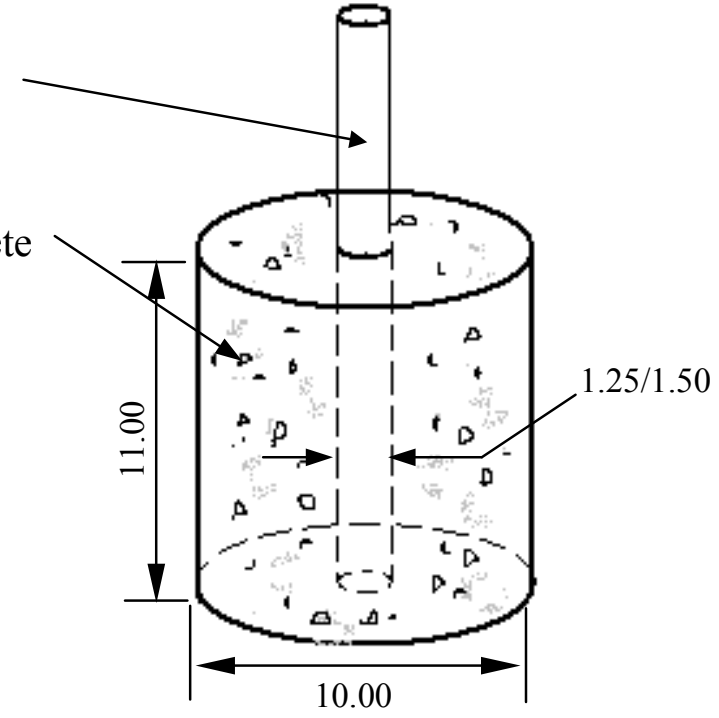

(b) Assumed cylindrical concrete specimen

Figure 4.6 Details of the geometry of the concrete specimens

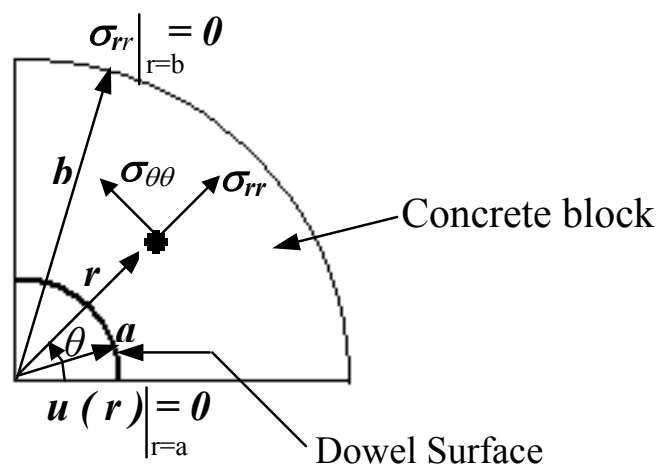

Figure 4.7 The quarter cross-section of the concrete specimen with dowel bar showing the radial and tangential stresses at the radial distance $r$ 


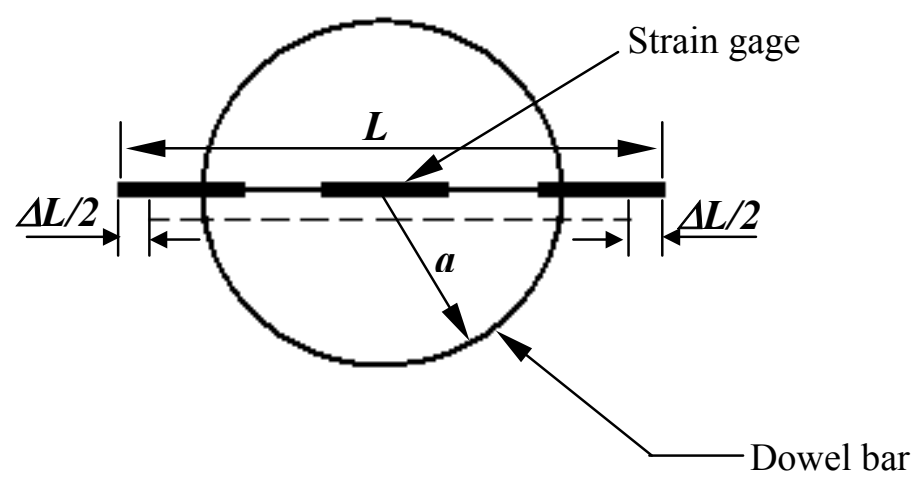

Figure 4.8 Strain gage installed in the concrete

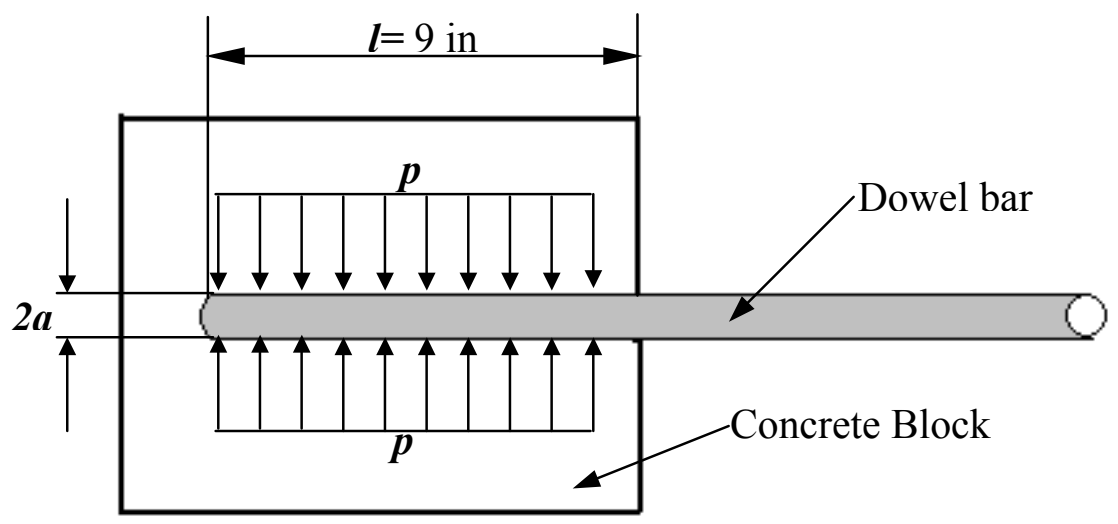

Figure 4.9 Geometry of the dowel bar embedded in the concrete block 


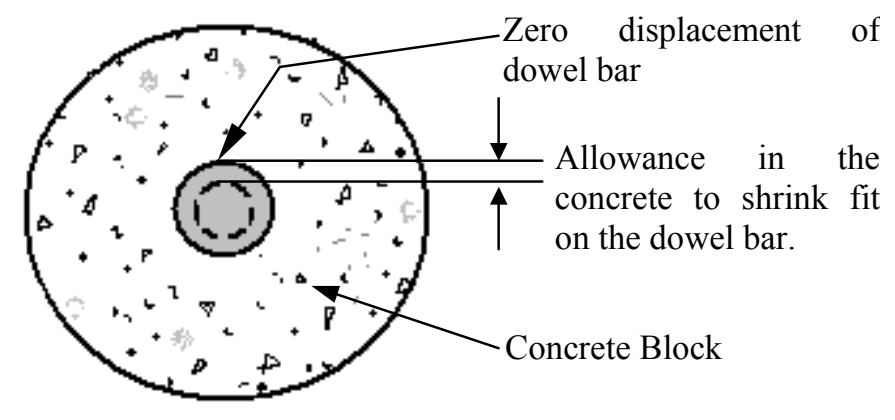

Figure 4.10 Magnified view of the shrink-fit of concrete cylinder on the dowel bar

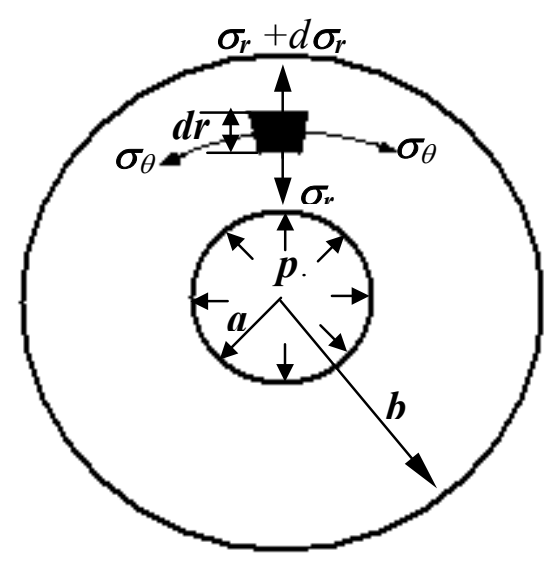

Figure 4.11 The cross-section of thick walled cylinder 


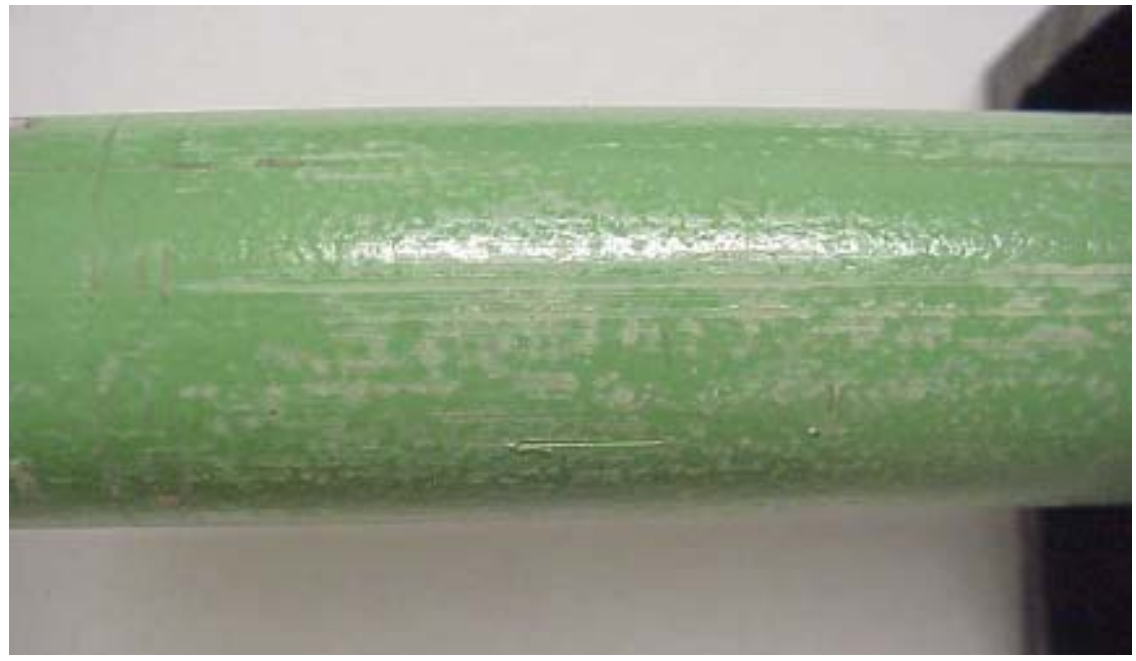

Figure 4.12 Uncoated dowel bar pulled out of the specimen

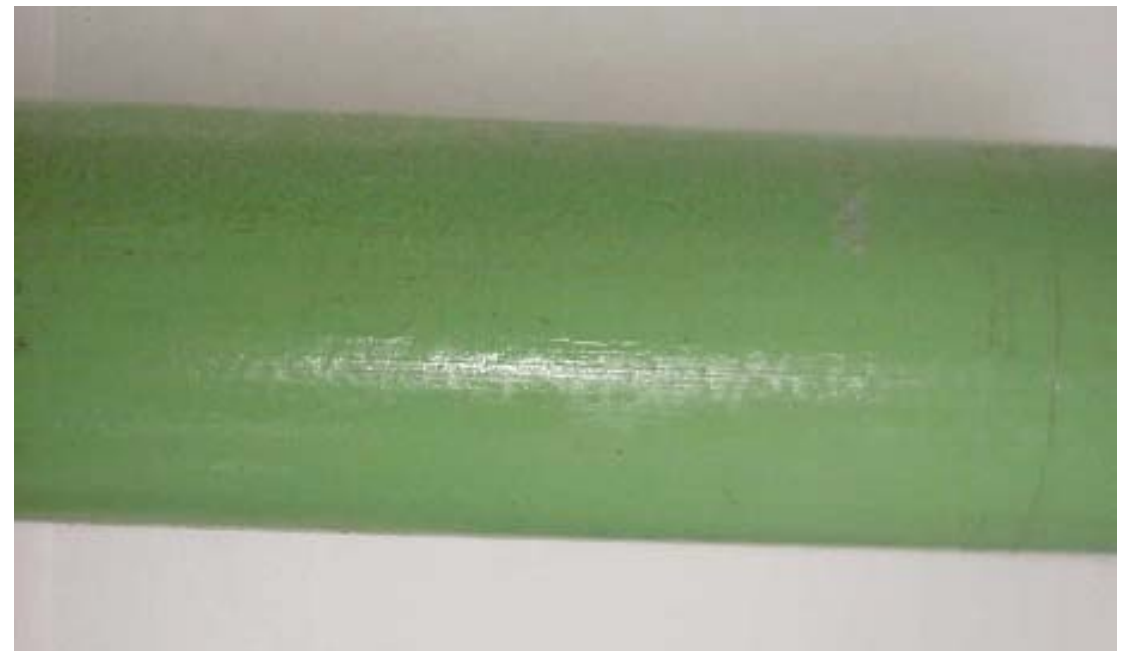

Figure 4.13 Silicon coated dowel bar pulled out of the specimen 


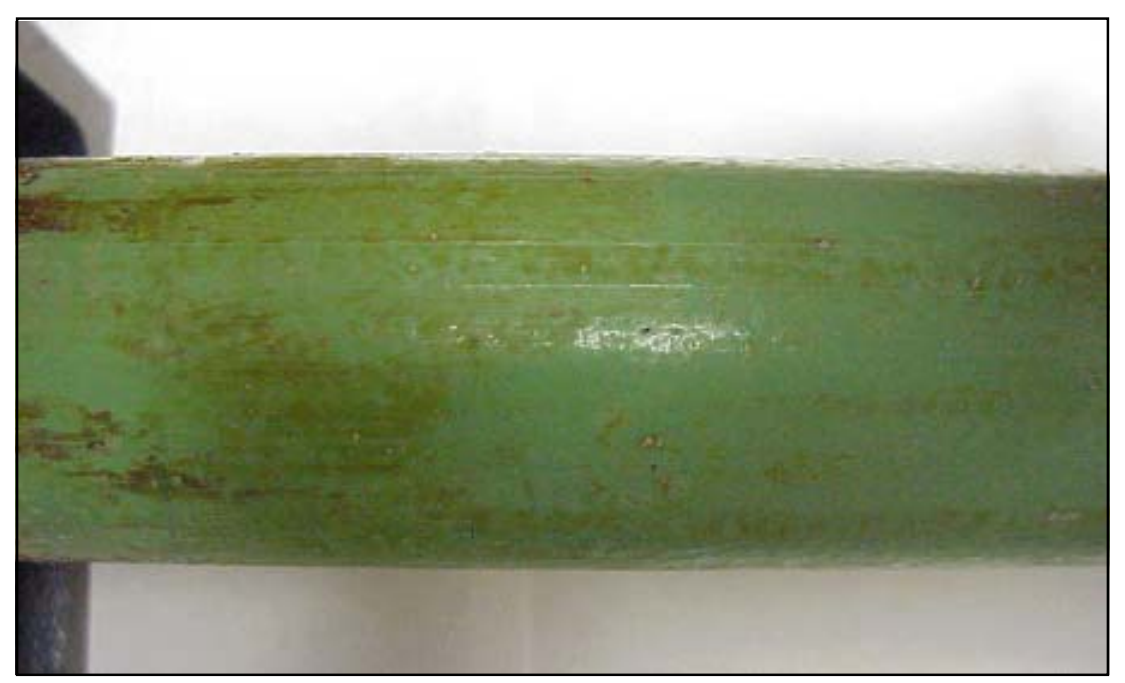

Figure 4.14 Tectyl coated dowel bar pulled out of the specimen 


\section{CHAPTER FIVE}

\section{FINITE ELEMENT MODELING}

\subsection{INTRODUCTION}

One of the objectives of current study was to characterize the stress fields in concrete at the dowel-concrete interface. The finite element method was chosen to achieve this objective, as it is an efficient and fast tool to further understand the measured response of a structure. A three dimensional (3D) finite element model of the concrete specimens was developed using DYNA. An explicit method was used to accurately estimate the stress fields during dynamic changes such as shrinkage of concrete and pullout of the dowel bar.

\subsection{FINITE ELEMENT MODEL}

\subsubsection{Meshing}

The model domain consists of a concrete block with an embedded dowel bar, positioned at the center of the block as shown in Figure 5.1. An eight-nodded solid element was selected for the analysis since the aim was to estimate the stress and strain distribution in the concrete around dowel bar; a very refined mesh was designed in this region. A large number of nodes were considered at the interface to maintain the circularity of the dowel bar and to keenly observe the stresses in all directions in concrete around the dowel. Figure 5.2 shows that each side of the concrete block was divided into eight elements and a total of 32 nodes were created along the circumference of the dowel bar. Hence, a butterfly or fan mesh was generated.

\subsubsection{Interfaces}

Realistic modeling of the dowel-concrete is very critical in creating an accurate model. The interface conditions were very critical for creating a flawless model. In the model the nodes, which lie along the circumference and the length of dowel-concrete interface, were designed in such a way that they lie above each other to avoid intersection or penetration of the boundaries of the dowel bar and the concrete into each other. To account for the voids that might be present along the interface of the dowel bar and 
concrete, sliding with voids-type interface was selected. The value of friction coefficient for sliding was chosen based on the type of bond breaking agent applied on the dowel bar in the iterative runs. With the selection of this particular interface, the nodes at the contact points of the dowel bar and concrete interface move with the same velocity and acceleration in a direction normal to the contact surfaces. Hence, the dowel-pulling mechanism could be accurately simulated without any problem of penetration of layers at the interface.

\subsubsection{Boundary Conditions}

The boundary conditions are imposed in a way that the realistic conditions were simulated during the pullout action of the dowel bar. In laboratory study, the specimen was positioned horizontally except while conducting the experiment. But in the finite element analysis, the specimen is positioned horizontal throughout the experiment. At the bottom surface of the block vertical degrees of freedom are constrained as shown in Figure 5.3. The horizontal movement of the concrete block during pulling and pushing of dowel bar is constrained against a steel plate. The gravity forces were also accounted for.

\subsubsection{Loading conditions}

The shrinkage of concrete is taken into account by defining a temperature drop throughout the concrete block. The pullout load is accounted for by applying a uniform pressure at the end of the dowel bar, which is projecting out of the concrete. The load is applied in steps to simulate real experimental conditions.

\subsubsection{Material Properties}

The material models of the concrete and the dowel bar are chosen as thermoelastic-plastic, as the forces due to the temperature drop in the concrete block provide equivalent forces to the shrinkage of the concrete block. The material properties were assumed to be constant with the temperature change. The values for the modulus of elasticity of concrete, as shown in Figure 5.4, were obtained from the maturity graph of concrete with reference to a pavement section constructed recently in Elkins. Poisson's ratio of concrete was taken to be 0.18 . The modulus of elasticity and Poisson's ratio for 
the steel dowel bar were taken as $28.2 \times 10^{7}$ psi and 0.3 respectively. The friction coefficient at the interface of concrete and dowel bar was assumed to be 0.343 in the case of uncoated dowel bar and 0.08195 and 0.09862 in the case of silicone coated and tectyl coated dowel bars, respectively.

\subsection{MODEL VALIDATION}

The validation of the finite element model was done by comparing strains induced in the concrete before pullout and maximum loads required to pullout the dowel bar with the results obtained from experimental study.

\subsubsection{Strains in concrete before dowel bar pullout}

The strains due to curing and shrinkage in the concrete before pulling the uncoated dowel bar were determined from the displacements of nodes from the model as $-60 \mu$ strain in the $y$ - direction and $-64 \mu$ strain in $z$ direction. To be able to compare with the results from the experimental study, the nodes were chosen in a way that they measure the same distance from the dowel bar as the edges of the strain gages measure from the dowel bar. Referring to Figures 3.1 and 3.2 in chapter 3, the shrinkage strains in the concrete from the laboratory study before pulling the uncoated dowel bar were 29 $\mu$ strain and -58 $\mu$ strain in $y$ and $z$ directions, respectively. The compressive strains in the $z$-direction from finite element model and laboratory study were observed to agree very closely. There was a discrepancy between the strains in the $y$ direction as it could be observed. In finite element model, the shrinkage of concrete was taken into account by defining equivalent temperature drop across the block. As a result, uniform compressive strains were produced in all directions due to uniform contraction of concrete. The finite element model was not able to simulate the tensile strains in $y$ direction, as it was determined from the laboratory study.

\subsubsection{Load}

Table 5.1 shows the maximum load required to initiate sliding of the dowel bar based on the finite element model and compares them with that of the experimental results. There was moderate match between the two sets of results. 


\subsection{RESULTS AND DISCUSSIONS}

The following results correspond to a modulus of elasticity of concrete value of 435 ksi.

\subsubsection{Maximum Principal Stress and Shear Stress}

Figures 5.5 - 5.7 represent the maximum principal stresses during pullout action, in the concrete layer of 0.5 -in. thickness around the dowel bar with and without coating. The maximum principal stresses in the concrete with uncoated dowel bar are much higher than that with coating. In the concrete with uncoated dowel bar, the highest maximum principal stress was $220 \mathrm{psi}$ on average. The peak values occurred at angles of $0^{\circ}$ and $180^{\circ}$ and in the case of coated dowel bars (both silicone and tectyl) and the maximum principal stresses in the concrete layer reached a peak value of about $27 \mathrm{psi}$.

The maximum shear stresses (Figures 5.8 - 5.10) showed similar trends with the uncoated dowel bar case exhibiting much higher values ( $220 \mathrm{psi})$ than the coated dowel bars (30 psi). The maximum shear stresses were comparatively high in concrete at angles of $0^{\circ}$ and $180^{\circ}$, at the embedded edge of dowel bar.

\subsubsection{Stresses in the $x$ direction}

Figure 5.11 shows the maximum stresses in the $x$ direction (axial) in concrete around the dowel bar during pulling. In the case of uncoated dowel bar, the stresses in concrete are compressive along the length of dowel bar at different angles. In general, higher compressive stresses are observed at either end of the embedded length of the dowel bar. The stresses were very low for the coated dowel bar.

\subsubsection{Stresses in the $y$ direction}

The maximum stresses in the concrete during pulling at the dowel-concrete interface in the $y$ direction are shown in Figure 5.12. The stresses are compressive at $90^{\circ}$ and $270^{\circ}$ whereas tensile at $0^{\circ}$ and $180^{\circ}$, as the concrete in the horizontal direction contract due to shrinkage. The maximum stress in the concrete around the uncoated 
dowel bar is about 240 psi. The stresses in the concrete with coated dowel bar were very low with an average value of 25 psi.

\subsubsection{Stresses in the $z$ direction}

Figure 5.13 represents the maximum stresses in the $z$ direction in the concrete layer around the dowel bar during pulling. The maximum stress in concrete in the $z$ direction is about 240 psi with uncoated dowel bar. The stresses in $z$ direction are compressive at $0^{\circ}$ and $180^{\circ}$ and tensile at $90^{\circ}$ and $270^{\circ}$. It can be attributed to the shrinkage of concrete in $z$ direction, which result in compressive stresses in vertical direction and tensile stresses in horizontal direction. Resembling the trend for of $\sigma_{\mathrm{x}}$ and $\sigma_{\mathrm{y}}$ the maximum stresses in the concrete in $z$ direction are also low with coated dowel bar. The stresses in $z$ direction were comparatively higher than the stresses in $x$ and $y$ directions. It could be due to the weight of the concrete acting in vertical direction in addition to the stresses due to shrinkage of concrete.

The stresses in the concrete layer around the coated dowel bar were very low when compared to the stresses in the concrete around the uncoated dowel bar. The results obtained from the FEM in the case of coated dowel bars with low friction values might not be very reliable, as the application of the debonding agent would not reduce the stresses by such a large scale. In the present model with the coated dowel bars, the thickness of the debonding agent was accounted for by assuming a fine gap to exist at the interface of dowel and concrete. This assumed gap did not simulate the actual pressure exerted by the debonding agent on the concrete during the pulling of the dowel bar. Hence, the stresses in the concrete were very low with the coated dowel bar.

\subsection{EFFECT OF MODULUS OF ELASTICITY}

The effect of modulus of elasticity of concrete on the stress and strain fields in concrete around the uncoated dowel bar was also examined. The compressive strength of the concrete increased as its modulus of elasticity increased with its age. The modulus of elasticity values considered were of $580 \mathrm{ksi}$ and $725 \mathrm{ksi}$. 


\subsubsection{Strains}

Figures 5.14 and 5.15 show the residual strains in vertical and horizontal directions on the face of concrete block with different moduli of elasticity before the dowel bar was pulled out. The variation in strains was negligible, when the modulus of elasticity was increased from $580 \mathrm{ksi}$ to $725 \mathrm{ksi}$. The strains in $y$ and $z$ directions were very high when the modulus of elasticity was raised to $725 \mathrm{ksi}$.

\subsubsection{Stresses}

The maximum stresses at the interface in the concrete during pulling of dowel bar are illustrated in Figures 5.16 - 5.17. The stresses in the $y$ and $z$ directions were observed to increase with the increase of modulus of elasticity when the dowel bar was pulled. We have already discussed that the clamping force around dowel bar increase with an increase in compressive strength of concrete, therefore stresses around the dowel bar increased. 
Table 5.1 Comparison of load to initiate sliding of dowel bar

\begin{tabular}{|c|c|c|}
\hline \multirow{2}{*}{ Specimen Description } & \multicolumn{2}{|c|}{ Maximum load required for onset of sliding of dowel bar } \\
\cline { 2 - 3 } & FEM (lb) & Experimental (lb) \\
\hline Uncoated dowel bar & 2800 & 4000 \\
\hline Silicon coated dowel bar & 1700 & 1200 \\
\hline Tectyl coated dowel bar & 1000 & 1200 \\
\hline
\end{tabular}




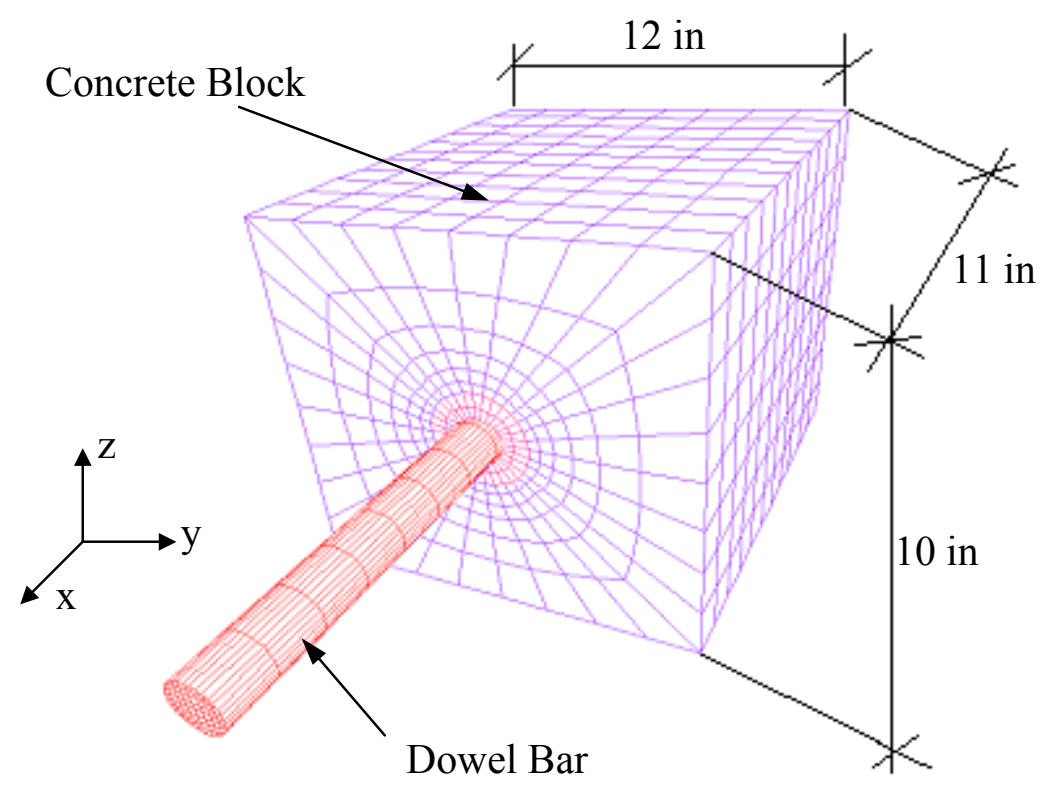

Figure 5.1 FEM of the concrete specimen with dowel bar

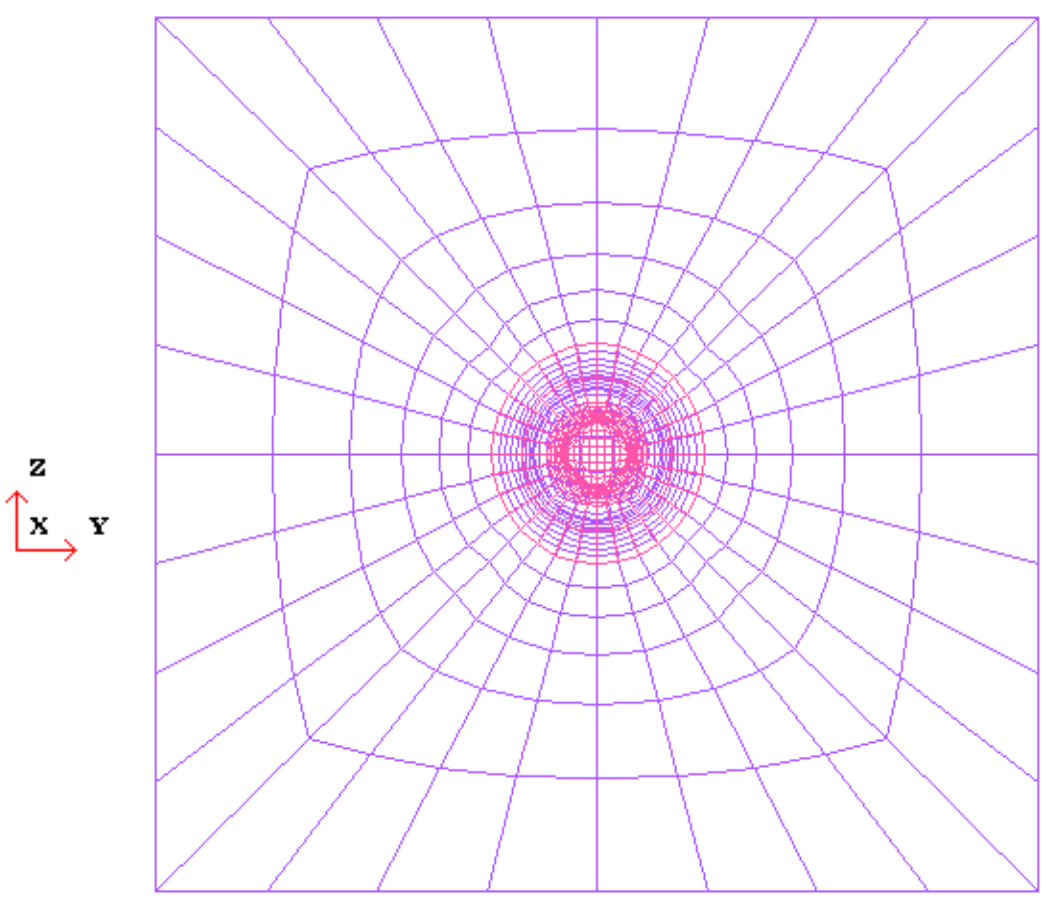

Figure 5.2 Side view of the FEM of the concrete specimen with dowel bar 


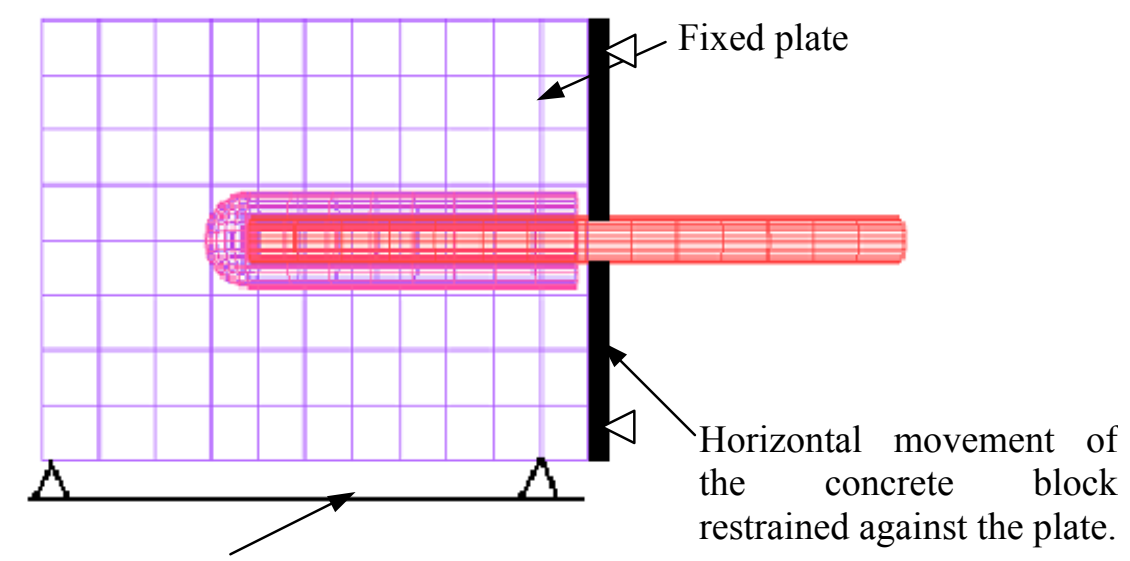

Vertical displacements are constrained at the bottom

Figure 5.3 FEM with boundary conditions

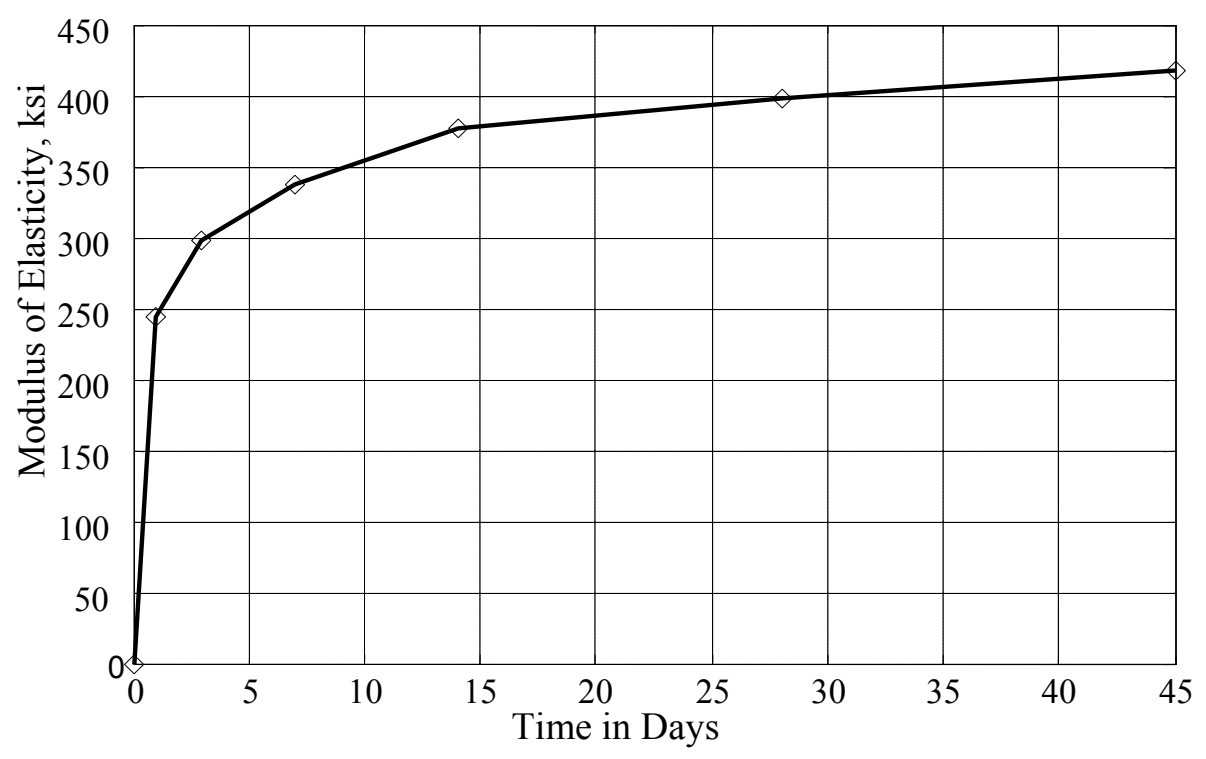

Figure 5.4 Maturity Graph of concrete 


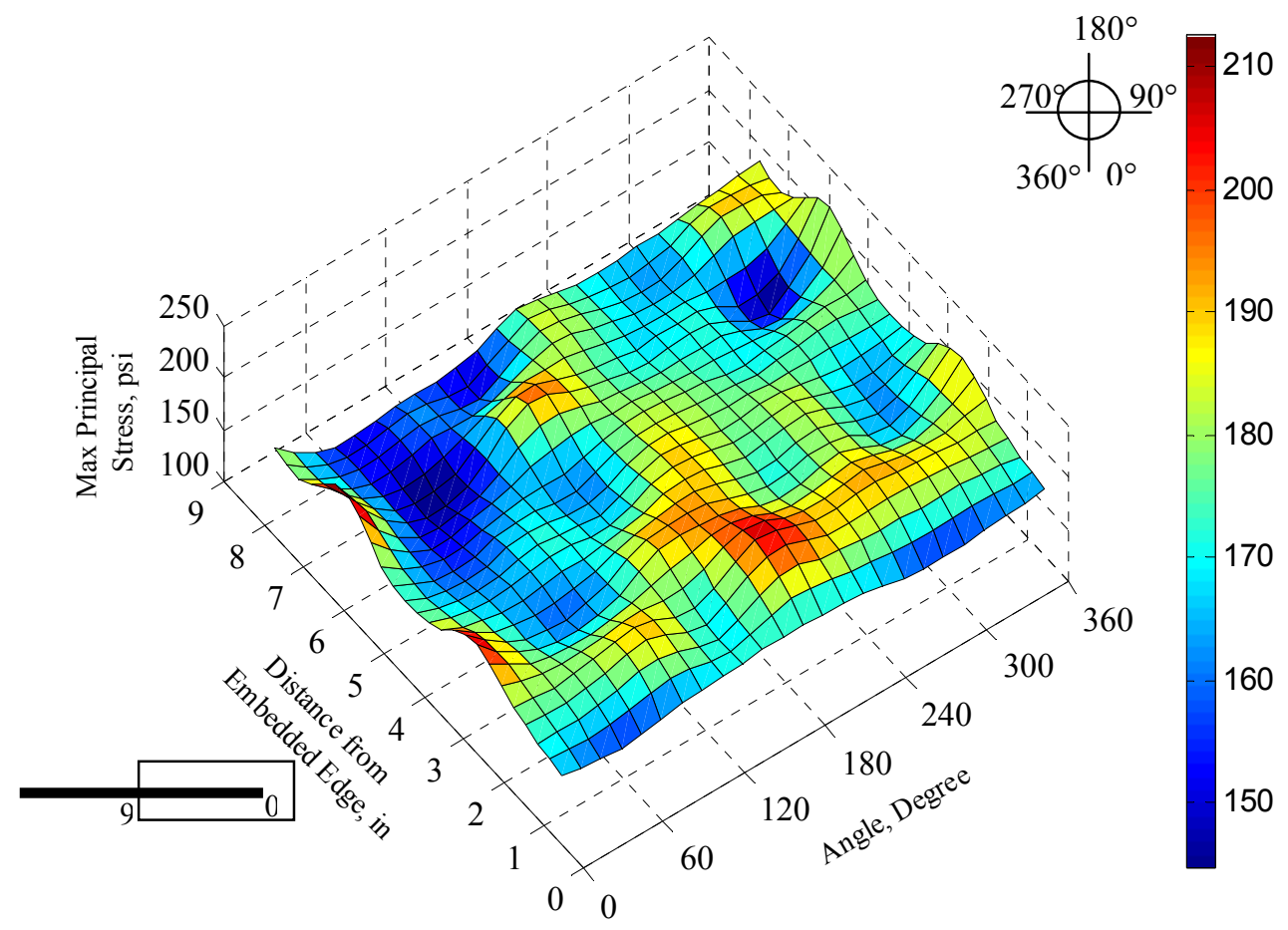

Figure 5.5 Maximum Principal Stress in concrete during pullout test of an uncoated dowel bar

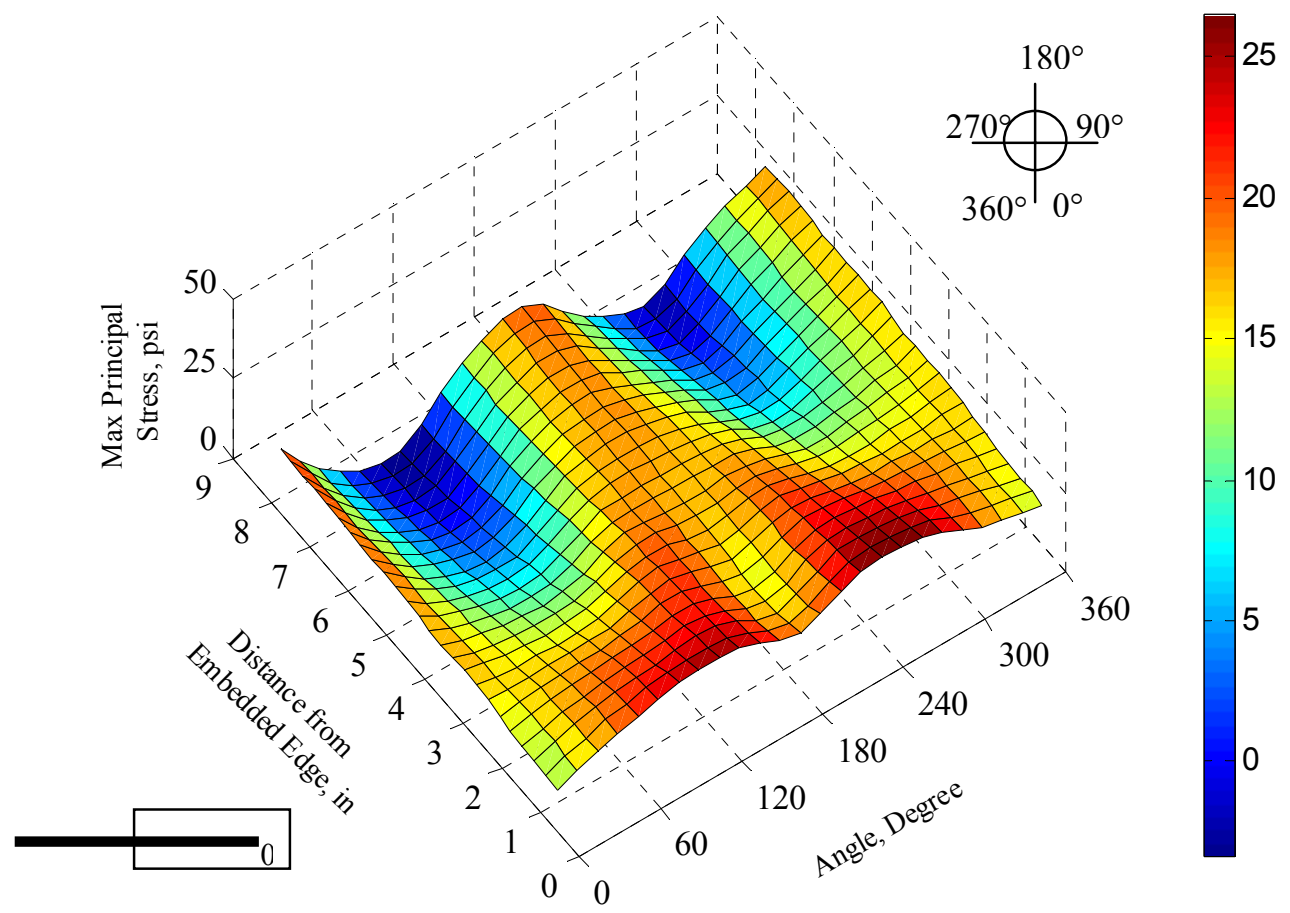

Figure 5.6 Maximum Principal Stress in concrete during pullout test of a silicon coated dowel bar 


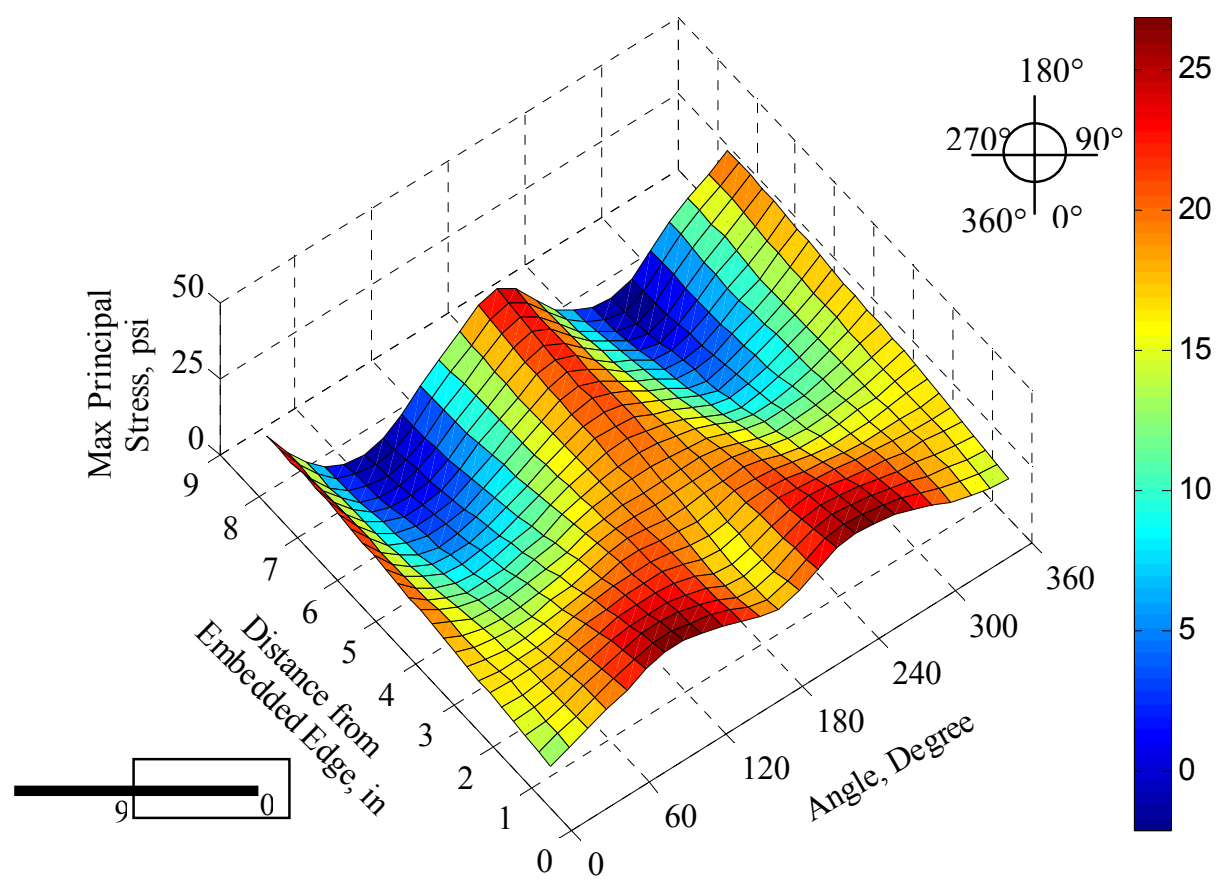

Figure 5.7 Maximum Principal Stress in concrete during pullout test of a tectyl coated dowel bar.

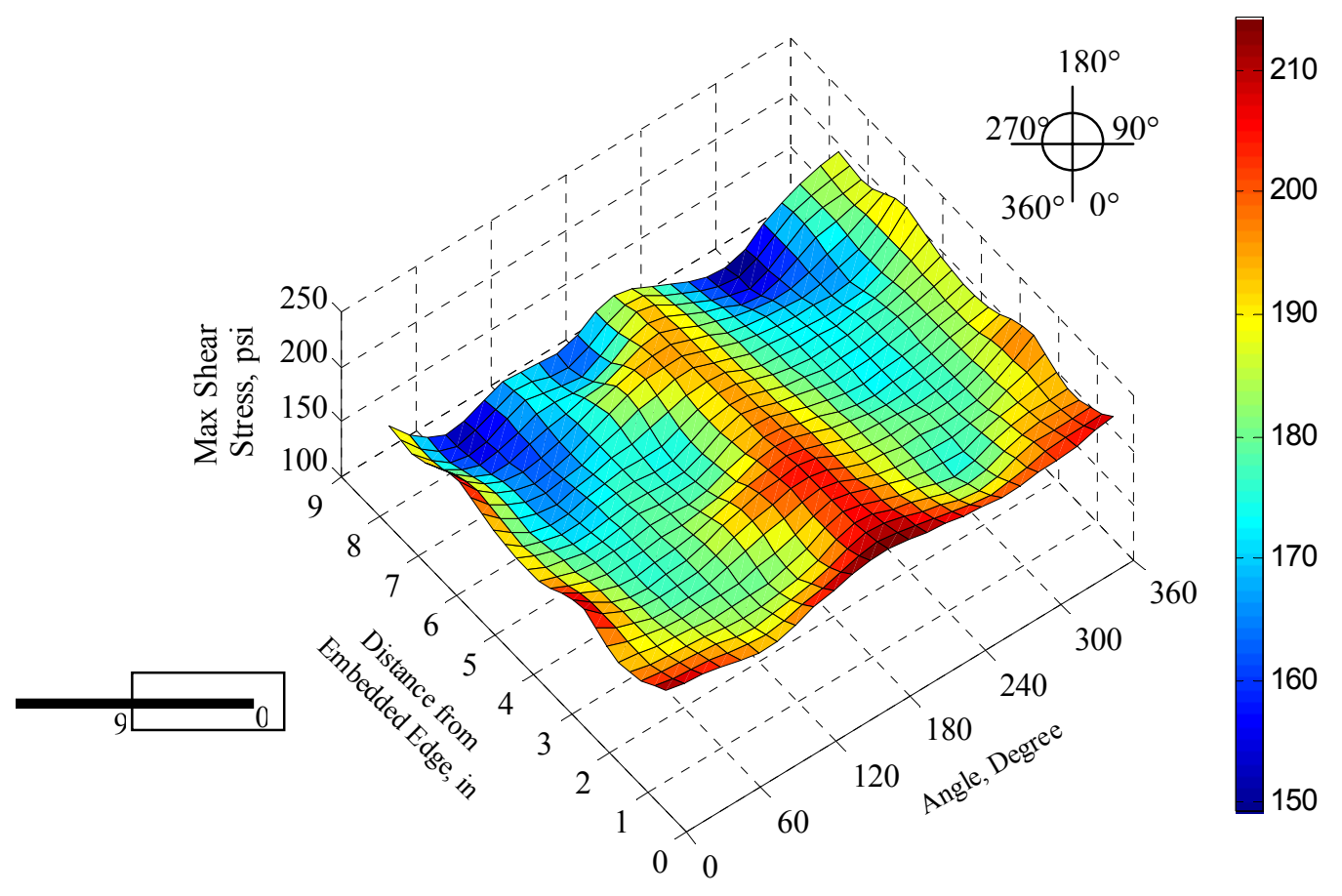

Figure 5.8 Maximum Shear Stress in concrete during pullout test of an uncoated dowel bar. 


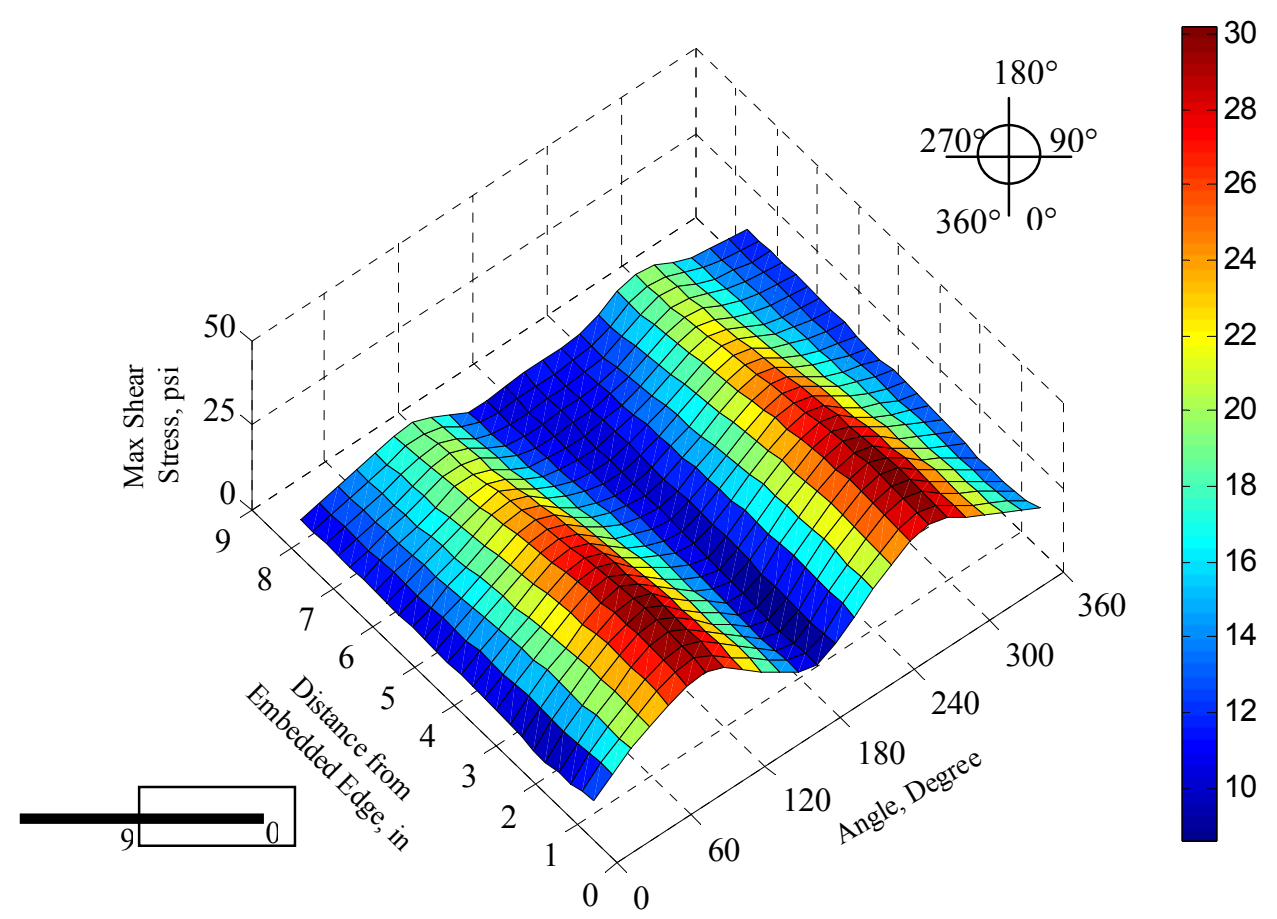

Figure 5.9 Maximum Shear Stress in concrete during pullout test of a silicon coated dowel bar. 


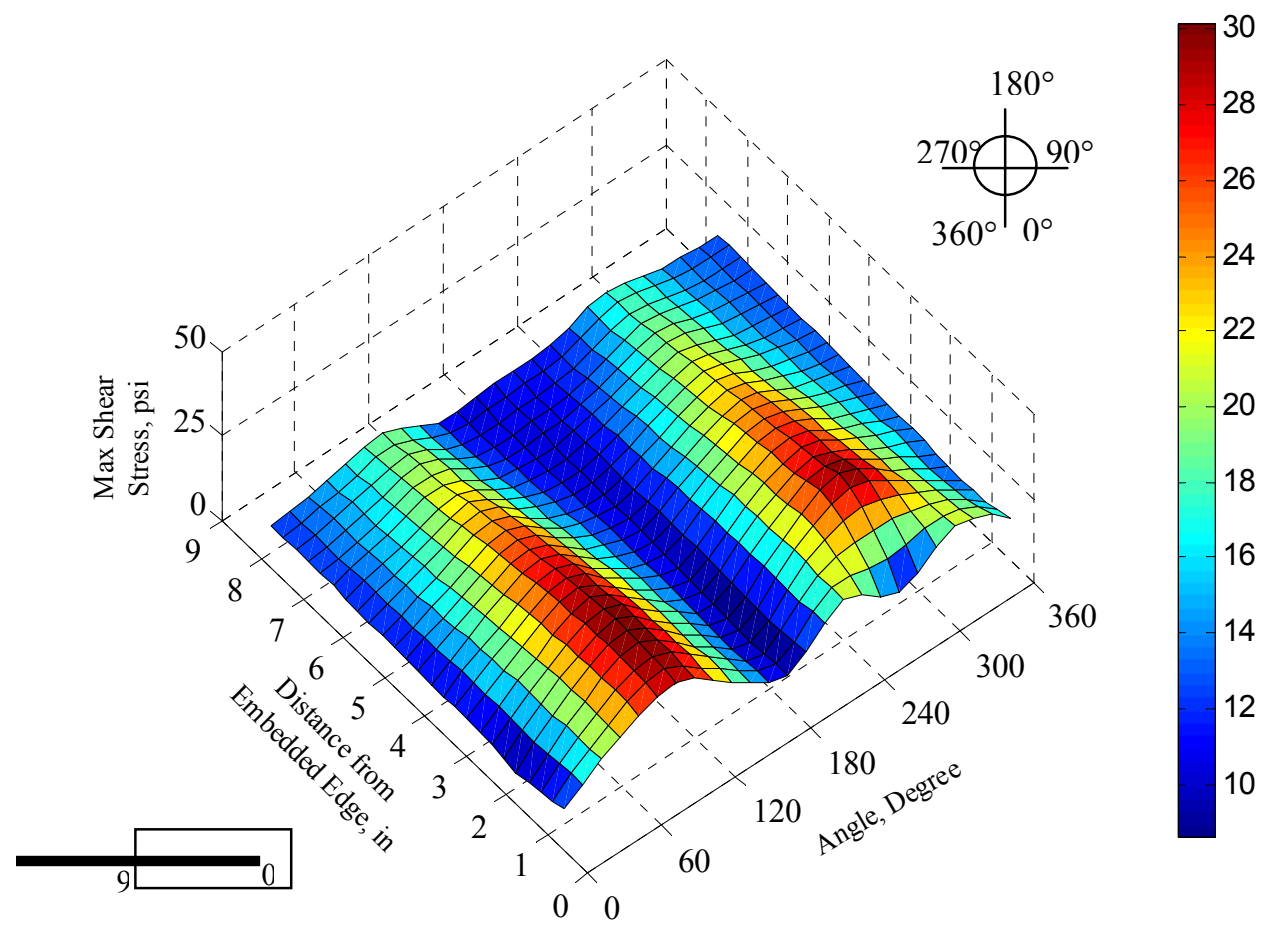

Figure 5.10. Maximum Shear Stress in concrete during pullout test of tectyl coated dowel bar. 

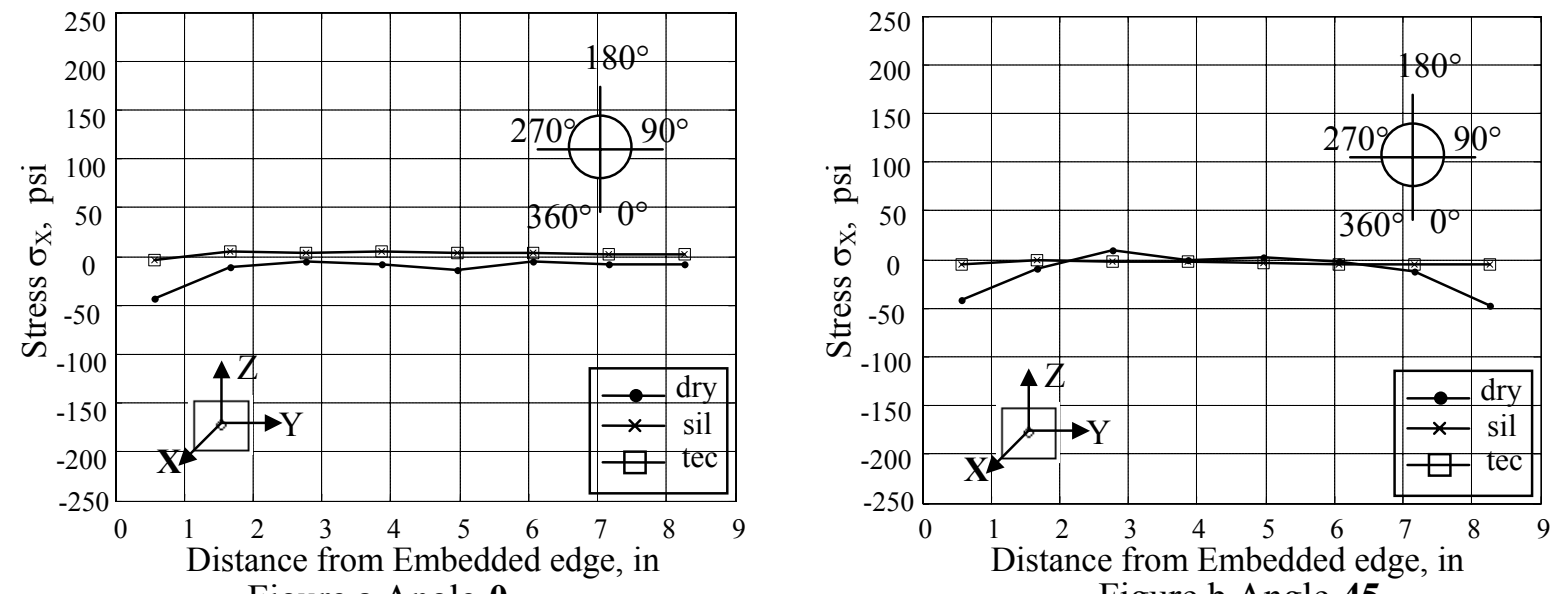

Figure.a.Angle-0

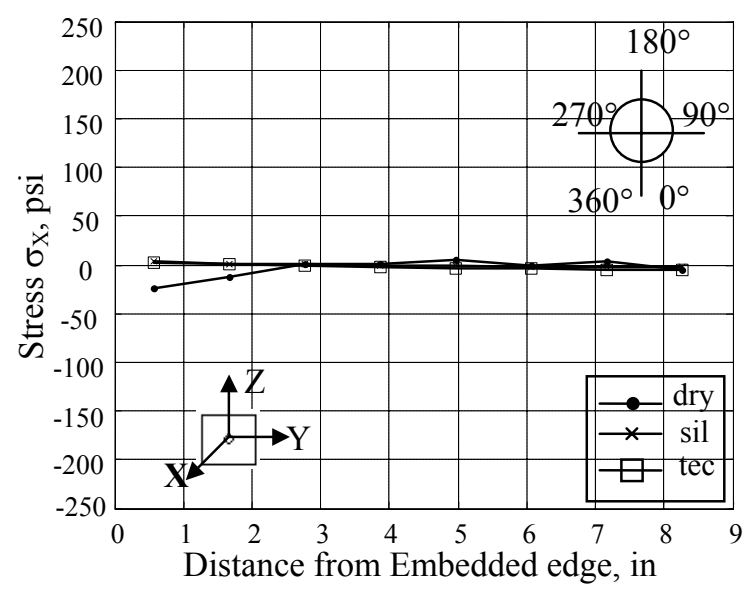

Figure.c.Angle-90

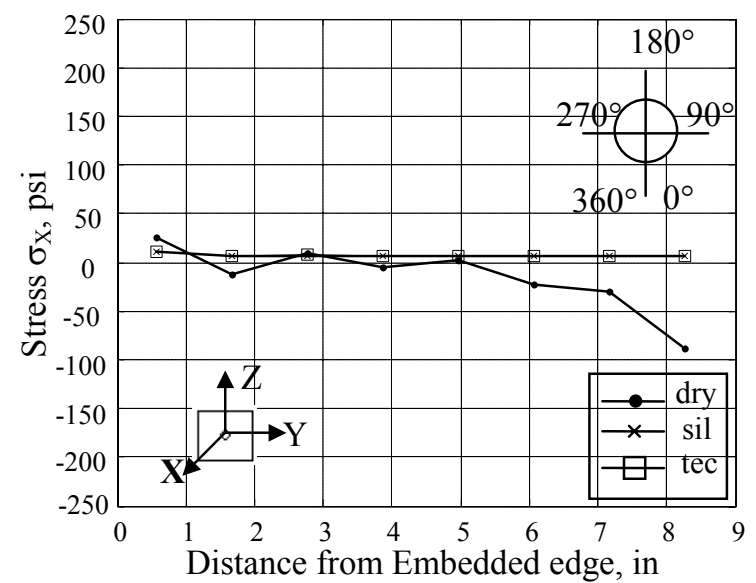

Figure.d.Angle-135

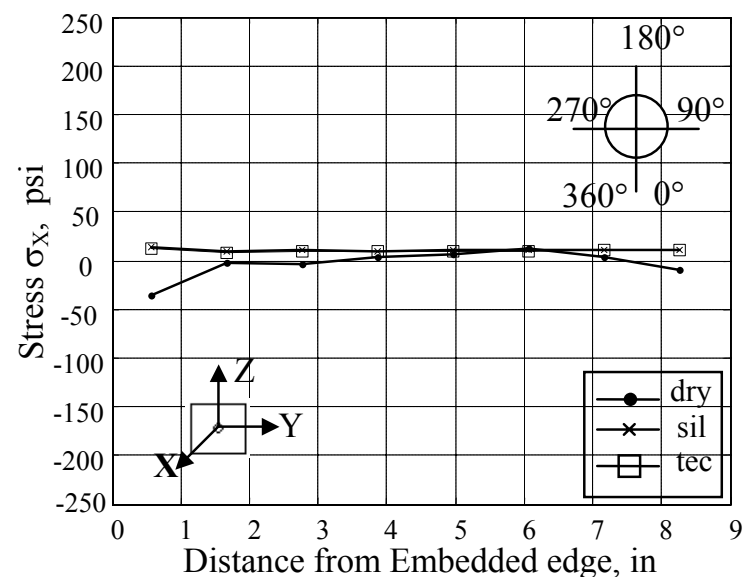

Figure.e.Angle-180

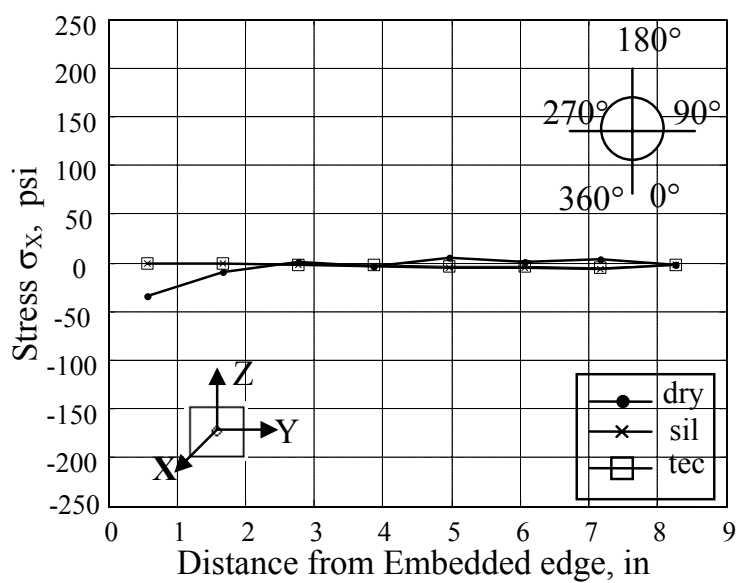

Figure.f. Angle-270

Figure 5.11. X-Stress Vs Angular position in concrete surrounding dowel bar 


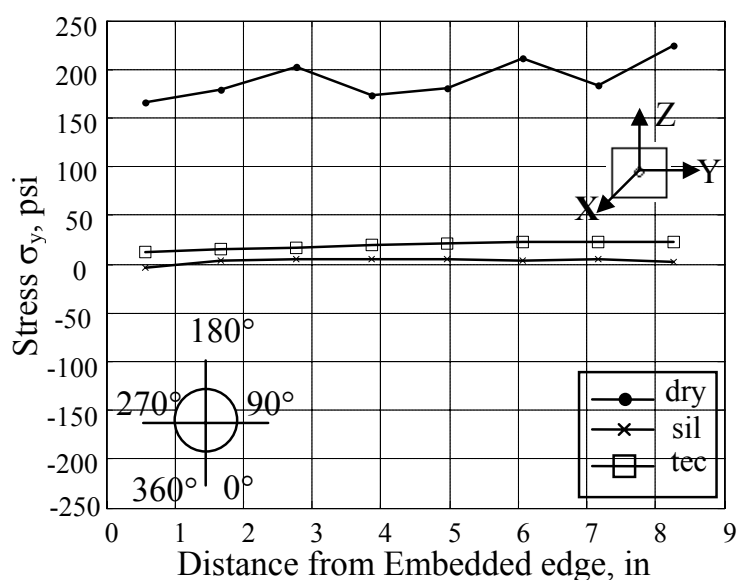

Figure.a.Angle-0

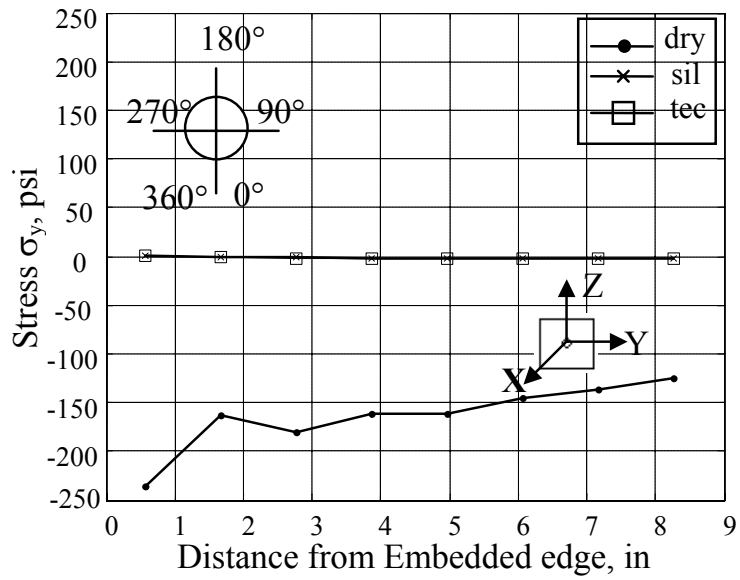

Figure.c.Angle-90

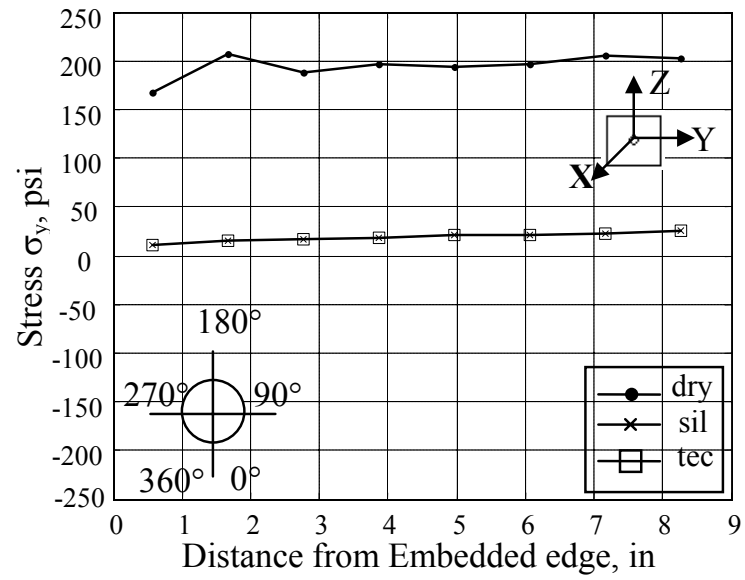

Figure.e.Angle-180

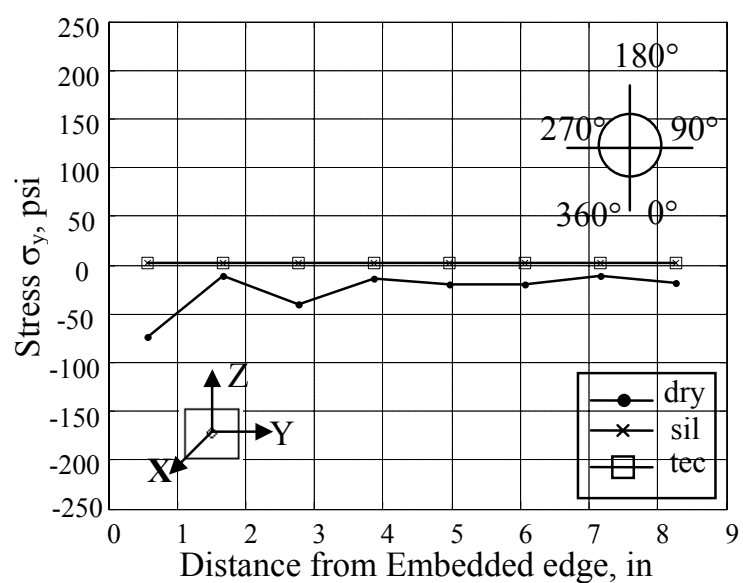

Figure.b.Angle-45

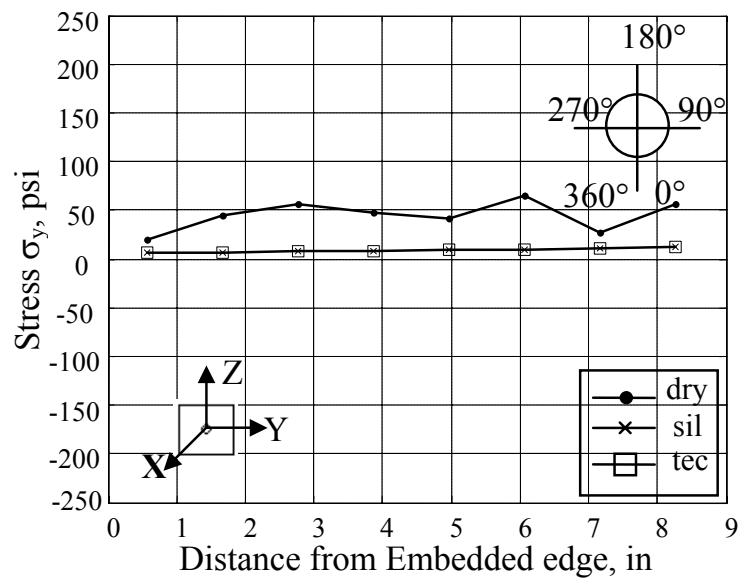

Figure.d.Angle-135

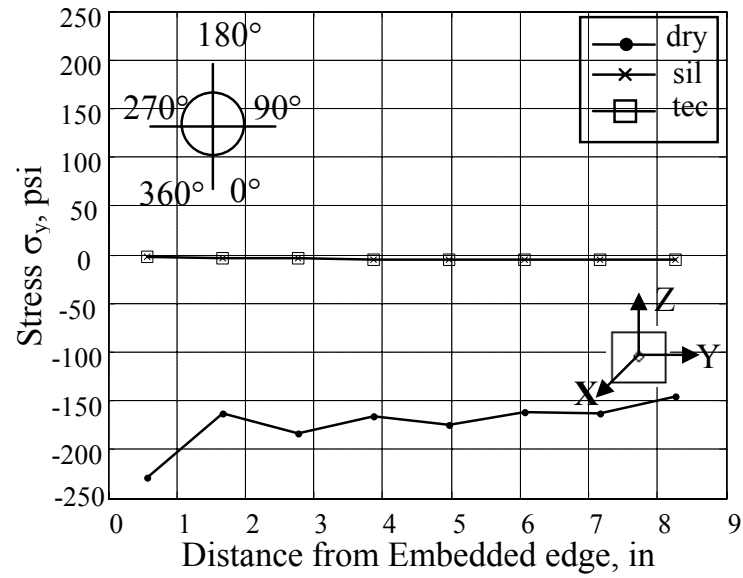

Figure.f.Angle-270

Figure 5.12. Y-Stress Vs Angular position in concrete surrounding dowel bar 


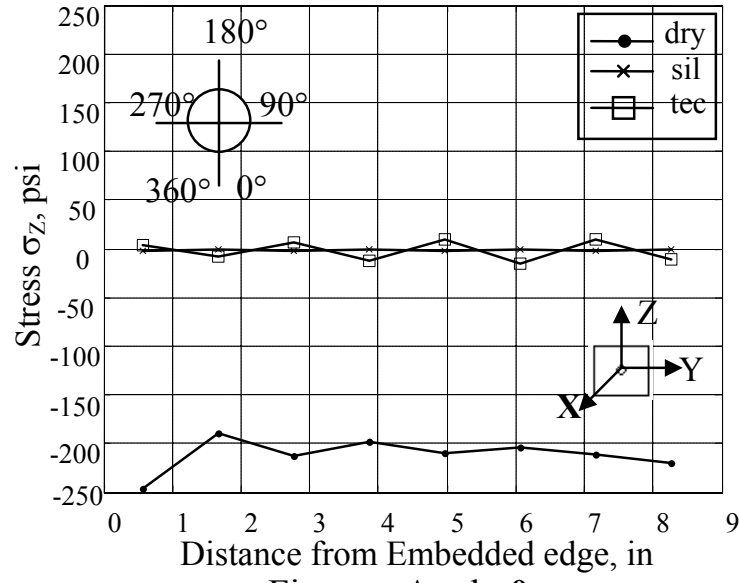

Figure.a.Angle-0

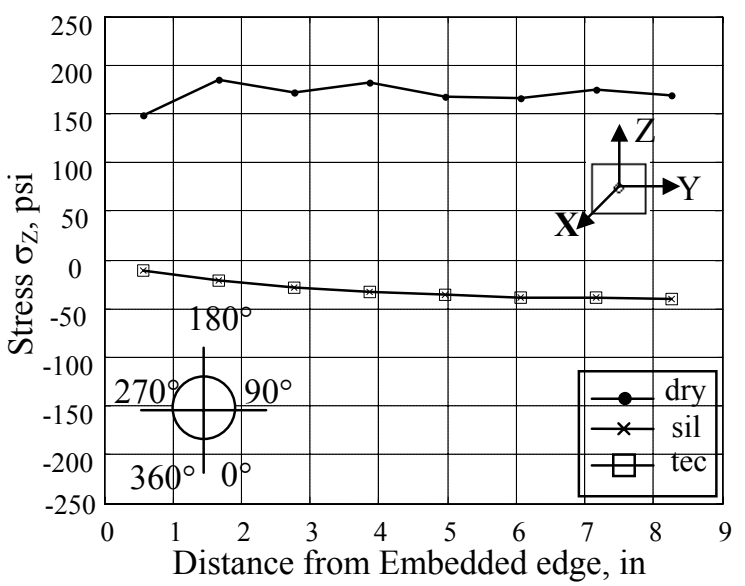

Figure.c.Angle-90

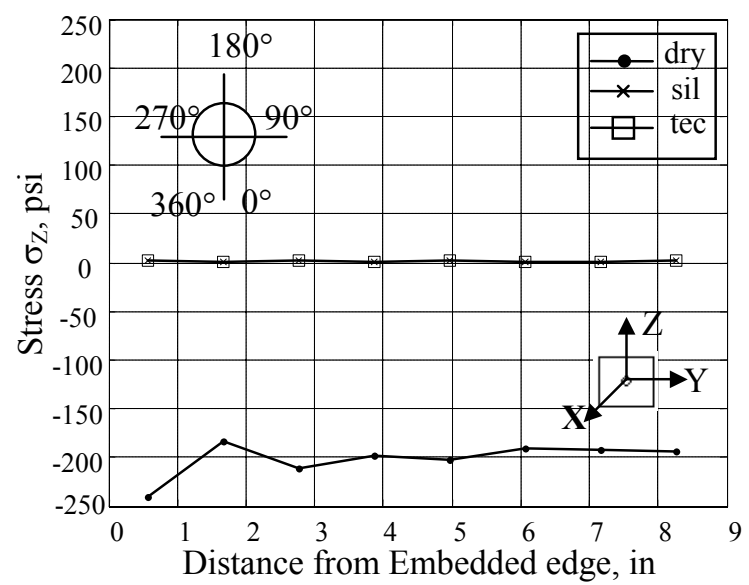

Figure.e.Angle-180

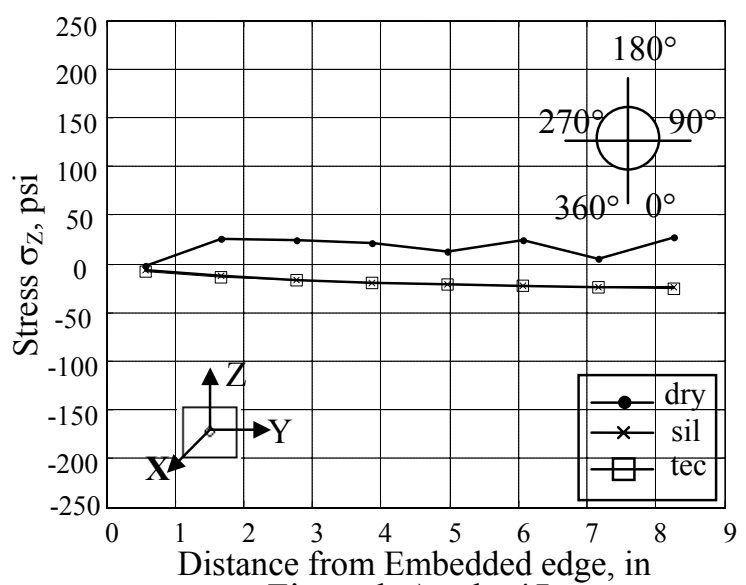

Figure.b.Angle-45

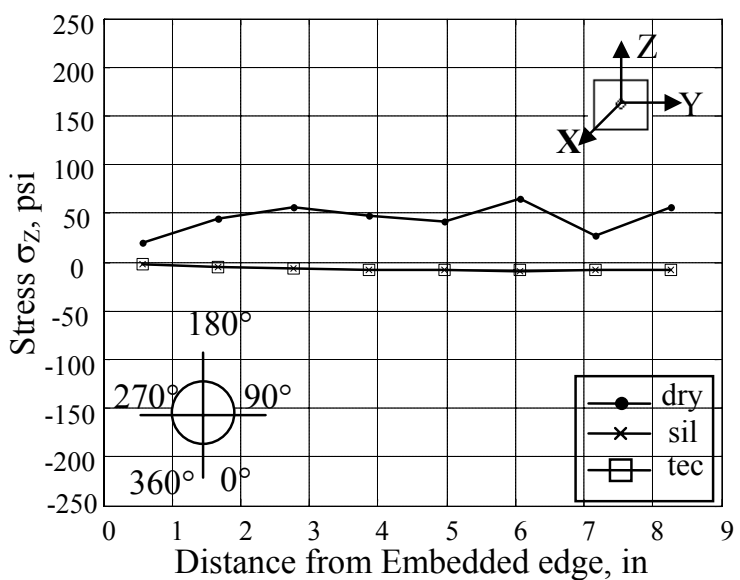

Figure.d.Angle-135

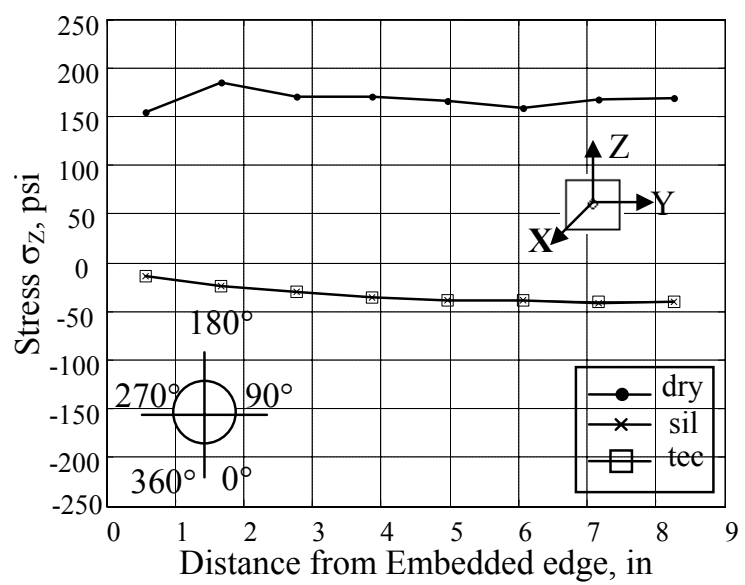

Figure.f.Angle-270

Figure 5.13 Z-Stress Vs Angular position in concrete surrounding dowel bar 


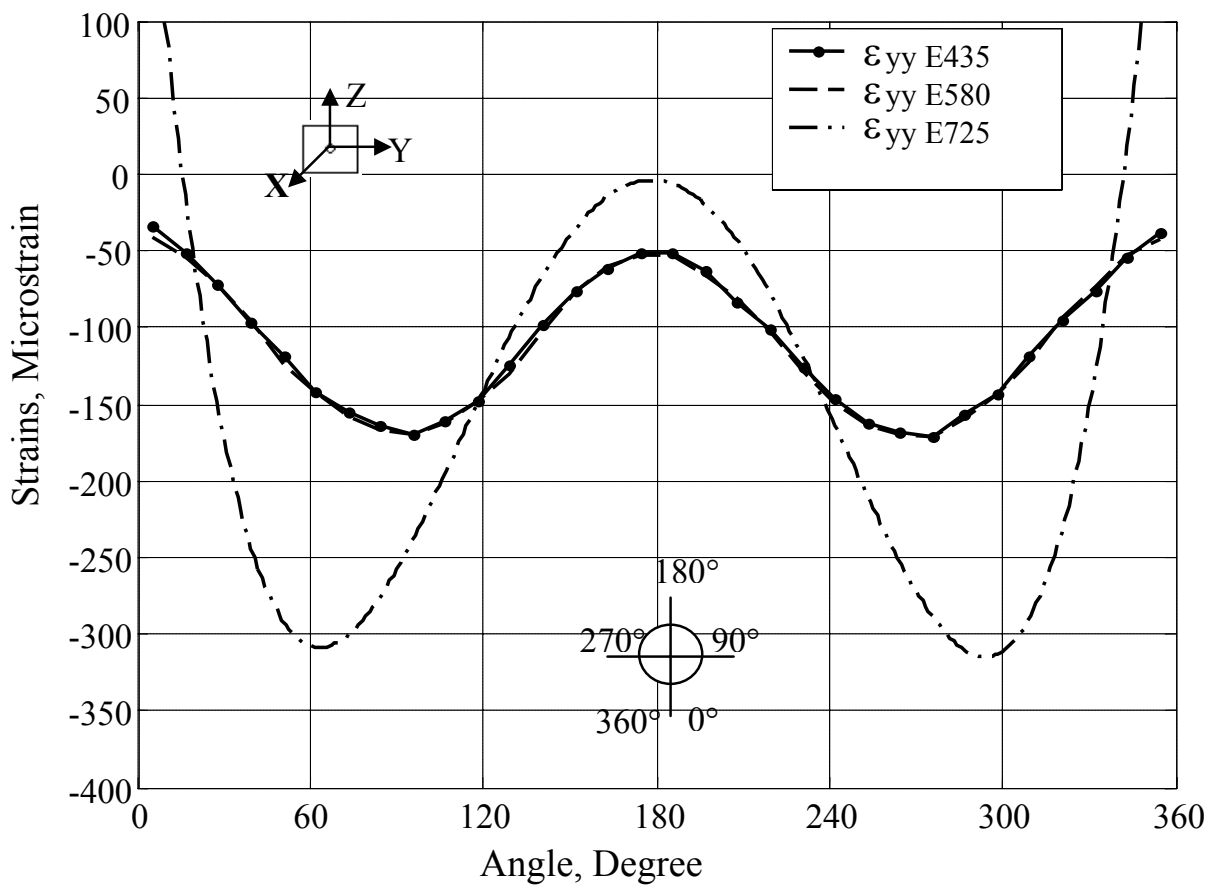

Figure 5.14 Y-Maximum strains around dowel bar during pullout test

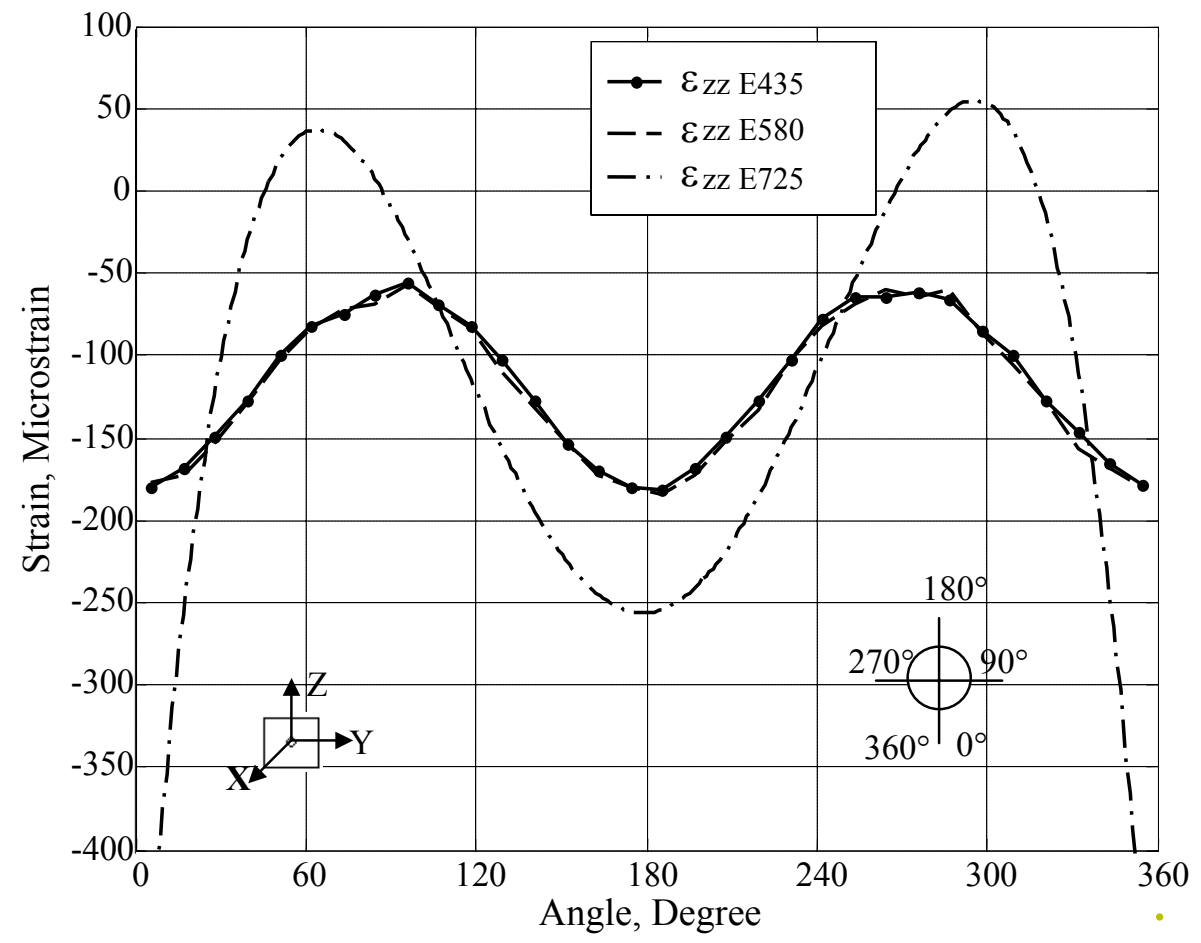

Figure 5.15 Z-Maximum strains around dowel bar during pullout test 


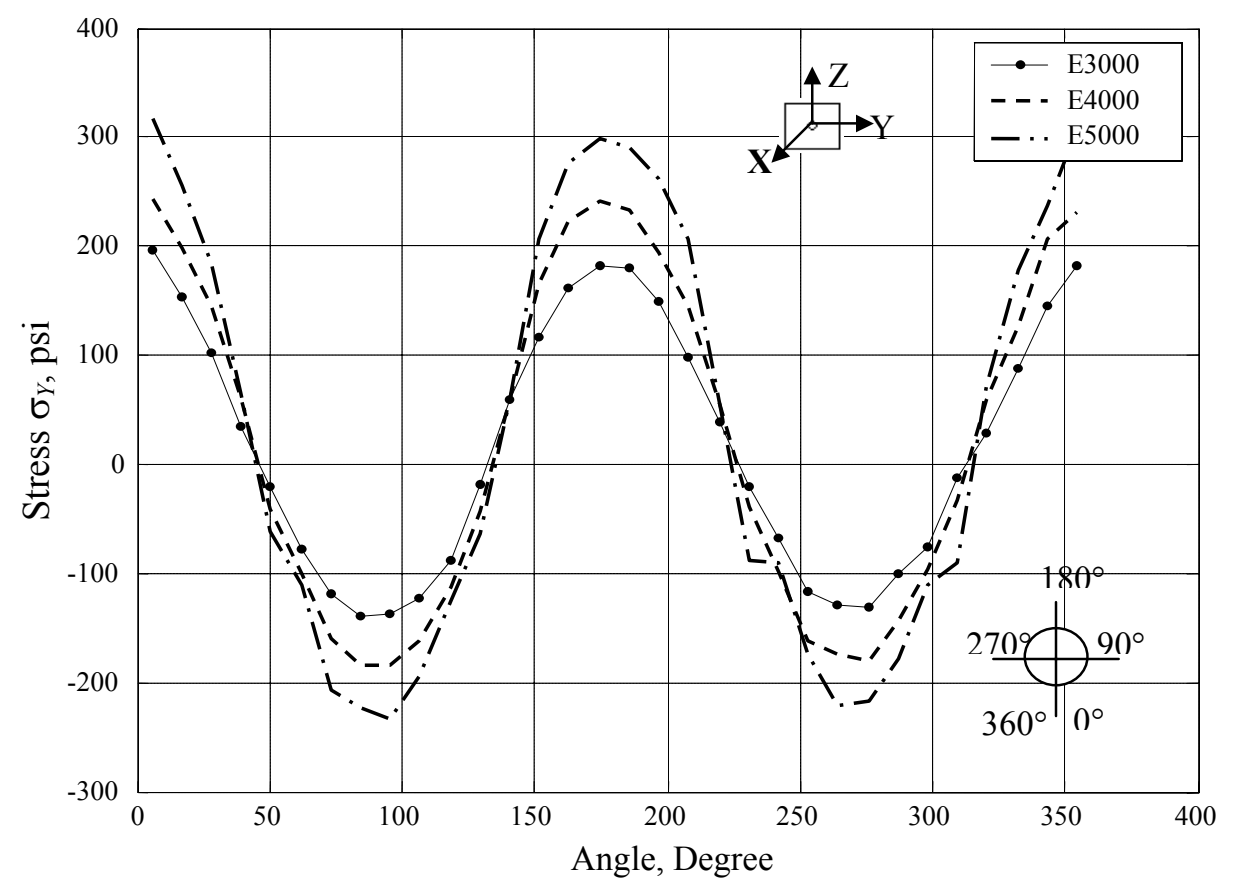

Figure 5.16 Y-Maximum stress around dowel bar during pullout test

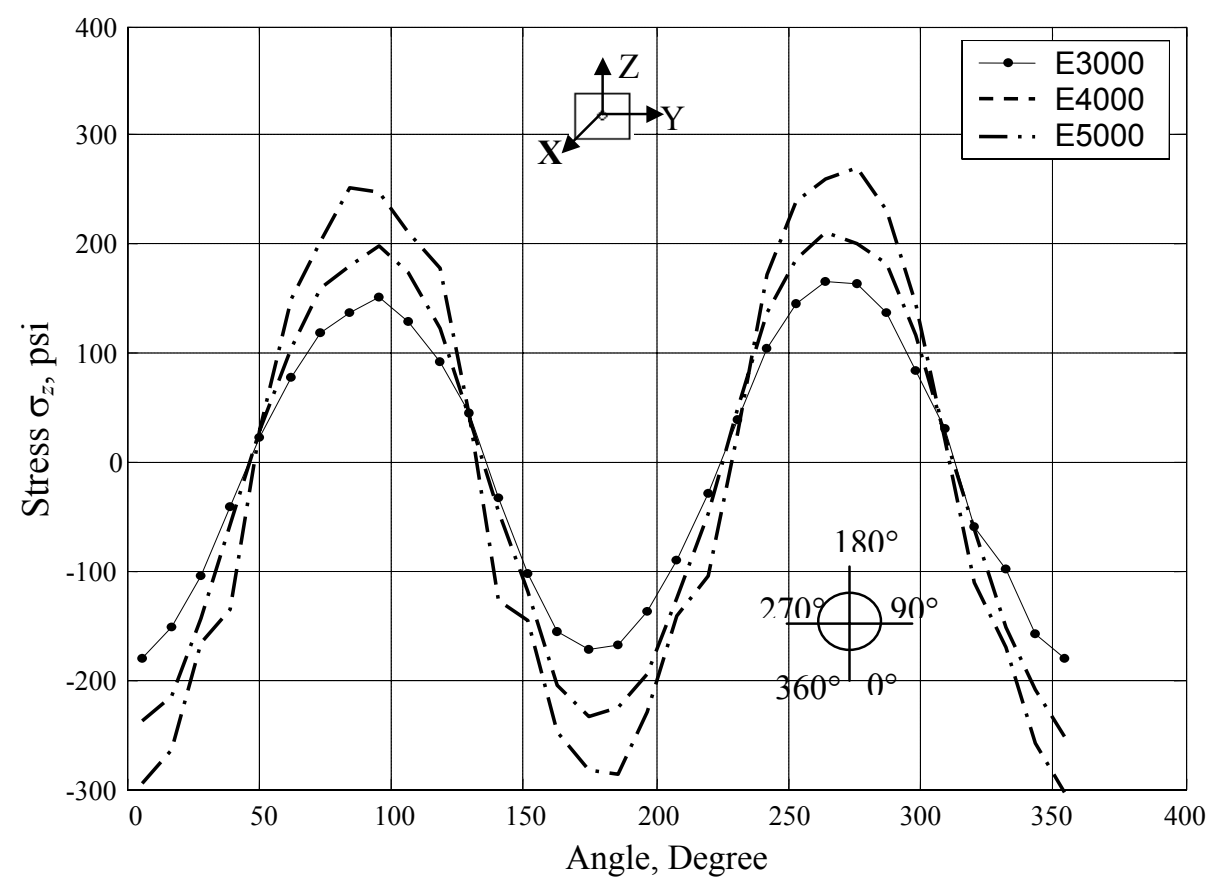

Figure 5.17 Z-Maximum stress around dowel bar during pullout test 
CHAPTER SIX

\section{CONCLUSIONS AND RECOMMENDATIONS}

\subsection{CONCLUSIONS}

This thesis dealt with the mechanics of the dowel-concrete interface during curing and the displacement of the dowel bar. The uncoated as well as silicone coated and tectyl coated dowel bars were considered. The strains in the concrete around dowel bar were recorded during curing and pullout and push-in actions. The pulling and pushing forces of dowel were measured. The friction coefficient at the dowel-concrete interface was estimated with two different debonding agents applied to the surface of dowel. From the results obtained the following conclusions are reached:

1. The strains developed in the concrete around the dowel bar were non-uniform.

2. The pullout forces and push-in forces were higher for the 1.5-in. diameter dowel bar than for the 1.25-in. diameter dowel bar.

3. The debonding agents reduced the pullout and push-in forces required for the displacement of the dowel bar.

4. Forces required for pulling and pushing the dowel bar reduced with the increase in the number of cycles in the case of uncoated dowel bar.

5. The pulling and pushing forces to displace the dowel bar increased with the increase in the shrinkage of concrete.

6. The uncoated dowel bar pulled slightly out of concrete could not be pushed back completely to its initial position which was the not case with coated dowel bars.

7. The radial and axial strains were high in specimens with uncoated dowel bars during the displacement of dowel bar.

8. The mathematical model developed to estimate the friction coefficient at the dowel-concrete interface, based on the shrink fit model proved to be valid.

9. The friction coefficient at the dowel-concrete interface was reduced to about onefourth with the application of a debonding agent.

10. Higher strains were released in concrete when the dowel bar was completely pulled out in uncoated coated dowel bars. 
11. The silicone coat was observed to be more durable than the tectyl coat, as patches of tectyl coat adhered to the surface of concrete at the interface.

12. The surface of silicone coated dowel bar was less damaged when compared to tectyl coat dowel bar during the test conducted.

13. The three dimensional finite element model predicted higher stress fields in the concrete around the uncoated dowel bar during pulling than that of coated bars. The stress field in concrete around coated dowels was very low. However, results were in poor agreement in the case of coated dowel bars.

14. The performance of the sensory system developed to record the strains continuously in concrete was very efficient.

15. The performance of test rig, which was built in the laboratory, was efficient with an error less than $5 \%$.

\subsection{RECOMMENDATIONS}

The current work estimated the friction coefficient at the interface of dowelconcrete interface with different debonding agents and identified the stress fields in the concrete around the dowel bar using a 3D finite element model. With this background, the future research studies recommended are as the following:

1. The friction coefficient at the dowel-concrete interface should be accounted for in future designs of PCC pavements.

2. The effect of temperature variations across the pavement section on the pulling and pushing forces of dowel bar should be investigated as the current study was carried at room temperature in laboratory.

3. An efficient 3D finite element model should be developed taking into account the pressure exerted by debonding agent on the concrete by simulating a fluid equivalent pressure at the interface. 


\section{REFERENCES}

(1) Westergaard, H.M. (1929). Spacing of Dowels. Proceedings of Highway Research Board No. 8, National Research Council, Washington D.C., pp. 154-158.

(2) Westergaard, H.M. (1927). Analysis of Stresses in Concrete Pavements Due to Variations of Temperature. Proceedings, Highway Research Board, U.S. Bureau of Public Roads, pp 201-215.

(3) Ioannides, A.M., and Khazanovitch, L. (1998). Nonlinear Temperature Effects on Multilayered Concrete Pavements. Journal of Transportation Engineering, ASCE, Vol. 124, No. 2, pp. 128-136.

(4) Shoukry, S.N., William. G., and Srinivasan. S. (2002). Analysis of Mid-Slab Cracking in Jointed Pavements. International Journal of Pavements, Vol. 1, No. 3, pp. 81-94.

(5) William, G.W., and Shoukry. S.N. (2001). 3D Finite Element Analysis of Temperature Induced Stresses in Dowel Jointed Concrete Pavements. The International Journal Of Geomechanics, Vol.1 No. 3, pp.291-307.

(6) Shoukry, S.N., William, G.W., and Riad, M. (2002). Characteristics of concrete contact stresses in doweled transverse joints. The International Journal of Pavement Engineering, Vol. 3 No. 2, pp. 117-129.

(7) McGhee, K.H. (1995). Design, Construction, and Maintenance of PCC Pavement Joints. NCHRP Synthesis No 211, National Cooperative Highway Research Program, Transportation Research Board, National Research Council, Washington, D.C. 
(8) Tabatbaie, A.M., and Barenberg, E.J. (1978). Finite-Element Analysis of Jointed or Cracked Pavements. Transportation Research Record No.671, transportation research board national research council, Washington, D.C., pp. 11-19.

(9) Buch, N.J. (1995). Development of Empirical-Mechanistic Based Faulting Models in the Design of Plain Jointed Concrete Pavements. Ph.D.Thesis, Texas A\&M University.

(10) Van Breeman, W. (1955). Experimental Dowel Installation in New Jersey. Bulletin of Highway Research Board, No.34, pp.8-33.

(11) Channell, B.C.(1998). Study of the Joint Movements of the $4.57 \mathrm{~m} \mathrm{(15} \mathrm{ft)}$ Concrete Highway Pavements. Master's Thesis, West Virginia University, Morgantown, WV.

(12) Crovetti, J.A (1999). Cost Effective Concrete Pavement Cross-Sections. Interim Report No.WI/SPR-12-99, Wisconsin Department of Transportation.

(13) American Association of State Highway and Transportation Officials (1995). Standard specifications for transportation materials and methods of sampling and testing adopted by the American Association of State Highway and Transportation Officials.

(14) ERES (2000). Evaluation Of Pennsylvania I-80 JPCP Performance in Penn Dot Districts 1-0 And 3-0. Final Draft Report for the American Concrete Pavement Association.

(15) American Association of State Highway and Transportation Officials (1998). Supplement to the AASHTO Guide for Design of Pavement Structures, Part II, Rigid Pavement Design and Rigid Pavement Joint Design. 
(16) American Society for Testing and Materials (2002). ASTM Book of Standards: Concrete and Aggregates, Volume 04.02, ASTM Standard C 143: Standard Test Method for Slump of Hydraulic Cement Concrete, ASTM, Philadelphia, USA.

(17) Edward G.N. (1997). Concrete Construction Engineering Hand Book, CRC Press, Boca Raton, Florida.

(18) American Society for Testing and Materials (2002). ASTM Book of Standards: Concrete and Aggregates, Volume 04.02, ASTM Standard C 49: Standard Test Method for Compressive Strength of Cylindrical Concrete Specimens, ASTM, Philadelphia, USA.

(19) Neville. A.M (1973). Properties of Concrete, Second Edition, John Wiley and Sons, New York.

(20) Boley Boley, B.A., and Weiner, J.H. (1985). Theory of Thermal Stresses, Robert E. Krieger Publishing Company, Inc., Malabar, Florida.

(21) Blau, P.J. (1996). Friction Science and Technology, Marcel Dekker, Inc., New York.

(22) Chen,W.F., and .Han, D.J (1995). Plasticity For Structural Engineers, Gau Lik Book Co., LTD. 


\section{APPENDIX-I}

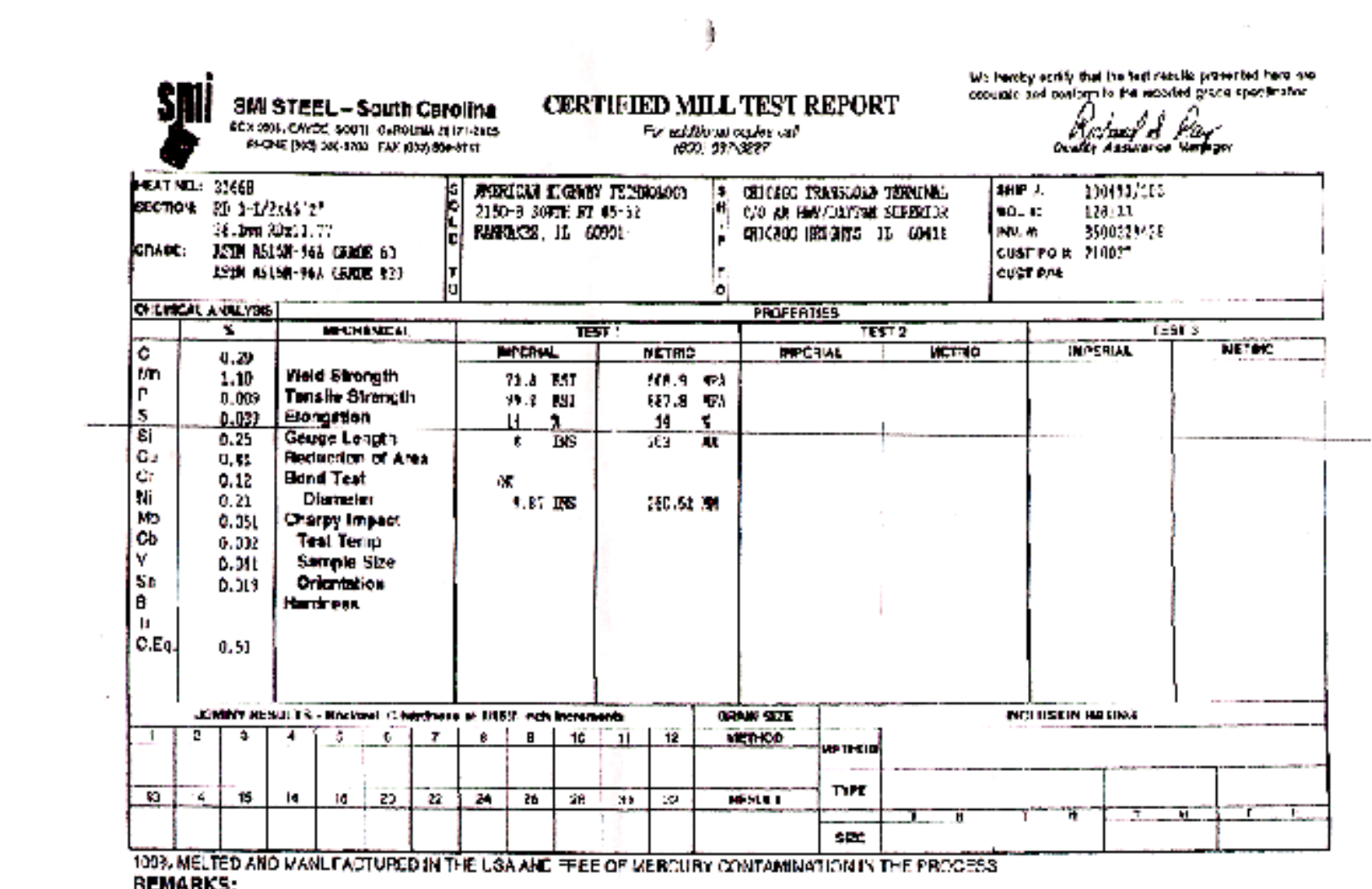

10M\% MELTED
REMARKS:

Mk-15-2yJ1 19:4:

Pece 1 OP 1 


\section{APPENDIX-II}

\section{Product Information}

\section{Specialty}

\section{Lubricants DOW CORNING 111 Silicone compound}

\section{FEATURES}

- Good resistacta no mast ebemicals

- Wide service temperature range

$\left(-40^{\circ} \mathrm{C} / 40^{\circ} \mathrm{F}\right.$ to $\left.200^{\circ} \mathrm{C} / 392^{\circ} \mathrm{F}\right)$

- Low vapor presarre

- Low volatility

- Excelleat p/uter resistance

\section{COMPOSITION}

\section{- Silieone oil \\ - Inorganic thickencr \\ - Additiver}

\section{Valve lubricant and sealant}

\section{APPLICATIONS}

- Lubricution for coutrol and presture plug valves, water soflenet and faucet values.

- Sealani for vacuuma and preassure systems

- Sealunt for ouldoor expipment (also shipboard) subject to washing and barsh enviruameralal exposure: meters, eloctrical service entruace and underground coanectione.

- Danping medium for duth pots in electrical and electronic equipment.

- Chenvical berrier conting.

- Usod us an nuti-stick and vealaut for tratsformer gacket and equipment enclosures. It prevends gaskets from sticking to metal and resists weathering and water washout.

- Rubber and plestic 0-rings, pusters and seals.

\section{TYPICAL PROPERTIES}

Speciffcadion wrivers: These values ate uxt Intewded for use in meparing speciflctions. Pleast combec your loesal Dow Coming sales represcatative prior to writing specification oa this product.

\begin{tabular}{|c|c|c|c|}
\hline Standmindt & Parnecter & Unit & Valae \\
\hline & $\begin{array}{l}\text { Phynical nanure } \\
\text { Color }\end{array}$ & & $\begin{array}{l}\text { Stiff compound } \\
\text { White on lightit } \\
\text { grty, transwuestm }\end{array}$ \\
\hline [SOL 2[3] & Penetration unworked & $\operatorname{mos} 10$ & 1750210 \\
\hline [SO 2137 & Penetration, worked 60, max. & $\operatorname{mm} 10$ & 260 \\
\hline CTN 0033A & Blood 24 houras $200^{\circ} \mathrm{C}\left(99^{\circ} \mathrm{F}\right)$, max. & $x$ & 0.5 \\
\hline \multirow[t]{3}{*}{$\operatorname{CTM~0033A~}$} & $\begin{array}{l}\text { Evaporalon } 24 \text { bourd } 200^{4} \mathrm{C}\left(392^{\circ} \mathrm{F}\right) \text {, } \\
\text { max. }\end{array}$ & $\%$ & 2.0 \\
\hline & Melting point & ${ }^{\circ} \mathrm{C}$ & Nobe \\
\hline & & ${ }^{*} \mathbf{F}$ & None \\
\hline
\end{tabular}

+ CTM: Corporak Test Method, onpies of CTMs are wailable on reqpest. 1SO. International Stanterdisation Orquisation

\section{HOW TO USE}

Bow to apply

DOW CORNING 11 I Silicone Compound can be apolied by hand, specinlly designed uutomated equipenent, bnushing or wiping. Cenrain dexigns of grape guts may seize up test prior to use.

A thinner comsistency can be achieved by dispersing in solvends such ag cylene, minerat spirits and methyl ethyl ketone. DOW CORNING 111 Silleoue Compound can then be applied by brushing, dipping or spraying.

DOW CORNINO 111 Silicene Compound should not be applied to any surfece which will be painted or fimished. Such contings may not 


\section{APPENDIX-III}

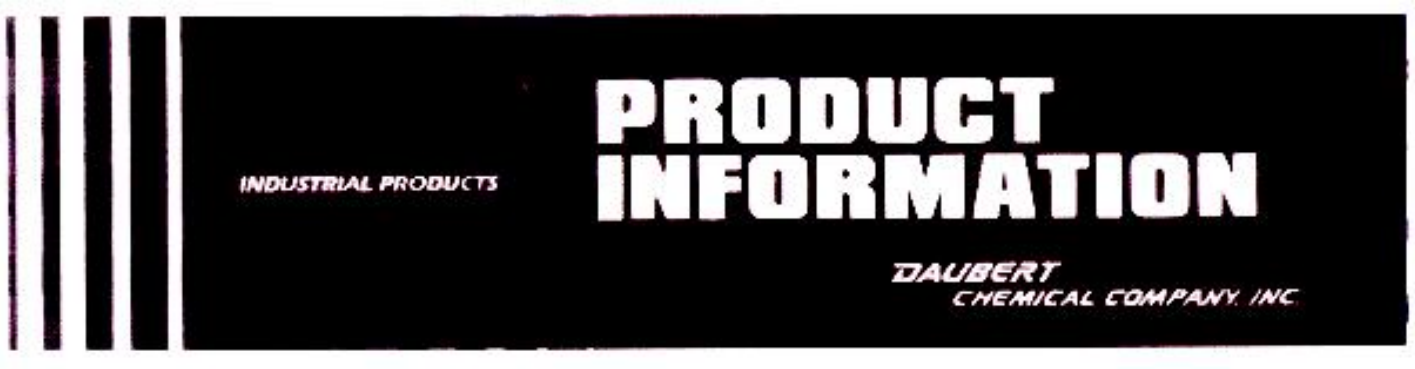

\section{TECTYL・506}

\section{Description}

TECTYL 506 is a solvent cutback corrosion presentive compound. The dry fitm is lirm, amber, and transtucent. TECTYL ${ }^{\Phi} 508$ is excellenl for protection of melallic surfaces againsi corrosion in long-lerm indoor or outdoor exposure and during domestic and aversees shipment.
Laboratory Data

Fhath, PACC", Minimum

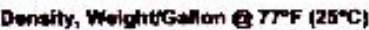

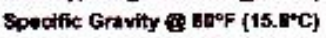

Racommendad Dry Film Thickneas over Matal Profile

Theonitic Coverage e Recommended DFT

Non-Yolatle $\%$ by Weight

Non-Votative \%o by Volume

Votwito Organit Content (VOC), Maximum

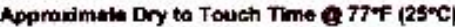

Cure Time

High Tomperature Flow Point, Elnimum

Accolinted Comotion Thet:

5\% salt Soray (Hours)

AsTin. B-117 .0 Recommended QFT (2xdxitio in. Polliahed Steel Panels)

100\% Relallve Humldity (Hours)

ASTI D-174. Rocommendad DFT (2ndri, in. Polithed Stoed Paneite)

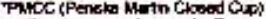

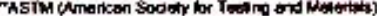

Typlcal Properties

\begin{tabular}{|c|c|}
\hline Enollob & Antric \\
\hline $\begin{array}{c}106^{\circ} \mathrm{F} \\
7.4 \pm 0.1 \text { lbes deation } \\
0.69\end{array}$ & $\begin{array}{c}41.1^{\circ} \mathrm{C} \\
\text { orr gramat. }\end{array}$ \\
\hline $1.3 \mathrm{mils}$ & 325 mierona \\
\hline $\begin{array}{c}59249 \text { thdgallon } \\
55 \pm 2 \\
46 \pm 2\end{array}$ & 14.5 8q. melerg/h \\
\hline $\begin{array}{c}3.44 \text { lbosgation } \\
1 \text { hour } \\
24 \text { hourt }\end{array}$ & 417 gramsh \\
\hline $300 \% F$ & $148,99 \mathrm{C}$ \\
\hline
\end{tabular}

2496

1500 


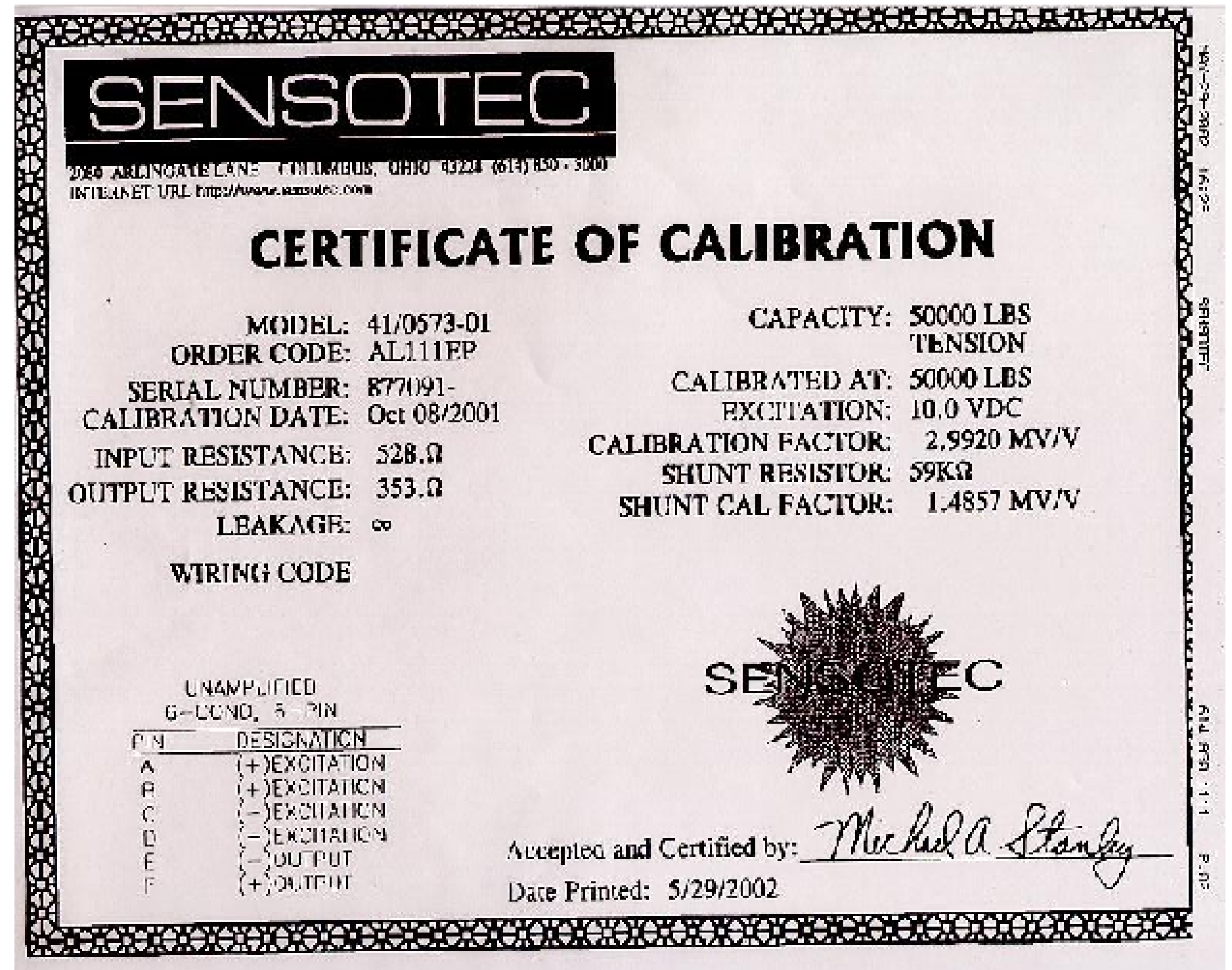




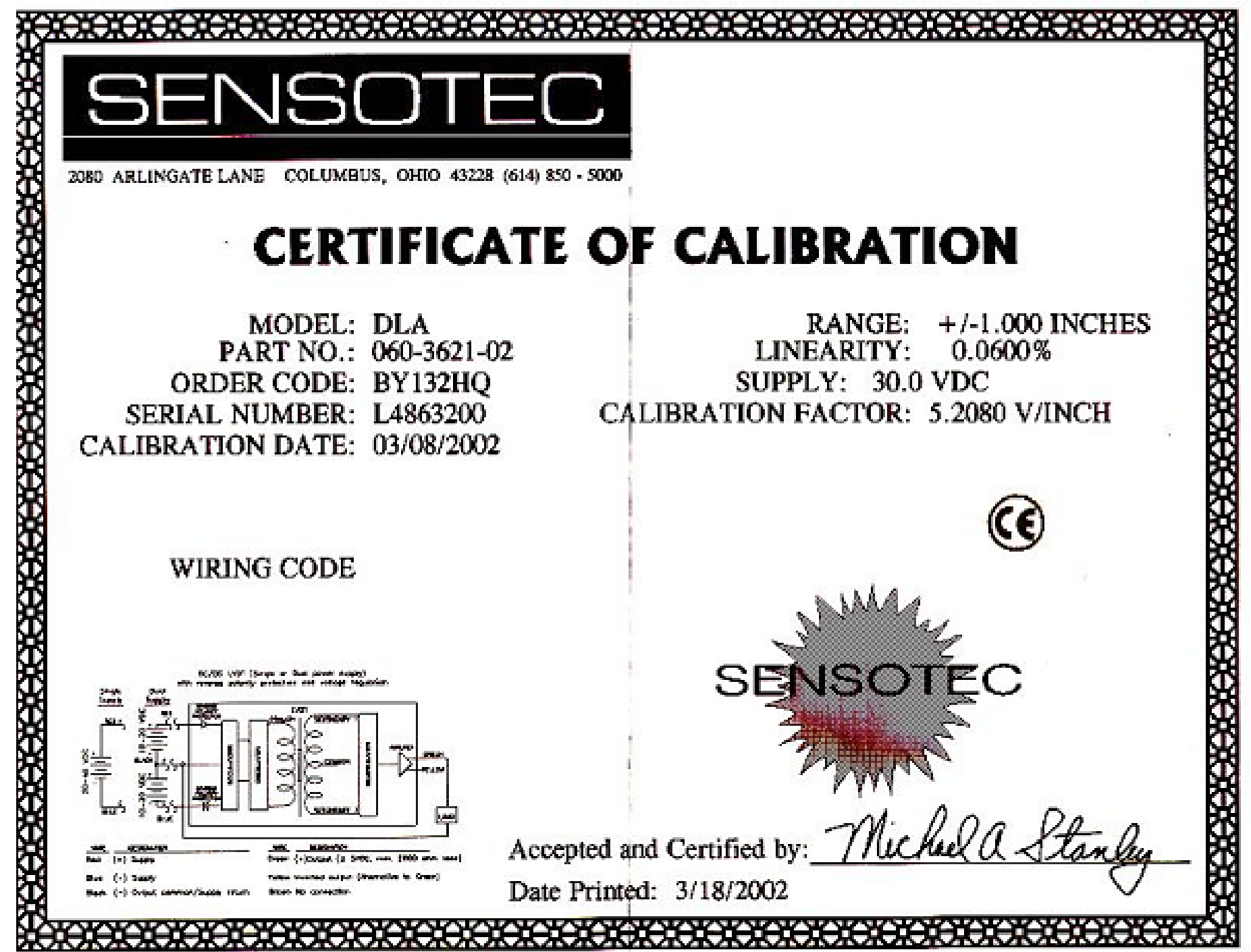




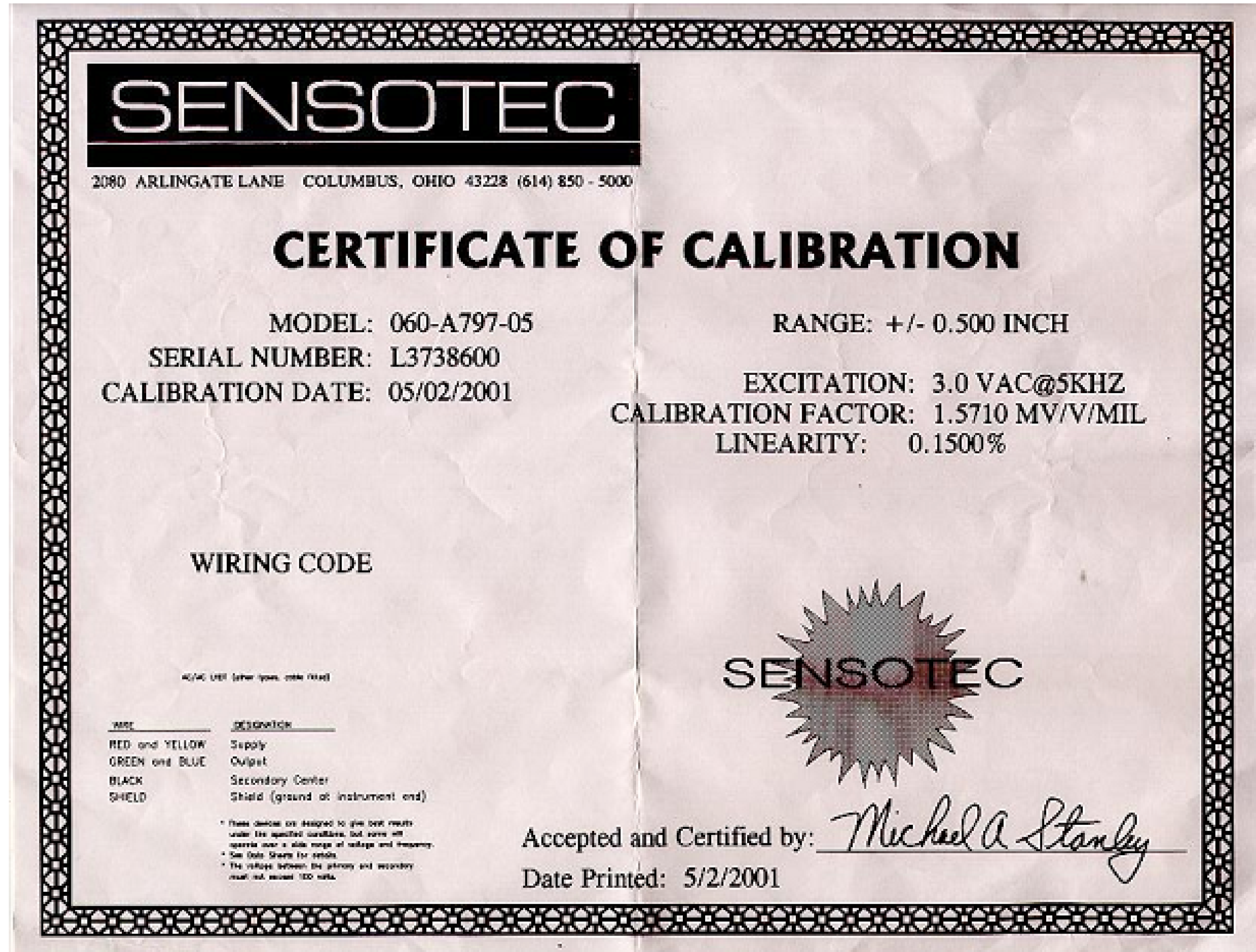




\section{APPENDIX-VI \\ 1.1. Steps followed to connect LVDT to CR10X Datalogger:}

The LVDT was connected to CR10X Datalogger the following steps:

1. The multiplexer was set to 16-channel mode, by setting the jumper pin to connect to terminals $\mathbf{1}$ and $\mathbf{2}$ on the circuit board of mutliplexer.

2. The green (+output) and black (-output) wires of the LVDT were connected $1 \mathrm{H}$ and $1 \mathrm{~L}$ terminals on the multiplexer respectively.

3. The Red (+Power) and Blue (-Power) wires of LVDT were connected to $2 \mathrm{H}$ and $2 \mathrm{~L}$ terminals on the multiplexer respectively

4. The multiplexer was connected to the terminal MUX 1 on the CR10X datalogger.

5. A wire was connected from RS 232 port on the datalogger to any serial port of CPU.

\subsection{Steps followed to configure the file in the Multiplexer Software when LVDT was} connected:

1. A new configuration file wass created.

2. Any number between land 511 was assigned as the datalogger ID.

3. The sampling rate was set to one second.

4. Multiplexer was programmed as the following:

4.1. The option Program was selected in the main menu bar.

4.2. In the multiplexer dialog box, the model was set to 8032, Gage Type was set to Multisensor, and the Channel was to 16.

4.3. Multiplexer 1 was selected.

4.4. "Edit Channels" button was pressed to navigate to the channels configuration menu.

4.5. A particular channel was selected to which the LVDT was connected.

4.6. In the channel configuration dialog box, Gage Type was set to "LVDT", Make was set to Sensotec and Model was set to DLA Series.

4.7. The initial settings of gage factor and zero readings should not be changed.

4.8. Clicking "Accept" button saved the above selections. 
5. The text monitor was configured to display the values of load applied during the experiment.

The entire configuration file was saved.

\subsection{Steps followed to connect Load Cell to CR10X Datalogger and Reading Unit:}

The load cell was connected to CR10X Datalogger and Reading Unit in the following steps:

1. A six-pin connector was connected to the load cell.

2. The other end of the wires from the six-pin connector were connected to the reading unit in the following ways:

2.1. the red and black wires were connected to +ve and -ve excitation terminals on the reading unit, which supply power to the load cell.

2.2. the white and green wires were connected to +ve and-ve supply terminals on the reading unit.

3. The multiplexer was set to 16-channel mode, by setting the jumper pin to connect to terminals $\mathbf{1}$ and $\mathbf{2}$ on the circuit board of mutliplexer.

4. Two wires were connected from -ve and +ve signal (output) terminals on the reading unit to $1 \mathrm{H}$ and $1 \mathrm{~L}$ terminals respectively in the multiplexer.

5. Similarly two more wires were connected from tve and -ve excitation (supply) terminals on the reading unit to $2 \mathrm{H}$ and $2 \mathrm{~L}$ terminals respectively in the multiplexer.

6. The multiplexer was connected to the terminal MUX 1 on the CR10X datalogger.

7. A wire was connected from RS 232 port on the datalogger to any serial port of CPU.

\subsection{Steps followed to configure the file in the Multiplexer Software when load cell is connected:}

1. A new configuration file was created.

2. Any number between 1and 511 was assigned as the datalogger ID.

3. The sampling rate was set to one second.

4. Multiplexer was programmed as the following:

4.1. The option Program was selected in the main menu bar. 
4.2. In the multiplexer dialog box, the model was set to 8032, Gage Type was set to Multisensor, and the Channel was to 16.

4.3. Multiplexer 1 was selected.

4.4."Edit Channels" button was pressed to navigate to the channels configuration menu.

4.5. A particular channel was selected to which the load cell was connected.

4.6. In the channel configuration dialog box, Gage Type was set to "Resistance SG", Make was set to Geokon and Model was set to 3000.

4.7.The initial settings of gage factor and zero readings should not be changed.

4.8. Clicking "Accept" button saved the above selections.

5. The text monitor was configured to display the values of load applied during the experiment.

6. The entire configuration file was saved. 


\begin{abstract}
APPENDIX-VII
Percentage of Error in Experimental Results:

The possible sources for error in the experimental results could be due to human error during installation and conduction of experiment, variation in the concrete mix (which was bought from Hoy-Redi Mix inc.,) and instrumentation used. The range of percentage of error contributed by instrumentation and data acquisition was 3\%-5\%. The human error was less than 5\%. The variation in the compressive strength of concrete estimated was $10 \%-15 \%$. The overall range of percentage of error in the experimental results was $18 \%-25 \%$.
\end{abstract}

